\title{
Untersuchungen zu den selbst-replizierenden Eigenschaften des pathogenen Prion-Proteins beim Menschen
}

\author{
Dissertation \\ zur Erlangung des mathematisch-naturwissenschaftlichen Doktorgrades \\ "Doctor rerum naturalium" \\ der Georg-August-Universität Göttingen \\ im Promotionsprogramm Grundprogramm Biologie \\ der Georg-August-University School of Science (GAUSS) \\ vorgelegt von \\ Maria Cramm \\ aus Helmstedt \\ Göttingen, 2016
}




\section{Betreuungsausschuss}

Prof. Dr. Uwe Groß

Institut für Medizinische Mikrobiologie

Universitätsmedizin Göttingen

Prof. Dr. André Fischer

Abteilung für Psychiatrie und Psychotherapie

Universitätsmedizin Göttingen

Deutsches Zentrum für Neurodegenerative Erkrankungen

Prof. Dr. Inga Zerr

Abteilung für Neurologie

Universitätsmedizin Göttingen

\section{Mitglieder der Prüfungskommission}

Referent:

Prof. Dr. Uwe Groß

Institut für Medizinische Mikrobiologie

Universitätsmedizin Göttingen

Korreferent:

Prof. Dr. André Fischer

Abteilung für Psychiatrie und Psychotherapie

Universitätsmedizin Göttingen

Deutsches Zentrum für Neurodegenerative Erkrankungen

Weitere Mitglieder der Prüfungskommission

Prof. Dr. Inga Zerr

Abteilung für Neurologie

Universitätsmedizin Göttingen

Prof. Dr. Mathias Bähr

Abteilung für Neurologie

Universitätsmedizin Göttingen

Prof. Dr. Markus Zweckstetter

AG Proteinstrukturbestimmung mittels NMR

Max-Planck-Institut für biophysikalische Chemie

Prof. Dr. Sigrid Hoyer-Fender

Abteilung für Entwicklungsbiologie

Johann-Friedrich-Blumenbach-Institut für Zoologie und Anthropologie

Georg-August-Universität Göttingen

Tag der mündlichen Prüfung: 08. Februar 2016 


\section{Danksagung}

Nach vielen Jahren intensiver Arbeit liegt sie nun vor Ihnen: meine Dissertation. Diese Gelegenheit möchte ich nutzen, um mich bei denjenigen zu bedanken, die mich in dieser herausfordernden, aber auch lohnenden Phase meiner akademischen Laufbahn begleitet haben.

Die Anfertigung dieser Arbeit wurde finanziell vom Deutschen Zentrum für Neurodegenerative Erkrankungen (DZNE) gefördert, wofür ich stellvertretend Herrn Prof. Dr. André Fischer, dem Sprecher des DZNE-Standorts Göttingen, danke.

Als Mitglieder des Betreuungskommitees trugen die Herren Prof. Dr. Uwe Groß und Prof. Dr. André Fischer mit stets bereichernden Anregungen zur Erweiterung meines wissenschaftlichen Horizonts bei. Meine Doktormutter Frau Prof. Dr. Inga Zerr lenkte mein Denken durch stets kritsches Hinterfragen und konstruktive Kritik wiederholt in neue fruchtbare thematische Bahnen. Als begleitender Postdoc stand mir Herr Dr. Matthias Schmitz mit seiner umfassenden wissenschaftlichen Expertise jederzeit zur Seite. Vielen Dank für die wissenschaftliche Förderung, die Sie mir offeriert haben.

Die Mitglieder meiner Arbeitsgruppe, dem Referenzzentrum für Prionkrankheiten, in der Abteilung für Neurologie der Universitätsmedizin Göttingen haben mich auf vielfältige Weise unterstützt. Die wissenschaftlichen Mitarbeiterinnen und Mitarbeiter sowie die Doktorandinnen und Doktoranden schärften meinen wissenschaftlichen Fokus mit stets hilfreichen Diskussionsbeiträgen. Die administrativen Mitarbeiterinnen eröffneten mir immer die effizientesten internen und externen Kommunikationswege und die technischen Mitarbeiterinnen standen mir stets in allen Belangen des Labormanagments bei. Vielen Dank für Eure Unterstützung, auf die ich jederzeit zurückgreifen durfte.

Privat hat mir meine Familie bei dem Promotionsvorhaben stets motivierend zur Seite gestanden. Zudem hielt mir insbesondere mein Ehemann Dominik immer den Rücken frei. Daher widme ich ihm diese Arbeit.

Maria Cramm 
„Ein Gelehrter in seinem Laboratorium ist nicht nur ein Techniker; er steht auch vor den Naturgesetzen wie ein Kind vor der Märchenwelt."

Marie Sklodowska Curie (1867 - 1934) 


\section{Inhalt}

Zusammenfassung III

Bilder IV

Tabellen $\quad$ V

$\begin{array}{lll}\text { Abkürzungen und Symbole } & \text { VII }\end{array}$

1. Einleitung 1

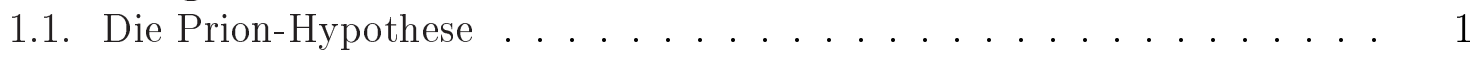

1.2. Das Prion-Protein . . . . . . . . . . . . . . 2

1.2.1. Die zelluläre Form $-\mathrm{PrP}^{\mathrm{C}} \ldots \ldots \ldots 2$

1.2.2. Die pathogene Form $-\mathrm{PrP}^{\mathrm{Sc}} \ldots \ldots \ldots \ldots 4$

1.3. Humane Prionkrankheiten . . . . . . . . . . . . 7

1.3.1. Formen ....................... 7

1.3.2. Klinik und Neuropathologie . . . . . . . . . . 8

1.3.3. Diagnose ...................... 9

1.3.4. Therapie ....................... 10

1.3.5. Charakterisierung von Prionstämmen . . . . . . . . . . 11

1.4. Methoden zur Untersuchung der Prionkonversion . . . . . . . . . . . 12

1.4.1. Zellfreie in-vitro-Methoden . . . . . . . . . . . . . . . 13

1.4.2. Real-Time Quaking-Induced Conversion . . . . . . . . . . 13

$\begin{array}{ll}\text { 2. Aufgabenstellung und Zielsetzung } & 16\end{array}$

3. Material und Methoden 17

3.1. Proben . . . . . . . . . . . . . . . . . 17

3.1.1. Deklaration .................... 17

3.1.2. Präanalytische Aufbereitung . . . . . . . . . . . . . 18

3.2. Bestimmung des Prnp Codon 129-Genotyps mittels RFLP . . . . . . . 19

3.3. Bestimmung des PrP ${ }^{\mathrm{Sc}}$-Typs mittels PK-Verdau und Western Blot . . . 20

3.4. Bestimmung von Proteinkonzentrationen mittels ELISA . . . . . . . . . 21

3.5. Bestimmung der PrP-Aggregation mittels RT-QuIC . . . . . . . . . 22

3.6. Statistische Auswertung der RT-QuIC-Ergebnisse . . . . . . . . . . . . 25

3.6.1. Bestimmung des Grenzwerts . . . . . . . . . . . . 25

3.6.2. Bestimmung der Validität . . . . . . . . . . . 26

3.6.3. Bestimmung der Reproduzierbarkeit . . . . . . . . . . 26

3.6.4. Bestimmung der Positivitätsrate . . . . . . . . . . 26

3.6.5. Charakterisierung des Fluoreszenzsignals . . . . . . . . . 27 
4. Ergebnisse 29

4.1. Methodische Optimierung der RT-QuIC . . . . . . . . . . . . 29

4.1.1. Bestimmung des Grenzwerts . . . . . . . . . . . . . 30

4.1.2. Bestimmung der Validität . . . . . . . . . . . . 30

4.1.3. Bestimmung der Reproduzierbarkeit . . . . . . . . . . . 32

4.1.4. Bestimmung der Stabilität . . . . . . . . . . . . 33

4.2. Charakterisierung der Fluoreszenzsignale . . . . . . . . . . . . 39

4.2.1. Einfluss von Alter und Geschlecht der Patienten bei sCJD . . . 42

4.2.2. Einfluss des Volumens der CJD-Probe . . . . . . . . . . . 42

4.2.3. Einfluss der Form der Prionkrankheit . . . . . . . . . . . . . . . 44

4.2.4. Einfluss der molekularen sCJD-Formen . . . . . . . . . . . 46

4.2.5. Einfluss des Prnp Codon 129-Genotyps bei gCJD . . . . . . . . 51

4.2.6. Einfluss von Krankheitsstadium und Krankheitsdauer bei sCJD 51

4.2.7. Einfluss von krankheitsassoziierten Proteinen . . . . . . . . . 55

4.3. Nutzung der RT-QuIC als Wirkstoff-Suchtest . . . . . . . . . 55

4.3.1. Zugabe von Stoffen zu Beginn des Prozesses . . . . . . . . . . 55

4.3.2. Zugabe von Stoffen während des Prozesses . . . . . . . . . . . 60

4.3.3. Einfluss der Vibration auf die Wirkung von Doxyzyklin . . . . . 60

5. Diskussion

5.1. Methodische Optimierung der RT-QuIC . . . . . . . . . . . 64

5.1.1. Hohe Validität . . . . . . . . . . . . . . . . 64

5.1.2. Sehr gute Reproduzierbarkeit . . . . . . . . . . . . 65

5.1.3. Hohe Stabilität . . . . . . . . . . . . . . . . . 65

5.2. Charakterisierung der Fluoreszenzsignale . . . . . . . . . 66

5.2.1. Differenzierung von gCJD, sCJD und FFI . . . . . . . . . 67

5.2.2. Einfluss des Prnp Codon 129-Genotyps . . . . . . . . . . . . 67

5.2.3. Einfluss weiterer Faktoren . . . . . . . . . . . 68

5.3. Nutzung der RT-QuIC als Wirkstoff-Suchtest . . . . . . . . . 69

$\begin{array}{ll}\text { Quellen } & 73\end{array}$

$\begin{array}{ll}\text { A. Material } & 91\end{array}$

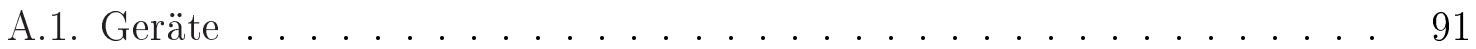

A.2. Verbrauchsmaterial . . . . . . . . . . . . . . 91

A.3. Anorganische und organische Stoffe . . . . . . . . . . . . . 92

A.4. Lösungen und Puffer . . . . . . . . . . . . . . . . . . . . . . . 92

A.5. Gebrauchsfertige Reaktionssysteme . . . . . . . . . . . . . 93

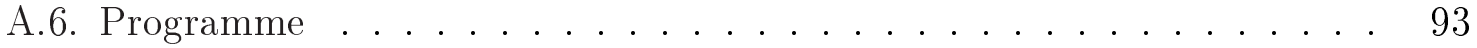

$\begin{array}{ll}\text { B. Tabellen } & 94\end{array}$

$\begin{array}{lr}\text { C. Bilder } & 104\end{array}$ 


\section{Zusammenfassung}

Prionkrankheiten sind übertragbare, tödliche neurodegenerative Erkrankungen beim Menschen und bei Tieren. Sie basieren auf der Konversion des zellulären Prion-Proteins $\left(\mathrm{PrP}^{\mathrm{C}}\right)$ in seine pathogene Form $\left(\mathrm{PrP}^{\mathrm{Sc}}\right)$. Durch diese Konversion sind Prionkrankheiten pathogen und übertragbar. Bis heute ist weder der dem zugrunde liegende Mechanismus verstanden noch eine Behandlung gefunden worden.

Die sichere Diagnose einer sporadischen Prionkrankheit ist ausschließlich mittels Gehirnbiopsie möglich, weswegen zu Lebzeiten des Patienten häufig nur die Diagnose einer wahrscheinlichen Prionkrankheit erfolgt. Zusammen mit der klinischen Heterogenität der Prionkrankheiten weisen neueste Erkenntnisse auf das Vorhandensein mehrerer humaner Prionstämme hin. Für die Suche nach Medikamenten fehlt ein geeigneter Wirkstoff-Suchtest, der auf der humanen Pathogenese basiert, für einen hohen Durchsatz geeignet und gut reproduzierbar ist.

Die real-time quaking-induced conversion (RT-QuIC), eine neu entwickelte in vitro-Methode, erlaubt den Nachweis von bisher nicht messbaren Mengen an $\mathrm{PrP}^{\mathrm{Sc}}$ in humanem Liquor cerebrospinalis (Liquor). Dazu werden die selbst-replizierenden Eigenschaften des $\mathrm{PrP}^{\mathrm{Sc}}$ genutzt. Erste Untersuchungen weisen auf distinkte Eigenschaften humaner Prionkrankheiten in der RT-QuIC hin. Zum Einsatz in Diagnostik und Forschung bedarf es jedoch einer umfassenden Validierung der Methode für die Anwendung mit humanem Liquor.

In dieser Arbeit beträgt die Sensitivität der RT-QuIC 85,5\% und die Spezifität 99,5 \% für humane Prionkrankheiten. Die Reproduzierbarkeit im Ringversuch ist gut bis exzellent. Die Kurzzeitlagerungen der Liquorproben bei Raumtemperatur und $+4{ }^{\circ} \mathrm{C}$ sowie die Langzeitlagerung bei $-80{ }^{\circ} \mathrm{C}$ und das wiederholte Einfrieren und Auftauen haben keinen Einfluss auf die Testergebnisse. Jedoch führt die Kontamination mit Blut zu falsch-negativen Resultaten. Diese Ergebnisse weisen auf eine Eignung der RT-QuIC zur sicheren Diagnose von Prionkrankheiten zu Lebzeiten der Patienten hin.

Zur Charakterisierung des Reaktionspotentials möglicher humaner Prionstämme wurden Liquorproben von verschiedenen humanen Prionkrankheiten wie bspw. der sporadischen und der genetischen Form mittels RT-QuIC untersucht. Die Auswertung der Daten zeigt distinkte Eigenschaften des $\mathrm{PrP}^{\mathrm{Sc}}$ im Liquor, die moduliert werden durch die Form der Prionkrankheit, den Prnp Codon 129-Genotyp und die Krankheitsdauer. Diese Ergebnisse zeigen das Potential der RT-QuIC, die selbst-replizierenden Eigenschaften des $\mathrm{PrP}^{\mathrm{Sc}}$ im Liquor zu untersuchen, womit erstmals eine Methode zur Verfügung steht, um diese Effekte in Patienten während der symptomatischen Phase zu studieren.

Zur Nutzung der RT-QuIC als neurartige Methode zur Wirkstoffsuche wurde die Wirkung mehrerer Stoffe auf die RT-QuIC-Reaktion untersucht. Doxyzyklin inhibiert diese Reaktion sowohl in Korrelation mit der Dosis als auch mit dem Zeitpunkt der Zugabe. Diese Ergebnisse weisen auf eine Eignung der RT-QuIC zur Suche von Stoffen hin, die den PrP-Konversionsprozess inhibieren und zeigen die inhibierende Wirkung von Doxyzyklin auf die in-vitro-Amplifikation von $\mathrm{PrP}^{\mathrm{Sc}}$. 


\section{Bilder}

1. Schematische Darstellung der biochemischen Struktur des $\mathrm{PrP}^{\mathrm{C}} \ldots \ldots$

2. Schematische Darstellung des RT-QuIC-Prozesses . . . . . . . . . . . 14

3. Schematische Darstellung der Versuchsdurchführung mittels RT-QuIC . 23

4. Schematische Darstellung des RT-QuIC-Fluoreszenzsignals . . . . . . . 28

5. Grenzwertoptimierungskurve der RT-QuIC . . . . . . . . . . . . 30

6. Signalmaxima von Liquorproben in der RT-QuIC . . . . . . . . . 31

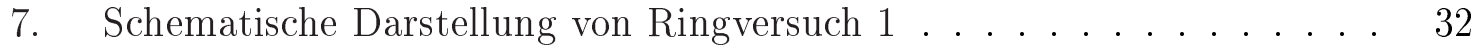

8. Schematische Darstellung von Ringversuch 2 . . . . . . . . . . . 33

9. Einfluss von Lagerung und Verwendung auf die Positivitätsraten . . . . 35

10. Einfluss von Lagerung und Verwendung auf die Fluoreszenzsignale . . . 36

11. Einfluss einer Blutkontamination auf die Positivitätsraten . . . . . . . 38

12. Einfluss einer Blutkontamination auf die Fluoreszenzsignale . . . . . . . 39

13. Einfluss der molekularen sCJD-Form auf das Fluoreszenzsignal - 1 . . . 40

14. Einfluss von Alter und Geschlecht auf die Fluoreszenzsignale . . . . . . 42

15. CJD-Positivitätsraten bei Verdünnung der Probe . . . . . . . . . . 43

16. Einfluss der Krankheitsform auf das Fluoreszenzsignal . . . . . . . . . . 44

17. Einfluss des Codon 129 und des $\mathrm{PrP}^{\mathrm{Sc}}$ auf die Fluoreszenzsignale . . . . 46

18. Einfluss der molekularen sCJD-Formen auf die Fluoreszenzsignale - 2 . 47

19. Einfluss der molekularen sCJD-Formen auf die Fluoreszenzsignale - 3 . 49

20. Einfluss möglicher sCJD-Prionstämme auf die Fluoreszenzsignale . . . . 50

21. Einfluss der gCJD-Mutation auf die Fluoreszenzsignale . . . . . . . 52

22. Einfluss von Krankheitsstadium und -dauer auf die Fluoreszenzsignale . 53

23. Einfluss von krankheitsassoziierten Proteinen auf die Lag-Phase . . . . 56

24. Einfluss von Doxyzyklin auf die sCJD-Fluoreszenzsignale . . . . . . 57

25. Einfluss von Doxyzyklin in versch. Konz. auf die AUC . . . . . . . . 58

26. Einfluss von Ampicillin und Sucrose in versch. Konz. auf die AUC . . . 59

27. Einfluss von Doxyzyklin auf die AUC bei Zugabe zu versch. Zeitpunkten 61

28. Einfluss von Amp und Suc auf die AUC bei Zugabe zu versch. Zeitp. . 62

29. Einfluss der Vibration auf die Wirkung von Doxyzyklin . . . . . . . . 63

30. Einfluss der Vibration auf die Wirkung von Doxyzyklin auf die AUC . . 63

31. Einfluss von Doxyzyklin auf den RT-QuIC-Prozess . . . . . . . . . . . 71

32. Einfluss von Dox, Amp und Suc in versch. Konz. auf die AUC von Kontr.104

33. Einfluss von Dox, Amp und Suc auf die AUC von Kontr. zu versch. Zeitp.104 


\section{Tabellen}

1. Verteilung der Prnp Codon 129-Genotypen: Normalpopulation vs. sCJD 3

2. Verteilung der $\mathrm{PrP}^{\mathrm{Sc}}$-Typen beim Prnp Codon 129-Polymorphismus . . 6

3. Anzahl der Liquorproben von Patienten mit Prionkrankheiten . . . . 18

4. Anzahl der Liquorproben von retrospektiven Kontroll-Patienten . . . . 18

5. Zusammensetzung des Lysepuffers . . . . . . . . . . . . . . 19

6. Zusammensetzung des Basismix für die RT-QuIC . . . . . . . . . 24

7. Zusammensetzung des finalen Mix für die RT-QuIC . . . . . . . . 25

8. Stoffkonzentrationen im RT-QuIC-Mix . . . . . . . . . . . 25

9. Daten der Liquorproben nach Gruppenzugehörigkeit . . . . . . . . . . . 31

10. Sensitivitäten der RT-QuIC nach Gruppenzugehörigkeit . . . . . . . . . 32

11. Testergebnisse der RT-QuIC nach Gruppenzugehörigkeit . . . . . . . . 32

12. Ergebnisse der Ringversuche . . . . . . . . . . . . . . . . 33

13. Einfluss der mol. sCJD-Formen auf die Fluoreszenzsignale von Gehirnpr. 41

14. Einfluss von Alter und Geschlecht auf die Fluoreszenzsignale - Daten . 43

15. Einfluss von Alter und Geschlecht auf die Fluoreszenzsignale - Stat. . . 43

16. Einfluss der Krankheitsform auf das Fluoreszenzsignal - Daten . . . . . 45

17. Einfluss der Krankheitsform auf das Fluoreszenzsignal - Stat. . . . . . 45

18. Einfluss der Krankheitsform auf das Fluoreszenzsignal - Stat. . . . . . 45

19. Einfluss von Codon 129 und $\mathrm{PrP}^{\mathrm{Sc}}$ auf die Fluoreszenzsignale - Daten . 48

20. Einfluss von Codon 129 und $\mathrm{PrP}^{\mathrm{Sc}}$ auf die Fluoreszenzsignale - Stat. . 48

21. Einfluss der molekularen sCJD-Formen auf die Fluoreszenzsignale - Daten 48

22. Einfluss der molekularen sCJD-Formen auf die Fluoreszenzsignale - Stat. 50

23. Einfluss der gCJD-Mutation auf die Fluoreszenzsignale - Daten . . . . 51

24. Einfluss der gCJD-Mutation auf die Fluoreszenzsignale - Stat. . . . . . 51

25. Einfluss des Krankheitsstadiums auf die Fluoreszenzsignale - Daten . . 54

26. Einfluss der Krankheitsdauer auf die Fluoreszenzsignale - Daten . . . . 54

27. Einfluss von Stadium und Dauer auf die Fluoreszenzsignale - Stat. . . . 54

28. Einfluss krankheitsassoziierter Proteine auf die Fluoreszenzsignale . . . 55

29. Geräte . . . . . . . . . . . . . . . . . . . . . 91

30. Verbrauchsmaterial . . . . . . . . . . . . . . . . . . 91

31. Anorganische und organische Stoffe . . . . . . . . . . . . . . . . 92

32. Gebrauchsfertige Lösungen und Puffer . . . . . . . . . . . . . . . . 93

33. Stoffkonzentrationen in den RT-QuIC-Mixen mit zusätzlichen Wirkstoffen 93

34. Gebrauchsfertige Reaktionssysteme . . . . . . . . . . . . . 93

35. Programme . . . . . . . . . . . . . . . . . . 94

36. Einfluss der Kurzzeitlagerung auf die Positivitätsraten - Daten . . . . . 94

37. Einfluss von Verw. und Kurzzeitlag. auf die Positivitätsraten - Daten . 94

38. Einfluss einer Blutkontamination auf die Positivitätsraten - Daten 1 . . 95

39. Einfluss einer Blutkontamination auf die Positivitätsraten - Daten 2 . . 95

40. Einfluss von Lagerung und Verw. auf die Positivitätsraten - Stat. . . . 96

41. Einfluss einer Blutkontamination auf die Positivitätsraten - Stat. . . . 96 
42. Einfluss der Kurzzeitlagerung auf die Fluoreszenzsignale - Daten 1 . . 96

43. Einfluss der Kurzzeitlagerung auf die Fluoreszenzsignale - Daten 2 . . . 97

44. Einfluss der Kurzzeitlagerung bei auf die Fluoreszenzsignale - Daten $3 \quad 97$

45. Einfluss von Einfrier-/Auftauzyklen auf die Fluoreszenzsignale - Daten 197

46. Einfluss von Einfrier-/Auftauzyklen auf die Fluoreszenzsignale - Daten 298

47. Einfluss von Lagerung und Verwendung auf die Positivitätsraten - Stat. 98

48. Einfluss einer Blutkontamination auf die Fluoreszenzsignale - Daten 1 . 98

49. Einfluss einer Blutkontamination auf die Fluoreszenzsignale - Daten 2 . 99

50. Einfluss einer Blutkontamination auf die Fluoreszenzsignale - Daten 3 . 99

51. Einfluss einer Blutkontamination auf die Fluoreszenzsignale - Daten 4 . 100

52. Einfluss einer Blutkontamination auf die Fluoreszenzsignale - Stat. . . 100

53. Einfluss der Kurzzeitlag. auf die Fluoreszenzsign. von Kontr. - Daten . 101

54. Einfluss der Verw. und Langzeitlag. auf die Fluoreszenzsign. von Kontr. 101

55. Einfluss einer Blutkont. auf die Fluoreszenzsign. von Kontr. - Daten 1 . 102

56. Einfluss einer Blutkont. auf die Fluoreszenzsign. von Kontr. - Daten 2 . 102

57. Einfluss von Dox in versch. Konz. auf die AUC von sCJD-Gehirnproben 103 


\section{Abkürzungen und Symbole}

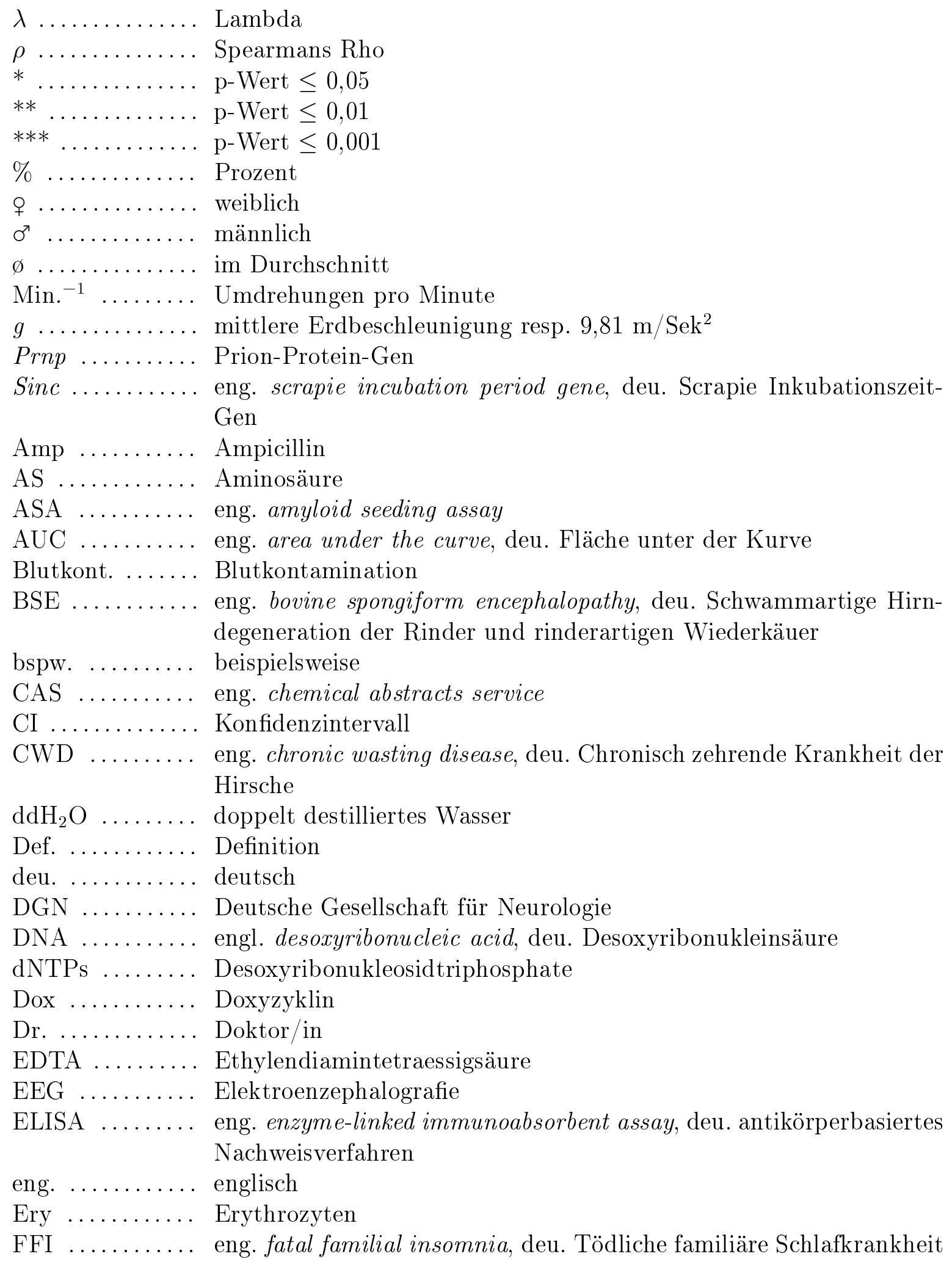


Fluoreszenzsign. Fluoreszenzsignal

FSE .......... eng. feline spongiform encephalopathy, deu. Schwammartige Hirndegeneration der Katzen

g ............ Gramm

gCJD ......... eng. genetic Creutzfeldt-Jakob disease, deu. genetische CreutzfeldtJakob-Krankheit

GPI .......... Glykophosphatidylinositol

iCJD .......... eng. iatrogenic Creutzfeldt-Jakob disease, deu. erworbene CreutzfeldtJakob-Krankheit

IQR .......... engl. interqartile range, deu. Interquartilsabstand resp. $\mathrm{Q}_{25}-\mathrm{Q}_{75}$

Jahrh. .......... Jahrhundert

kDa $\ldots . . . . . .$. Kilodalton

Kontr. ......... Kontrolle

Kurzzeitlag. .... Kurzzeitlagerung

1 ............ Liter

Langzeitlag. .... Langzeitlagerung

lat. .......... lateinisch

Liquor ........ lat. Liquor cerebrospinalis, deu. Gehirn-Rückenmarks-Flüssigkeit

m ............ Meter

Max rfu ....... Signalmaximum

mg $\ldots \ldots \ldots \ldots$ Milligramm

Min. .......... Minute

$\mathrm{ml} \ldots \ldots \ldots \ldots$ Milliliter

MM ......... Codon 129-Genotyp Methionin/Methionin

mM .......... Millimolar

MM1 ......... Codon 129-Genotyp Methionin/Methionin und $\mathrm{PrP}^{\mathrm{Sc}}$-Typ 1

MM2 ......... Codon 129-Genotyp Methionin/Methionin und $\mathrm{PrP}^{\mathrm{Sc}}$-Typ 2

mol. .......... molekularen

MRT ......... Magnetresonanztomographie

MV .......... Codon 129-Genotyp Methionin/Valin

MV1 ........ Codon 129-Genotyp Methionin/Valin und PrP ${ }^{\text {Sc }}$-Typ 1

MV2 ........ Codon 129-Genotyp Methionin/Valin und PrP ${ }^{\mathrm{Sc}}$-Typ 2

Mw ........... Mittelwert

$\mathrm{N} \ldots \ldots \ldots \ldots$ Anzahl gesamt

$\mathrm{n}$............. Anzahl in jeder experimentellen Gruppe

$\mathrm{NaCl} \ldots \ldots \ldots$ Natriumchlorid

nm ........... Nanometer

Nr. ........... Nummer

NRZ für TSE ... Nationales Referenzzentrum für die Surveillance transmissibler spongiformer Enzephalopathien

ns $\ldots \ldots \ldots \ldots$ nicht signifikant resp. p-Wert $>0,05$

nvCJD ........ eng. new variant Creutzfeldt-Jakob disease, deu. neue Variante der Creutzfeldt-Jakob-Krankheit 
o.D. .......... ohne Datum

p-Wert ....... eng. probability value, deu. Signifikanzwert

PBS .......... eng. phoshate buffered saline, deu. phosphatgepufferte Salzlösung

PCR .......... engl. polymerase chain reaction, deu. Polymerasekettenreaktion

$\mathrm{pH} \ldots \ldots \ldots \ldots$ pH-Wert

PIPES …... 1,4-Piperazindiethansulfonsäure

PK ........... Protease K

pmol ......... Pikomolar

Prof. ......... Professor/in

$\operatorname{PrP} \ldots \ldots \ldots$...... Prion-Protein

$\mathrm{PrP}^{\mathrm{C}} \ldots \ldots \ldots$ engl. cellular prion-protein, deu. zelluläres Prion-Protein

$\mathrm{PrP}^{\text {Res }} \ldots \ldots \ldots$ eng. PK-resistant prion-protein, deu. PK-resistentes Prion-Protein

$\mathrm{PrP}^{\mathrm{Sc}} \ldots \ldots \ldots$ engl. scrapie prion-protein, deu. pathogenes Prion-Protein

$\mathrm{Q}_{25} \ldots \ldots \ldots \ldots 25 \%$-Perzentil

$\mathrm{Q}_{75} \ldots \ldots \ldots . . . .75 \%$-Perzentil

recPrP $\mathrm{P}^{\mathrm{C}} \ldots \ldots$ engl. recombinant cellular prion-protein, deu. rekombinantes zelluläres Prion-Protein

resp. ......... respektive

retr. Kontr. .... retrospektive Kontrollen

RFLP ........ Restriktionsfragmentlängenpolymorphismus

$\mathrm{rfu}$........... eng. relative fluorescence units, deu. relative Fluoreszenzeinheiten

ROC-Kurve .... eng. receiver operating characteristic, deu. Grenzwertoptimierungskurve

rPrP-PMCA ... eng. recombinant prion-protein protein misfolding cyclic amplification

RT .......... Raumtemperatur resp. $\varnothing 22^{\circ} \mathrm{C}$

RT-QuIC ....... eng. real-time quaking-induced conversion

$\mathrm{S}-\mathrm{QuIC} \ldots \ldots \ldots$ eng. standard quaking-induced conversion

S. ............ Seite

sCJD ......... engl. sporadic Creutzfeldt-Jakob disease, deu. sporadische CreutzfeldtJakob-Krankheit

Scrapie ........ eng. scrapie, deu. Traberkrankheit der Schafe und Ziegen

SD ........... eng. standard deviation, deu. Standardabweichung

SDS ........... eng. sodium dodecyl sulfate, deu. Natriumdodecylsulfat

Sek. .......... Sekunde

sog. ........... sogenannte

Stat. .......... Statistik

Std ........... Stunde

Suc ........... Sucrose

$\mathrm{t}_{10^{4}} \ldots \ldots \ldots \ldots$ Lag-Phase

Th-T ........ Thioflavin-T

TME ......... eng. transmissible mink encephalopathy, deu. Übertragbare Hirndegeneration der Nerze 
Tris/HCl ..... Tris(hydroxymethyl-)aminomethan

u.a. .......... und andere

UMG ......... Universitätsmedizin Göttingen

UV ............ Ultraviolett

V ............ Volt

versch. ....... verschiedene

vgl. .......... vergleiche

vs. ........... versus

VV .......... Codon 129-Genotyp Valin/Valin

VV1 .......... Codon 129-Genotyp Valin/Valin und PrP $\mathrm{P}^{\mathrm{Sc}}$-Typ 1

VV2 .......... Codon 129-Genotyp Valin/Valin und PrPSc_Typ 2

$\mathrm{w} / \mathrm{v} \ldots \ldots \ldots$ engl. weight per volume, deu. Gewicht pro Volumen

Zeitp. ........ Zeitpunkte

${ }^{\circ} \mathrm{C} \ldots \ldots \ldots \ldots$ Grad Celsius

$\mu g \ldots \ldots \ldots$ Mikrogramm

$\mathrm{l}$ l.......... Mikroliter 


\section{Einleitung}

Prionkrankheiten sind übertragbare, tödlich verlaufende neurodegenerative Erkrankungen, die sowohl beim Tier als auch beim Menschen auftreten. Beim Tier wurde die Traberkrankheit der Schafe und Ziegen (Scrapie) erstmals im Jahr 1732 beschrieben, die übertragbare Hirndegeneration der Nerze (TME) im Jahr 1965, die chronisch zehrende Krankheit der Hirsche (CWD) im Jahr 1980, die schwammartige Hirndegeneration der Rinder und der rinderartigen Wiederkäuer (BSE) in den Jahren 1987 und 1988 sowie die der Katzen (FSE) im Jahr 1990 (McGowan 1922, Burger 1965, Hartsough 1965, Williams u. a. 1980, Wells u. a. 1987, Jeffrey u. a. 1988, Aldhous 1990). Beim Menschen wurde das Gerstmann-Sträussler-Scheinker-Syndrom (GSS) erstmals im Jahr 1935 beschrieben, die Kuru-Krankheit im Jahr 1957, die Creutzfeldt-Jakob-Krankheit (CJD) in den Jahren 1920 und 1921 und die Tödliche Familiäre Schlafkrankheit (FFI) im Jahr 1986 (Gerstmann u. a. 1935, Zigas u. a. 1957, Creutzfeldt 1920, Jakob 1921a, Jakob 1921b, Lugaresi u. a. 1986). Wegen ihrer Übertragbarkeit (Transmissibilität) sowie der durch sie verursachten schwammartigen Hirndegeneration entstand die deskriptive Bezeichnung Transmissible Spongiforme Enzephalopathien (TSE), wohingegen die Bezeichnung Prionkrankheiten auf den Erreger hinweist (Hörnlimann 2001).

\subsection{Die Prion-Hypothese}

Im Jahr 1936 wurde gezeigt, dass Scrapie experimentell übertragbar ist (Cuille u. a. 1936). Im Jahr 1959 wurde auf die neuropathologischen Gemeinsamkeiten und die langen Inkubationszeiten von Scrapie und Kuru aufmerksam gemacht und 1966 wurde gezeigt, dass Kuru experimentell auf Affen übertragbar ist (Hadlow 1959, Gajdusek u. a. 1966). Basierend auf dem damaligen Wissensstand, der ausschließlich auf Nukleinsäure basierende Krankheitserreger kannte, vermutete man Viren mit langen Inkubationszeiten als Krankheitserreger hinter den TSEs und kategorisierte diese als ,Slow Virus Disease“ - deu. „Langsame Viruskrankheit“ (Sigurdsson 1954, Diringer u. a. 1988). Bisher konnten jedoch keine krankheitsauslösenden Viren isoliert werden (Prusiner 2001).

Im Jahr 1967 wurde anhand von Untersuchungen der Scrapie-Krankheit erstmals die Vermutung formuliert, das infektiöse Agens könnte sich ohne Beteiligung eigener Erbinformation in Form von Nukleinsäuren vermehren (replizieren), und es wurde der Vorschlag gemacht, der Erreger könnte ein sich replizierendes Protein sein (Alper u. a. 1967, Gibbons u. a. 1967, Griffith 1967). Dieses bisher vorwiegend theoretische Konstrukt wurde weiterentwickelt, durch biochemische Forschungen untermauert und es wurde im Jahr 1982 postuliert, dass das infektiöse Agens vorwiegend proteinartigen Charakter habe (Prusiner 1982). Dies wurde unter anderem damit begründet, dass sich der Erreger durch Behandlungen, die die natürliche Struktur von Nukleinsäuren auflösen (denaturieren) nicht inaktivieren lasse, jedoch durch solche, die Proteine denaturierten. Folglich wäre der Erreger von neuartiger Natur, da die Denaturierung von Nukleinsäuren bei den bis dato bekannten Krankheitserregern zu deren Inaktivierung führte. Zur Unterscheidung diesen Erregers von den bisher bekannten wurde die Be- 
zeichnung Prion eingeführt, abgeleitet von eng. proteinaceous infectious particle (deu. proteinöses infektiöses Partikel). Darauf folgend wurde entdeckt, dass Prionen konstant ein Protein enthalten, und es wurde als dessen Bezeichnung $\operatorname{Pr} P$ eingeführt, abgeleitet vom eng. prion-protein (Bolton u. a. 1982, Prusiner, Bolton u. a. 1982). Im Jahr 1985 wurde das Gen identifiziert, welches für das PrP kodiert, und es wurde dafür die Bezeichnung Prnp eingeführt, abgeleitet vom eng. prion-protein gene (Oesch u. a. 1985). Im Jahr 1989 wurde die vormals aufgestellte Prion-Hypothese zur eng. protein-onlyhypothesis (deu. Nur-Protein-Hypothese) spezifiziert (Prusiner 1989). Diese besagt, dass das PrP in zwei Formen vorkommt, einer harmlosen zellulären Form und einer veränderten krankmachenden (pathogenen) Form, die den alleinigen Bestandteil des infektiösen Agens darstellt. Die zelluläre Form wurde mit $\mathrm{PrP}^{\mathrm{C}}$ von eng. cellular (deu. zellulär) und die pathogene Form mit $\mathrm{PrP}^{\mathrm{Sc}}$ von eng. Scrapie bezeichnet.

\subsection{Das Prion-Protein}

Prionkrankheiten basieren auf der Konversion des $\mathrm{PrP}^{\mathrm{C}}$ in seine pathogene Form $\mathrm{PrP}^{\mathrm{Sc}}$. Beide weisen die gleiche Aminosäuresequenz auf, unterscheiden sich jedoch in ihrer Struktur und den chemisch-physikalischen Eigenschaften (Prusiner 1989).

\subsubsection{Die zelluläre Form - $\operatorname{Pr} \mathrm{P}^{\mathrm{C}}$}

Das $\mathrm{PrP}^{\mathrm{C}}$ ist ein körpereigenes, membranständiges Protein, das überwiegend an der Oberfläche von Nervenzellen exprimiert wird und vorwiegend in neuronalen Geweben wie dem Gehirn und dem Rückenmark vorkommt (Kretzschmar, Prusiner u. a. 1986). Es wurde jedoch auch in geringeren Mengen in bspw. lymphoiden Zellen, Lunge, Herz, Leber, Skelettmuskulatur und dem Gastrointestinaltrakt nachgewiesen (Horiuchi u. a. 1995, Bosque u. a. 2002, Morel u. a. 2004).

Seine physiologische Funktion ist noch nicht abschließend geklärt. Erste Untersuchungen an genetisch veränderten Mäusen, die kein $\mathrm{PrP}^{\mathrm{C}}$ exprimierten $\left(\operatorname{sog}\right.$. $\mathrm{PrP}^{0 / 0_{-}}$ Mäusen), zeigten sowohl eine normale Entwicklung als auch ein normales Verhalten dieser Mäuse (Büeler u. a. 1992). Jedoch wurden später Hinweise auf eine erhöhte Anfälligkeit für neuronale Schädigungen sowie altersabhängige Verhaltensdefizite bei Gedächtnisleistung, assoziativem Lernen, basalem Angstverhalten und Nestbauvermögen gefunden (Sakaguchi u. a. 1996, Schmitz, Greis u. a. 2014, Schmitz, Zafar u. a. 2015). Physiologische Studien zeigten, dass $\mathrm{PrP}^{\mathrm{C}}$ Kupfer in vivo bindet und sowohl prä- als auch postsynaptisch an den neuromuskulären Endplatten lokalisiert ist, was als Hinweis auf eine mögliche Schutzfunktion gegenüber zerstörerischen oxidativen Effekten durch bspw. reaktive Sauerstoffspezies gedeutet wird (D. R. Brown u. a. 1997, Kramer u. a. 2001). Weiterhin ist $\operatorname{PrP}^{\mathrm{C}}$ vermutlich in den Metabolismus von Neurotransmittern, die Aktivierung von Immunzellen, die Zelladhäsion, die Signaltransduktion und den programmierten Zelltod involviert (Cashman u. a. 1990, B.-H. Kim u. a. 2004, Mazzoni u. a. 2005, Zomosa-Signoret u. a. 2008). Zudem scheint es eine Rolle in der Regulation von Proteinen, die an der Pathogenese des Morbus Alzheimer beteiligt sind, innezuhaben 
(Ramljak u. a. 2008). Außerdem zeigten $\mathrm{PrP}^{0 / 0}{ }_{-}$Mäuse ein Defizit bei der Prozessierung von Geruchssignalen (Le Pichon, Claire E u. a. 2009). Diese benötigten im Vergleich zu Kontrolltieren deutlich länger zur Ortung von Nahrung mittels Geruchssinn.

Das $\operatorname{PrP}^{\mathrm{C}}$ wird im endoplasmatischen Retikulum synthetisiert und nachfolgend im Golgiapparat modifiziert, von wo aus es in sekretorischen Vesikeln zur Zelloberfläche transportiert und dort an die Zellmembran gebunden wird (Stahl, Borchelt u. a. 1987, Harris 2003). Auf der Zellmembran befindet es sich vorwiegend in Membraneinbuchtungen (Calveolae), welche sich ins Innere der Zelle abschnüren und mit Endosomen fusionieren können, aus denen es nach einer gemittelten Halbwertszeit von etwa fünf Std wieder in die Zelle aufgenommen und in Endolysosomen abgebaut wird (Shyng u. a. 1993, Vey u. a. 1996,Peters u. a. 2003 Walmsley u. a. 2009).

Das $\operatorname{PrP}^{\mathrm{C}}$ wird durch das Prnp kodiert, das beim Menschen auf dem kurzen Arm des Chromosoms Nr. 20 liegt (Oesch u. a. 1985, Puckett u. a. 1991). Die DNA-Sequenz des Prnp ist unter den Säugetieren sehr konserviert, gemessen an den Homologien, die in der Regel $>90 \%$ betragen (Gabriel u. a. 1992, Schätzl u.a. 1995). An Position (Codon) 129 des Prnp besteht beim Menschen ein Methionin/Valin-Polymorphismus (M129V), d.h. der Mensch kann dort homozygot für die AS Methionin (MM) oder Valin (VV) sein oder für beide heterozygot (MV). Dieser Polymorphismus ist nicht pathogen, beinflusst jedoch die Empfänglichkeit für Prionkrankheiten und deren Pathogenese, die Neuropathologie der sCJD und die Oligomerisation des $\mathrm{PrP}^{\mathrm{Sc}}$ sowie die Amyloidformation (Palmer u. a. 1991, Goldfarb, Petersen u. a. 1992, Silva u. a. 1994, Schulz-Schaeffer u. a. 1996, Deslys, Jaegly u. a. 1998, Parchi, Giese u. a. 1999, Alpérovitch u. a. 1999, Parchi, Zou u. a. 2000, Brandel u. a. 2003, Pocchiari, Puopolo u. a. 2004, Baskakov u. a. 2005, Cali u. a. 2006, Kobayashi u. a. 2015). Insbesondere die Träger einer Homozygotie für Methionin, aber auch für Valin am Prnp Codon 129 sind empfänglicher für eine Prionkrankheit, wohingegen solche mit einer Heterozygotie weniger empfänglich sind (Palmer u. a. 1991, Laplanche, Delasnerie-Lauprêtre, Brandel, Chatelain u. a. 1994, Salvatore u.a. 1994, Parchi, Giese u. a. 1999, Heinemann u. a. 2007). Tabelle 1 auf S. 3 zeigt die Verteilung der drei Genotypen des Prnp Codon 129-Polymorphismus in der Normalpopulation im Vergleich zu an sCJD erkrankten Patienten.

Tabelle 1: Verteilung der Prnp Codon 129-Genotypen: Normalpopulation vs. sCJD

Verteilung der Genotypen des Prnp Codon 129-Polymorphismus in der Normalpopulation $(\mathrm{N}=544)$ im Vergleich zu dieser bei an sCJD erkrankten Patienten $(\mathrm{N}=265)$ (Parchi, Giese u. a. 1999).

\begin{tabular}{ccc}
\hline Codon 129 & Normalpopulation & sCJD \\
\hline MM & $37,0 \%$ & $72,1 \%$ \\
MV & $51,0 \%$ & $10,9 \%$ \\
VV & $12,0 \%$ & $17,0 \%$ \\
\hline
\end{tabular}

Das unprozessierte $\mathrm{PrP}^{\mathrm{C}}$ besteht aus $253 \mathrm{AS}$ und wird in eine N-terminale, unstrukturiertere und flexiblere (AS 23 -120) sowie eine C-terminale, strukturiertere und 
stabilere Domäne (AS 121 - 231) unterteilt (Kretzschmar, Stowring u.a. 1986, Riek u. a. 1996, Donne u. a. 1997, James u. a. 1997, Zahn u. a. 2000, Acevedo-Morantes u. a. 2014). Seine Aminosäuresequenz beginnt N-terminal mit einem Signalpeptid (AS 1 22), das während der Prozessierung abgespalten wird. Dann folgt eine Region aus fünf sich wiederholenden Sequenzen, die Oktarepeat-Region (AS 51 - 90), die vermutlich der Bindung von Kupfer-Ionen dient und in die Neuroprotektion involviert ist (Hornshaw u. a. 1995, D. R. Brown u. a. 1997, Stöckel u. a. 1998,Viles u. a. 1999 Cappai u. a. 2001, Mitteregger u. a. 2007). Die Insertion von einem oder mehreren Oktapeptiden ist pathogen (Owen u. a. 1990, Goldfarb, P. Brown, McCombie u. a. 1991, van Gool, W A u. a. 1995, Laplanche, Delasnerie-Lauprêtre, Brandel, Dussaucy u. a. 1995, Laplanche, Hachimi u. a. 1999, Goldfarb, P. Brown, Little u. a. 1993). Zentral befindet sich eine hydrophobe Region (AS 113 - 135), die möglicherweise als Transmembrandomäne fungiert (Bartz u. a. 2000). Diese Region enthält einen palindromischen Anteil (AS 113 - 120), dessen Deletion die Konversion von sowohl verändertem als auch co-exprimiertem Wildtyp-PrP ${ }^{\mathrm{C}}$ verhindert (Hölscher u. a. 1998, Norstrom u. a. 2005). Zudem inhibieren aus diesem Palindrom generierte Peptide die in vitro-Erzeugung von PK-Resistenz (Chabry u. a. 1998). In der C-terminalen Domäne befinden sich drei $\alpha$ Helices: $\alpha$-Helix 1 (AS 144 -154), $\alpha$-Helix 2 (AS 175 - 193) und $\alpha$-Helix 3 (AS 200 - 219) sowie ein antiparalleles $\beta$-Faltblatt, bestehend aus dem $\beta$-Faltblatt 1 (AS 128 - 131) und $\beta$-Faltblatt 2 (AS 161 - 164) (Riek u.a. 1996, Surewicz u.a. 2011). An Position 179 und 214 befinden zwei ein Cysteinreste, die während der Prozessierung durch eine Disulfidbrücke verbunden werden, wodurch eine Verbindung von $\alpha$-Helix 2 und $\alpha$-Helix 3 entsteht (Prusiner 1993, Maiti u. a. 2001, Riesner 2003). An Position 181 und 197 befinden sich zwei Asparaginreste resp. N-Glykosylierungsstellen, an die während der Prozessierung Oligosaccharide gebunden werden können (Haraguchi u. a. 1989, Lawson u. a. 2005). Deren Modifikation führt zu drei $\mathrm{PrP}^{\mathrm{C}}$-Isoformen: unglykosyliertes $(27 \mathrm{kDa})$, monoglykosyliertes $(33 \mathrm{kDa})$ und diglykosyliertes $\operatorname{PrP}^{\mathrm{C}}(36 \mathrm{kDa})$, die mittels Western Blot unterschieden werden können (Beringue 2003, Zou u. a. 2003, Kuczius u. a. 2007). Das $\operatorname{PrP}^{\mathrm{C}}$ endet C-terminal mit einem GPI-Anker-Signal (AS 232 - 253), das während der Prozessierung durch den GPI-Anker ersetzt wird. Damit wird das $\mathrm{PrP}^{\mathrm{C}}$ nachfolgend an der äußeren Plasmamenbran der Zelle befestigt (Stahl 1987, Baldwin u. a. 1990). Bild 1 auf S. 5 zeigt die unprozessierte biochemische Struktur des $\mathrm{PrP}^{\mathrm{C}}$ schematisch.

\subsubsection{Die pathogene Form - PrPSc}

Das $\mathrm{PrP}^{\mathrm{Sc}}$ besitzt die gleiche Aminosäuresequenz wie das $\mathrm{PrP}^{\mathrm{C}}$, unterscheidet sich jedoch von diesem in seiner Struktur resp. Proteinfaltung und den chemisch-physikalischen Eigenschaften (Borchelt u. a. 1990, Stahl, Baldwin u.a. 1993). Das $\operatorname{PrP}^{\mathrm{C}}$ ist wasserlöslich und empfindlich gegenüber dem PK-Verdau, wohingegen das $\mathrm{PrP}^{\mathrm{Sc}}$ unlöslich und in seiner amyloiden Form partiell resistent gegenüber dem PK-Verdau ist (Bolton u. a. 1982, McKinley u. a. 1983, Oesch u. a. 1985, Meyer u. a. 1986). Diese Differenzen basieren auf den strukturellen Unterschieden der beiden Proteine. Das $\operatorname{PrP}^{\mathrm{C}}$ 


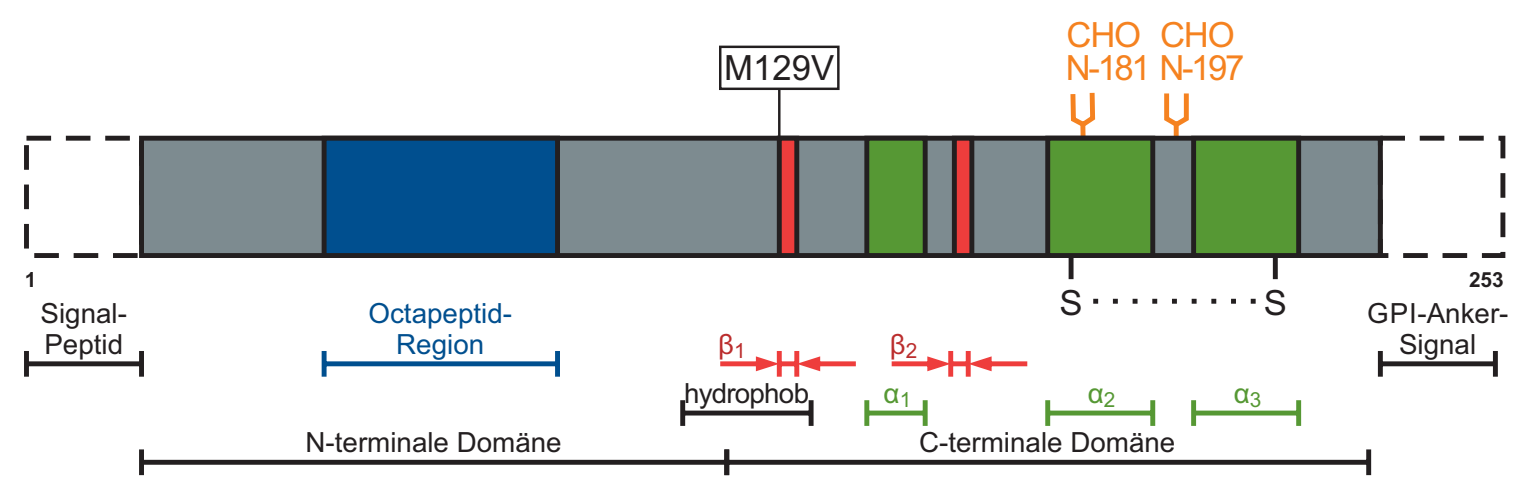

Bild 1: Schematische Darstellung der unprozessierten biochemischen Struktur des $\mathrm{PrP}^{\mathrm{C}}$

Das unprozessierte $\mathrm{PrP}^{\mathrm{C}}$ besteht aus $253 \mathrm{AS}$. Die AS-Sequenz beginnt N-terminal mit einem Signalpeptid, gefolgt von zwei Domänen, einer unstrukturierteren und flexibleren Nterminalen sowie einer strukturierteren und stabileren C-terminalen Domäne und endet Cterminal mit einem GPI-Anker-Signal. Die N-terminale Domäne enthält eine funktionelle Oktarepeat-Region. Übergreifend befindet sich eine hydrophobe Region. Die C-terminale Domäne enthält drei $\alpha$-Helices $\left(\alpha_{1}, \alpha_{2}\right.$ und $\left.\alpha_{3}\right)$ ein kleines antiparalleles $\beta$-Faltblatt $\left(\beta_{1}\right.$ und $\left.\beta_{2}\right)$, eine Disulfidbrücke (S-S) und zwei Glykosylierungsstellen (N-181 und N-197). (Modifiziert nach Acevedo-Morantes u.a. 2014)

besteht vorwiegend aus $\alpha$-Helices (42\%) und besitzt nur einen geringen $\beta$-FaltblattAnteil (3\%), wohingegen das $\mathrm{PrP}^{\mathrm{Sc}}$ vorwiegend aus $\beta$-Faltblättern $(>43 \%)$ besteht und einen geringeren Anteil an $\alpha$-Helices (30 \%) besitzt (Caughey u. a. 1991, Pan u. a. 1993). Das durch limitierte Proteolyse N-terminal gekürzte $\mathrm{PrP}^{\mathrm{Sc}}$ resp. $\operatorname{PrP} 27-30$ weist einen noch höheren Anteil an $\beta$-Faltblättern (>54\%) und einen noch geringeren Anteil an $\alpha$-Helices (21 \%) auf (Pan u. a. 1993). Im Gegensatz zum PrP 27 - 30, welches $\mathrm{zu}$ Amyloid-Fibrillen polymerisiert, formt das $\mathrm{PrP}^{\mathrm{C}}$ keine per Elektronenmikroskopie detektierbaren Aggregate (Merz u. a. 1981, Prusiner, McKinley u.a. 1983, Pan u.a. 1993, Riesner 2003, Acevedo-Morantes u. a. 2014). Neueste Erkenntnisse weisen auf einen Zusammenhang zwischen der Stabilität der Amyloide und der Inkubationszeit dieser im Tierversuch hin. Je instabiler die Amyloide sind, desto kürzer die Inkubationszeit. Dies deutet auf eine stärkere Aggregationsneigung des $\mathrm{PrP}^{\mathrm{Sc}}$ in den instabilen Amyloiden im Vergleich zu den stabilen hin, was zu einer schnelleren Aggregation und in Folge dessen zu einem früheren Tod des Wirtes führt (Colby, Giles u. a. 2009).

Nach dem PK-Verdau können mittels Western Blot zwei distinkte PrP ${ }^{\mathrm{Sc}}$-Typen Typ 1 und Typ 2 - unterschieden werden. Der PrP ${ }^{\text {Sc }}$-Typ 1 wird dabei an AS 82 gespalten, wodurch ein Fragment von $\approx 21 \mathrm{kDa}$ entsteht, wohingegen der PrP $\mathrm{P}^{\mathrm{Sc}}$-Typ 2 stattdessen an AS 97 gespalten wird, was zu einem Fragment von $\approx 19 \mathrm{kDa}$ führt (Parchi, Castellani u. a. 1996, Parchi, Capellari u. a. 1997). Ursächlich dafür sind wahrscheinlich strukturelle Unterschiede, wie bspw. in der Glykosylierung (Parchi, Zou u. a. 2000). Der PrP ${ }^{\mathrm{Sc}}$-Typ 1 kommt bei sCJD vorwiegend in Kombination mit einer Homozygotie für MM am Prnp Codon 129 vor, wohingegen der PrP ${ }^{\mathrm{Sc}}$-Typ 2 vorwiegend bei ebendieser für VV auftritt (Parchi, Giese u. a. 1999). Tabelle 2 auf S. 6 zeigt die 
Anteile der beiden $\mathrm{PrP}^{\mathrm{Sc}}$-Typen in Beziehung zu den drei Genotypen des Prnp Codon 129-Polymorphismus bei an sCJD erkrankten Patienten. Die Resistenz gegenüber

Tabelle 2: Verteilung der PrP $\mathrm{P}^{\mathrm{Sc}}$-Typen beim Prnp Codon 129-Polymorphismus

Verteilung der $\mathrm{PrP}^{\mathrm{Sc}}$-Typen bezogen auf den Prnp Codon 129-Polymorphismus bei an sCJD erkrankten Patienten ( $\mathrm{N}=265)$ (Parchi, Giese u. a. 1999).

\begin{tabular}{lrrrr}
\hline \multirow{2}{*}{ PrP $^{\text {Sc }}$} & \multirow{2}{*}{ Gesamt } & \multicolumn{3}{c}{ Codon 129 } \\
\cline { 3 - 5 } & & $\mathrm{MM}$ & $\mathrm{MV}$ & $\mathrm{VV}$ \\
\hline Typ 1 & $73,2 \%$ & $95,3 \%$ & $27,6 \%$ & $4,5 \%$ \\
Typ 2 & $26,8 \%$ & $4,7 \%$ & $72,4 \%$ & $95,5 \%$ \\
\hline
\end{tabular}

dem Verdau durch Proteasen scheint allerdings keine notwendige Voraussetzung für Pathogenität zu sein, denn einige $\mathrm{PrP}^{\mathrm{Sc}}$-Formen können vollständig proteolysiert werden, wobei die entstehenden löslichen PrP-Fragmente trotzdem Pathogenität aufweisen (Gambetti, Dong u. a. 2008, Colby, Wain u. a. 2010).

Der Grund für die Umwandlung vom $\mathrm{PrP}^{\mathrm{C}}$ zum $\mathrm{PrP}^{\mathrm{Sc}}$ sowie dessen Mechanismus sind noch nicht aufgeklärt. Es wurde sowohl das $\mathrm{PrP}^{\mathrm{C}}$ als auch das $\mathrm{PrP}^{\mathrm{Sc}}$ in den Calveolae nachgewiesen, was die Hypothese der dortigen Konversion unterstützt (Vey u. a. 1996). Zudem unterliegt das $\mathrm{PrP}^{\mathrm{C}}$ einem für GPI-Anker-Proteine untypischen endozytotischen Abbaumechanismus, der die Konversion von $\mathrm{PrP}^{\mathrm{Sc}}$ wahrscheinlich determiniert (Peters u. a. 2003). Der Prnp Codon 129-Polymorphismus beeinflusst die molekulare Konformation und die Neigung zur Aggregatbildung des $\operatorname{PrP}^{\mathrm{C}}$ (Pham u. a. 2008). Steht Methionin am Prnp Codon 129 (129M), dann weist das daraus resultierende $\operatorname{PrP}^{\mathrm{C}}$ eine exponiertere $\alpha$-Helix 1 Region auf als das $\operatorname{PrP}^{\mathrm{C}}$ mit Valin an dieser Position (129V). Prnp 129M aggregiert schneller und formt mehr Aggregate als Prnp 129V. Dies führt zu dem Schluss, dass die Konformation von $\alpha$-Helix 1 den Aggregationsprozess beeinflusst. Zusätzliche Mutationen in der Oktarepeat-Region, wie sie auch bei genetischen Prionkrankheiten auftreten können, verstärken den Aggregationsprozess von Prnp 129M mehr als den von Prnp 129V. Posttranslationale Prozesse wie die Phosphorylierungen können ebenfalls zur Entwicklung von Pathogenität beitragen (Giannopoulos u. a. 2009). Die Phosphorylierung von PrP 23 - 231 an Serin 43 führte in vitro zu einer Änderung der chemisch-physikalischen Eigenschaften, es wurde resistent gegenüber dem PK-Verdau und bildete sog. PrP-Amyloide, unlösliche PrP-Aggregate, die in Form von Fasern - sog. Fibrillen - vorliegen. In vivo wurde PK-resistentes, an Serin 43 phosphoryliertes PrP in Scrapie-infizierten Tieren gefunden, jedoch nicht in den Kontroll-Tieren. Diese Erkenntnisse deuten auf die Involvierung der Phosphorylierung in die in vivo-PrP-Konversion hin. Ein Teil der aktuellen Debatte um den Konversionsmechanismus vom $\mathrm{PrP}^{\mathrm{C}}$ zum $\mathrm{PrP}^{\mathrm{Sc}}$ ist auch die mögliche Involvierung von Co-Faktoren wie bspw. Lipid-ähnlichen Molekülen (Wang u. a. 2013). Jedoch konnte in vitro generiertes PK-resistentes PrP im Tiermodell eine TSE auslösen (J.-I. Kim u. a. 2010). Dass dessen Herstellung ohne den Zusatz biologischer Co-Faktoren wie Nukleinsäuren, 
anderen Polyanionen und Lipiden erfolgte, spricht für die Nur-Protein-Hypothese.

\subsection{Humane Prionkrankheiten}

Die Inzidenz der humanen Prionkrankheiten in Deutschland betrug über die Jahre 1998 - 2005 etwa 1,6 pro Million Einwohner pro Jahr, womit sie zu den seltenen Erkrankungen zählen (Heinemann u.a. 2007). Humane Prionkrankheiten werden in drei ätiologische Kategorien unterteilt: Prionkrankheiten, die erworben werden (Kuru, iCJD, nvCJD), die genetisch bedingt sind (gCJD, GSS, FFI) und solche, die sporadisch, d.h. ohne erkennbare Ursache auftreten (bspw. sCJD). Allen gemein sind pathologische, spongiforme Veränderungen des Gehirngewebes und amyloide $\mathrm{PrP}^{\mathrm{Sc}}$-Ablagerungen, deren Ausprägung abhängig von der Prionkrankheit ist. Zudem gibt es eine enge Korrelation zwischen molekularen Eigenschaften resp. der Kombination aus $\mathrm{PrP}^{\mathrm{Sc}}$-Typ und Prnp Codon 129-Genotyp und pathologischen Eigenschaften, definiert über die Kombination aus spongiformen Veränderungen und $\mathrm{PrP}^{\mathrm{Sc}}$-Ablagerungen im Gehirn und klinischen Eigenschaften wie bspw. Krankheitsdauer, Alter bei Krankheitsbeginn und klinische Symptome (Parchi, Strammiello u. a. 2011).

Humane Prionkrankheiten sind nicht im üblichen Sinne infektiös, d.h. sie werden nicht durch gängige soziale Kontakte oder pflegerische Maßnahmen von Mensch zu Mensch übertragen (Simon u.a. 1998). Die Übertragung auf Versuchstiere erfordert im Allgemeinen große Mengen erregerhaltigen Materials und die Übertragbarkeit wird per Infektionsroute moduliert (Diringer 1990). Im Tierversuch ist die intrazerebrale Infektionsroute die effizienteste, bei der eine infektiöse Einheit ausreichend ist, um Tiere mit einer Wahrscheinlichkeit von 50 \% zu infizieren. Darauf folgen die intravenöse (10 Einheiten), die intraperitoneale (100 Einheiten), die subkutane $\left(10^{4}\right.$ Einheiten) und die orale Infektionsroute $\left(10^{5}\right.$ Einheiten). Die Inkubationszeiten der erworbenen humanen Prionkrankheiten können beim Menschen Jahre bis Jahrzehnte betragen und stehen wie auch die klinischen Symptome im Zusammenhang mit der Infektionsroute (Ricketts u. a. 1997, Centers for Disease Control and Prevention 1997, Collinge, Whitfield u. a. 2006, P. Brown, Brandel u. a. 2012).

\subsubsection{Formen}

Die Kuru-Krankheit trat im 20. Jahrhundert beim Volk der Fore auf Papua-Neuguinea epidemieartig auf und blieb grundsätzlich auf dieses beschränkt. Rückblickend begann die Epidemie wahrscheinlich Ende des 19. Jahrhunderts, ausgehend von einem einzigen sporadischen Fall. Die Ursache der Verbreitung war Kannibalismus, der in Form des rituellen Verzehrs von Fleisch verstorbener Stammesmitglieder und des intensiven Kontakts mit deren hoch infektiösem Gehirn durchgeführt wurde. Im Jahr 1954 wurde dieser auf der Insel verboten, wonach Kuru immer seltener auftrat (Collinge, Whitfield u. a. 2006). Die iCJD wird durch das Einbringen humaner Prionen in den Körper während medizinischer Eingriffe verursacht, bspw. bei der Transplantantion kontaminierter Augenhornhaut oder Hirnhaut, der Gabe humaner Wachstumshormone oder 
der Verwendung unzureichend sterilisierten Operationsbestecks (Duffy u. a. 1974, Bernoulli u. a. 1977, Koch u. a. 1985, Thadani u. a. 1988, P. Brown 1996, Simon u. a. 1998, P. Brown, Preece u. a. 2000). Die Homozygotie für Methionin am Prnp Codon 129 ist mit einer höheren Empfänglichkeit gegenüber der iCJD assoziiert (Collinge, Palmer u. a. 1991, P. Brown, Cervenáková u. a. 1994, Deslys, Marcé u. a. 1994, Kretzschmar 2001). Die nvCJD wird mit dem Verzehr von BSE-infiziertem Rindfleisch in Verbindung gebracht (Hill, Desbruslais u. a. 1997, Collinge 1999). Alle bis zum Jahr 2001 identifizierten Patienten mit nvCJD zeigten am Prnp Codon 129 eine Homozygotie für Methionin (Will 2001). Zudem konnte eine experimentelle Transmission mittels Übertragung von Blutprodukten gezeigt werden (Andréoletti u. a. 2012, Douet u. a. 2014).

Bisher wurden mehr als 30 pathogene Mutationen des Prnp mit den genetischen bzw. vererbbaren humanen Prionkrankheiten assoziiert (Lloyd u. a. 2013). Einige dieser Mutationen zeigen eine Penetranz von 100 \%, d.h. jeder davon Betroffene erkrankt im Laufe des Lebens an der entsprechenden Prionkrankheit, andere sind weniger penetrant. Die klassischen Phänotypen der genetischen Prionkrankheiten - gCJD, GSS und FFI - wurden schon über ihre klinischen und neuropathologischen Eigenschaften definiert, bevor die dem zugrunde liegende genetische Basis entdeckt wurde. Zum GSS führt bspw. der Austausch (Substitution) von Leuzin (P) gegen Prolin (L) an Codon 102 (P102L) (Hsiao, Baker u. a. 1989, Doh-ura u. a. 1989). Zur gCJD führt bspw. die Substitution von Glutamin (E) gegen Lysin (K) an Codon 200 (E200K) oder die von Valin (V) gegen Isoleuzin (I) an Codon 210 (V210I) (Goldgaber u. a. 1989, Pocchiari, Salvatore u. a. 1993). Die Substitution von Asparaginsäure (D) gegen Asparagin (N) am Codon 178 (D178N) kann sowohl zur FFI als auch zur gCJD führen (Goldfarb, Haltia u.a. 1991, Medori u. a. 1992). Dies hängt von der Ausprägung des Prnp Codon 129-Polymorphismus ab. Kodiert dieser homozygot für Methionin, so führt dies zur Pathogenese einer FFI, kodiert er homozygot für Valin, dann führt dies zur Pathogenese einer gCJD.

Die sCJD ist mit etwa $85 \%$ die am häufigsten vorkommende CJD (Prusiner und DeArmond 1994). Diese zeigt eine hohe klinisch-pathologische Variabilität, welche wesentlich durch den Prnp Codon 129-Genotyp und den PrP ${ }^{\text {Sc }}$-Typ moduliert wird (Parchi, Castellani u. a. 1996). Die Kombination dieser beiden Determinanten führt zu sechs molekularen sCJD-Formen: MM1, MM2, MV1, MV2, VV1 und VV2, mit distinkten klinisch-neuropathologischen Phänotypen (Parchi, Giese u. a. 1999, Hill, Joiner, Wadsworth u. a. 2003, Cali u. a. 2006).

\subsubsection{Klinik und Neuropathologie}

Beide Geschlechter sind etwa gleichermaßen von Prionkrankheiten betroffen. Die symptomatische Phase beginnt bei den genetischen Formen meist früher als bei der sCJD. Das Alter bei Krankheitsbeginn liegt bei diesen häufig im vierten bis fünften und bei der sCJD im sechsten Lebensjahrzehnt. Die Krankheitsdauer wird definiert als die Zeit vom Auftreten der ersten Symptome bis zum Tod. Diese dauert bei den genetischen Formen typischerweise fünf bis sieben Jahre und bei der sCJD vier bis sechs Monate 
(Sturzenegger 2001).

Bei der gCJD steht klinisch eine progrendiente Demenz im Vordergrund. Die neuropathologischen Veränderungen betreffen vorwiegend den Kortex und $\mathrm{PrP}^{\mathrm{Sc}}$-Ablagerungen sind immunhistochemisch nachweisbar. Beim GSS treten zwei klinische Formen auf: der klassisch-ataktische und der dementielle Phänotyp (Hsiao und Prusiner 1990). Die neuropathologischen Veränderungen betreffen vorwiegend die Klein- bzw. die Großhirnrinde und $\mathrm{PrP}^{\mathrm{Sc}}$-Ablagerungen sind immunhistochemisch nachweisbar (P. Brown, Kenney u. a. 1995, Budka 2001b). Bei der FFI steht klinisch eine zunehmende Schlafstörung im Vordergrund. Die neuropathologischen Veränderungen betreffen vorwiegend den Thalamus und den Olivenkern und $\mathrm{PrP}^{\mathrm{Sc}}$-Ablagerungen sind immunhistochemisch nicht oder nur schwer nachweisbar (Gambetti, Parchi u.a. 1995 , Budka u.a. 1997, Budka 2001a).

Die sCJD kann in sechs molekulare Formen unterteilt werden, die über die Kombination aus Prnp Codon 129-Genotyp und $\mathrm{PrP}^{\mathrm{Sc}}$-Typ definiert sind (Parchi, Giese u.a. 1999). Die molekulare Form sCJD MM1 ist mit etwa $70 \%$ die am häufigsten vorkommende Kombination aus Prnp Codon 129-Genotyp und $\mathrm{PrP}^{\mathrm{Sc}}$-Typ und mit der typischen CJD-Erkrankung assoziiert. Klinisch steht ein rasch fortschreitender Verlauf mit Demenz im Vordergrund. Die neuropathologischen Veränderungen betreffen vorwiegend den Kortex und $\mathrm{PrP}^{\mathrm{Sc}}$-Ablagerungen sind immunhistochemisch nachweisbar. Die sCJD-MM2 kommt in etwa $4 \%$ der Fälle vor und kann in zwei weitere Formen unterteilt werden, die kortikale und die thalamische Form, die je $2 \%$ der Fälle ausmachen. Bei der kortikalen Form steht klinisch eine progressive Demenz im Vordergrund. Die neuropathologischen Veränderungen betreffen vorwiegend den Kortex und $\mathrm{PrP}^{\mathrm{Sc}}$-Ablagerungen sind immunhistochemisch nachweisbar. Bei der thalamischen Form ähneln die Symptome denen der FFI und die neuropathologischen Veränderungen betreffen vorwiegend den Thalamus und die untere Olive. Die sCJD MV1 kommt in etwa $3 \%$ der Fälle vor und ist klinisch und neuropathologisch grundsätzlich nicht von der sCJD MM1 zu unterscheiden. Die sCJD MV2 liegt in etwa $8 \%$ der Fälle vor. Klinisch steht eine Ataxie im Vordergrund. Die neuropathologischen Veränderungen betreffen vorwiegend das Kleinhirn. Die sCJD VV1 kommt in etwa $1 \%$ der Fälle vor. Klinisch steht eine progressive Demenz im Vordergrund. Die neuropathologischen Veränderungen betreffen vorwiegend den Kortex und die Basalganglien, das Kleinhirn ist nur minimal betroffen. $\mathrm{PrP}^{\mathrm{Sc}}$-Ablagerungen sind immunhistochemisch nicht oder nur schwer nachweisbar. Die sCJD VV2 kommt in etwa $14 \%$ der Fälle vor. Klinisch steht eine Ataxie im Vordergrund. Die neuropathologischen Veränderungen betreffen vorwiegend das Kleinhirn und den Hirnstamm, der Kortex ist nur in tiefen Rindenschichten betroffen. $\mathrm{PrP}^{\mathrm{Sc}}$-Ablagerungen sind immunhistochemisch nachweisbar (Kretzschmar 2001).

\subsubsection{Diagnose}

Die sCJD kann als mögliche, wahrscheinliche oder definitive sCJD diagnostiziert werden. Dabei werden die diagnostischen Kriterien von der möglichen bis zur definitiven 
Diagnose schrittweise eingeschränkt, um diese gegen andere Krankheiten mit ähnlicher Symptomatik abzugrenzen. Als technische Untersuchungen können der Nachweis periodischer Sharp-Wave-Komplexe im EEG, der hyperintenser Basalganglien in der MRT, der einer erhöhten 14-3-3-Protein-Konzentration im Liquor, der einer erhöhten Tau-Protein-Konzentration im Liquor und der spongiformer Veränderungen und/oder des $\mathrm{PrP}^{\mathrm{Sc}}$ im Gehirn mittels neuropathologischer Untersuchungen verwendet werden (Hsich u.a. 1996, Finkenstaedt u. a. 1996, Zerr, Bodemer u. a. 1998, Otto u. a. 2002, Zerr, Kallenberg u. a. 2009).

Die Kriterien für die Diagnose einer möglichen sCJD lauten: eine progressive Demenz mit einer Krankheitsdauer von unter zwei Jahren und zwei der folgenden vier klinischen Erscheinungen: Myoklonus (Muskelzuckungen), visuelle oder zerebelläre Symptome (bspw. Doppeltsehen oder Gangstörungen), pyramidale/extrapyramidale Störungen (Bewegungsstörungen) und akinetischer Mutismus. Darauf aufbauend müssen für die Diagnose einer wahrscheinlichen sCJD zusätzlich ein positives EEG und/oder ein positiver 14-3-3-Protein Befund vorliegen. Zur Diagnose einer definitiven sCJD ist eine neuropathologische Untersuchung erforderlich, bei der eine spongiforme Veränderung des Gewebes und/oder das Vorhandensein von $\mathrm{PrP}^{\mathrm{Sc}}$ nachgewiesen wird. Differenzial-diagnostisch sind bei älteren Patienten vorwiegend der Morbus Alzheimer und bei jüngeren Patienten Entzündungen des Zentralnervensystems in Betracht zu ziehen (Collins 2006, Deutsche Gesellschaft für Neurologie 2008).

Zur Diagnose der genetischen Prionkrankheiten sind, neben der Analyse des Prnp auf Mutationen, keine weiteren formalen Kriterien definiert, gleichwohl können die der sCJD verwendet werden. Von einer genetischen Prionkrankheit wird gesprochen, wenn diese erstmals in der Familie des Betroffenen auftritt, wohingegen bei einer familiären Prionkrankheit weitere Fälle in der Familie identifiziert werden konnten (Lloyd u. a. 2013).

Die klinische Heterogenität der Prionkrankheiten macht deren Diagnose zu einer Herausforderung, da die Symptome insbesondere zu Beginn wenig spezifisch sind. Neue diagnostische Methoden, wie die Messung der 14-3-3-Protein-Konzentration im Liquor und die Testung mittels MRT, ermöglichen eine frühere Diagnose als zuvor. Jedoch wird - bspw. aufgrund der kurzen symptomatischen Phase - die Diagnose einer wahrscheinlichen sCJD häufig erst im mittleren oder späten Krankheitsstadium gestellt. $\mathrm{Zu}$ diesem Zeitpunkt leiden die Betroffenen meist schon an schweren neurologischen Defiziten. Daher ist eine frühere Diagnose von entscheidender Bedeutung für einen Behandlungsbeginn (Zerr 2009).

\subsubsection{Therapie}

Bisher ist jedoch keine effektive Behandlung für Prionkrankheiten verfügbar (Zerr 2009). Um klinische Studien mit aussagekräftigen Ergebnissen zu erstellen, müssen Wirkstoffe an einer großen Anzahl von Patienten getestet werden. Da Prionkrankheiten selten vorkommen, kann dies in einzelnen Ländern lange Studiendauern erfordern. Daher können aussagekräftige Studien in vertretbarer Zeit nur mittels länderübergreifen- 
der Zusammenarbeit von Studienzentren erstellt werden. Dies unterstreicht die Wichtigkeit einer sorgfältigen Auswahl von Wirkstoffen, die in klinischen Studien getestet werden können. Bei der Auswahl potentieller Wirkstoffe müssen deren pharmakokinetischen Eigenschaften sorgfältig bedacht werden. Der Weg des Wirkstoffs zum Gehirn spielt hierbei eine entscheidende Rolle. Aufgrund der geringeren Komplikationsgefahr ist die Verabreichung über die orale oder subkutane Route besser geeignet als bspw. die intraventrikuläre Verabreichung. Dafür muss der Wirkstoff jedoch in der Lage sein, die bei CJD intakte Blut-Hirn-Schranke in ausreichender Menge zu überwinden. Weiterhin müssen durch den Wirkstoff verursachte Nebenwirkungen und dessen Toxizität auf den Menschen in die Auswahl mit einbezogen werden. Obwohl Wirkstoffe gefunden wurden, die der PrP-Konversion im Zell- und/oder im Tiermodell entgegenwirkten, stellte sich deren Nutzbarkeit für die humane Therapie aufgrund dieser Limitationen als begrenzt heraus (Rossi u. a. 2003, Ludewigs u. a. 2007). Die Veröffentlichungen von Trevitt u. a. 2006 und Stewart u. a. 2008 fassen die bis dato untersuchten Wirkstoffe zusammen.

Die Gruppe der Tetrazykline ist nur begrenzt toxisch und einige ihrer Derivate, darunter auch Doxyzyklin, passieren die Blut-Hirn-Schranke (Sande u. a. 1991, Colovic u. a. 2003). Tetrazykline interagierten mit PrP-Aggregaten, die sowohl aus synthetischen PrP-Peptiden bestehen als auch TSE-Gehirnen entstammen konnten. Sie destabilisierten die Struktur von Amyloid-Fibrillen, indem sie ihre Resistenz gegenüber dem PK-Verdau reduzierten, und inhibierten die mit dem $\mathrm{PrP}^{\mathrm{Sc}}$ assoziierte Proteinkonversion. Diese wurden von einer Reduktion der Infektiosität begleitet, welche durch die kurativen Effekte der Behandlung mit Doxyzyklin nach peripherer oder intrazerebraler Infektion bekräftigt wurden. Die in vitro-Inkubation mit Doxyzyklin, in Konzentrationen von $10 \mu \mathrm{M}$ bis $1 \mathrm{mM}$, führte zu einer dosisabhängigen Reduktion der PK-Resistenz von $\mathrm{PrP}^{\mathrm{Sc}}$ und wurde Gehirnhomogenat von Scrapie-infizierten Hamstern zuerst mit $1 \mathrm{mM}$ Doxyzyklin inkubiert und nachfolgend in gesunde Hamster inokuliert, dann verlängerte dies die Überlebenszeit der Hamster (Forloni, Iussich u. a. 2002). Nach vorangegangener Infektion verlängerte Doxyzyklin die Überlebenszeit Scrapie-infizierter Hamster auch bei subkutaner Gabe (Luigi u. a. 2008, Forloni, Salmona u. a. 2009). Zur Wirkung von Doxyzyklin bei Patienten mit CJD wurde eine doppelt-verblindete, Placebo-kontrollierte Phase 2-Studie veröffentlicht (Haïk u. a. 2014). Darin wurden 162 Patienten mit sCJD oder gCJD täglich mit $100 \mathrm{mg}$ Doxyzyklin $(\mathrm{n}=62)$ oder Placebo $(\mathrm{n}=59)$ behandelt. Die Studie ergab jedoch keinen signifikanten Unterschied zwischen den beiden Gruppen, gemessen an der Überlebenszeit der Patienten.

\subsubsection{Charakterisierung von Prionstämmen}

Prion-Isolate, die nach der Übertragung von infektiösem Material im in vivo-Tiermodell unterschiedliche Krankheitsphänotypen hervorrufen, werden oft als Stämme bezeichnet. Prionstämme können anhand von sieben Kriterien unterschieden werden: klinische Symptomatik, Inkubationszeit, Übertragbarkeit, histopathologische Läsionsprofile, Inaktivierungsverhalten, PK-Resistenz des $\mathrm{PrP}^{\mathrm{Sc}}$ und $\mathrm{PrP}^{\mathrm{Sc}}$-Glykosylierung (Pattison u. a. 1961, Kimberlin u. a. 1978, Fraser u.a. 1973, Taraboulos u. a. 1992,Bessen u. a. 
1994, Safar, J., G. u. a. 1998). Dabei stellen die Inkubationszeit und das histopathologische Läsionsprofil die wesentlichen Unterscheidungskriterien dar (Bruce 1996, Bruce und Dickinson 1979).

Die heterogenen klinischen und pathologischen Eigenschaften der humanen Prionkrankheiten sowie Untersuchungen zum Molekulargewicht, zur Proteinase-Resistenz und zur Glykosylierung des humanen $\mathrm{PrP}^{\mathrm{Sc}}$ weisen auf das Vorhandensein mehrerer humaner Prionstämme hin (Parchi, Castellani u. a. 1996, Collinge, Sidle, Katie C L u. a. 1996, Bruce, Will u. a. 1997, Parchi, Boni u. a. 2012). Wurde bspw. Gehirnmaterial von Patienten mit den molekularen sCJD-Formen (MM1, MM2, MV1, MV2, VV1, VV2) auf transgene Mäuse übertragen, welche die verschiedenen humanen Prnp Codon 129Genotypen exprimierten (MM, MV oder VV), dann wurden charakteristische Inkubationszeiten und histopathologische Läsionsprofile beobachtet. Diesen Experimenten folgend und basierend auf den Transmissionscharakteristika und PK-Resistenzen dieser sCJD-Formen (Alpérovitch u. a. 1999) wurde die Existenz von vier humanen sC.JDPrionstämmen postuliert: MM1/MV1 als klassischer Phänotyp, MV2/VV2, VV1 und MM2 (Bishop u. a. 2010).

\subsection{Methoden zur Untersuchung der Prionkonversion}

Die größte Einschränkung bei der Verwendung von in vivo-Tiermodellen ist, dass die Prionkonversion während der Inkubationsphase sehr langsam voranschreitet und einige Monate oder sogar Jahre vergehen können, bis eine detektierbare Menge an $\mathrm{PrP}^{\mathrm{Sc}}$ im Gehirn abgelagert ist. Zudem gilt die Konversion von $\operatorname{PrP}^{\mathrm{C}}$ zu $\mathrm{PrP}^{\mathrm{Sc}}$ zwar als essentielles Element der Krankheitsursache, dieses wurde jedoch noch nicht vollständig verstanden. Insbesondere müssen die Fragen nach dem grundlegenden dies verursachenden Mechanismus und danach, ob andere Faktoren dabei eine Rolle spielen, noch beantwortet werden. Zum besseren Verständnis des Mechanismus der Prionkonversion, der Natur des infektiösen Agens und in der Bestrebung, eine weniger invasive und schnellere diagnostische Methode als die Gehirnbiopsie und den Bioassay verfügbar zu machen, wurde eine in vitro-Methode entwickelt, bei der die Prionkonversion in einem Reagiergefäß simuliert wird - die PMCA (Saborio u. a. 2001, Soto u. a. 2002). Bei dieser werden die replizierenden Eigenschaften des $\mathrm{PrP}^{\mathrm{Sc}}$ als Basis genutzt, um eine experimentell beschleunigte Prionkonversion herbeizuführen. Es wird infiziertes Gehirnmaterial zu nicht infiziertem gegeben und die Mischung abwechselnden Inkubationsund Fragmentationsphasen unterzogen. In der Inkubationsphase wandelt das $\mathrm{PrP}^{\mathrm{Sc}}$ aus dem infizierten Gehirnmaterial in Funktion einer Saat das $\mathrm{PrP}^{\mathrm{C}}$ aus dem nicht infizierten in Funktion eines Substrats in neue Saatpartikel um. Diese aggregieren zu partiell PK-resistenten PrP-Amyloiden, die in der anschließenden Fragmentationsphase durch Ultraschallwellen fragmentiert werden. Durch abwechselnde Wiederholung der beiden Phasen wird die Anzahl an Saatpartikeln exponentiell erhöht. Am Ende des Experiments werden die PrP-Amyloide mittels Kombination aus PK-Verdau und Western Blot detektiert. Die bei der PMCA generierten Saatpartikel, das sog. $\mathrm{PrP}^{\text {Res }}$, zeigten zum $\mathrm{PrP}^{\mathrm{Sc}}$ vergleichbare biochemische und strukturelle Eigenschaften und deren In- 
okulation in Wildtyp-Hamster führte zu einem Scrapie-ähnlichen Krankheitsbild, das identisch mit dem durch Scrapie-infiziertes Gehirnmaterial erzeugten war (Castilla, Saá, Hetz u. a. 2005, Castilla, Saá, Morales u. a. 2006).

\subsubsection{Zellfreie in-vitro-Methoden}

Auf der Grundlage der PMCA wurden mehrere zellfreie in vitro-Methoden, wie bspw. die rPrP-PMCA, der ASA und die S-QuIC, entwickelt (Orrú, Wilham, Vascellari u. a. 2012). Bei diesen wird im Unterschied zur PMCA dem $\mathrm{PrP}^{\mathrm{Sc}}$ aus der Probe recPrP $\mathrm{P}^{\mathrm{C}}$ als Substrat zur Verfügung gestellt. Bei der rPrP-PMCA werden die PrP-Amyloide in der Fragmentationsphase durch Ultraschallwellen und bei der S-QuIC durch Vibration zerstört und bei beiden erfolgt die Detektion mittels PK-Verdau und Western Blot (Saá u. a. 2006, Atarashi, Moore u. a. 2007, Atarashi, Wilham u.a. 2008, Orrú, Wilham, Hughson u. a. 2009). Bei der ASA werden die PrP-Amyloide durch Vibration zerstört und die Detektion erfolgt in Echt-Zeit mittels Fluoreszenzfarbstoffanalyse (Colby, Zhang u. a. 2007, Colby, Wain u. a. 2010). Obwohl diese drei Methoden schnellere und praktikablere Methoden zur Detektion des Prionreplikationsvermögens sind als bspw. das in vivo-Tiermodell, unterliegen sie dennoch einigen Einschränkungen (Wilham u. a. 2010, Orrú, Wilham, Raymond u. a. 2011, Orrú und Caughey 2011, Atarashi, Satoh u. a. 2011, Atarashi, Sano u. a. 2011, Orrú, Wilham, Vascellari u. a. 2012). Die rPrPPMCA erfordert eine Ultraschallbehandlung, die schwierig zu kontrollieren sein und infolge dessen inkonsistente Ergebnisse produzieren kann. In der S-QuIC und der ASA wird diese Ultraschallbehandlung durch die leichter zu kontrollierende und zu reproduzierende Vibration ersetzt. Jedoch wird bei der S-QuIC wie auch bei der PMCA jede Reaktion in einem separaten Reaktionsgefäß durchgeführt und das Reaktionsprodukt mittels eines zeitaufwändigen PK-Verdaus und Western Blot nachgewiesen. In der ASA werden die Reaktionen auf Multiwell-Mikrotiterplatten zusammengefasst. Jedoch steigen die Fluoreszenzsignale Prion-negativer Proben bei dieser in ähnlicher Weise an wie die Prion-positiver Proben, sodass eine Unterscheidung nur über einen sehr sorgfältigen Vergleich der Signale möglich ist.

\subsubsection{Real-Time Quaking-Induced Conversion}

Die RT-QuIC ist eine Weiterentwicklung der Methoden rPrP-PMCA, ASA und SQuIC und kombiniert die für einen hohen Probendurchsatz geeignete Multiwell-Mikrotiterplatte mit der leichten Reproduzierbarkeit der automatisierten Vibration sowie mit Konditionen, die wie in der S-QuIC die spontane Formation falsch-positiver PrP-Amyloide minimieren (Orrú, Wilham, Vascellari u. a. 2012). Die RT-QuIC besteht ebenso wie ihre Vorgänger aus abwechselnden Inkubations- und Fragmentationsphasen. In der Inkubationsphase wandelt das $\mathrm{PrP}^{\mathrm{Sc}}$ aus der Probe in Funktion der Saat das recPrP $\mathrm{P}^{\mathrm{C}}$ in Funktion des Substrats um und induziert dadurch das Wachstum von PrP-Amyloiden. In der Fragmentationsphase werden diese Amyloide mittels Vibration fragmentiert, wodurch die Anzahl von Saatpartikeln in jedem Zyklus exponentiell 
gesteigert wird. Eine voreingestellte Anzahl an Phasen wird in einem Mikrotiterplatten-Lesegerät vollautomatisch und temperaturkontrolliert durchgeführt, während das Gerät die Menge der PrP-Amyloide mittels Fluoreszenzfarbstoffanalyse in regelmäßigen Abständen detektiert (Wilham u. a. 2010, Atarashi, Sano u. a. 2011). Bild 2 auf S. 14 zeigt diesen Prozess schematisch.

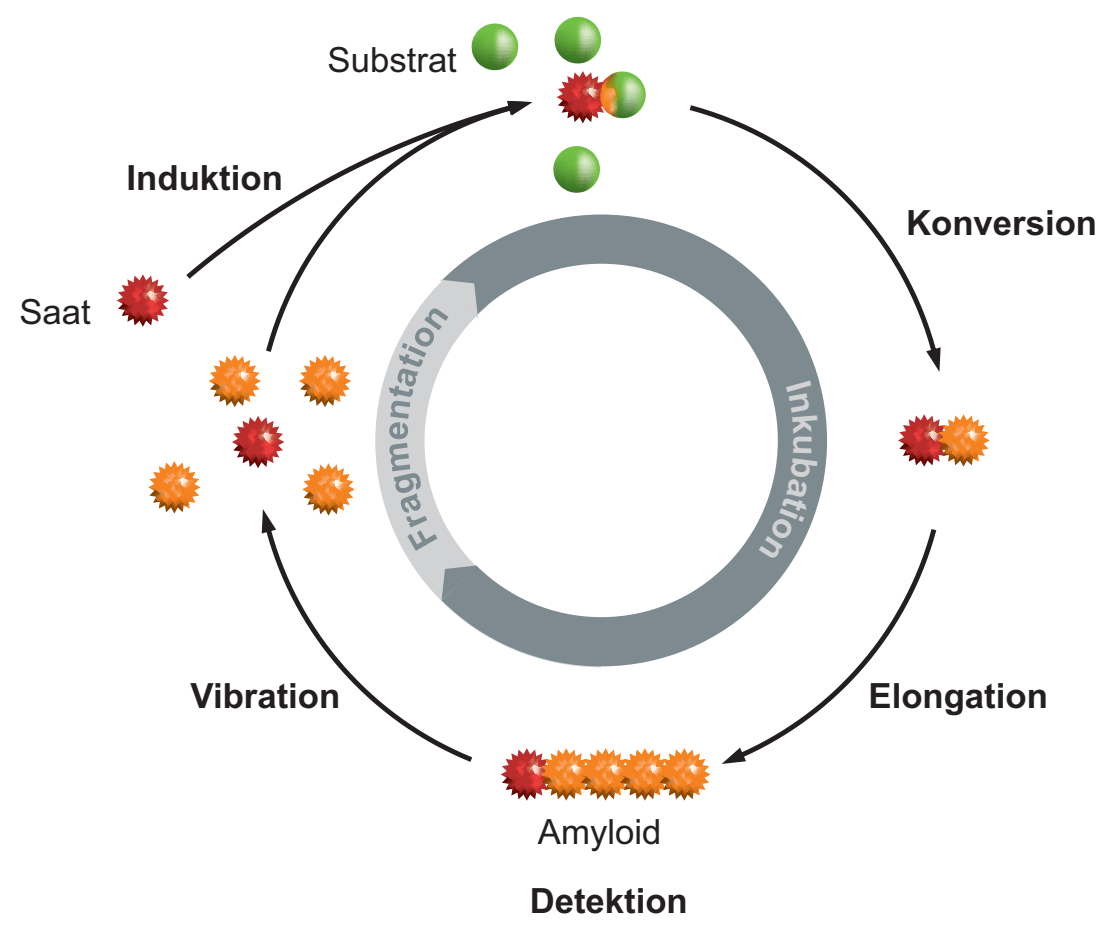

Bild 2: Schematische Darstellung des RT-QuIC-Prozesses

Die RT-QuIC besteht aus abwechselnd durchgeführten Inkubations- und Fragmentationsphasen. In der Inkubationsphase wandelt das $\mathrm{PrP}^{\mathrm{Sc}}$ aus der Probe in Funktion der Saat recPrP $\mathrm{P}^{\mathrm{C}}$ in Funktion des Substrats um, wodurch das Wachstum von PrP-Amyloiden induziert wird. In der Fragmentationsphase werden diese Amyloide mittels Vibration fragmentiert, wodurch die Anzahl von potentiellen Saatpartikeln exponentiell gesteigert wird. Eine voreingestellte Anzahl an Phasen wird in einem Mikrotiterplatten-Lesegerät vollautomatisch und temperaturkontrolliert durchgeführt, während das Gerät die Menge der PrP-Amyloide mittels Fluoreszenzfarbstoffanalyse in regelmäßigen Abständen detektiert.

Mit humanem Gehirnmaterial generierte RT-QuIC-Ergebnisse zeigten erstmals distinkte Fluoreszenzsignale für verschiedene sCJD-Formen (Peden u.a. 2012). Verglichen mit den häufiger vorkommenden sCJD MM1- und sCJD MV1-Formen zeigten die atypischen CJD-Formen sCJD MM2 und sCJD VV1 sowie die nvCJD längere Zeiten bis zum Signalanstieg und/oder niedrigere Signalmaxima, was auf einen verzögerten und langsameren Konversionsprozess hindeutet. Ob die verschiedenen Signale eine allgemeine Eigenschaft dieser sCJD-Formen sind oder ausschließlich dem untersuchten eher kleinen Probensatz zuzuordnen waren, gilt es noch zu prüfen. Die Analyse von humanem Liquor mittels RT-QuIC ergab eine Sensitivität von über $80 \%$ und eine 
Spezifität von $98-100 \%$, was deren Potential zeigt, ein spezifischerer diagnostischer Test für sCJD zu sein als vorhandene Liquortests (Atarashi, Satoh u. a. 2011, McGuire u. a. 2012). Obwohl die Natur der die RT-QuIC-Reaktion auslösenden Saat im Liquor noch nicht vollständig geklärt ist, erscheint eine krankheitsassoziierte Form des PrP plausibel. Diese Hypothese kann die höhere Spezifität der RT-QuIC im Vergleich zum 14-3-3-Protein im Liquor erklären, welches als Folge allgemeiner neuronaler Schäden in diesen entlassen wird. Zudem ergaben Untersuchungen des mit humanem Gehirn als Saat generierten $\mathrm{PrP}^{\text {Res }}$ eine PK-Resistenz, die auch bei mit humanem Liquor produzierten $\operatorname{PrP}^{\text {Res }}$ gefunden wurde (McGuire u. a. 2012). 


\section{Aufgabenstellung und Zielsetzung}

Die Verfügbarkeit einer Methode zum sicheren Nachweis des $\operatorname{PrP}^{\mathrm{Sc}}$ im Liquor kann die Diagnostik von Prionkrankheiten verbessern und neue Wege zur Behandlung eröffnen. Die hohe Spezifität, die Nutzung des pathologischen Prozesses und das hohe Standardisierungspotential sprechen für eine Eignung der RT-QuIC zum Einsatz in der Diagnostik. Jedoch ist zur Klärung der Eignung noch eine umfassende Evaluierung der Methode notwendig. Neue Erkenntnisse im Bereich der humanen Prionstämme können zu einem besseren Verständnis der der Heterogenität zugrunde liegenden molekularen Prozesse und daraus folgend zur Entwicklung neuer Therapiestrategien beitragen. Die Durchführbarkeit der RT-QuIC mit humanem Liquor bietet eine neue Möglichkeit, diese potentiellen Erreger-Stämme zu charakterisieren. Die Verfügbarkeit eines WirkstoffSuchtests, der auf den pathologischen Eigenschaften humaner Proben basiert, kann die Suche nach Medikamenten zur Behandlung von Prionkrankheiten erleichtern und somit beschleunigen. Die Nutzung des pathologischen Prozesses, der hohe Automatisierungsgrad und die Eignung zum Hochdurchsatz-Screening sprechen für eine Eignung der RT-QuIC als Wirkstoff-Suchtest, die jedoch noch geprüft werden muss. Basierend auf diesen Schlussfolgerungen wurden folgende Aufgaben für diese Arbeit formuliert:

1. Methodische Optimierung der RT-QuIC. Mittels Analyse einer möglichst großen Anzahl humaner Liquorproben sollen die Gütekriterien der Methode bestimmt werden. Eine positive Bewertung der Methode, gemessen an einer hohen Validität, guten Reproduzierbarkeit und hohen Stabilität, ist eine notwendige Voraussetzung für die Durchführung der zweiten und dritten Aufgabe.

2. Charakterisierung des Reaktionspotentials potentieller humaner Prionstämme mittels RT-QuIC. Hierfür soll eine möglichst große Anzahl Liquorproben von humanen Prionkrankheiten mittels RT-QuIC analysiert werden. Nachfolgend sollen die Ergebnisse sowohl auf Übereinstimmungen mit potentiellen humanen Prionstämmen als auch auf Korrelationen mit klinischen und pathologischen Eigenschaften der humanen Prionkrankheiten, wie bspw. der Einfluss des Prnp Codon 129Polymorphismus, geprüft werden.

3. Nutzung der RT-QuIC als neuartige Methode zur Wirkstoffsuche. Dazu soll die Wirkung von mehreren Stoffen auf die RT-QuIC-Reaktion untersucht werden darunter auch Doxyzyklin, der bis dato vielversprechendste potentielle Wirkstoff.

Die Erkenntnisse dieser Arbeit sollen dazu dienen, die methodischen Möglichkeiten in der Diagnostik von und der Forschung an humanen Prionkrankheiten zu verbessern sowie mehr Informationen über potentielle humane Prionstämme zu erlangen, um letztendlich neue Ansätze zur Behandlung von Prionkrankheiten zu finden. 


\section{Material und Methoden}

In Anhang A sind die häufig verwendeten Geräte (Unterabschnitt A.1), Verbrauchsmateriale (Unterabschnitt A.2), anorganischen und organischen Stoffe (Unterabschnitt A.3), gebrauchsfertigen Lösungen und Puffer (Unterabschnitt A.4) sowie Reaktionssysteme (Unterabschnitt A.5) aufgeführt.

\subsection{Proben}

In dieser Arbeit wurden humane Proben verwendet. Diese Proben wurden vom NRZ für TSE zur Verfügung gestellt, vertreten durch die Leiterin Frau Prof. Dr. Inga Zerr. Das NRZ für TSE ist an die UMG angegliedert, bei deren Ethik-Komitee es die Verwendung dieser Proben zu Forschungszwecken beantragte.

\subsubsection{Deklaration}

Die hier verwendeten humanen Proben wurden im Rahmen des Ethik-Antrags „Biomarker based diagnosis or rapid progressive dementias - optimisation of diagnostic protocols" zur Verfügung gestellt. Das Ethikvotum liegt mit der Antragsnummer 24/8/12 vor (Zerr 2012). Das NRZ für TSE stellte außerdem folgende Daten zu den Proben zur Verfügung: Alter, Geschlecht, Diagnose, Krankheitsdauer, Krankheitsstadium zum Zeitpunkt der Probenentnahme, Prnp Codon 129-Genotyp, Prnp-Mutation, PrPSc Nachweis, $\mathrm{PrP}^{\mathrm{Sc}}$-Typ sowie die Konzentrationen des PrP-Proteins, Tau-Proteins und 14-3-3-Proteins im Liquor. Die Krankheitsdauer wurde definiert als der Zeitraum vom Auftreten der ersten Symptome bis zum Tod des Patienten. Um das Krankheitsstadium zum Zeitpunkt der Probenentnahme zu ermitteln, wurde die Krankheitsdauer in drei Intervalle gleichen Zeitumfangs geteilt. Das frühe Stadium wurde definiert als der Zeitraum vom Beginn der ersten Symptome bis zum Ende des ersten Intervalls. Es folgte das mittlere Stadium, definiert als zweites Intervall, und das späte Stadium, definiert als letztes Intervall der gesamten Krankheitsdauer.

Es wurden Proben von Patienten mit Prionkrankheiten verwendet. Die Diagnosen der Prionkrankheiten wurden mittels klinischer und neuropathologischer Untersuchungen gestellt und gesichert (nach World Health Organization 1998, Zerr, Pocchiari u. a. 2000 und Zerr, Kallenberg u. a. 2009). Diese Gruppe bestand aus Proben von Patienten mit sCJD, gCJD und FFI. Tabelle 3 führt die Anzahl der Liquorproben von Patienten mit Prionkrankheiten nach Gruppenzugehörigkeit resp. Diagnose auf. Außerdem wurden Proben von Patienten mit anderen Krankheiten verwendet. Die Diagnosen dieser 200 retrospektiven Kontrollen wurden überwiegend mittels klinischer Untersuchungen gestellt, wobei kein Verdacht auf eine Prionkrankheit bestand. Diese Gruppe bestand aus Proben von Patienten mit Morbus Alzheimer (mit klassischem oder schnellem Verlauf), vaskulärer Demenz, Synucleinopathien (bspw. Morbus Parkinson), Entzündungen des Zentralnervensystems (bspw. Meningitis), psychischen Erkrankungen (bspw. Depression), Epilepsie, Multiple Sklerose und anderen Krankheiten (bspw. Normaldruckhydrozephalus). Weiterhin wurden Proben von Patienten verwendet, die 
sich zum Zeitpunkt der Erhebung noch im diagnostischen Prozess befanden. Von diesen 200 prospektiven Kontrollen lag zum Zeitpunkt der Verwendung keine Diagnose vor. Tabelle 4 führt die Anzahl der Liquorproben von retrospektiven Kontroll-Patienten nach Gruppenzugehörigkeit resp. Diagnose auf.

Tabelle 3: Anzahl der Liquorproben von Patienten mit Prionkrankheiten nach Gruppenzugehörigkeit

\begin{tabular}{lr}
\hline Gruppe & Anzahl \\
\hline sCJD & 64 \\
gCJD (E200K-Mutation) & 33 \\
gCJD (V210I-Mutation) & 6 \\
FFI & 7 \\
\hline Gesamt & 110 \\
\hline
\end{tabular}

Tabelle 4: Anzahl der Liquorproben von retrospektiven Kontroll-Patienten nach Gruppenzugehörigkeit

\begin{tabular}{lr}
\hline Gruppe & Anzahl \\
\hline Morbus Alzheimer & 42 \\
Vaskuläre Demenz & 40 \\
Synucleinopathien & 32 \\
Entzündungen des Zentralnervensystems & 30 \\
Andere (Nicht-Prion) Erkrankungen & 25 \\
Psychische Erkrankungen & 12 \\
Epilepsie & 11 \\
Multiple Sklerose & 8 \\
\hline Gesamt & 200 \\
\hline
\end{tabular}

\subsubsection{Präanalytische Aufbereitung}

Die Liquorproben wurden den Patienten mittels Lumbalpunktion in Polypropylenröhren entnommen und für 10 Min bei 720 x $g$ zentrifugiert. Anschließend wurden Störfaktoren wie Hämolyse oder Trübung durch eine visuelle Kontrolle geprüft und dokumentiert. Dann wurden die Liquorproben auf Blutkontamination untersucht mittels eines kommerziell erhältlichen Hemastix-Teststreifens nach den Anweisungen des Herstellers Siemens Healthcare Diagnostics (Siemens Healthcare Diagnostics 2011). Nachfolgend wurden die Liquorproben in 2,0 ml-Reagiergefäßen (Eppendorf) bei $-80{ }^{\circ} \mathrm{C}$ gelagert. Blutkontaminierte Liquorproben wurden von der Verwendung in dieser Arbeit ausgeschlossen. Vor der weiteren Verwendung wurden die Liquorproben für $1-2 \mathrm{Std}$ bei $4{ }^{\circ} \mathrm{C}$ 
aufgetaut und für 30 Sek auf Stufe 10 gevortext, um eine optimale Durchmischung zu gewährleisten.

Die Gehirnproben stammten aus dem frontalen Kortex von Patienten mit neuropathologisch gesicherter sCJD. Diese wurden den Patienten nach dem Tod mittels Biopsie entnommen und unbehandelt in 2,0 ml-Reagiergefäßen bei $-80{ }^{\circ} \mathrm{C}$ gelagert. Die Gehirnproben wurden nachfolgend in einem Lysepuffer für 30 Sek homogenisiert, wobei das Verhältnis Gehirnprobe zu Lysepuffer 10 \% (w/v) betrug. Die Zusammensetzung des Lysepuffers ist in Tabelle 5 auf S. 19 aufgeführt. Danach wurden die Gehirnproben für 10 Min bei $10.000 \times \mathrm{g}$ zentrifugiert, um die Zelltrümmer zu entfernen. Das Pellet wurde verworfen und es wurde mit dem Überstand fortgefahren. Dieser wurde in 2,0 ml-Reagiergefäßen (Eppendorf) bei $-80{ }^{\circ} \mathrm{C}$ gelagert. Vor der weiteren Verwendung wurden die homogenisierten Gehirnproben für $1-2$ Std bei $4{ }^{\circ} \mathrm{C}$ aufgetaut und für 30 Sek auf Stufe 10 gevortext, um eine optimale Durchmischung zu gewährleisten. Direkt vor der Verwendung im Experiment wurden die homogenisierten Gehirnproben im Verhältnis 1:100.000.000 (in Unterabschnitt 4.2) oder 1:1.000 (in Unterabschnitt 4.3) in PBS (Biochrome) verdünnt.

Tabelle 5: Zusammensetzung des Lysepuffers

\begin{tabular}{lr}
\hline Stoff & Konzentration \\
\hline SDS & $1 \%(\mathrm{w} / \mathrm{v})$ \\
Tris $/ \mathrm{HCl}$ & $100 \mathrm{mM}$ \\
$\mathrm{NaCl}$ & $100 \mathrm{mM}$ \\
EDTA & $100 \mathrm{mM}$ \\
\hline
\end{tabular}

\subsection{Bestimmung des Prnp Codon 129-Genotyps mittels RFLP}

Der Begriff Polymorphismus bezeichnet die Koexistenz von zwei oder mehr deutlich verschiedenen Formen eines Merkmals bei den Individuen einer Population. Bei der RFLP-Methode führen Veränderungen in der DNA-Sequenz homologer Chromosomen zu unterschiedlichen Restriktionsfragmentmustern, von denen auf die Ausprägung des dem zugrunde liegenden Polymorphismus geschlossen werden kann (Grieß u. a. 1999).

Restriktionsenzyme sind in der Lage, spezifische DNA-Sequenzen, sogenannte Restriktionsschnittstellen, in der DNA zu erkennen, daran zu binden und diese an dieser Stelle zu verdauen (spalten). Die dabei entstehenden DNA-Abschnitte werden als Restriktionsfragmente bezeichnet. Diese Fragmente können mittels Gelelektrophorese der Länge nach geordnet werden (Campbell u. a. 2003). Wenn innerhalb einer Restriktionsschnittstelle eines Restriktionsenzyms Basen ausgetauscht sind, dann kann dies bei der Spaltung der DNA durch das Restriktionsenzym zum Verlust oder neuen Auftreten eines DNA-Fragments sowie zur Verlängerung oder Verkürzung vorhandener DNAFragmente führen. Daraus resultieren Veränderungen im Restriktionsfragmentmuster (Grießs u. a. 1999). 
Bei der Gelelektrophorese werden Makromoleküle, wie bspw. Nukleinsäuren oder Proteine, aufgrund ihrer Wanderungsgeschwindigkeiten durch ein Gel unter dem Einfluss eines elektrischen Feldes voneinander getrennt. Die Wanderungsgeschwindigkeit hängt von ihrer Größe, elektrischen Ladung und anderen Eigenschaften ab. Die Nukleinsäuren der DNA tragen negative Ladungen, deren Anzahl proportional zu ihrer Länge ist. Wird eine elektrische Spannung an das Gel angelegt, dann wandern diese vom Minus- zum Pluspol. Je größer (länger) die Nukleinsäuren sind, desto stärker werden sie dabei von der Gelmatrix an der Fortbewegung gehindert, der sog. Siebeffekt des Gels. Zur Analyse von Nukleinsäuren kann als Gelbildner bspw. Agarose verwendet werden. Das Agarosegel wird durch Aufkochen von Agarose in einem Elektrophoresepuffer hergestellt und enthält Taschen, in die später die Proben eingefüllt werden. Durch Erhitzen und Abkühlen bildet sich ein Agarosegel, dessen kettenförmige Moleküle über Wasserstoffbrücken vernetzt sind. Die dabei entstehenden Poren im Gel sind umso kleiner, je höher die Agarose konzentriert ist. Der Siebeffekt des Gels hängt von dessen Härte ab, je höher die Agarose konzentriert ist, desto härter resp. fester wird das Gel und desto stärker wirkt der Siebeffekt. Dann wird das Gel in eine Gelelektrophoresekammer gelegt, mit Gelelektrophoresepuffer bedeckt und die zu untersuchenden Proben werden zusammen mit Ladepuffer in die Geltaschen gefüllt. Die unterschiedlichen Wanderungsgeschwindigkeiten der Nukleinsäuren in den Gemischen führen zu spezifischen Bandenmustern im Agarosegel. Dabei enthält jede Bande $\mathrm{Nu}-$ kleinsäuren derselben Länge (Campbell u. a. 2003). Zur Analyse dieser Bandenmuster wird dem Gel Ethidiumbromid hinzugefügt, welches zwischen die Basen der Nukleinsäuren interkaliert und nach Anregung mit UV-Licht im sichtbaren Bereich des Lichts als orange-rot leuchtende Bande erscheint (Jansohn 2012).

Der Polymorphismus am Prnp Codon 129 wurde mittels RFLP-Analyse nach Windl u.a. 1999 bestimmt. Zuerst wurde DNA isoliert, dann das Prnp mittels PCR vervielfältigt, nachfolgend die PCR-Produkte mit einem spezifischen Restriktionsenzym verdaut, anschließend die Restriktionsfragmente mittels Agarose-Gelelektrophorese der Länge nach aufgetrennt und dann das Restriktionsfragmentmuster einer Ausprägung des Prnp Codon 129 Polymorphismus zugeordnet. Die Bestimmungen der Prnp V210I-, E200K- und D178N-Mutationen wurden ebenfalls mittels RFLP-Analyse nach Windl u. a. 1999 durchgeführt.

\subsection{Bestimmung des PrPsc-Typs mittels PK-Verdau und Western Blot}

Das $\mathrm{PrP}^{\mathrm{C}}$ ist gegenüber dem Verdau durch Proteasen sensitiver als das $\mathrm{PrP}^{\mathrm{Sc}}$, sodass das nach dem Protease-Verdau verbliebene $\mathrm{PrP}$ vorwiegend aus $\mathrm{PrP}^{\mathrm{Sc}}$ besteht (McKinley u. a. 1983). Die beiden PrP ${ }^{\text {Sc }}$-Typen, Typ 1 und Typ 2, unterscheiden sich nach dem PK-Verdau in ihren gelelektrophoretischen Bandenmustern (Parchi, Castellani u. a. 1996).

Beim Western Blot werden die Proteine zuerst mittels Gelelektrophorese nach ihrer Größe aufgetrennt, dann auf eine Membran geblottet (transferiert) und dort anschlie- 
ßend detektiert und visualisiert. Die Gelelektrophorese für Proteine folgt demselben Prinzip wie die für DNA (vgl. Unterabschnitt 3.2). Zur Analyse von Proteingemischen kann Polyacrylamid als Gelbildner verwendet werden. Außerdem kann dem Gel die negativ geladene Substanz SDS zugesetzt werden zur Solubilisierung (Erhöhung der Löslichkeit) und Denaturierung sowie zur Einführung einer negativen Gesamtladung der Proteine. Nach der gelelektrophoretischen Trennung werden die Proteine durch Anlegen einer elektrischen Spannung horizontal auf eine Trägermembran geblottet, wo sie stärker als im Gel fixiert sind. Nach der Fixierung auf der Membran können die Proteine mittels eines antikörperbasierten Nachweisverfahrens, nach demselben Prinzip wie beim ELISA (vgl. Unterabschnitt 3.4), detektiert werden (Burnette 1981; Jansohn 2012).

Der Nachweis des $\mathrm{PrP}^{\mathrm{Sc}}$ und dessen Unterscheidung in Typ 1 und Typ 2 wurden mittels PK-Verdau und Western Blot nach Parchi, Castellani u.a. 1996 erbracht. Zuerst wurde post mortem entnommenes Gehirngewebe in Lysepuffer lysiert, um die Zellen aufzuschließen. Danach wurde ein PK-Verdau durchgeführt, um $\mathrm{PrP}^{\mathrm{C}}$ und andere Proteine zu verdauen und zwischen PrPSc-Typ 1 und -Typ 2 zu unterscheiden. Nachfolgend wurden die Proteine auf einem SDS-Polyacrylamid-Gel gelelektrophoretisch aufgetrennt. Dann wurden diese vom Gel horizontal auf eine Trägermembran geblottet. Anschließend wurde das verbliebene $\mathrm{PrP}^{\mathrm{Sc}}$ mit dem Primärantikörper $3 \mathrm{~F} 4$ detektiert und anhand des spezifischen Bandenmusters einem der beiden $\mathrm{PrP}^{\mathrm{Sc}}$-Typen zugeordnet.

\subsection{Bestimmung von Proteinkonzentrationen mittels ELISA}

Der ELISA ist ein antikörperbasiertes Nachweisverfahren, bei dem die Eigenschaft von Antikörpern genutzt wird, spezifisch an nachzuweisende Stoffe (auch Antigene) zu binden (Engvall u. a. 1971; Weemen u. a. 1971). Dazu werden zwei Antikörper verwendet. Der Primärantikörper bindet spezifisch an das gesuchte Protein. Der Sekundärantikörper bindet spezifisch an den Primärantikörper und ist mit einem Enzym verbunden. Hat sich ein Komplex aus Primärantikörper, Protein und Sekundärantikörper gebildet, kann das Enzym ein Substrat umsetzen und das entstehende Reaktionsprodukt kann durch eine kolorimetrische Reaktion nachgewiesen werden (Janeway 2002).

Zur Bestimmung der PrP-Konzentration im Liquor wurde das kommerziell erhältliche Testsystem BetaPrion BSE EIA Test-Kit nach Schmitz, Lüllmann u. a. 2014 und den Anweisungen des Herstellers AJ Roboscreen verwendet (AJ Roboscreen GmbH 2014). Der PK-Verdau wurde nicht durchgeführt und die Liquorproben wurden unverdünnt eingesetzt. Die kolorimetrische Reaktion wurde mit einem ELISA-PlattenLesegerät (Perkin-Elmer) bei $\lambda=450 \mathrm{~nm}$ gemessen.

Zur Bestimmung der 14-3-3-Protein-Konzentration im Liquor wurde das kommerziell erhältliche Testsystem CircuLex 14-3-3 Gamma ELISA Kit nach den Anweisungen des Herstellers MBL International verwendet (MBL International 2015). Die Liquorproben wurden 1:5 in Probenpuffer verdünnt. Alle Arbeits- und Inkubationsschritte fanden bei $\varnothing 25{ }^{\circ} \mathrm{C}$ statt. Die kolorimetrische Reaktion wurde mit einem ELISA-Platten-Lesegerät 
(Perkin-Elmer) bei $\lambda=450 \mathrm{~nm}$ gemessen. Die 14-3-3-Protein-Konzentration wurde in $\mathrm{AU} / \mathrm{ml}$ gemessen, wobei $1 \mathrm{AU} \approx 1 \mathrm{pg}$ entsprach.

Zur Bestimmung der Tau-Protein-Konzentration im Liquor wurde das kommerziell erhältliche Testsystem INNOTEST hTAu Ag nach den Anweisungen des Herstellers Innogenetics verwendet (Innogenetics 2010). Die Liquorproben wurden 1:1 mit Probenpuffer verdünnt. Alle Arbeits- und Inkubationsschritte fanden bei $\varnothing 25{ }^{\circ} \mathrm{C}$ statt. Die kolorimetrische Reaktion wurde mit einem ELISA-Platten-Lesegerät (Perkin-Elmer) bei $\lambda=450 \mathrm{~nm}$ gemessen.

\subsection{Bestimmung der PrP-Aggregation mittels RT-QuIC}

Die Versuchsdurchführung zur Analyse von Proben mittels RT-QuIC beinhaltet 11 Arbeitsschritte. Die Aufbereitung der Proben (vgl. Unterunterabschnitt 3.1.2) sowie die Herstellung des Basismix und der Th-T-Lösung können unabhängig von den weiteren Schritten durchgeführt werden, da sie die Möglichkeit beinhalten die hergestellten Produkte zeitweilig zu lagern (Schritt $1-3$ ). Die Aufbereitung des recPrP ${ }^{\mathrm{C}}$ und die Herstellung des finalen Mix müssen am Tag des Experiments durchgeführt werden zum Entfernen von recPrP ${ }^{\mathrm{C}}$-Aggregaten und zum Vermeiden der Entstehung neuer recPrP $\mathrm{P}^{\mathrm{C}}$-Aggregate vor dem Start des Experiments (Schritt 4 und 5). Hierzu dürfen weder das rcPrP ${ }^{\mathrm{C}}$ noch der dies enthaltende finale Mix zum Mischen gevortext werden. Hierauf folgen die Einrichtung des FLUOstar ${ }^{\circledR}$ Optima, die Vereinigung von finalem Mix und Probe auf der Mikrotiterplatte, das Verschließen der Mikrotiterplatte mit einer Klebefolie, deren Einlegen in den FLUOstar ${ }^{\circledR}$ Optima und der Start des Experiments (Schritt 6-10). Die Dauer jedes einzelnen Experiments betrug in dieser Arbeit mindestens 80 Std. Die Datenerhebung erfolgte mittels des Programms Optima Data Analysis von BMG LABTECH, Hersteller des FLUOstar ${ }^{\circledR}$ Optima (Schritt 11). Zur Auswertung der Ergebnisse wurden quantifizierende statistische Variablen herangezogen, die in Unterunterabschnitt 3.6.5 beschrieben werden. Bild 3 auf S. 23 zeigt die Versuchsdurchführung zur Analyse von Proben mittels RT-QuIC schematisch.

Es wurde ein Basismix hergestellt, bestehend aus $\mathrm{ddH}_{2} \mathrm{O}, 5 \times \mathrm{PBS}$ pH 6,9-Puffer, $\mathrm{NaCl}$ (5 M, SAFC Biosciences) und EDTA (0,5 M, Fluka Analytical). Die Herstellung des $5 \times$ PBS pH 6,9-Puffers erfolgte bei RT. Dazu wurden 0,67 g Natriumdihydrogenphosphat (Sigma-Aldrich), 0,35 g Dinatriumhydrogenphosphat (Sigma-Aldrich) und $1,90 \mathrm{~g}$ Natriumchlorid (Roth) ad $48 \mathrm{ml}$ mit dd $\mathrm{H}_{2} \mathrm{O}$ aufgefüllt und durch Vortexen für 30 Sek auf Stufe 10 gelöst. Dann wurde der pH-Wert mit 50 \% (w/v) NatriumhydroxidLösung (Roth) auf 6,9 eingestellt und die Lösung ad $50 \mathrm{ml}$ mit dd $\mathrm{H}_{2} \mathrm{O}$ aufgefüllt. Nachfolgend wurde die Lösung steril filtriert und für maximal 3 Monate bei $-20{ }^{\circ} \mathrm{C}$ gelagert. Vor der weiteren Verwendung wurde der $5 \times$ PBS pH 6,9-Puffer bei RT aufgetaut und für 30 Sek auf Stufe 10 gevortext, um alle Stoffe wieder vollständig in Lösung zu bringen. Die Herstellung des Basismix erfolgte bei RT und dessen Zusammensetzung ist für eine Reaktion in Tabelle 6 auf S. 24 aufgeführt. Der Basismix wurde steril filtriert und für maximal 3 Monate bei $-20{ }^{\circ} \mathrm{C}$ gelagert. Vor der weiteren Verwendung wurde der Basismix bei RT aufgetaut und für 30 Sek auf Stufe 10 gevortext, um alle Stoffe 


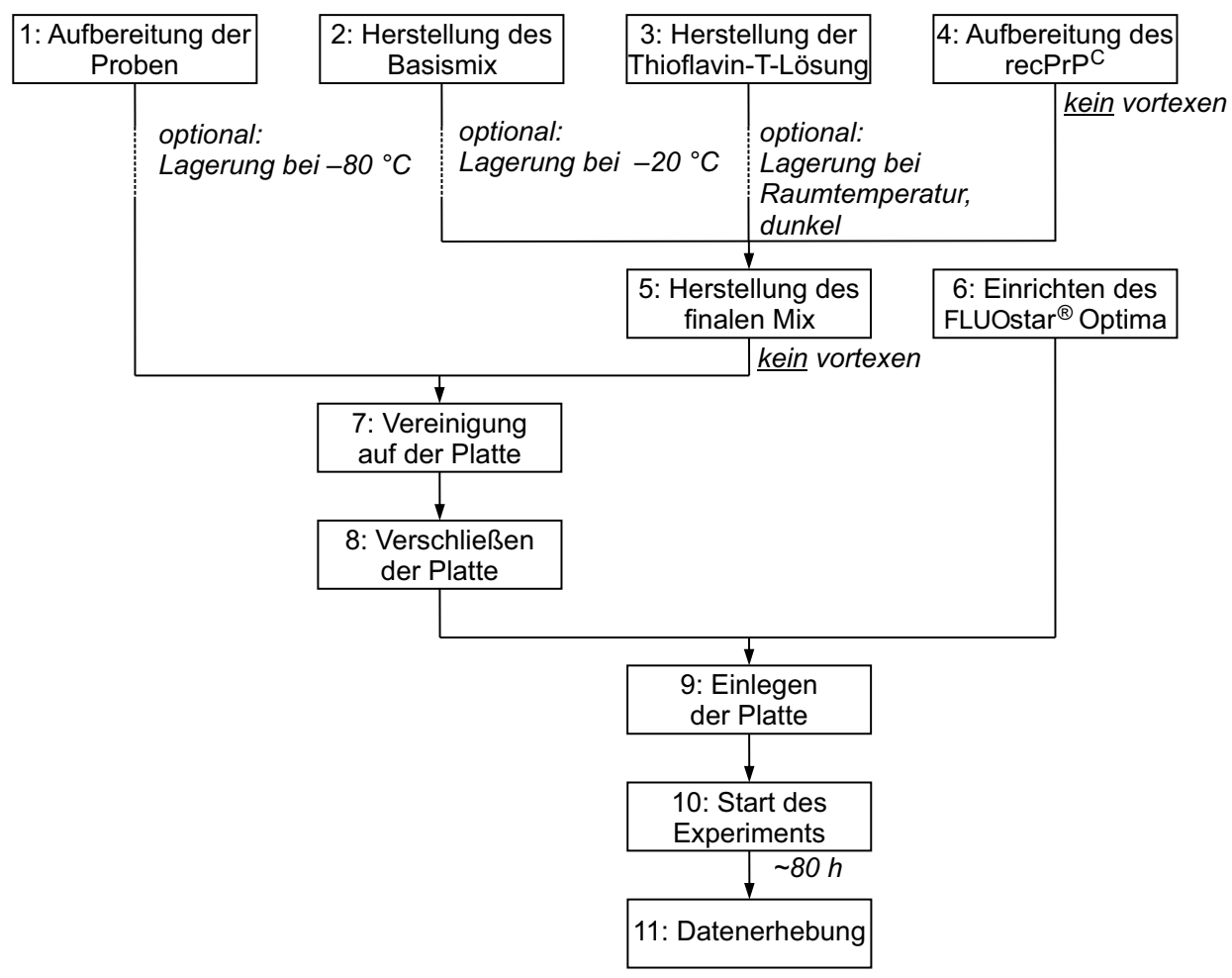

Bild 3: Schematische Darstellung der Versuchsdurchführung mittels RT-QuIC

Die Analyse von Proben mittels RT-QuIC beinhaltet 11 Arbeitsschritte. Die Aufbereitung der Proben sowie die Herstellung des Basismix und der Th-T-Lösung können unabhängig von den weiteren Schritten durchgeführt werden (Schritt $1-3$ ). Die Aufbereitung des recPrPC und die Herstellung des finalen Mix müssen am Tag des Experiments durchgeführt werden (Schritt 4 und 5). Hierauf folgen die Einrichtung des FLUOstar ${ }^{\circledR}$ Optima, die Vereinigung von finalem Mix und Probe auf der Platte, das Verschließen der Platte mit einer Klebefolie, deren Einlegen in den FLUOstar ${ }^{\circledR}$ Optima und der Start des Experiments (Schritt 6 - 10). Die Datenerhebung erfolgte mittels des Programms Optima Data Analysis von BMG LABTECH, Hersteller des FLUOstar ${ }^{\circledR}$ Optima (Schritt 11). 
wieder vollständig in Lösung zu bringen.

Tabelle 6: Zusammensetzung des Basismix für die RT-QuIC

\begin{tabular}{|c|c|}
\hline Stoff & $\begin{array}{l}\text { Volumen } \\
\text { pro Reaktion }\end{array}$ \\
\hline $\mathrm{ddH}_{2} \mathrm{O}$ & $33,4 \mu \mathrm{l}$ \\
\hline $5 \times$ PBS pH 6,9-Puffer & $20,0 \mu \mathrm{l}$ \\
\hline $\mathrm{NaCl}(5 \mathrm{M})$ & $3,4 \mu \mathrm{l}$ \\
\hline $\operatorname{EDTA}(0,5 \mathrm{M})$ & $0,2 \mu \mathrm{l}$ \\
\hline Gesamt & $57,0 \mu \mathrm{ll}$ \\
\hline
\end{tabular}

Th-T fluoresziert bei Bindung an Amyloidfibrillen (Naiki u.a. 1989, Khurana u. a. 2005). Die Herstellung der $1 \mathrm{mM}$ Th-T-Lösung erfolgte bei RT. Dazu wurden 0,0036 g Th-T (Sigma) ad $10 \mathrm{ml}$ mit dd $\mathrm{H}_{2} \mathrm{O}$ aufgefüllt und durch Vortexen für 30 Sek auf Stufe 10 gelöst. Dann wurde die Lösung steril filtriert und für maximal 3 Monate dunkel bei RT gelagert. Vor der weiteren Verwendung wurde die Th-T-Lösung bei RT aufgetaut und für 30 Sek auf Stufe 10 gevortext, um das Th-T wieder vollständig in Lösung zu bringen.

Als Substrat wurde recPrP ${ }^{\mathrm{C}}$ der Firma Prionics/Thermo Fisher Scientific verwendet, welche die Herstellung nach Wilham u. a. 2010 übernahm. Das recPrP ${ }^{\mathrm{C}}$ besteht aus den Aminosäuren 14 - 28 des syrischen Hamsters, gefolgt von den Aminosäuren 141 - 234 des $R_{154} Q_{171}$ polymorphen Schafs. Dieses wurde bei $-80{ }^{\circ} \mathrm{C}$ gelagert und vor der Verwendung für $1-2 \mathrm{Std}$ bei $+4{ }^{\circ} \mathrm{C}$ aufgetaut. Nach dem Auftauen wurden je $500 \mu \mathrm{l}$ des recPrP ${ }^{\mathrm{C}}$ auf $100 \mathrm{kDa}$-Filter (Pall) pipettiert und die Filter für 5 Min bei $1.310 \times \mathrm{g}$ und RT zentrifugiert. Danach wurde das Filtrat unmittelbar zur Herstellung des finalen Reaktionsmix weiter verwendet. Die Filtration dient der Entfernung von recPrP $\mathrm{P}^{\mathrm{C}}$-Aggregaten, die in der $\mathrm{RT}$-QuIC $\mathrm{zu}$ falsch-positiven Testergebnissen führen können. Durch die Filtration geht $\mathrm{recPrP}^{\mathrm{C}}$ verloren, sodass die Konzentration von ursprünglich $0,6 \mathrm{mg} / \mathrm{ml}$ auf $0,37 \mathrm{mg} / \mathrm{ml}$ im Filtrat sinkt.

Der finale Mix wurde für jeden Versuch frisch hergestellt, bestehend aus Basismix, recPrP ${ }^{\mathrm{C}}$ als Substrat und Th-T als Fluoreszenzfarbstoff. Um die Gefahr der PrP-Aggregation während der Herstellung des finalen Reaktionsmix zu verringern, wurde dieser zum Mischen nicht gevortext, sondern durch $10 \times$ invertieren gemischt. Die Herstellung des finalen Mix erfolgte bei RT und dessen Zusammensetzung ist für eine Reaktion in Tabelle 7 auf S. 25 aufgeführt.

Pro Reaktion wurden $15 \mu \mathrm{l}$ Probe mit $85 \mu \mathrm{l}$ finalem Mix in eine schwarze 96-WellMikrotiterplatte mit transparentem Deckglasboden (Fisher-Scientific) pipettiert. Die Konzentrationen der Stoffe in diesem RT-QuIC-Mix sind in Tabelle 8 auf S. 25 aufgeführt, berechnet auf ein Gesamtvolumen von $100 \mu l$. Anschließend wurde die Platte mit einer Klebefolie (Nunc) verschlossen und in ein Mikrotiterplattenlesegerät eingelegt, einen FLUOstar ${ }^{\circledR}$ Optima (BMG LABTECH). Darin wurde diese für mehrere 
Tabelle 7: Zusammensetzung des finalen Mix für die RT-QuIC

\begin{tabular}{lr}
\hline Stoff & $\begin{array}{r}\text { Volumen } \\
\text { pro Reaktion }\end{array}$ \\
\hline Basismix $^{\mathrm{r}}(0,37 \mathrm{mg} / \mathrm{ml})$ & $57,0 \mathrm{\mu l}$ \\
$\operatorname{recPrP}$ & $27,0 \mu \mathrm{ll}$ \\
$\operatorname{Th}-\mathrm{T}(1 \mathrm{mM})$ & $1,0 \mu \mathrm{l}$ \\
\hline Gesamt & $85,0 \mathrm{\mu l}$ \\
\hline
\end{tabular}

Stunden bei $42{ }^{\circ} \mathrm{C}$ wiederholt automatisch abwechselnd für 1 Min inkubiert und für 1 Min bei 600 Min. $^{-1}$ horizontal, doppelt-orbital vibriert. Die Fluoreszenz des Th-T wurde regelmäßig durch den transparenten Mikrotiterplattenboden gemessen, mit der Exitation bei $\lambda=450 \mathrm{~nm}$ und der Emission bei $\lambda=480 \mathrm{~nm}$. Abweichungen von diesen Angaben sind im entsprechenden Abschnitt beschrieben.

Tabelle 8: Stoffkonzentrationen im RT-QuIC-Mix

\begin{tabular}{lr}
\hline Stoff & Konzentration \\
\hline $\mathrm{NaCl}(5 \mathrm{M})$ & $170 \mathrm{mM}$ \\
$5 \times \operatorname{PBS}(\mathrm{pH} 6,9)$ & $1 \times$ \\
EDTA $(0,5 \mathrm{M})$ & $1 \mathrm{mM}$ \\
$\mathrm{Th}-\mathrm{T}(1 \mathrm{mM})$ & $10 \mu \mathrm{M}$ \\
$\operatorname{recPrP}^{\mathrm{C}}(0,37 \mathrm{mg} / \mathrm{ml})$ & $0,1 \mathrm{mg} / \mathrm{ml}$ \\
\hline
\end{tabular}

\subsection{Statistische Auswertung der RT-QuIC-Ergebnisse}

Es wurden der Grenzwert (vgl. Unterunterabschnitt 3.6.1), die Validität (vgl. Unterunterabschnitt 3.6.2) und die Reproduzierbarkeit (vgl. Unterunterabschnitt 3.6.3) der RT-QuIC bestimmt. Außerdem wurden die RT-QuIC-Ergebnisse der experimentellen Gruppen über die Positivitätsraten (vgl. Unterunterabschnitt 3.6.4) und die Fluoreszenzsignale (vgl. Unterunterabschnitt 3.6.5) der Proben miteinander verglichen.

\subsubsection{Bestimmung des Grenzwerts}

Physikalische Messungen führen meist nicht zu Testergebnissen, deren Merkmale alternativ ausgeprägt sind, wie: ,positiv“ und ,negativ“, sondern zu solchen, deren Merkmale stetig ausgeprägt sind. Um im diagnostischen Test eine positive von einer negativen Probe zu unterscheiden, wird daher ein Grenzwert festgelegt. Dieser Grenzwert trennt den pathologischen (positiven) vom physiologischen (negativen) Bereich. Jedem Grenzwert werden eine Sensitivität und eine Spezifität zugeordnet. Wird für jeden Grenzwert 
der Anteil falsch-positiver Proben (1 minus Spezifität) gegen den Anteil richtig-positiver Proben (Sensitivität) in ein Koordinatensystem eingetragen und werden die Punkte linear miteinander verbunden, dann entsteht eine Grenzwertoptimierungskurve. Mittels dieser kann der optimale Grenzwert zur Unterscheidung zwischen positiver und negativer Probe bestimmt werden (Weiß 2013).

\subsubsection{Bestimmung der Validität}

Die Validität ist die Fähigkeit eines diagnostischen Tests, zwischen positiven und negativen Proben zu unterscheiden. Diese wird durch die Sensitivität und die Spezifität bestimmt. Die Sensitivität ist die bedingte Wahrscheinlichkeit $P\left(T_{+} \mid K\right)$, mit der ein Test eine Probe richtig als positiv erkennt. Dabei steht $T_{+}$für den Anteil richtig-positiv erkannter Proben und $K$ für den Anteil positiv erkannter Proben. Die Spezifität ist die bedingte Wahrscheinlichkeit $P\left(T_{-} \mid \bar{K}\right)$, mit der ein Test eine Probe richtig als negativ erkennt. Dabei steht $T_{-}$für den Anteil richtig-negativ erkannter Proben und $\bar{K}$ für den Anteil negativ erkannter Proben. Die Sensitivität und die Spezifität werden durch die Vorhersagewerte - die Wahrscheinlichkeiten, dass das Testergebnis den richtigen Status der Probe anzeigt - ergänzt. Unter dem positiven Vorhersagewert wird die bedingte Wahrscheinlichkeit $P\left(K \mid T_{+}\right)$verstanden. Unter dem negativen Vorhersagewert wird die bedingte Wahrscheinlichkeit $P\left(\bar{K} \mid T_{-}\right)$verstanden (Weiß 2013).

\subsubsection{Bestimmung der Reproduzierbarkeit}

Die Reliabilität ist ein Maß für die Reproduzierbarkeit von Testergebnissen unter ähnlichen Bedingungen. Der $\kappa$-Koeffizient nach Cohen wird verwendet, um den Grad der Übereinstimmungen zwischen zwei Untersuchern - die interindividuelle Variabilität zu messen. Diese Zahl quantifiziert, inwieweit die Testergebnisse vom Untersucher abhängen und stellt somit ein Maß für die Objektivität eines Tests dar. Der $\kappa$-Koeffizient nach Cohen ist definiert als $\kappa=\frac{p_{o}-p_{e}}{1-p_{e}}$. Dabei steht $p_{o}$ für den Anteil der übereinstimmenden Urteile, die beobachtet wurden, und $p_{e}$ für die Anteile, die rein zufällig erwartet würden. $\kappa<0,20$ zeigt eine schwache, $\kappa=0,21-0,40$ eine leichte, $\kappa=0,41-0,60$ eine mittelmäßige, $\kappa=0,61-0,80$ eine gute und $\kappa>0,80$ eine sehr gute Übereinstimmung zwischen den Untersuchern (Altman 1991, Weiß 2013).

\subsubsection{Bestimmung der Positivitätsrate}

Ein Fluoreszenzsignal wurde entweder als positiv bewertet, wenn das Signal den Grenzwert mindestens erreichte, oder als negativ, wenn es unterhalb des Grenzwerts blieb. Die Positivitätsrate wurde definiert als der Anteil der positiven Replikate an der Gesamtmenge der Replikate einer Probe. Wenn $>50 \%$ der Replikate einer Probe positiv waren, dann wurde die Probe als positiv bewertet, und wenn $>50 \%$ der Replikate einer Probe negativ waren, dann wurde die Probe als negativ bewertet. Die statistischen Auswertungen erfolgten wie jeweils anwendbar mittels T-Test oder Varianzanalyse für 
normal verteilte oder nicht normal verteilte Daten sowie für gepaarte oder nicht gepaarte Daten, gefolgt von den jeweiligen Post-hoc-Tests. Für jede vergleichende Analyse wurde der p-Wert ermittelt. Ein $\mathrm{p}$-Wert $\leq 0,001$ wurde als extrem signifikant, $\leq 0,01$ als sehr signifikant, $\leq 0,05$ als signifikant und $>0,05$ als nicht signifikant bewertet. Die Bilder zeigen $\mathrm{p} \leq 0,001$ mittels drei Sternen $(* * *), \mathrm{p} \leq 0,01$ mittels zwei Sternen $(* *)$, $\mathrm{p} \leq 0,05$ mittels eines Sterns $\left(^{*}\right)$ und und $\mathrm{p} \geq 0,05$ nicht.

\subsubsection{Charakterisierung des Fluoreszenzsignals}

In der RT-QuIC beginnt das Fluoreszenzsignal einer $\mathrm{PrP}^{\mathrm{Sc}}$-positiven Probe auf demselben Niveau wie das einer $\mathrm{PrP}^{\mathrm{Sc}}$-negativen Probe. Nach einer Phase des konstanten Niveaus steigt es exponentiell bis zu einem Signalmaximum an (exponentielles Wachstum) und verweilt auf diesem Niveau bis zum Ende des Versuchs (Plateau-Phase). Demgegenüber bleiben die Fluoreszenzsignale von $\mathrm{PrP}^{\mathrm{Sc}}$-negativen Proben auf einem konstanten Niveau. Das Fluoreszenzsignal wurde in dieser Arbeit mittels Quantifizierung dreier Variablen, die Fläche unter der Kurve, das Signalmaximum und die Lag-Phase - die Zeit, bis das Fluoreszenzsignal den Grenzwert erreichte - charakterisiert. Bild 4 auf S. 28 zeigt diese Variablen am Beispiel eines $\mathrm{PrP}^{\mathrm{Sc}}$-positiven Signals schematisch.

In Abschnitt 4 sind die Fluoreszenzsignale grafisch als Verlauf über die Zeit dargestellt. Während der Versuche wurde die Fluoreszenz alle 30 Min gemessen. Nachfolgend wurde zu jedem Messpunkt der Mittelwert aller Messungen jeder Probe ermittelt und daraus der Mittelwert jeder experimentellen Gruppe bestimmt. Dann wurden diese Werte mittels linearer Interpolation verbunden und als Verlauf über die Zeit dargestellt. Diese Darstellung zeigt aggregierte Daten, denen keine individuellen Informationen über die Fläche unter der Kurve, das Signalmaximum und die Lag-Phase entnommen werden können. Die statistischen Auswertungen erfolgten nach Prüfung auf Normalverteilung wie jeweils anwendbar mittels T-Test oder Varianzanalyse für normal verteilte oder nicht normal verteilte Daten sowie für gepaarte oder nicht gepaarte Daten, gefolgt von den jeweiligen Post-hoc-Tests. Für jede vergleichende Analyse wurde der p-Wert ermittelt. Ein p-Wert $\leq 0,001$ wurde als extrem signifikant $(* * *), \leq$ 0,01 als sehr signifikant $(* *), \leq 0,05$ als signifikant $(*)$ und $>0,05$ als nicht signifikant bewertet. 


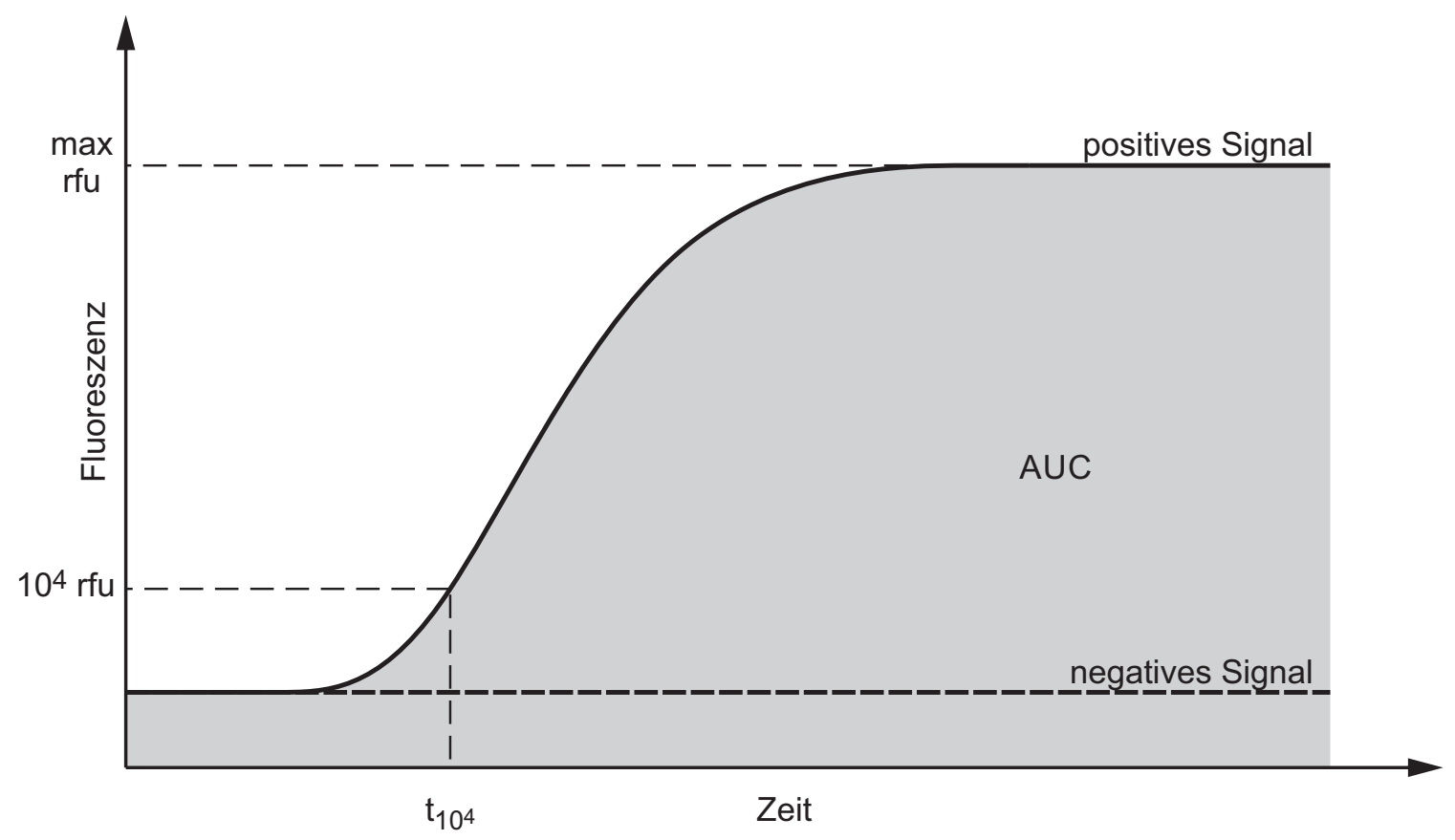

Bild 4: Schematische Darstellung des RT-QuIC-Fluoreszenzsignals

In der RT-QuIC beginnt das Fluoreszenzsignal einer $\mathrm{PrP}^{\mathrm{Sc}}$-positiven Probe auf demselben Niveau wie das einer $\mathrm{PrP}^{\mathrm{Sc}}$-negativen Probe. Nach einer Phase des konstanten Niveaus steigt es exponentiell bis zu einem Signalmaximum (max rfu) an und verweilt auf diesem Niveau bis zum Ende des Versuchs. Demgegenüber bleiben die Fluoreszenzsignale von $\mathrm{PrP}^{\mathrm{Sc}}$-negativen Proben auf einem konstanten Niveau. Das Fluoreszenzsignal wurde in dieser Arbeit mittels Quantifizierung dreier Variablen, die Fläche unter der Kurve (AUC), das Signalmaximum und die Lag-Phase $\left(t_{10^{4}}\right)$ - der Zeit, bis das Fluoreszenzsignal den Grenzwert $\left(10^{4} \mathrm{rfu}\right.$ ) erreichte - charakterisiert. 


\section{Ergebnisse}

Im Rahmen dieser Arbeit wurde die RT-QuIC in der Arbeitsgruppe etabliert und methodisch optimiert. Basierend auf den im Folgenden gezeigten Ergebnissen wird sie seitdem in der Arbeitsgruppe in der Forschung, der humanen Diagnostik und zur Suche von Wirkstoffen gegen Prionkrankheiten genutzt. Wesentliche Teile dieser Arbeit wurden bereits oder werden veröffentlicht in:

- Cramm, Maria ${ }^{1}$; Schmitz, Matthias ${ }^{1}$; Karch, André; Zafar, Saima; Varges, Daniela; Mitrova, Eva; Schroeder, Bjoern; Raeber, Alex; Kuhn, Franziska; Zerr, Inga (2015). Characteristic CSF prion seeding efficiency in humans with prion diseases. In: Molecular Neurobiology 51.1, S. 396 - 405. ISSN: 1559-1182. DOI: $10.1007 / \mathrm{s} 12035-014-8709-6$.

- Cramm, Maria ${ }^{1}$; Schmitz, Matthias ${ }^{1}$; Karch, André; Mitrova, Eva; Kuhn, Franziska; Schroeder, Bjoern; Raeber, Alex; Varges, Daniela; Kim, Yong-Sun; Satoh, Katsuya; Collins, Steven; Zerr, Inga (2015). Stability and Reproducibility Underscore Utility of RT-QuIC for Diagnosis of Creutzfeldt-Jakob Disease. In: Molecular Neurobiology. ISSN: 1559-1182. DOI: 10.1007/s12035-015-9133-2.

- Schmitz, Matthias ${ }^{1}$; Cramm, Maria ${ }^{1}$; Llorens, Franc; Müller, Dominik, Zafar, Saima; Schulz-Schaeffer, Walter J.; Varges, Daniela; Zerr, Inga (2015). Application of RT-QuIC as a novel screening assay revealed that doxycycline prevents the in vitro amplification of PrPScrapie. Manuskript wird zurzeit begutachtet von Scientifc Reports.

\subsection{Methodische Optimierung der RT-QuIC}

Zur Anwendung der RT-QuIC in der Forschung und der humanen Diagnostik bedarf es einer umfassenden Validierung und Standardisierung der Methode. Bisher mangelte es an Studien, welche die laborübergreifende Reproduzierbarkeit sowie den Einfluss von Lagerung, Verwendung und Kontamination humaner Liquorproben auf das RT-QuICErgebnis untersuchen. Um diese Lücke zu schließen, wurden in dieser Arbeit sowohl der bestmögliche Grenzwert und die Validität als auch die Reproduzierbarkeit und die Stabilität des Testverfahrens bestimmt.

Die Sensitivität der RT-QuIC betrug für alle getesteten Prionkrankheiten gemittelt 85,5 \% und die Spezifität 99,5 \%. Die Reproduzierbarkeit zwischen den internationalen Referenzlaboren war gut bis exzellent. Die Lagerung und die Verwendung der Liquorproben beeinflussten die RT-QuIC-Ergebnisse nicht. Die Kontamination der Liquorproben mit Blut führte zu falsch-negativen Testergebnissen.

\footnotetext{
${ }^{1}$ Maria Cramm und Matthias Schmitz haben gleichermaßen zu dieser Veröffentlichung beigetragen.
} 


\subsubsection{Bestimmung des Grenzwerts}

Um den bestmöglichen Grenzwert der RT-QuIC zu bestimmen, wurde ein Trainingsprobensatz aus 37 zufällig ausgewählten Liquorproben analysiert. Dieser Trainingsprobensatz bestand aus 28 sCJD und neun retrospektiven Kontrollen. Die RT-QuIC wurde wie in Unterabschnitt 3.5 durchgeführt. Mittels einer Grenzwertoptimierungskurve wurden $10.000 \mathrm{rfu}$ als optimaler Grenzwert zur Unterscheidung zwischen $\mathrm{PrP}^{\mathrm{Sc}}$-positiver und $\mathrm{PrP}^{\mathrm{Sc}}$-negativer Probe ermittelt. Folgend wurde ein Fluoreszenzsignal entweder als positiv bewertet, wenn es $10.000 \mathrm{rfu}$ mindestens erreichte ( $\geq 10.000 \mathrm{rfu})$, oder als negativ, wenn es unterhalb von 10.000 rfu blieb $(<10.000$ rfu). Die Signalmaxima der Kontrollen blieben unter dem Grenzwert. Bild 5 auf S. 30 zeigt die Grenzwertoptimierungskurve und Bild 6 auf S. 31 zeigt die Signalmaxima der sCJD und Kontrollen aus dem Trainingsprobensatz.

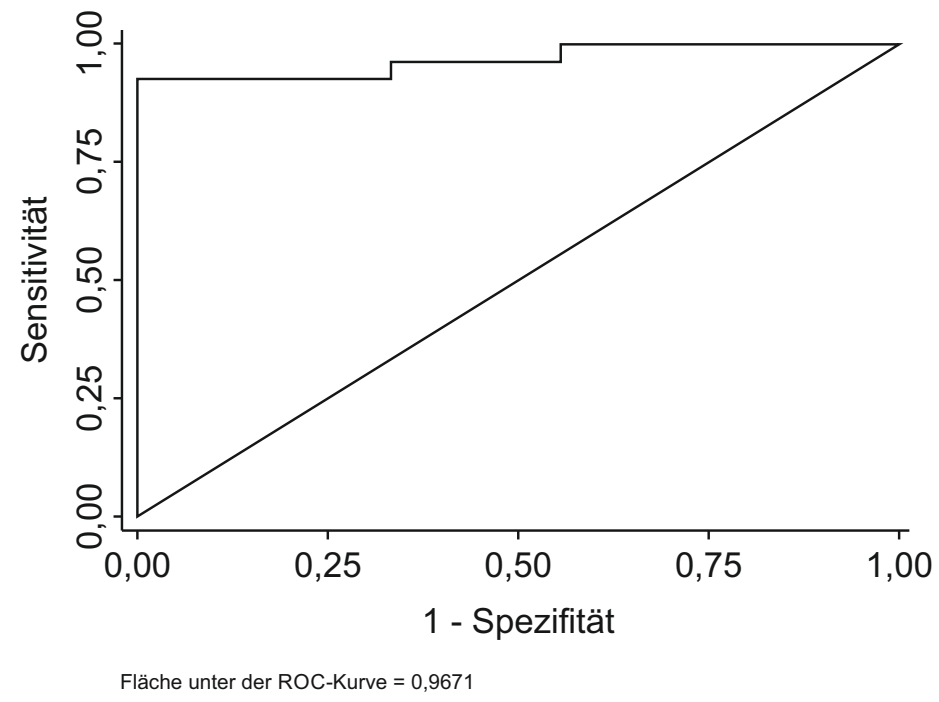

Bild 5: Grenzwertoptimierungskurve der RT-QuIC

Der bestmögliche Grenzwert der RT-QuIC liegt bei 10.000 rfu. Zur Erstellung der Kurve wurden die RT-QuIC-Ergebnisse eines Trainingsprobensatzes aus Liquorproben von 28 sCJD und neun retrospektiven Kontrollen verwendet.

\subsubsection{Bestimmung der Validität}

Um die Validität der RT-QuIC zu bestimmen, wurden 110 Liquorproben von Patienten mit Prionkrankheiten analysiert. Diese Gruppe bestand aus 64 sCJD-, 39 gCJD- und sieben FFI-Liquorproben. Von den 39 gCJD-Liquorproben stammten 33 von Patienten mit gCJD E200K- und sechs von Patienten mit gCJD V210I-Mutation, auf dem Prnp. Außerdem wurden 400 Liquorproben von zwei Kontrollgruppen analysiert, bestehend aus 200 retrospektiven und 200 prospektiven Kontrollen. Tabelle 9 auf S. 31 führt die Liquorproben der Prionkrankheiten und der retrospektiven Kontrollen mit Anzahl, 


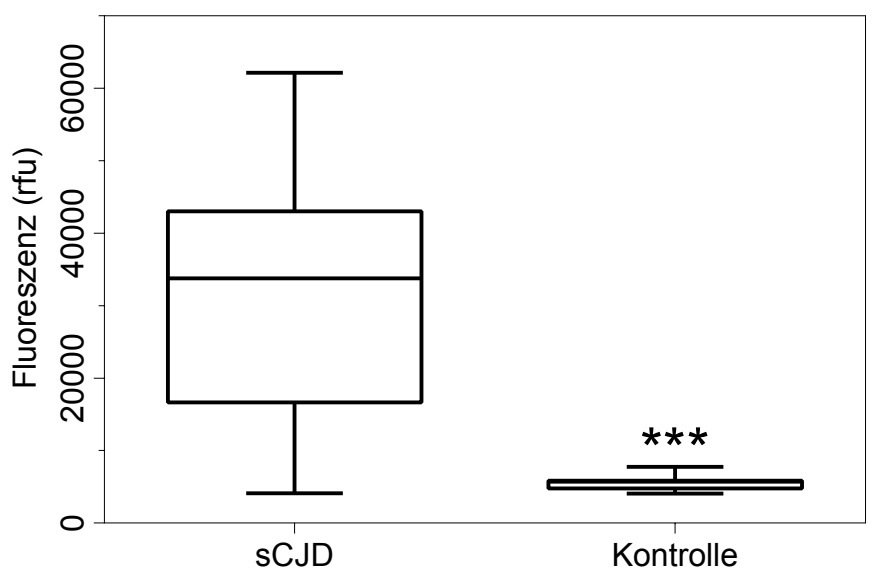

Bild 6: Signalmaxima von Liquorproben in der RT-QuIC

Signalmaxima der 28 sCJD und neun Kontrollen aus dem Trainingsprobensatz, grafisch dargestellt als Boxplot-Diagramme. Die Signalmaxima der Kontrollen blieben unter dem Grenzwert von $10.000 \mathrm{rfu}$. Zur statistischen Auswertung wurden die Daten der Gruppen auf Normalverteilung geprüft und mittels T-Test verglichen. Ein p-Wert $\leq 0,001$ wurde als extrem signifikant $(* * *), \leq 0,01$ als sehr signifikant $(* *), \leq 0,05$ als signifikant $(*)$ und $>0,05$ als nicht signifikant bewertet.

Geschlecht und Alter auf. Die RT-QuIC wurde wie in Unterabschnitt 3.5 über eine Versuchsdauer von 80 Std durchgeführt. Dann wurden die Sensitivität, die Spezifität sowie der positive und der negative Vorhersagewert der RT-QuIC nach Unterunterabschnitt 3.6.2 ermittelt.

Tabelle 9: Daten der Liquorproben nach Gruppenzugehörigkeit

\begin{tabular}{lcccc}
\hline \multirow{2}{*}{ Gruppe } & \multirow{2}{*}{ Anzahl } & \multicolumn{2}{c}{ Geschlecht } & Alter / Jahre \\
\cline { 3 - 4 } & & $q$ & $\sigma^{\pi}$ & Median $\left(\mathrm{Q}_{25}-\mathrm{Q}_{75}\right)$ \\
\hline sCJD & 64 & 28 & 36 & $65,2(56,9-73,4)$ \\
gCJD E200K & 33 & 20 & 13 & $59,9(54,0-68,0)$ \\
gCJD V210I & 6 & 3 & 3 & $56,8(56,0-66,0)$ \\
FFI & 7 & 1 & 6 & $58,0(56,5-62,2)$ \\
retrospektive Kontrolle & 200 & 92 & 108 & $66,0(57,0-75,0)$ \\
\hline
\end{tabular}

Die Sensitivität betrug für alle getesteten Prionkrankheiten 85,5\%, für gCJD 100,0 \%, für sCJD 79,9 \% und für FFI 57,1 \%. Die Spezifität betrug 99,5\%. Der positive Vorhersagewert betrug $61 \%$ und der negative Vorhersagewert 99,7\%. Der Test ergab bei zwei von 400 Kontrollen ein falsch-positives Ergebnis. Tabelle 10 auf S. 32 führt die Sensitivitäten und Tabelle 11 auf S. 32 die Testergebnisse geordnet nach Gruppenzugehörigkeit auf. 
Tabelle 10: Sensitivitäten der RT-QuIC nach Gruppenzugehörigkeit

\begin{tabular}{lccccc}
\hline \multirow{2}{*}{ Gruppe } & \multirow{2}{*}{ Prion } & \multicolumn{2}{c}{ gCJD } & \multirow{2}{*}{ sCJD } & FFI \\
\cline { 3 - 4 } & & E200K & V210I & & \\
Sensitivität & $85,5 \%$ & $100,0 \%$ & $100,0 \%$ & $79,7 \%$ & $57,1 \%$ \\
\hline
\end{tabular}

Tabelle 11: Testergebnisse der RT-QuIC nach Gruppenzugehörigkeit

\begin{tabular}{ccccccc}
\hline \multirow{2}{*}{ Testergebnis } & \multirow{2}{*}{ Prion } & \multicolumn{2}{c}{ gCJD } & \multirow{2}{*}{ sCJD } & FFI & \multirow{2}{*}{ Kontrollen } \\
\cline { 2 - 6 } & & E200K & V210I & & & \\
\hline positiv & 94 & 33 & 6 & 51 & 4 & 2 \\
negativ & 16 & 0 & 0 & 13 & 3 & 398 \\
\hline
\end{tabular}

\subsubsection{Bestimmung der Reproduzierbarkeit}

Um den Einfluss verschiedener Experimentatoren auf das RT-QuIC-Ergebnis zu bestimmen, wurden zwei Ring-Versuche durchgeführt. An Ringversuch 1 nahmen die Labore von zwei Institutionen teil, das NRZ für TSE der UMG in Deutschland und die Firma Thermo Fisher Scientific Prionics AG in der Schweiz. In diesem Ringversuch wurden Liquorproben von 54 sCJD und 32 retrospektiven Kontrollen mittels RT-QuIC analysiert. Bild 7 auf S. 32 zeigt Ringversuch 1 schematisch. An Ringversuch 2 nahmen

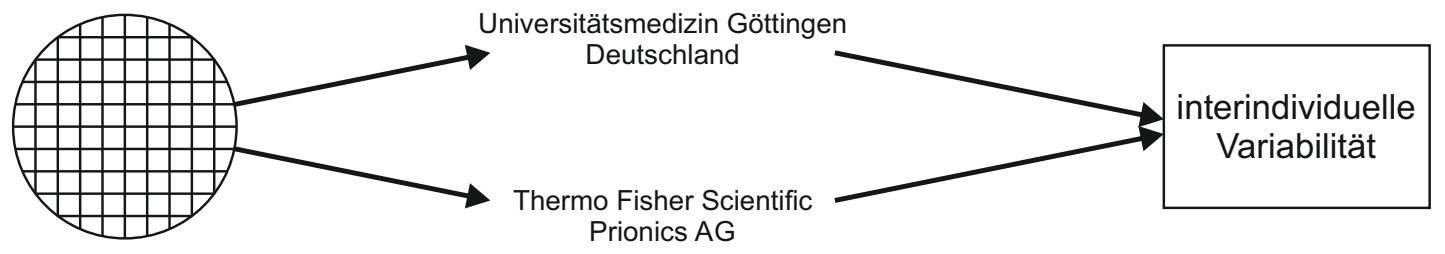

Bild 7: Schematische Darstellung von Ringversuch 1

In Ringversuch 1 wurden Liquorproben von 54 sCJD und 32 retrospektiven Kontrollen mittels RT-QuIC analysiert (Kreis auf der linken Seite). Jede Liquorprobe wurde grundsätzlich in Triplikaten und für die Diagnose verblindet analysiert. An Ringversuch 1 nahmen die Labore von zwei Institutionen teil (Aufzählung in der Mitte). Dann wurde das Ausmaß der Übereinstimmungen der Ergebnisse zwischen den Experimentatoren, die interindividuelle Variabilität, ermittelt (Rechteck auf der rechten Seite).

die Labore von 4 Institutionen teil: das NRZ für TSE der UMG in Deutschland, das Ilsong Institut für Lebenswissenschaften der Hallym Universität in Korea, die Abteilung für Molekulare Mikrobiologie und Immunologie der Nagasaki Universität in Japan und die Abteilung für Pathologie der Universität von Melbourne in Australien. In diesem Ringversuch wurden Liquorproben von einer sCJD und fünf retrospektiven Kontrollen mittels RT-QuIC analysiert. Bild 8 auf S. 33 zeigt Ringversuch 2 schematisch. Jede 


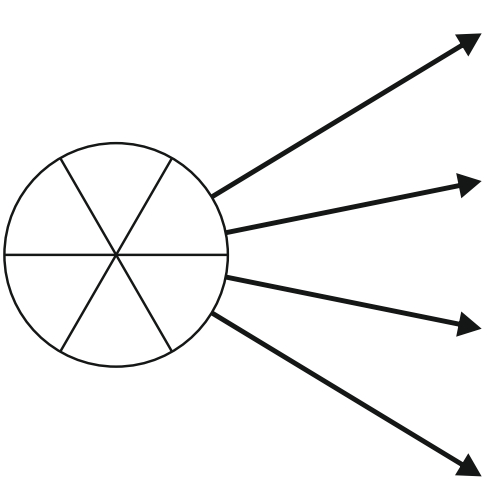
Deutschland

Hallym Universität Korea

Nagasaki Universität Japan

Universität von Melbourne Australien

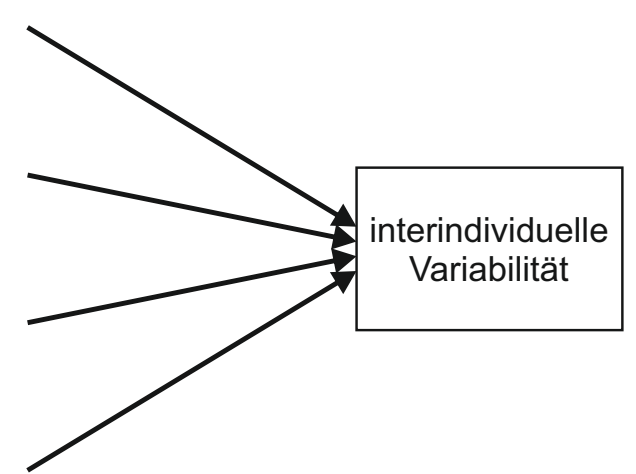

Bild 8: Schematische Darstellung von Ringversuch 2

In Ringversuch 2 wurden Liquorproben von einer sCJD und fünf retrospektiven Kontrollen mittels RT-QuIC analysiert (Kreis auf der linken Seite). Jede Liquorprobe wurde grundsätzlich in Triplikaten und für die Diagnose verblindet analysiert. An Ringversuch 2 nahmen die Labore von vier Institutionen teil (Aufzählung in der Mitte) Dann wurde das Ausmaß der Übereinstimmungen der Ergebnisse zwischen den Experimentatoren, die interindividuelle Variabilität, ermittelt (Rechteck auf der rechten Seite).

Liquorprobe wurde grundsätzlich in Triplikaten und für die Diagnose verblindet analysiert. Die RT-QuIC wurde nach Unterabschnitt 3.5 durchgeführt. Dann wurde das Ausmaß der Übereinstimmungen der Ergebnisse zwischen den Experimentatoren, die interindividuelle Variabilität, nach Unterunterabschnitt 3.6.3 ermittelt.

Für Ringversuch 1 betrug $\kappa=0,75$. Für Ringversuch 2 betrug $\kappa=0,83$. Tabelle 12 auf S. 33 führt die beiden Ringversuche mit der Anzahl der Teilnehmer und Proben sowie der interindividuellen Variabilität auf.

Tabelle 12: Ergebnisse der Ringversuche

\begin{tabular}{lcccc}
\hline \multirow{2}{*}{ Ringversuch } & \multirow{2}{*}{ Teilnehmer } & \multirow{2}{*}{ Proben } & \multicolumn{2}{c}{ Interindividuelle Variabilität } \\
\cline { 3 - 5 } & & & $\kappa$-Koeffizient & $\mathbf{9 5}$ \% CI \\
\hline Ringversuch 1 & 2 & 84 & 0,75 & $0,40-1,00$ \\
Ringversuch 2 & 4 & 6 & 0,83 & $0,40-1,00$ \\
\hline
\end{tabular}

\subsubsection{Bestimmung der Stabilität}

Zwischen der Probenentnahme beim Patienten und der proteinbiochemischen Untersuchung im Labor können kurze Zeiten der Lagerung der Probe bei verschiedenen Temperaturen liegen, bspw. durch die Transportbedingungen. Bei Verwendung der Probe zu Forschungszwecken kann eine Probe mehrmals aufgetaut und wieder eingefroren oder über viele Jahre bei $-80{ }^{\circ} \mathrm{C}$ gelagert werden. Bei der Abnahme des Liquors mittels Lumbalpunktion kann die Probe durch Blut des Patienten kontaminiert werden. Die 
Faktoren Lagerung, Verwendung und Kontamination einer Probe können das Ergebnis eines proteinbiochemischen Tests beeinflussen. Bisher mangelte es an Studien, welche den Einfluss dieser Faktoren auf die Analyse humaner Liquorproben mittels RT-QuIC untersuchen. Um diese Lücke zu schließen, wurde in dieser Arbeit der Einfluss dieser Faktoren auf die Positivitätsraten und die Fluoreszenzsignale von Liquorproben in der RT-QuIC untersucht.

Die Kurzzeitlagerungen bei RT $\left(\varnothing 22{ }^{\circ} \mathrm{C}\right)$ und $+4{ }^{\circ} \mathrm{C}$ für jeweils bis zu acht Tage, die Langzeitlagerung bei $-80{ }^{\circ} \mathrm{C}$ für bis zu neun Jahre sowie das bis zu $16 \times$ Einfrieren und Auftauen (Verwendung) der Liquorproben hatten keinen Einfluss auf die Positivitätsraten und Fluoreszenzsignale. Die Kontamination mit hämolysiertem Blut führte $\mathrm{ab} \geq 1.250$ Ery/ul und die Inkubation mit frischem Blut (5.000 Ery/ul) ab drei Tagen Inkubationsdauer zu falsch-negativen Testergebnissen. Um den Einfluss der Lagerung und der Verwendung auf die Positivitätsraten und die Fluoreszenzsignale zu bestimmen, wurden Liquorproben mit Stufen dieser Faktoren vorbehandelt. Zur Bestimmung des Einflusses der Kurzzeitlagerung bei RT ( $\varnothing 22{ }^{\circ} \mathrm{C}$ ) wurde von 12 sCJD und sechs retrospektiven Kontrollen je ein Aliquot für null, einen, drei oder acht Tage bei RT $\left(\varnothing 22{ }^{\circ} \mathrm{C}\right)$ gelagert. Um den Einfluss der Kurzzeitlagerung bei $+4{ }^{\circ} \mathrm{C} z u$ bestimmen, wurde von $12 \mathrm{sCJD}$ und sechs retrospektiven Kontrollen je ein Aliquot für null, einen, drei oder acht Tage bei $+4{ }^{\circ} \mathrm{C}$ gelagert. Zur Bestimmung des Einflusses der Langzeitlagerung bei $-80{ }^{\circ} \mathrm{C}$ wurden je 12 sCJD und sechs retrospektive Kontrollen verwendet, die für zwei bis drei, fünf bis sechs oder acht bis neun Jahre bei $-80{ }^{\circ} \mathrm{C}$ gelagert haben. Um den Einfluss der Verwendung zu bestimmen, wurde von 12 sCJD und sechs retrospektiven Kontrollen je ein Aliquot $0 \times, 2 \times, 4 \times, 8 \times$ oder $16 \times$ Einfrier-/Auftauzyklen unterzogen. Dabei bestand ein Zyklus aus mindestens 2 Std Lagerung bei $-80{ }^{\circ} \mathrm{C}$, gefolgt von mindestens 2 Std Lagerung bei RT ( $\left.\varnothing 22^{\circ} \mathrm{C}\right)$. Nachfolgend wurden die vorbehandelten Aliquots mittels RT-QuIC wie in Unterabschnitt 3.5 in Triplikaten und über eine Versuchsdauer von 80 Std analysiert. Dann wurden die Positivitätsraten wie in Unterunterabschnitt 3.6.4 bestimmt und die Fluoreszenzsignale nach Unterunterabschnitt 3.6.5 charakterisiert.

Bild 9 auf S. 35 zeigt die Positivitätsraten der sCJD-Liquorproben bei Lagerung und die bei Verwendung, simuliert durch wiederholte Einfrier-/Auftauzyklen. Beide Faktoren hatten unter den getesteten Bedingungen keinen Einfluss auf die Positivitätsraten ( $\mathrm{p}>0,05$, vgl. Tabelle 36, Tabelle 37 und Tabelle 40 in Anhang B). Bild 10 auf S. 36 zeigt die Fluoreszenzsignale der sCJD-Liquorproben bei Lagerung und Verwendung. Deren jeweiligen Flächen unter der Kurve, Signalmaxima und Lag-Phasen änderten sich mit zunehmender Faktorstufe nicht ( $\mathrm{p}>0,05$; vgl. Tabelle 42, Tabelle 43, Tabelle 44, Tabelle 45, Tabelle 46 und Tabelle 47 in Anhang B). Die retrospektiven Kontrollen waren negativ (vgl. Tabelle 53 und Tabelle 54 in Anhang B).

Um den Einfluss der Kontamination durch Blut auf die Positivitätsraten und die Fluoreszenzsignale zu bestimmen, wurden Liquorproben mit Stufen dieses Faktors vorbehandelt. Dazu wurden Liquorproben mit Blut von retrospektiven Kontrollen kontaminiert. Direkt nach der Entnahme des Blutes in Blutabnahmeröhren wurden die Erythrozytenkonzentrationen der Blutproben gemessen und diese dann entweder frisch 


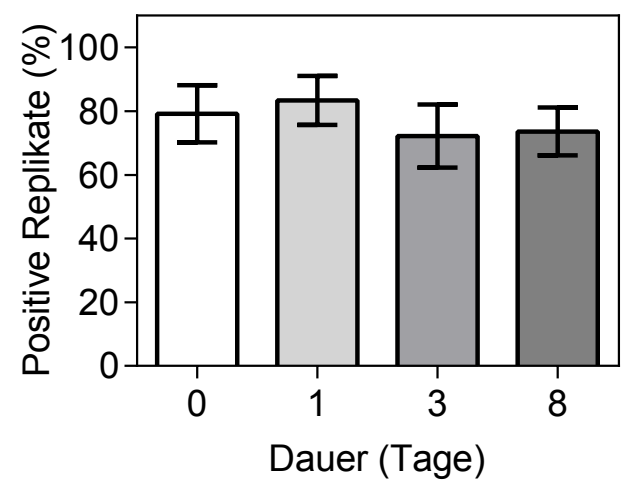

(a) Lagerung bei RT $\left(\varnothing 22{ }^{\circ} \mathrm{C}\right)$

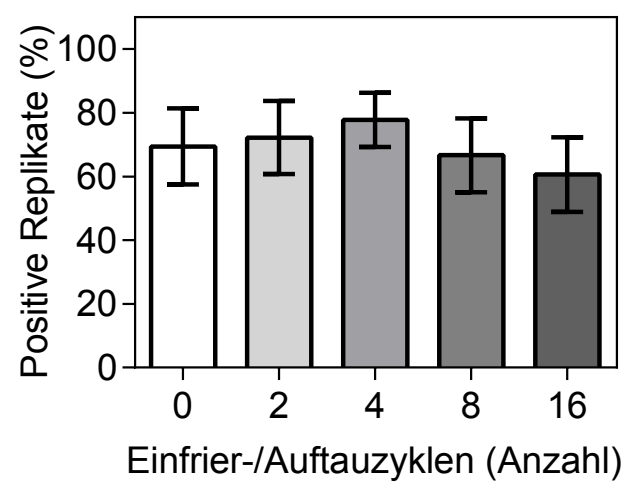

(c) Verwendung

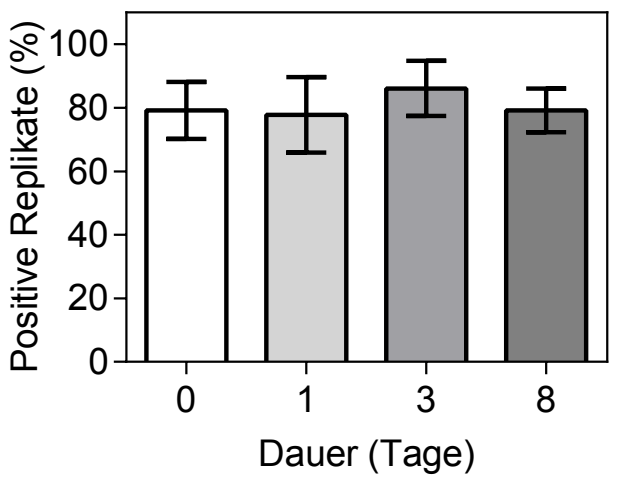

(b) Lagerung bei $+4{ }^{\circ} \mathrm{C}$

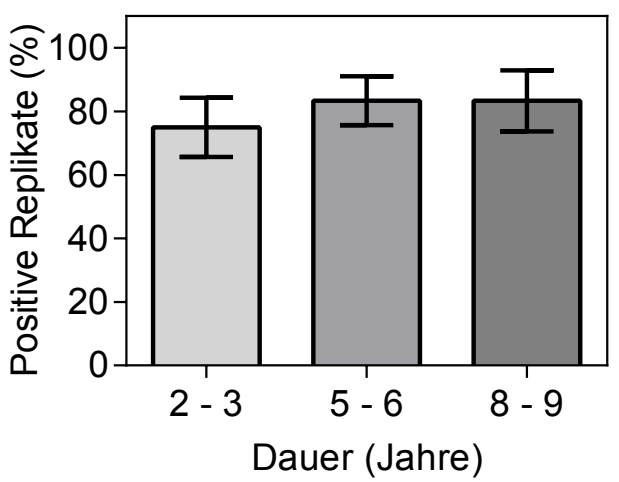

(d) Lagerung bei $-80{ }^{\circ} \mathrm{C}$

Bild 9: Einfluss von Lagerung und Verwendung auf die Positivitätsraten

Sowohl die Lagerung der Proben als auch die Verwendung, simuliert durch mehrere Einfrier/Auftauzyklen, der sCJD-Liquorproben hatten unter den getesteten Bedingungen keinen Einfluss auf deren Positivitätsraten in der RT-QuIC $(\mathrm{p}>0,05)$. Bild 9 (a) und (b) zeigen die sCJD-Positivitätsraten bei Kurzzeitlagerung, Bild 9 (c) die bei Verwendung und Bild 9 (d) die bei Langzeitlagerung, für jeweils $n=12$ Proben.

Die Positivitätsraten sind grafisch dargestellt als Säulendiagramme mit Mittelwert \pm Standardfehler. Zur statistischen Auswertung wurden die Daten der Gruppen auf Normalverteilung geprüft und mittels einfaktorieller Varianzanalyse verglichen. Ein $\mathrm{p}$-Wert $\leq 0,001$ wurde als extrem signifikant $\left({ }^{* * *}\right), \leq 0,01$ als sehr signifikant $(* *), \leq 0,05$ als signifikant $\left({ }^{*}\right)$ und $>$ 0,05 als nicht signifikant bewertet. 


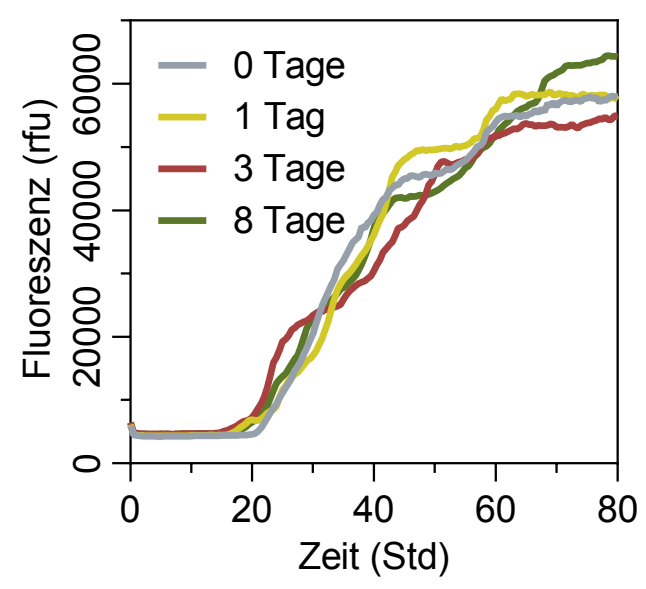

(a) Lagerung bei $\mathrm{RT}\left(\varnothing 22{ }^{\circ} \mathrm{C}\right)$

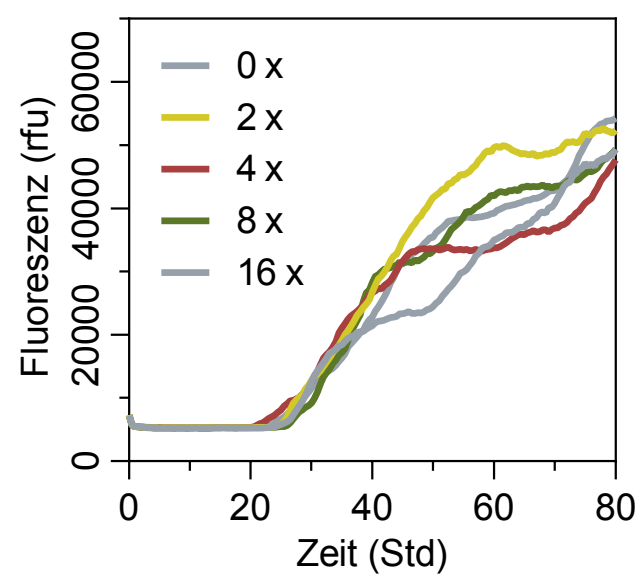

(c) Einfrier-/Auftauzyklen (Anzahl)

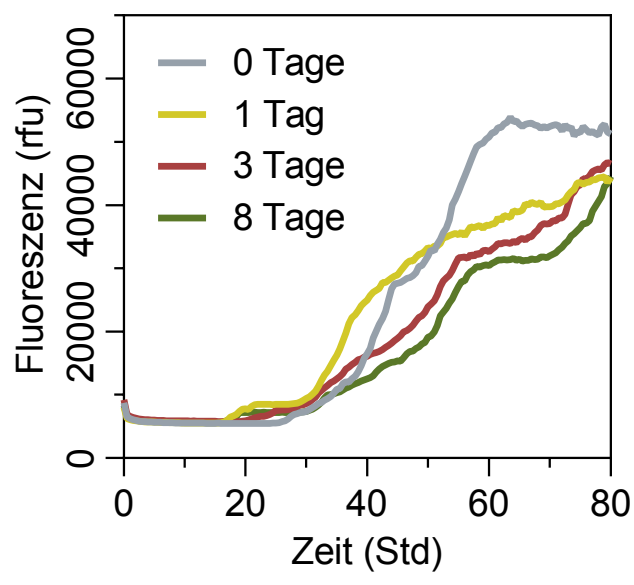

(b) Lagerung bei $+4{ }^{\circ} \mathrm{C}$

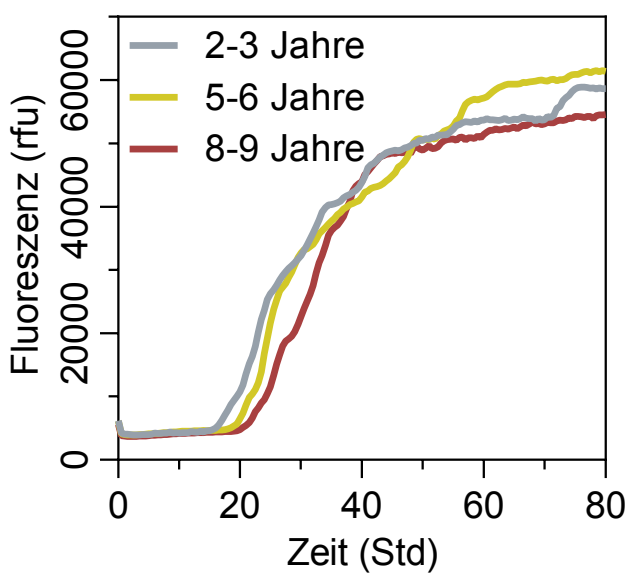

(d) Lagerung bei $-80{ }^{\circ} \mathrm{C}$

Bild 10: Einfluss von Lagerung und Verwendung auf die Fluoreszenzsignale

Sowohl die Lagerung als auch die Verwendung der sCJD-Liquorproben hatten unter den getesteten Bedingungen keinen Einfluss auf deren Fluoreszenzsignale in der RT-QuIC. Bild 10 (a) und (b) zeigen die sCJD-Fluoreszenzsignale bei Kurzzeitlagerung, Bild 10 (c) die bei Verwendung, simuliert mittels Einfrier-/Auftauzyklen, und Bild 10 (d) die bei Langzeitlagerung, für jeweils $\mathrm{n}=12$ Proben.

Während der Versuche wurde die Fluoreszenz alle 30 Min. gemessen. Nachfolgend wurden aus den Mittelwerten der positiven Fluoreszenzsignale der Proben die Mittelwerte der Gruppen bestimmt. Diese wurden dann mittels linearer Interpolation verbunden und grafisch als Verlauf über die Zeit dargestellt. Diese Darstellung zeigt aggregierte Daten, weshalb ihr keine individuellen Informationen über die Fläche unter der Kurve, das Signalmaximum und die Lag-Phase entnommen werden können. 
und unbehandelt oder hämolysiert, durch eine zehnminütige Ultraschallbehandlung gefolgt von mindestens 2 Std Lagerung bei $-80{ }^{\circ} \mathrm{C}$, weiter verwendet. Um den Einfluss der Blutmenge zu bestimmen, wurde von sechs bis acht sCJD- und sechs bis acht retrospektiven Kontrollen je ein Aliquot mit hämolysiertem Blut, entsprechend 0, 78, 313, 1.250, 5.000 oder 10.000 Erythrozyten pro $\mu l$ Liquor, kontaminiert. Zur Bestimmung des Einflusses der Inkubationsdauer der Blutkontamination auf das Fluoreszenzsignal wurden acht sCJD- und acht retrospektive Kontrollen mit frischem Blut, entsprechend 5.000 Erythrozyten pro $\mu 1$ Liquor, kontaminiert. Von jeder kontaminierten Probe wurde je ein Aliquot für null, einen, drei oder acht Tage bei RT $\left(\varnothing 22^{\circ} \mathrm{C}\right)$ gelagert. Anschließend wurden die Aliquots für 10 Min. bei 720 x $g$ zentrifugiert, um die Blutkontamination wieder zu entfernen. Nachfolgend wurden die vorbehandelten Aliquots mittels RT-QuIC wie in Unterabschnitt 3.5 in Triplikaten und über eine Versuchsdauer von 80 Std analysiert. Dann wurden die Positivitätsraten wie in Unterunterabschnitt 3.6.4 bestimmt und die Fluoreszenzsignale nach Unterunterabschnitt 3.6.5 charakterisiert.

Sowohl die Menge des hämolysierten Blutes als auch die Dauer der Inkubation mit frischem Blut hatten einen Einfluss auf die Positivitätsraten. Bild 11 auf S. 38 zeigt die Positivitätsraten der sCJD-Liquorproben bei Kontamination durch Blut. Diese nahmen mit zunehmender Blutmenge $(\mathrm{p} \leq 0,0001)$ und Inkubationsdauer $(\mathrm{p} \leq 0,001)$ ab (vgl. Tabelle 38, Tabelle 39 und Tabelle 41 in Anhang B). Bild 11 (a) zeigt die Positivitätsraten der sCJD-Liquorproben bei Kontamination durch verschiedene Mengen hämolysierten Blutes. Die Positivitätsraten von 79 und 313 Ery/ul waren im Vergleich zur unbehandelten Kontrolle (0 Ery/ $\mu \mathrm{l} ; 73 \%$ ) nicht verschieden ( $\mathrm{p}>0,05)$. Bei 1.250 Ery/ul sank die Positivitätsrate auf $39 \%$ und lag für 5.000 und 10.000 Ery/ul bei $0 \%$ ( $\leq \leq 0,01$ ). Bild 11 (b) zeigt die Positivitätsraten der sCJD-Liquorproben bei verschiedenen Inkubationsdauern mit einer konstanten Menge frischen Blutes. Die Positivitätsraten nach null, eins, zwei und drei Tagen waren im Vergleich zur unbehandelten Kontrolle (Ref; $63 \%$ ) nicht verschieden ( $\mathrm{p}>0,05)$. Nach acht Tagen Inkubationsdauer sank die Positivitätsrate auf $4 \%(\mathrm{p} \leq 0,01)$. Die retrospektiven Kontrollen waren negativ (vgl. Tabelle 55 und Tabelle 56 in Anhang B).

Sowohl die Konzentration des hämolysierten Blutes als auch die Dauer der Inkubation mit einer konstanten Menge frischen Blutes hatten einen Einfluss auf die Fluoreszenzsignale der sCJD-Liquorproben. Bild 12 auf S. 39 zeigt die sCJD-Fluoreszenzsignale bei Kontamination durch Blut. Deren jeweilige Signalmaxima und Flächen unter der Kurve nahmen mit zunehmender Blutmenge $(\mathrm{p} \leq 0,001)$ und Inkubationsdauer ab $(\mathrm{p} \leq$ 0,001; vgl. Tabelle 48, Tabelle 49, Tabelle 50, Tabelle 51 und Tabelle 52 in Anhang B). Bild 12 (a) zeigt die sCJD-Fluoreszenzsignale bei Kontamination durch verschiedene Konzentrationen hämolysierten Blutes. Die Fluoreszenzsignale von 79, 313 und 1.250 Ery/ $\mu$ l waren im Vergleich zur unbehandelten Kontrolle (0 Ery/ $\mathrm{ll})$ nicht verschieden ( $p$ $>0,05)$. Ab 5.000 Ery/ul Liquor sanken die jeweiligen Signalmaxima und Flächen unter der Kurve ab $(\mathrm{p} \leq 0,01)$. Bild 12 (b) zeigt die sCJD-Fluoreszenzsignale bei verschiedenen Inkubationsdauern mit frischem Blut (5.000 Ery/ul). Die Inkubationsdauern von null, eins, zwei und drei Tagen waren im Vergleich zur unbehandelten Kontrolle (Ref) nicht verschieden $(\mathrm{p}>0,05)$. Ab drei Tagen sanken die jeweiligen Signalmaxima und 


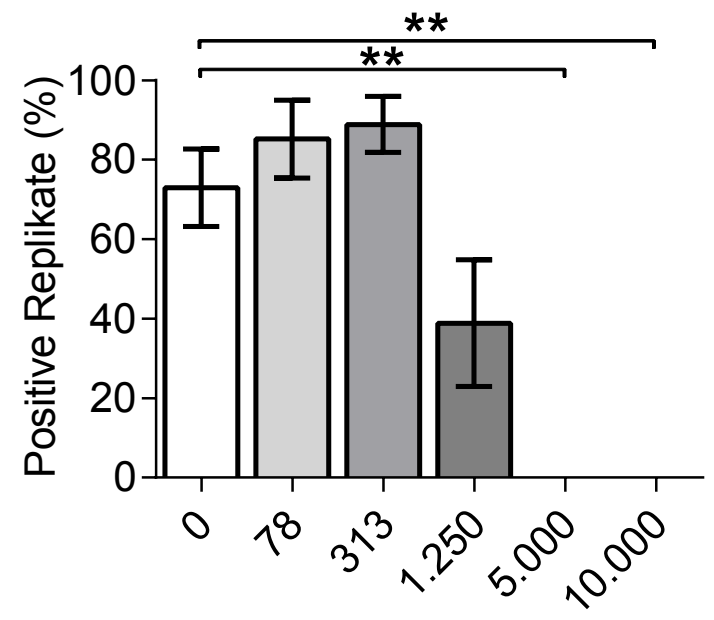

Erythrozyten / $\mu$ l Liquor (n)

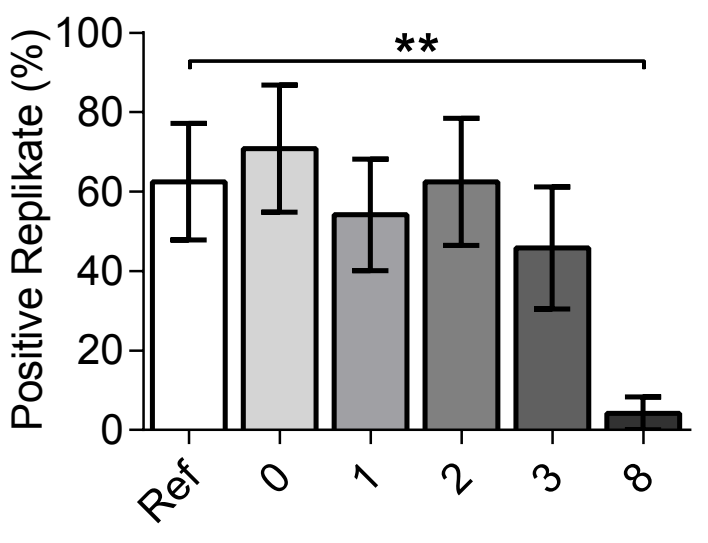

Inkubation bei RT (Tage)

(a) Zellzahl

(b) Hämolyse

Bild 11: Einfluss einer Blutkontamination auf die Positivitätsraten

Sowohl die Konzentration des hämolysierten Blutes als auch die Dauer der Inkubation mit frischem Blut hatten einen Einfluss auf die Positivitätsraten der sCJD-Liquorproben. Diese nahmen mit zunehmender Blutmenge und Inkubationsdauer ab. Bild 11 (a) zeigt die sCJD-Positivitätsraten bei Kontamination mit verschiedenen Konzentrationen hämolysierten Blutes pro $\mu \mathrm{l}$ Liquor und Bild 11 (b) diese bei verschiedenen Inkubationsdauern mit einer konstanten Menge frischen Blutes (5.000 Ery/ul Liquor). Als Referenz (Ref) wurde der Liquor nicht mit Blut kontaminiert. Bei der Faktorstufe null Tage wurde der Liquor mit Blut kontaminiert, dieses jedoch vor Ablauf von 24 Std mittels Zentrifugation, für 10 Min. bei $720 \times \mathrm{g}$, wieder entfernt. Die Positivitätsraten sind grafisch dargestellt als Säulendiagramme mit Mittelwert \pm Standardfehler, für je $n=6-8$ (Zellzahl) und $n=8$ (Hämolyse) Proben.

Zur statistischen Auswertung wurden die Daten der Gruppen auf Normalverteilung geprüft und mittels einfaktorieller Varianzanalyse verglichen. Ein p-Wert $\leq 0,001$ wurde als extrem signifikant $(* * *), \leq 0,01$ als sehr signifikant $(* *), \leq 0,05$ als signifikant $(*)$ und $>0,05$ als nicht signifikant bewertet. 
Flächen unter der Kurve ab $(\mathrm{p} \leq 0,001)$.

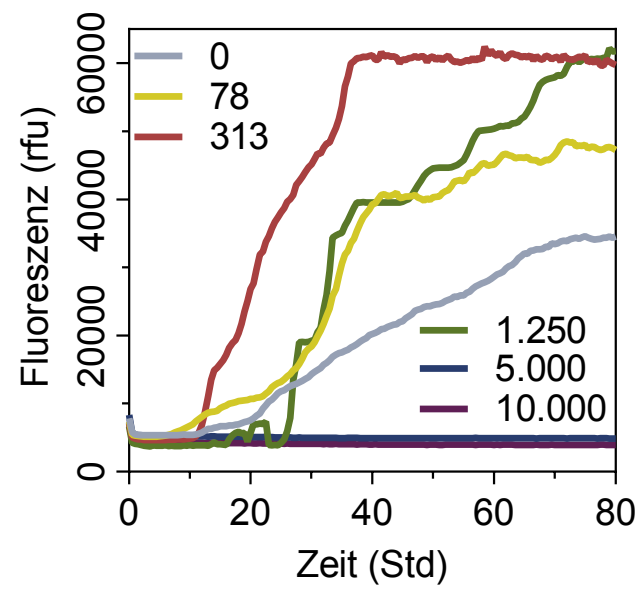

(a) Zellzahl (Erythrozyten / pl Liquor (n))

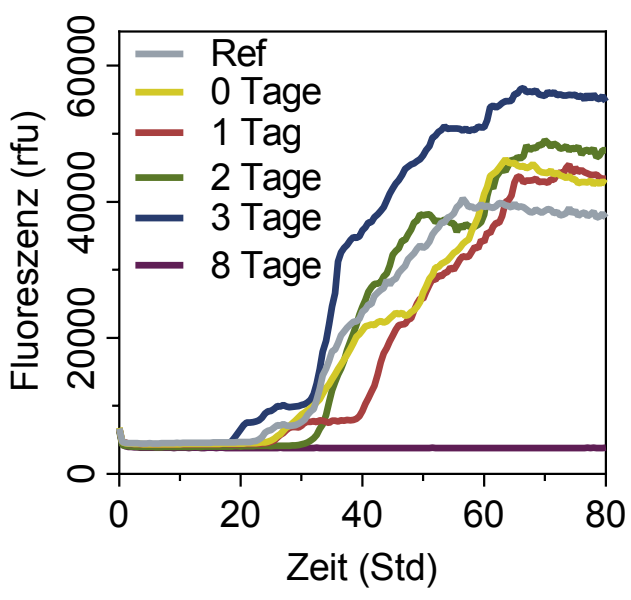

(b) Hämolyse (Inkubation bei RT)

Bild 12: Einfluss einer Blutkontamination auf die Fluoreszenzsignale

Sowohl die Konzentration des hämolysierten Blutes als auch die Dauer der Inkubation mit frischem Blut hatten einen Einfluss auf die Fluoreszenzsignale der sCJD-Liquorproben in der RT-QuIC. Deren jeweilige Signalmaxima und Flächen unter der Kurve nahmen mit zunehmender Blutmenge und Inkubationsdauer ab. Bild 12 (a) zeigt die sC.JD-Fluoreszenzsignale bei Kontamination durch verschiedene Mengen hämolysierten Blutes. Bild 12 (b) zeigt diese bei verschiedenen Inkubationsdauern mit einer konstanten Menge frischen Blutes (5.000 Ery/pl). Als Referenz (Ref) wurden der Liquor nicht mit Blut kontaminiert. Bei der Faktorstufe null Tage wurde der Liquor mit Blut kontaminiert, dieses jedoch vor Ablauf von 24 Std mittels Zentrifugation wieder entfernt.

Während der Versuche wurde die Fluoreszenz alle 30 Min. gemessen. Nachfolgend wurden aus den Mittelwerten der positiven Fluoreszenzsignale der Proben $(\mathrm{n}=6-8$ (Zellzahl) und $\mathrm{n}=8$ (Hämolyse)) die Mittelwerte der Gruppen bestimmt. Diese wurden dann mittels linearer Interpolation verbunden und grafisch als Verlauf über die Zeit dargestellt. Diese Darstellung zeigt aggregierte Daten, weshalb ihr keine individuellen Informationen über die Fläche unter der Kurve, das Signalmaximum und die Lag-Phase entnommen werden können.

\subsection{Charakterisierung der Fluoreszenzsignale}

Mit humanem Gehirnmaterial generierte RT-QuIC-Ergebnisse zeigten erstmals distinkte Fluoreszenzsignale für verschiedene sCJD-Formen (Peden u. a. 2012). Zur Überprüfung, ob die verschiedenen Signale eine allgemeine Eigenschaft der molekularen sCJD-Formen sind oder ausschließlich dem untersuchten Probensatz zuzuordnen waren, wurden in dieser Arbeit Proben aus dem frontalen Kortex von je acht Patienten mit sCJD MM1 oder sCJD VV2 mittels RT-QuIC untersucht. Die RT-QuIC wurde wie in Unterabschnitt 3.5 beschrieben und über eine Versuchsdauer von 80 Std durchgeführt. 
Dann wurden die Verläufe der Fluoreszenzsignale mittels der Fläche unter der Kurve nach Unterunterabschnitt 3.6.5 charakterisiert und zwischen den Gruppen verglichen. Die Fluoreszenzsignale der sCJD MM1 zeigten eine kürzere Lag-Phase $(\mathrm{p}<0,05)$ sowie größere Fläche unter der Kurve $(\mathrm{p}<0,05)$ und assoziierten mit einem höheren Signalmaximum $(\mathrm{p}>0,05)$ als die der sCJD VV2. Bild 13 auf S.40 zeigt die Fluoreszenzsignale der sCJD-Gehirnproben, gruppiert nach den molekularen sCJD-Formen. Tabelle 13 auf S.41 führt die dazugehörenden Datenanalysen auf.

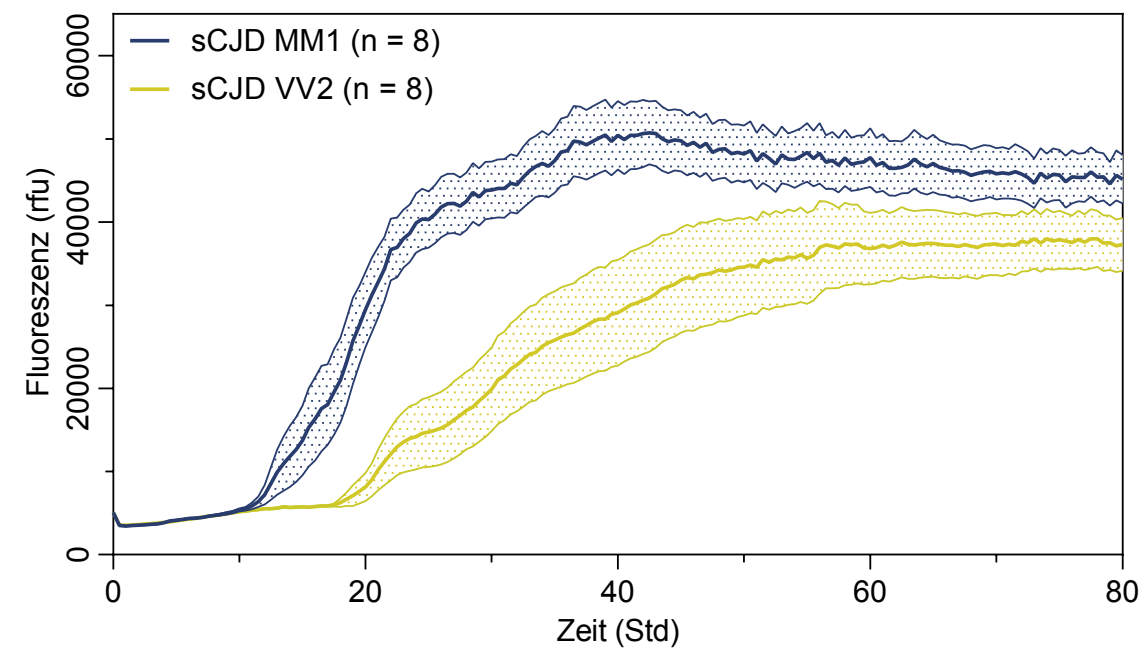

Bild 13: Einfluss der molekularen sCJD-Form auf das Fluoreszenzsignal - 1

Wurden die Fluoreszenzsignale der sCJD-Gehirnproben nach den molekularen sCJD-Formen getrennt, dann zeigten die sCJD MM1 eine kürzere Lag-Phase sowie größere Fläche unter der Kurve und assoziierten mit einem höheren Signalmaximum als die der sCJD VV2.

Während der Versuche wurde die Fluoreszenz alle 30 Min. gemessen. Nachfolgend wurden aus den Mittelwerten der Fluoreszenzsignale der Proben die Mittelwerte der Gruppen \pm Standardfehler bestimmt. Diese wurden dann mittels linearer Interpolation verbunden und in Form einer Mittelwert- (dicke Linie) \pm Standardfehlerlinie (dünne Linien) grafisch als Verlauf über die Zeit dargestellt. Das Fehlerfeld ist farblich markiert. Diese Darstellung zeigt aggregierte Daten, weshalb ihr keine individuellen Informationen über die Fläche unter der Kurve, das Signalmaximum und die Lag-Phase entnommen werden können.

Nachfolgend wurden die Einflüsse der Form der Prionkrankheit (bspw. gCJD vs. sCJD) und der molekularen Form der sCJD (bspw. sCJD MM1), patientenbezogener Faktoren (bspw. das Alter), krankheitsbezogener Faktoren (bspw. die Krankheitsdauer) und krankheitsspezifischer Biomarker (bspw. das 14-3-3-Protein) auf die Fluoreszenzsignale von Liquorproben untersucht. Die gCJD unterschieden sich durch eine kürzere Lag-Phase sowie größere Fläche unter der Kurve und ein höheres Signalmaximum von den sCJD und FFI. In der Gruppe der gCJD E200K unterschieden sich die gCJD E200K MM durch eine kürzere Lag-Phase von den gCJD E200K MV. In der Gruppe der sCJD hatten sowohl der Prnp Codon 129-Genotyp als auch der PrP ${ }^{\text {Sc }}$-Typ 
Tabelle 13: Einfluss der molekularen sCJD-Formen auf die Fluoreszenzsignale von Gehirnproben

\begin{tabular}{rlcc}
\hline \multicolumn{2}{c}{ Variable } & sCJD MM1 & sCJD VV2 \\
\hline \multirow{2}{*}{ AUC } & Mw & 21.842 & 12.329 \\
& SD & 5.205 & 7.046 \\
Max rfu & Mw & 53.465 & 41.640 \\
& SD & 9.736 & 11.935 \\
Lag-Phase & Median & 16,75 & 26,88 \\
& IQR & $16,26-19,00$ & $23,88-49,38$ \\
\hline
\end{tabular}

alleine keinen Einfluss auf die Fluoreszenzsignale. Wurden diese nach den molekularen Formen der sCJD gruppiert (MM1, MM2, MV1, MV2, VV1 und VV2), assoziierte die sCJD MM1 mit einer kürzeren Lag-Phase und einem höheren Signalmaximum, verglichen mit den sCJD MV1 und sCJD VV1. Die gCJD MM zeigte eine kürzere LagPhase und ein höheres Signalmaximum im Vergleich zur gCJD MV. Das Alter und das Geschlecht der Patienten sowie die Konzentrationen des $\mathrm{PrP}^{\mathrm{C}}$, des 14-3-3- und des Tau-Proteins hatten keinen Einfluss auf die Fluoreszenzsignale. Die kurze Krankheitsdauer zeigte eine kürzere Lag-Phase und ein höheres Signalmaximum, verglichen mit der mittleren und langen Krankheitsdauer.

Es wurden 110 Liquorproben von Patienten mit Prionkrankheiten sowie 189 retrospektive Kontrollen mittels RT-QuIC analysiert. Die Gruppe der Prionkrankheiten bestand aus 64 sCJD-, 39 gCJD- und sieben FFI Liquorproben. Von den 39 gCJDLiquorproben stammten 33 von Patienten mit gCJD E200K- und sechs von Patienten mit gCJD V210I-Mutation, auf dem Prnp. Diese Liquorproben sind in Tabelle 9 auf S. 31 mit Anzahl, Geschlecht und Alter aufgeführt. Die Gruppe der sCJD bestand aus 14 sCJD MM1, sieben sCJD MM2, 13 sCJD MV1, 12 sCJD MV2, sechs sCJD MV1 und 12 sCJD VV2. In der Gruppe der gCJD E200K trugen 14 Patienten den Genotyp MM und 19 MV am Prnp Codon 129. In der Gruppe der gCJD V210I trugen fünf Patienten den Genotyp MM und einer VV am Prnp Codon 129. In der Gruppe der FFI trugen vier Patienten den Genotyp MM, zwei MV und einer VV am Prnp Codon 129. Die 189 retrospektiven Kontrollen waren eine Teilmenge der 200 retrospektiven Kontrollen aus Unterunterabschnitt 4.1.2. Von den 189 Patienten dieser retrospektiven Kontrollen waren 86 weiblichen und 103 männlichen Geschlechts und das durchschnittliche Alter betrug 66,5 Jahre (Median), wobei die mittleren $50 \%$ der Patienten 57,0 bis 75,0 Jahre alt waren (IQR). Die RT-QuIC wurde wie in Unterabschnitt 3.5 beschrieben und über eine Versuchsdauer von 80 Std durchgeführt. Dann wurden die Verläufe der Fluoreszenzsignale mittels der Fläche unter der Kurve, des Signalmaximums und der Lag-Phase nach Unterunterabschnitt 3.6.5 charakterisiert und zwischen den Gruppen verglichen. 


\title{
4.2.1. Einfluss von Alter und Geschlecht der Patienten bei sCJD
}

Weder das Alter der Patienten bei Krankheitsbeginn $(\mathrm{p}>0,05)$ noch ihr Geschlecht ( $\mathrm{p}$ $>0,05)$ hatte einen Einfluss auf die Fluoreszenzsignale der sCJD-Liquorproben. Bild 14 auf S. 42 zeigt die Fluoreszenzsignale von sCJD-Liquorproben, gruppiert nach dem Alter und dem Geschlecht der Patienten. Tabelle 14 auf S. 43 führt die Datenanalysen und Tabelle 15 auf S. 43 die Statistik zu den Variablen geordnet nach Gruppenzugehörigkeit auf.

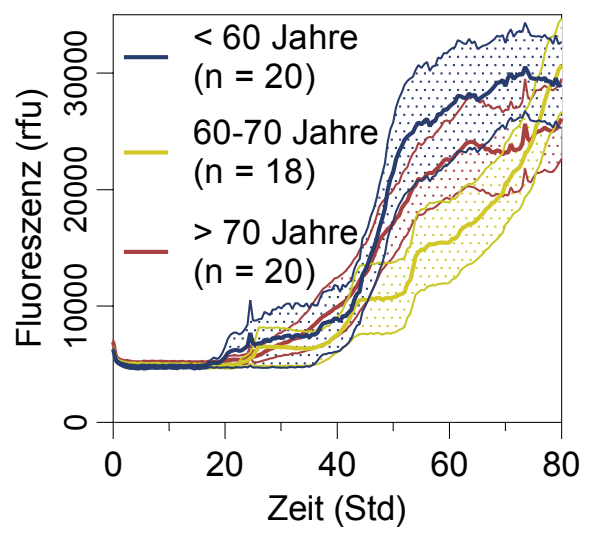

(a) Alter

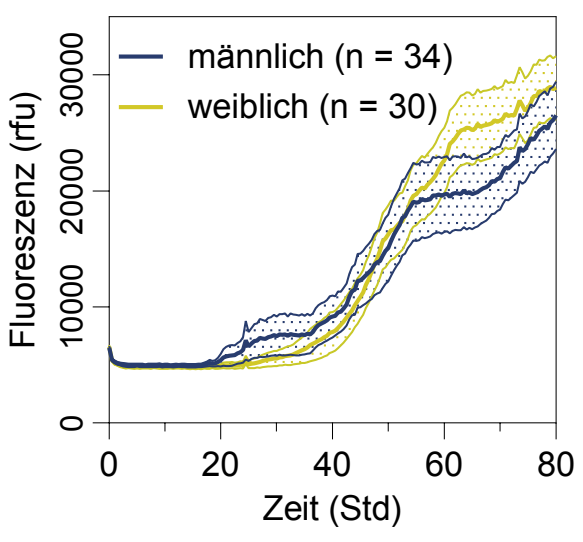

(b) Geschlecht

Bild 14: Einfluss von Alter und Geschlecht auf die Fluoreszenzsignale

\begin{abstract}
Weder das Alter der Patienten bei Krankheitsbeginn noch ihr Geschlecht hatte einen Einfluss auf die Fluoreszenzsignale der sCJD-Liquorproben. Bild 14 (a) zeigt die Fluoreszenzsignale der sCJD-Liquorproben gruppiert nach dem Alter der Patienten und Bild 14 (b) zeigt diese gruppiert nach dem Geschlecht der Patienten.

Während der Versuche wurde die Fluoreszenz alle 30 Min. gemessen. Nachfolgend wurden aus den Mittelwerten der Fluoreszenzsignale der Proben die Mittelwerte der Gruppen \pm Standardfehler bestimmt. Diese wurden dann mittels linearer Interpolation verbunden und in Form einer Mittelwert- (dicke Linie) \pm Standardfehlerlinie (dünne Linien) grafisch als Verlauf über die Zeit dargestellt. Das Fehlerfeld ist farblich markiert. Diese Darstellung zeigt aggregierte Daten, weshalb ihr keine individuellen Informationen über die Fläche unter der Kurve, das Signalmaximum und die Lag-Phase entnommen werden können.
\end{abstract}

\subsubsection{Einfluss des Volumens der CJD-Probe}

Je stärker die CJD-Liquorproben verdünnt wurden, desto kleiner waren deren Positivitätsraten. Der Anteil positiver Replikate korrelierte mit dem Verdünnungsfaktor, gleichermaßen bei den sCJD $\left(\mathrm{R}^{2}=0,7525\right)$ wie bei den gCJD $\left(\mathrm{R}^{2}=0,9369\right)$. Zwischen sCJD und gCJD bestand kein signifikanter Unterschied ( $\mathrm{p}>0,05)$. Bild 15 auf S. 43 zeigt die Positivitätsraten der sCJD- und gCJD-Liquorproben bei serieller Verdünnung. 
Tabelle 14: Einfluss von Alter und Geschlecht auf die Fluoreszenzsignale - Daten

\begin{tabular}{|c|c|c|c|c|c|c|}
\hline \multicolumn{2}{|c|}{ Variable } & \multirow{2}{*}{$\begin{array}{c}<\mathbf{6 0} \\
15.119\end{array}$} & \multirow{2}{*}{$\frac{60-70}{10.704}$} & \multirow{2}{*}{$\begin{array}{l}>\mathbf{7 0} \\
13.000\end{array}$} & \multirow{2}{*}{$\frac{q}{13.125}$} & \multirow{2}{*}{$\frac{\sigma^{7}}{12,391}$} \\
\hline $4 \mathrm{I}$ & $\mathrm{Mw}$ & & & & & \\
\hline${ }^{A}$ & SD & 9490 & 6.423 & 7.025 & 6.652 & 8.684 \\
\hline \multirow{2}{*}{ Max rfu } & $\mathrm{Mw}$ & 45. & 40. & 38. & 40 & 41.019 \\
\hline & SD & & & & 11.821 & 15.810 \\
\hline \multirow{2}{*}{ Lag-Phase } & Media & 48,5 & 67,5 & 48,5 & 59,0 & 49,0 \\
\hline & IQR & $43,0-66,0$ & $52,0-77,5$ & $42,5-78,5$ & $42,5-80,0$ & $43,5-68,5$ \\
\hline
\end{tabular}

Tabelle 15: Einfluss von Alter und Geschlecht auf die Fluoreszenzsignale - Stat.

\begin{tabular}{rcc}
\hline Variable & $<\mathbf{6 0}$ vs. $\mathbf{6 0}-\mathbf{7 0}$ vs. $>\mathbf{7 0}$ & o vs. o $^{7}$ \\
\hline AUC & $\mathrm{p}>0,05$ & $\mathrm{p}>0,05$ \\
Max rfu & $\mathrm{p}>0,05$ & $\mathrm{p}>0,05$ \\
Lag-Phase & $\mathrm{p}>0,05$ & $\mathrm{p}>0,05$ \\
\hline
\end{tabular}

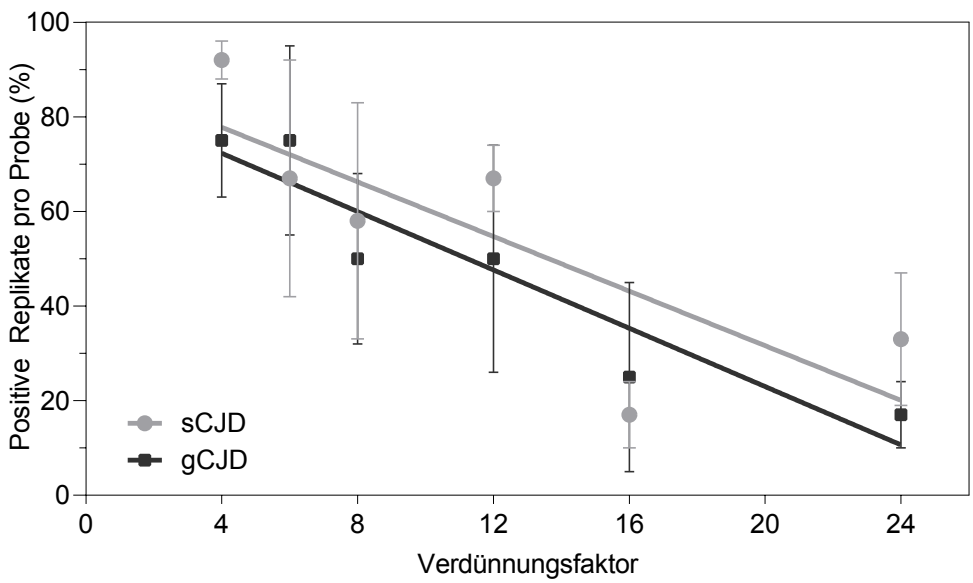

Bild 15: CJD-Positivitätsraten bei Verdünnung der Probe

Je stärker die gCJD- und sCJD-Liquorproben (je $\mathrm{n}=3$ ) verdünnt wurden, desto kleiner waren deren Positivitätsraten. Es wurden je drei sCJD- und gCJD-Liquorproben seriell verdünnt. Nachfolgend wurden die verdünnten Proben mittels RT-QuIC analysiert. Die RT-QuIC wurde über eine Versuchsdauer von 80 Std durchgeführt. Jedes Aliquot wurde in Quadruplikaten analysiert. Dann wurden die Positivitätsraten bestimmt und zwischen den experimentellen Gruppen $(4 \times, 6 \times, 8 \times, 12 \times, 16 \times, 24 \times)$ verglichen. Grafisch dargestellt sind die Mittelwerte der Gruppen \pm Standardabweichungen, mit linearer Regressionsgeraden. 


\subsubsection{Einfluss der Form der Prionkrankheit}

Die Fluoreszenzsignale der gCJD zeigten eine kürzere Lag-Phase und ein höheres Signalmaximum als die der sCJD- und FFI-Liquorproben. Die Liquorproben der retrospektiven Kontrollen blieben negativ. Die gCJD V210I erreichten nach 38,5 Std den Grenzwert, gefolgt von den gCJD E200K nach 41,0 Std, den sCJD nach 52,5 Std und den FFI nach 75,0 Std. Die gCJD zeigten sowohl größere Flächen unter der Kurve als auch höhere Signalmaxima sowie kürzere Lag-Phasen als die sCJD ( $p<0,001)$. Die sCJD unterschieden sich nicht von den FFI $(\mathrm{p}>0,05)$ und die gCJD E200K nicht von den gCJD V210I ( $\mathrm{p}>0,05)$. Bild 16 auf S. 44 zeigt die Fluoreszenzsignale der gCJD, sCJD, FFI und Kontrollen, gemittelt nach Gruppenzugehörigkeit. Tabelle 16 auf S. 45 führt die Datenanalysen und Tabelle 17 auf S. 45 sowie Tabelle 18 auf S. 45 führen die Statistik zu den Variablen geordnet nach Gruppenzugehörigkeit auf.

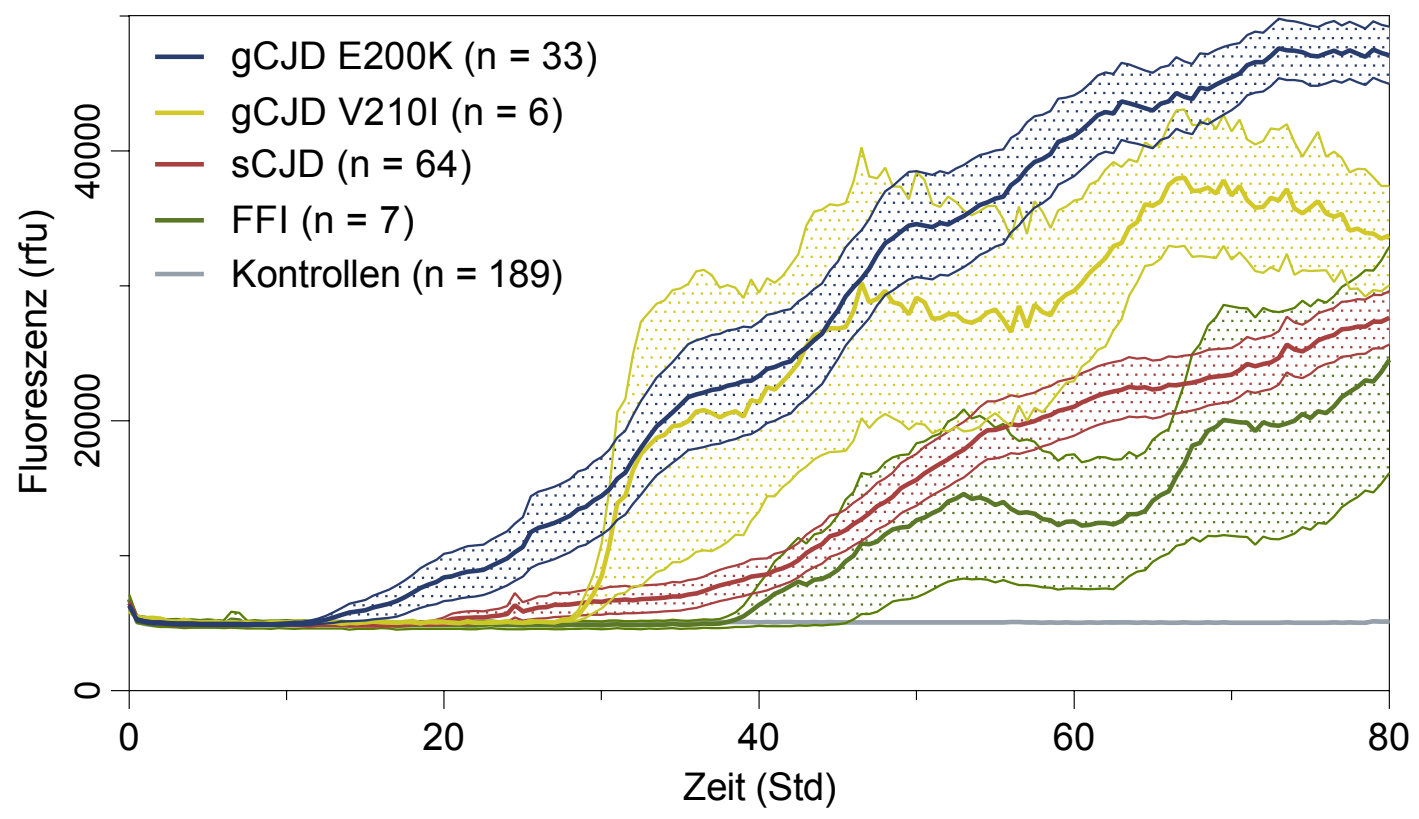

Bild 16: Einfluss der Krankheitsform auf das Fluoreszenzsignal

Die Fluoreszenzsignale der gCJD zeigten eine kürzere Lag-Phase und ein höheres Signalmaximum als die der sCJD- und FFI-Liquorproben. Die Liquorproben der retrospektiven Kontrollen blieben negativ.

Während der Versuche wurde die Fluoreszenz alle 30 Min. gemessen. Nachfolgend wurden aus den Mittelwerten der Fluoreszenzsignale der Proben die Mittelwerte der Gruppen \pm Standardfehler bestimmt. Diese wurden dann mittels linearer Interpolation verbunden und in Form einer Mittelwert- (dicke Linie) \pm Standardfehlerlinie (dünne Linien) grafisch als Verlauf über die Zeit dargestellt. Das Fehlerfeld ist farblich markiert. Diese Darstellung zeigt aggregierte Daten, weshalb ihr keine individuellen Informationen über die Fläche unter der Kurve, das Signalmaximum und die Lag-Phase entnommen werden können. 
Tabelle 16: Einfluss der Krankheitsform auf das Fluoreszenzsignal - Daten

\begin{tabular}{rlccccc}
\hline \multirow{2}{*}{ Variable } & & \multicolumn{2}{c}{ gCJD } & \multirow{2}{*}{ sCJD } & \multirow{2}{*}{ FFI } & \multirow{2}{*}{ Kontrollen } \\
\cline { 3 - 4 } & & E200K & V210I & & & \\
\hline \multirow{2}{*}{ AUC } & Mw & 28.642 & 23.557 & 18.492 & 16.149 & 4.809 \\
& SD & 9.694 & 6.969 & 8.441 & 7.291 & 961 \\
Max rfu & Mw & 54.725 & 48.353 & 40.745 & 33.194 & 6.986 \\
& SD & 10.024 & 13.505 & 13.976 & 13.607 & 1.672 \\
Lag-Phase & Median & 41,0 & 38,5 & 52,5 & 75,0 & nur ein Wert \\
& IQR & $27,5-51,5$ & $30,0-54,5$ & $43,0-76,5$ & $47,5-80,0$ & \\
\hline
\end{tabular}

Tabelle 17: Einfluss der Krankheitsform auf das Fluoreszenzsignal - Stat.

\begin{tabular}{rccccc}
\hline \multirow{2}{*}{ Variable } & $\begin{array}{c}\text { Prion vs. } \\
\text { Kontr. }\end{array}$ & $\begin{array}{c}\text { gCJD vs. } \\
\text { sCJD }\end{array}$ & $\begin{array}{c}\text { gCJD vs. } \\
\text { FFI }\end{array}$ & $\begin{array}{c}\text { E200K vs. } \\
\text { V210I }\end{array}$ & $\begin{array}{c}\text { sCJD vs. } \\
\text { FFI }\end{array}$ \\
\hline AUC & $\mathrm{p}<0,001$ & $\mathrm{p}<0,001$ & $\mathrm{p}<0,05$ & $\mathrm{p}>0,05$ & $\mathrm{p}>0,05$ \\
Max rfu & $\mathrm{p}<0,001$ & $\mathrm{p}<0,001$ & $\mathrm{p}>0,05$ & $\mathrm{p}>0,05$ & $\mathrm{p}>0,05$ \\
Lag-Phase & $\mathrm{p}<0,001$ & $\mathrm{p}<0,001$ & $\mathrm{p}<0,001$ & $\mathrm{p}>0,05$ & $\mathrm{p}>0,05$ \\
\hline
\end{tabular}

Tabelle 18: Einfluss der Krankheitsform auf das Fluoreszenzsignal - Stat.

\begin{tabular}{rcccccccc}
\hline \multirow{2}{*}{ Variable } & $\begin{array}{c}\text { E200K vs. } \\
\text { Kontr. }\end{array}$ & $\begin{array}{c}\text { V210I vs. } \\
\text { Kontr. }\end{array}$ & $\begin{array}{c}\text { sCJD vs. } \\
\text { Kontr. }\end{array}$ & $\begin{array}{c}\text { FFI vs. } \\
\text { Kontr. }\end{array}$ & $\begin{array}{c}\text { E200K vs. } \\
\text { sCJD }\end{array}$ & $\begin{array}{c}\text { E200K vs. } \\
\text { FFI }\end{array}$ & $\begin{array}{c}\text { V210I vs. } \\
\text { SCJD }\end{array}$ & $\begin{array}{c}\text { V210I vs. } \\
\text { FFI }\end{array}$ \\
\hline AUC & $\mathrm{p}<0,001$ & $\mathrm{p}<0,001$ & $\mathrm{p}<0,001$ & $\mathrm{p}<0,001$ & $\mathrm{p}<0,001$ & $\mathrm{p}<0,05$ & $\mathrm{p}>0,05$ & $\mathrm{p}>0,05$ \\
Max rfu & $\mathrm{p}<0,001$ & $\mathrm{p}<0,001$ & $\mathrm{p}<0,001$ & $\mathrm{p}<0,001$ & $\mathrm{p}<0,001$ & $\mathrm{p}>0,05$ & $\mathrm{p}>0,05$ & $\mathrm{p}>0,05$ \\
Lag-Phase & $\mathrm{p}<0,001$ & $\mathrm{p}<0,001$ & $\mathrm{p}<0,001$ & $\mathrm{p}<0,05$ & $\mathrm{p}<0,001$ & $\mathrm{p}<0,001$ & $\mathrm{p}>0,05$ & $\mathrm{p}<0,05$ \\
\hline
\end{tabular}




\subsubsection{Einfluss der molekularen sCJD-Formen}

Bild 17 auf S. 46 zeigt die sCJD-Fluoreszenzsignale getrennt nach dem (a) Prnp Codon 129-Genotyp (MM vs. MV vs. VV) und dem (b) $\mathrm{PrP}^{\mathrm{Sc}}$-Typ (1 vs. 2). Allein hatte weder der Prnp Codon 129-Genotyp, noch der PrP ${ }^{\mathrm{Sc}}$-Typ einen Einfluss auf die Fluoreszenzsignale von sCJD-Liquorproben $(\mathrm{p}>0,05)$. Tabelle 19 auf S. 48 führt die Datenanalysen und Tabelle 20 auf S. 48 die Statistik zu den Variablen geordnet nach Gruppenzugehörigkeit auf.

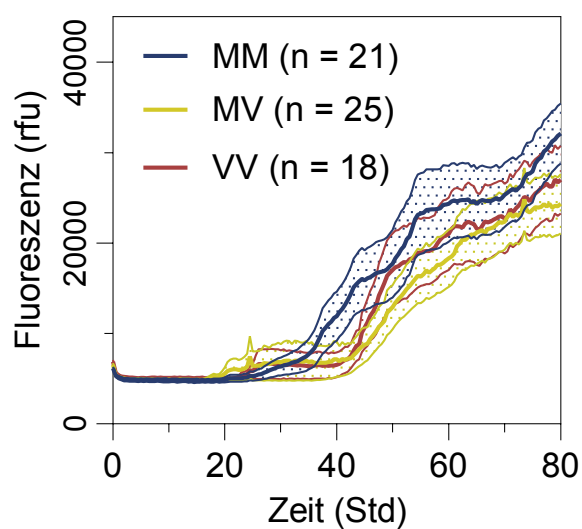

(a) Prnp Codon 129-Genotyp

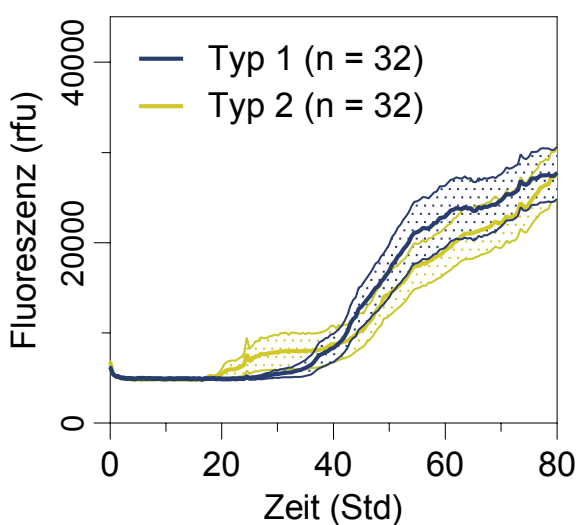

(b) $\operatorname{PrP}^{\mathrm{Sc}}-\mathrm{Typ}$

Bild 17: Einfluss des Codon 129 und des $\mathrm{PrP}^{\mathrm{Sc}}$ auf die Fluoreszenzsignale

Allein hatte weder der Prnp Codon 129-Genotyp noch der PrPSc-Typ einen Einfluss auf die Fluoreszenzsignale der sCJD-Liquorproben in der RT-QuIC. Bild 17 (a) zeigt die sCJDFluoreszenzsignale gruppiert nach dem Prnp Codon 129-Genotyp (MM vs. MV vs. VV) und Bild 17 (b), diese gruppiert nach dem $\mathrm{PrP}^{\mathrm{Sc}}$-Typ (1 vs. 2).

Während der Versuche wurde die Fluoreszenz alle 30 Min. gemessen. Nachfolgend wurden aus den Mittelwerten der Fluoreszenzsignale der Proben die Mittelwerte der Gruppen \pm Standardfehler bestimmt. Diese wurden dann mittels linearer Interpolation verbunden und in Form einer Mittelwert- (dicke Linie) \pm Standardfehlerlinie (dünne Linien) grafisch als Verlauf über die Zeit dargestellt. Das Fehlerfeld ist farblich markiert. Diese Darstellung zeigt aggregierte Daten, weshalb ihr keine individuellen Informationen über die Fläche unter der Kurve, das Signalmaximum und die Lag-Phase entnommen werden können.

Bild 18 auf S. 47 zeigt die sCJD-Fluoreszenzsignale, getrennt nach dem $\mathrm{PrP}^{\mathrm{Sc}}$ Typ und gruppiert nach dem Prnp Codon 129-Genotyp. Wenn die Fluoreszenzsignale nach den $\mathrm{PrP}^{\mathrm{Sc}}$-Typen getrennt und innerhalb dieser Gruppen die Prnp Codon 129Genotypen verglichen wurden, dann assoziierten die sCJD MM1 mit einer kürzeren Lag-Phase (45,0 Std) als die sCJD MV1- (67,5 Std) und sCJD VV1-Formen (48,0 Std) $(\mathrm{p}>0,05)$ und zeigten ein höheres Signalmaximum als diese $(\mathrm{p}<0,05)$. Die Fluoreszenzsignale der sCJD MM2, sCJD MV2 und sCJD VV2 unterschieden sich nicht voneinander $(\mathrm{p}>0,05)$. Tabelle 21 auf S. 48 führt die Datenanalysen und Tabelle 22 auf S. 50 die Statistik zu den Variablen geordnet nach Gruppenzugehörigkeit auf. 


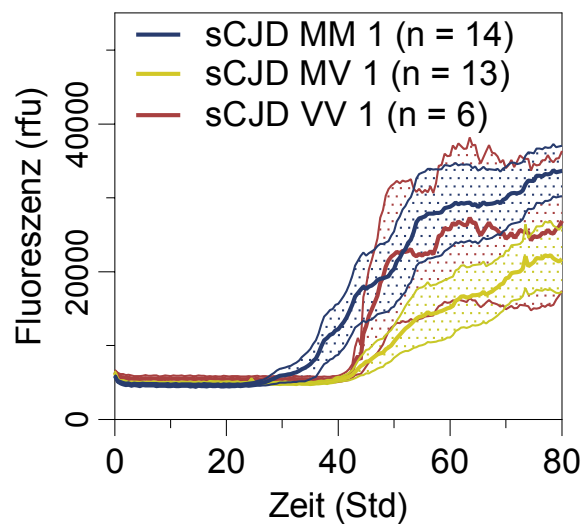

(a) $\mathrm{PrP}^{\mathrm{Sc}}$-Typ 1

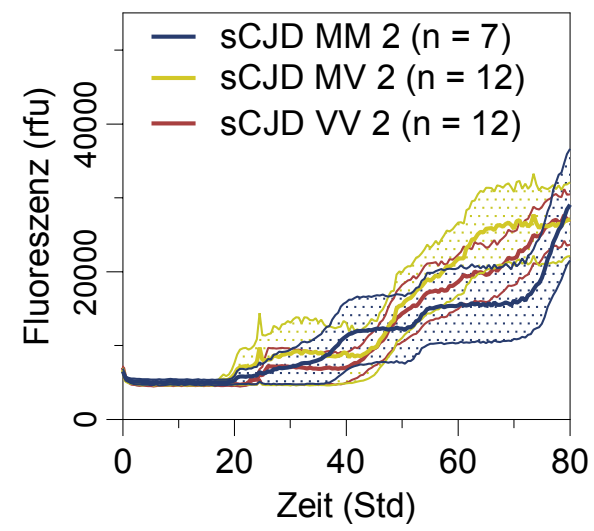

(b) $\mathrm{PrP}^{\mathrm{Sc}}$-Typ 2

Bild 18: Einfluss der molekularen sCJD-Formen auf die Fluoreszenzsignale - 2

Wenn die Fluoreszenzsignale der sCJD-Liquorproben nach den $\mathrm{PrP}^{\mathrm{Sc}}$-Typen getrennt und innerhalb dieser Gruppen die Prnp Codon 129-Genotypen verglichen wurden, dann assoziierte die sCJD MM1 mit einer kürzeren Lag-Phase und zeigte ein höheres Signalmaximum als die sCJD MV1 und die sCJD VV1. Die Fluoreszenzsignale der sCJD MM2, sCJD MV2 und sCJD VV2 unterschieden sich nicht voneinander. Bild 18 (a) zeigt die sCJD-Fluoreszenzsignale des $\mathrm{PrP}^{\mathrm{Sc}}$-Typ 1 und Bild 18 (b) zeigt die des $\mathrm{PrP}^{\mathrm{Sc}}$-Typ 2, jeweils gruppiert nach dem Prnp Codon 129-Genotyp.

Während der Versuche wurde die Fluoreszenz alle 30 Min. gemessen. Nachfolgend wurden aus den Mittelwerten der Fluoreszenzsignale der Proben die Mittelwerte der Gruppen \pm Standardfehler bestimmt. Diese wurden dann mittels linearer Interpolation verbunden und in Form einer Mittelwert- (dicke Linie) \pm Standardfehlerlinie (dünne Linien) grafisch als Verlauf über die Zeit dargestellt. Das Fehlerfeld ist farblich markiert. Diese Darstellung zeigt aggregierte Daten, weshalb ihr keine individuellen Informationen über die Fläche unter der Kurve, das Signalmaximum und die Lag-Phase entnommen werden können. 
Tabelle 19: Einfluss von Codon 129 und $\mathrm{PrP}^{\mathrm{Sc}}$ auf die Fluoreszenzsignale - Daten

\begin{tabular}{rlccccc}
\hline \multicolumn{2}{c}{ Variable } & MM & MV & VV & Typ 1 & Typ 2 \\
\hline \multirow{2}{*}{ AUC } & Mw & 14.288 & 11.627 & 12.463 & 13.146 & 12.298 \\
& SD & 8.351 & 7.677 & 7.228 & 7.944 & 7.636 \\
\multirow{2}{*}{ Max rfu } & Mw & 42.878 & 37.377 & 42.934 & 42.551 & 38.822 \\
& SD & 14.917 & 13.981 & 12.601 & 14.353 & 13.529 \\
Lag-Phase & Median & 52,5 & 59,0 & 51,0 & 55,5 & 52,5 \\
& IQR & $39,0-68,0$ & $46,5-80,0$ & $43,5-79,0$ & $43,0-79,0$ & $43,5-75,5$ \\
\hline
\end{tabular}

Tabelle 20: Einfluss von Codon 129 und $\operatorname{PrP}^{\mathrm{Sc}}$ auf die Fluoreszenzsignale - Stat.

\begin{tabular}{rcc}
\hline Variable & MM vs. MV vs VV & Typ 1 vs. Typ 2 \\
\hline AUC & $\mathrm{p}>0,05$ & $\mathrm{p}>0,05$ \\
Max rfu & $\mathrm{p}>0,05$ & $\mathrm{p}>0,05$ \\
Lag-Phase & $\mathrm{p}>0,05$ & $\mathrm{p}>0,05$ \\
\hline
\end{tabular}

Bild 19 auf S. 49 zeigt die sCJD-Fluoreszenzsignale, getrennt nach dem Prnp Codon 129-Genotyp und gruppiert nach dem $\mathrm{PrP}^{\mathrm{Sc}}$-Typ. Wenn die Fluorezenzsignale nach den Prnp Codon 129-Genotypen getrennt und innerhalb dieser Gruppen die $\mathrm{PrP}^{\mathrm{Sc}}$-Typen verglichen wurden, dann wurde in keiner Gruppe ein Unterschied zwischen dem $\mathrm{PrP}^{\mathrm{Sc}}$ Typ 1 und 2 beobachtet $(\mathrm{p}>0,05)$. Tabelle 21 auf S. 48 führt die Datenanalysen und Tabelle 22 auf S. 50 die Statistik zu den Variablen geordnet nach Gruppenzugehörigkeit auf.

Tabelle 21: Einfluss der molekularen sCJD-Formen auf die Fluoreszenzsignale - Daten

\begin{tabular}{rlcccccc}
\hline \multicolumn{2}{c}{ Variable } & MM1 & MM2 & MV1 & MV2 & VV1 & VV2 \\
\hline \multirow{2}{*}{ AUC } & Mw & 15.935 & 10.994 & 9.900 & 13.497 & 13.670 & 11.859 \\
& SD & 8.553 & 7.417 & 5.140 & 9.614 & 10.039 & 5.808 \\
Max rfu & Mw & 43.860 & 40.914 & 36.106 & 38.754 & 53.462 & 37.669 \\
& SD & 13.336 & 18.699 & 12.023 & 16.274 & 15.926 & 6.279 \\
Lag-Phase & Median & 45,0 & 52,5 & 67,5 & 52,0 & 48,0 & 51,0 \\
& IQR & $38,5-59,5$ & $39,0-76,5$ & $48,5-80,0$ & $45,5-65,0$ & $43,0-79,5$ & $43,5-72,5$ \\
\hline
\end{tabular}

Wenn Mäusen, die verschiedene humane Prnp Codon 129-Genotypen exprimierten (MM, MV oder VV), Gehirnmaterial von sCJD-Patienten, mit unterschiedlichen sCJDFormen (MM1, MM2, MV1, MV2, VV1, VV2), inokuliert wurde, dann konnten, anhand charakteristischer Inkubationszeiten und neuropathologischer Lesionsprofile, vier sCJD-Prionstämme unterschieden werden: MM1/MV1, MV2/V22, VV1 und MM2 (Bishop u.a. 2010). Bild 20 auf S. 50 zeigt die sCJD-Fluoreszenzsignale, gruppiert nach den von Bishop u. a. 2010 postulierten sCJD-Prionstämmen. Diese unterschieden sich in allen drei Variablen nicht signifikant $(\mathrm{p}>0,05)$. 


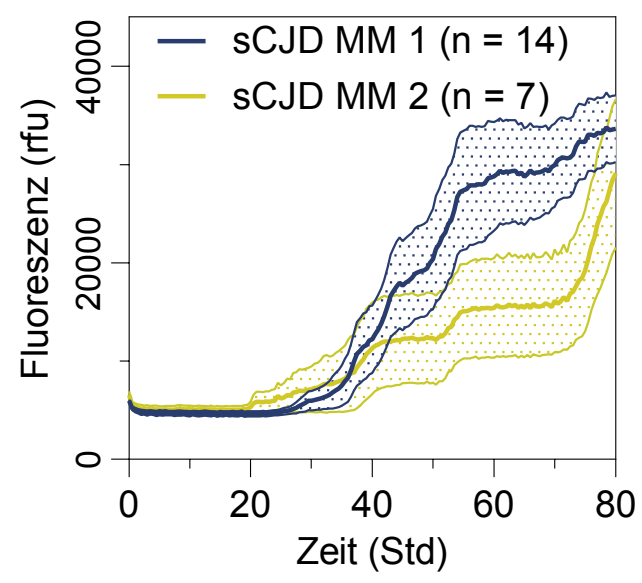

(a) SCJD MM

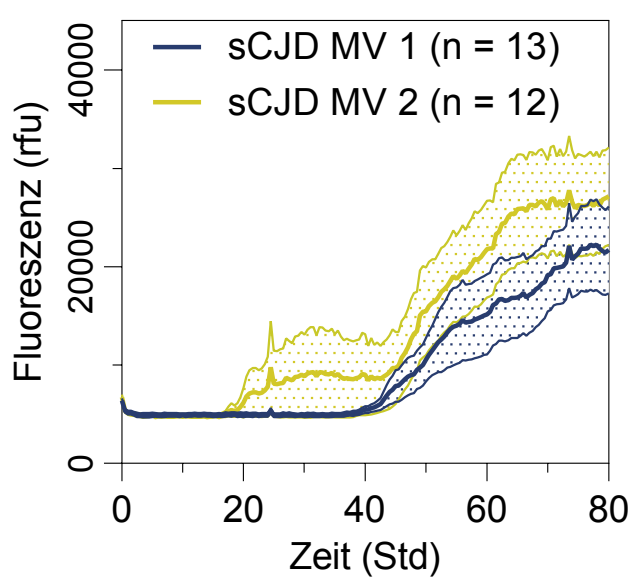

(b) SCJD MV

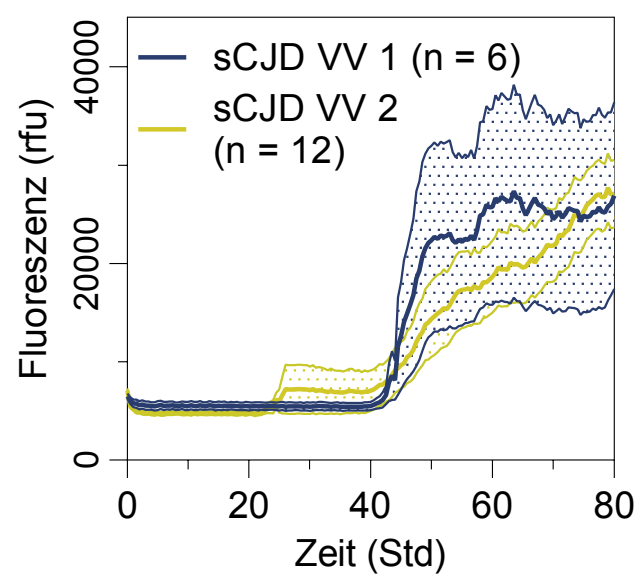

(c) SCJD VV

Bild 19: Einfluss der molekularen sCJD-Formen auf die Fluoreszenzsignale - 3

Wenn die Fluoreszenzsignale der sCJD-Liquorproben nach den Prnp Codon 129-Genotypen getrennt und innerhalb dieser Gruppen die $\mathrm{PrP}^{\mathrm{Sc}}$-Typen verglichen wurden, dann zeigte keine der Gruppen einen Unterschied zwischen dem PrPSc-Typ 1 und 2. Bild 19 (a) zeigt Prnp Codon 129 MM, Bild 19 (b) Prnp Codon 129 MV und Bild 19 (c) Prnp Codon 129 VV, jeweils in Kombination mit PrPSc-Typ 1 und 2.

Während der Versuche wurde die Fluoreszenz alle 30 Min. gemessen. Nachfolgend wurden aus den Mittelwerten der Fluoreszenzsignale der Proben die Mittelwerte der Gruppen \pm Standardfehler bestimmt. Diese wurden dann mittels linearer Interpolation verbunden und in Form einer Mittelwert- (dicke Linie) \pm Standardfehlerlinie (dünne Linien) grafisch als Verlauf über die Zeit dargestellt. Das Fehlerfeld ist farblich markiert. Diese Darstellung zeigt aggregierte Daten, weshalb ihr keine individuellen Informationen über die Fläche unter der Kurve, das Signalmaximum und die Lag-Phase entnommen werden können. 
Tabelle 22: Einfluss der molekularen sCJD-Formen auf die Fluoreszenzsignale - Stat.

\begin{tabular}{|c|c|c|c|c|c|c|c|c|}
\hline Variable & $\begin{array}{l}\text { MM1 vs. } \\
\text { MV1 vs. VV1 }\end{array}$ & $\begin{array}{c}\text { MM2 vs. } \\
\text { MV2 vs. VV2 }\end{array}$ & $\begin{array}{l}\text { MM1 vs. } \\
\text { MM2. }\end{array}$ & $\begin{array}{l}\text { MV1 vs. } \\
\text { MV2 }\end{array}$ & $\begin{array}{l}\text { VV1 vs. } \\
\text { VV2 }\end{array}$ & $\begin{array}{l}\text { MM1 vs. } \\
\text { MV1 }\end{array}$ & $\begin{array}{l}\text { MV1 vs. } \\
\text { VV2 }\end{array}$ & $\begin{array}{l}\text { MM1 vs. } \\
\text { VV1 }\end{array}$ \\
\hline $\mathrm{AUC}$ & $\mathrm{p}>0,05$ & $\mathrm{p}>0,05$ & $\mathrm{p}>0,05$ & 0,05 & $\mathrm{p}>0,05$ & 0,05 & 0,05 & $\mathrm{p}>0,05$ \\
\hline Max rfu & $\mathrm{p}<0,05$ & $\mathrm{p}>0,05$ & $\mathrm{p}>0,05$ & $\mathrm{p}>0,05$ & $\mathrm{p}>0,05$ & $\mathrm{p}>0,05$ & $\mathrm{p}<0,05$ & $\mathrm{p}>0,05$ \\
\hline Lag-Phase & $\mathrm{p}>0,05$ & $\mathrm{p}>0,05$ & $\mathrm{p}>0,05$ & $\mathrm{p}>0,05$ & $\mathrm{p}>0,05$ & $\mathrm{p}>0,05$ & $\mathrm{p}>0,05$ & $\mathrm{p}>0,05$ \\
\hline
\end{tabular}

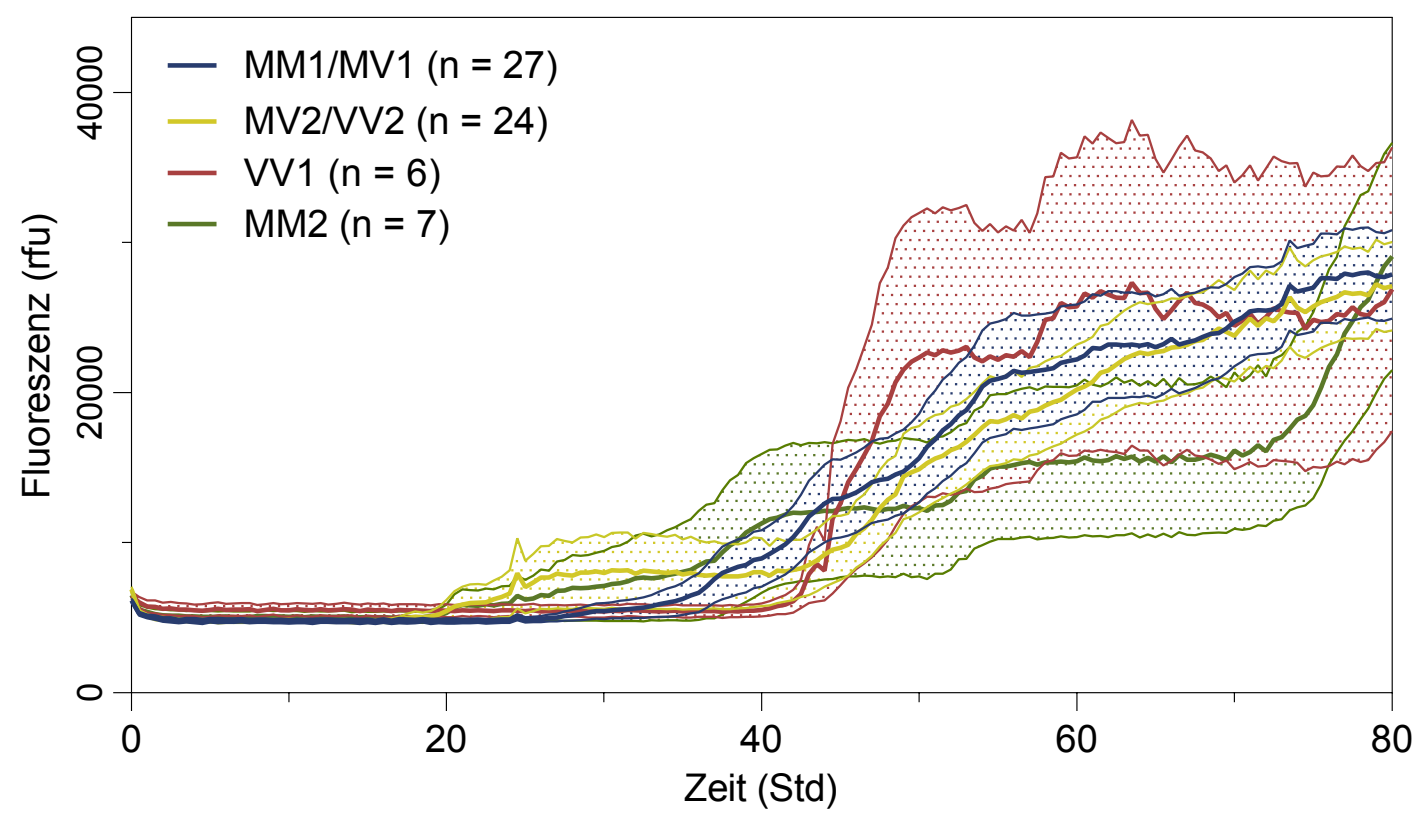

Bild 20: Einfluss möglicher sCJD-Prionstämme auf die Fluoreszenzsignale

Wenn die Fluoreszenzsignale der sCJD-Liquorproben nach den von Bishop u. a. 2010 postulierten sCJD-Prionstämmen gruppiert wurden, dann unterschieden sich diese Gruppen nicht signifikant voneinander.

Während der Versuche wurde die Fluoreszenz alle 30 Min. gemessen. Nachfolgend wurden aus den Mittelwerten der Fluoreszenzsignale der Proben die Mittelwerte der Gruppen \pm Standardfehler bestimmt. Diese wurden dann mittels linearer Interpolation verbunden und in Form einer Mittelwert- (dicke Linie) \pm Standardfehlerlinie (dünne Linien) grafisch als Verlauf über die Zeit dargestellt. Das Fehlerfeld ist farblich markiert. Diese Darstellung zeigt aggregierte Daten, weshalb ihr keine individuellen Informationen über die Fläche unter der Kurve, das Signalmaximum und die Lag-Phase entnommen werden können. 


\subsubsection{Einfluss des Prnp Codon 129-Genotyps bei gCJD}

Bild 21 auf S. 52 zeigt die gCJD-Fluoreszenzsignale, gruppiert nach dem Prnp Codon 129 und der Mutation des Prnp. Gruppen mit weniger als fünf Proben (bspw. gCJD V210I MV mit $\mathrm{n}=1$ und FFI MM mit $\mathrm{n}=4$ ) wurden in diese Auswertungen nicht mit einbezogen. Innerhalb der gCJD E200K war die Lag-Phase der gCJD E200K MM kürzer $(\mathrm{p}<0,001)$ als die der gCJD E200K MV. Der frühere und stärkere Anstieg des Fluoreszenzsignals der gCJD E200K im Vergleich zu gCJD V210 und sCJD wurde unabhängig vom Prnp Codon 129-Genotyp beobachtet. Die Fläche unter der Kurve der gCJD E200K MM war größer als die der gCJD V210I MM ( $<<0,001)$. Die Fläche unter der Kurve der gCJD E200K MM war größer und die Lag-Phase kürzer als die der sCJD MM ( $<<0,001)$. Die Fläche unter der Kurve der gCJD E200K MV war größer ( $\mathrm{p}$ $<0,001)$, das Signalmaximum höher $(\mathrm{p}<0,001)$ und die Lag-Phase kürzer $(\mathrm{p}<0,01)$ als die der sCJD MV. Tabelle 23 auf S. 51 führt die Datenanalysen und Tabelle 24 auf S. 51 die Statistik zu den Variablen geordnet nach Gruppenzugehörigkeit auf.

Tabelle 23: Einfluss der gCJD-Mutation auf die Fluoreszenzsignale - Daten

\begin{tabular}{rlccccc}
\hline \multicolumn{2}{c}{ Variable } & MM E200K & MM V210I & MM sCJD & MV E200K & MV sCJD \\
\hline \multirow{2}{*}{ AUC } & Mw & 28.281 & 20.844 & 14.288 & 22.266 & 11.626 \\
& SD & 9.881 & 8.229 & 8.351 & 9.215 & 7.677 \\
\multirow{2}{*}{ Max rfu } & Mw & 51.367 & 48.858 & 42.878 & 57.200 & 37.377 \\
& SD & 11.035 & 15.036 & 14.917 & 8.687 & 13.981 \\
Lag-Phase & Median & 27,0 & 38,5 & 52,5 & 44,5 & 59,0 \\
& IQR & $19,0-42,0$ & $30,0-42,0$ & $39,0-58,0$ & $34,0-58,0$ & $46,5-85,0$ \\
\hline
\end{tabular}

Tabelle 24: Einfluss der gCJD-Mutation auf die Fluoreszenzsignale - Stat.

\begin{tabular}{rccccc}
\hline Variable & $\begin{array}{c}\text { MM E200K vs. } \\
\text { MV E200K }\end{array}$ & $\begin{array}{c}\text { MM E200K vs. } \\
\text { MM V210I }\end{array}$ & $\begin{array}{c}\text { MM E200K vs. } \\
\text { MM sCJD }\end{array}$ & $\begin{array}{c}\text { MM V210I vs. } \\
\text { MM sCJD }\end{array}$ & $\begin{array}{c}\text { MV E200K vs. } \\
\text { MV sCJD }\end{array}$ \\
\hline AUC & $\mathrm{p}>0,05$ & $\mathrm{p}<0,001$ & $\mathrm{p}<0,001$ & $\mathrm{p}>0,05$ & $\mathrm{p}<0,001$ \\
Max rfu & $\mathrm{p}>0,05$ & $\mathrm{p}>0,05$ & $\mathrm{p}>0,05$ & $\mathrm{p}>0,05$ & $\mathrm{p}<0,001$ \\
Lag-Phase & $\mathrm{p}<0,001$ & $\mathrm{p}>0,05$ & $\mathrm{p}<0,001$ & $\mathrm{p}>0,05$ & $\mathrm{p}<0,01$ \\
\hline
\end{tabular}

\subsubsection{Einfluss von Krankheitsstadium und Krankheitsdauer bei sCJD}

Die Krankheitsdauer wurde definiert als der Zeitraum vom Auftreten der ersten Symptome bis zum Tod des Patienten. Um das Krankheitsstadium zum Zeitpunkt der Probenentnahme zu ermitteln, wurde die Krankheitsdauer in drei Intervalle gleichen Zeitumfangs geteilt. Das frühe Stadium wurde definiert als der Zeitraum vom Beginn der ersten Symptome bis zum Ende des ersten Intervalls. Es folgte das mittlere Stadium, definiert als zweites Intervall, und das späte Stadium, definiert als letztes Intervall der gesamten Krankheitsdauer. 


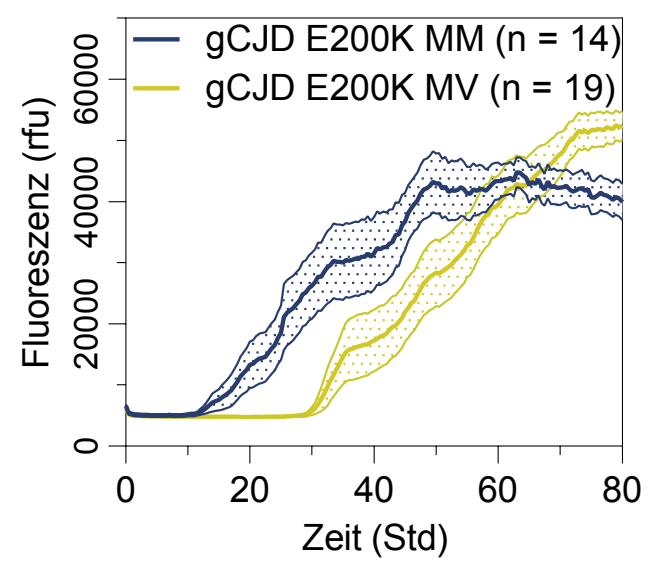

(a) gCJD E200K MM vs. MV

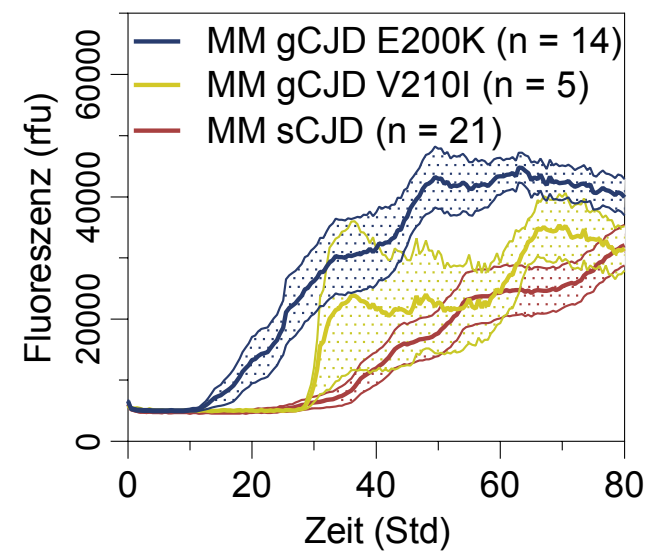

(b) gCJD MM E200K vs. V210I vs. sCJD

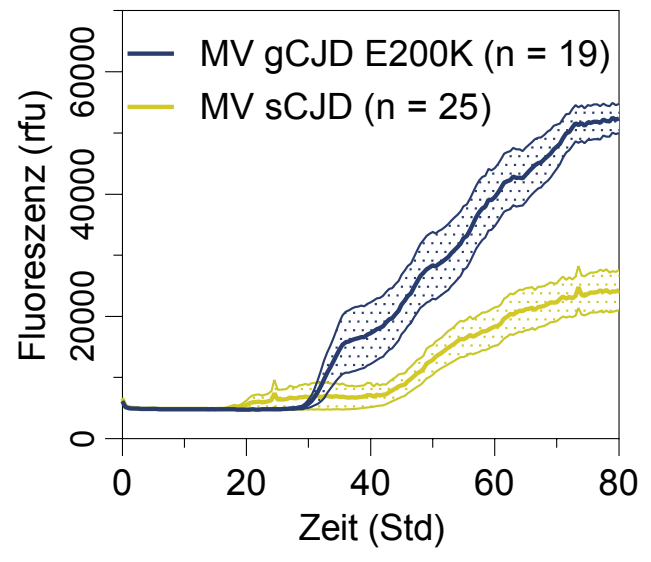

(c) gCJD MV E200K vs. sCJD

Bild 21: Einfluss der gCJD-Mutation auf die Fluoreszenzsignale

Die Fluoreszenzsignale der gCJD E200K-Liquorproben zeigten unabhängig vom Prnp Codon 129-Genotyp einen früheren und stärkeren Signalanstieg als die der gCJD V210I und sCJD. Bild 21 (a) zeigt die Fluoreszenzsignale von gCJD E200K-Liquorproben, gruppiert nach dem Prnp Codon 129, Bild 21 (b) zeigt die von Prnp Codon 129 MM gruppiert nach der gCJD-Mutation und im Vergleich zu sCJD und Bild 21 (c) die von gCJD E200K MV im Vergleich zu sCJD MV.

Während der Versuche wurde die Fluoreszenz alle 30 Min. gemessen. Nachfolgend wurden aus den Mittelwerten der Fluoreszenzsignale der Proben die Mittelwerte der Gruppen \pm Standardfehler bestimmt. Diese wurden dann mittels linearer Interpolation verbunden und in Form einer Mittelwert- (dicke Linie) \pm Standardfehlerlinie (dünne Linien) grafisch als Verlauf über die Zeit dargestellt. Das Fehlerfeld ist farblich markiert. Diese Darstellung zeigt aggregierte Daten, weshalb ihr keine individuellen Informationen über die Fläche unter der Kurve, das Signalmaximum und die Lag-Phase entnommen werden können. 
Das frühe Krankheitsstadium assoziierte mit einer kürzeren Lag-Phase und größeren Fläche unter der Kurve, verglichen mit dem mittleren und späten Krankheitsstadium, dieser Einfluss war jedoch nicht signifikant $(\mathrm{p}>0,05)$. Die Fluoreszenzsignale der kurzen $(\leq 3$ Monate), mittleren ( $3-6$ Monate) und langen $(>6$ Monate) Krankheitsdauer unterschieden sich hinsichtlich ihrer jeweiligen Flächen unter der Kurve, Signalmaxima und Lag-Phasen voneinander $(\mathrm{p}<0,01)$. Die sCJD-Liquorproben von Patienten mit kurzer Krankheitsdauer zeigten eine kürzere Lag-Phase (41,0 Std) und größere Fläche unter der Kurve als die von Patienten mit mittlerer (48,0 Std) und langer Krankheitsdauer (68,0 Std). Bild 22 auf S. 53 zeigt die Fluoreszenzsignale von sC.JD-Liquorproben, gruppiert nach dem Krankheitsstadium und der Krankheitsdauer. Tabelle 25 auf S. 54 führt die Datenanalysen der Variablen zum Krankheitsstadium und Tabelle 26 auf S. 54 die zur Krankheitsdauer geordnet nach Gruppenzugehörigkeit auf. Tabelle 27 auf S. 54 führt die Statistik zu den Variablen auf.

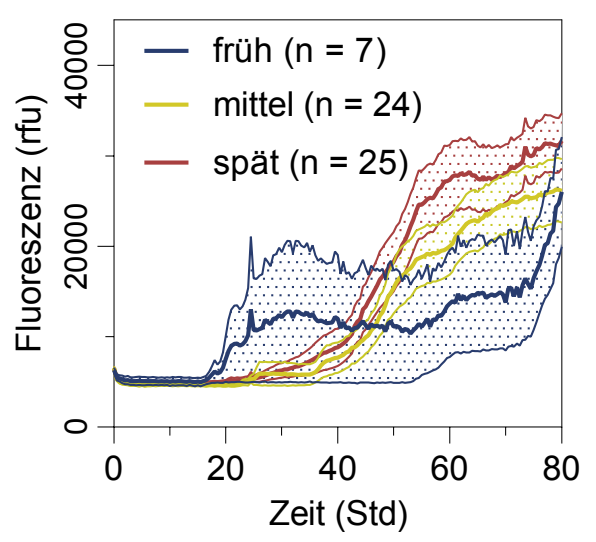

(a) Krankheitsstadium

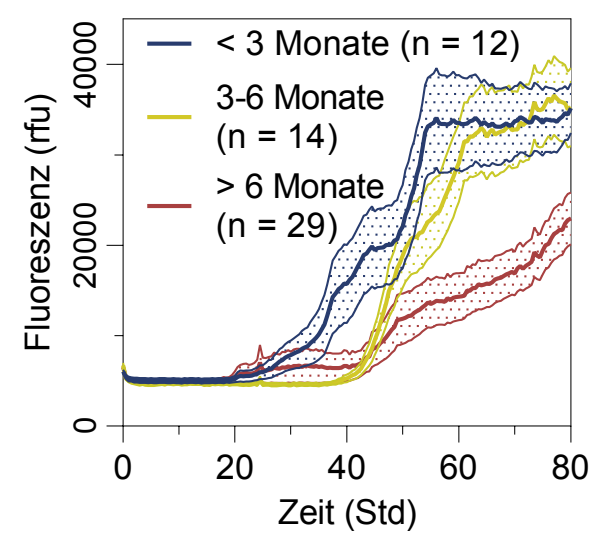

(b) Krankheitsdauer

Bild 22: Einfluss von Krankheitsstadium und -dauer auf die Fluoreszenzsignale

Das frühe Krankheitsstadium assoziierte mit einer kürzeren Lag-Phase und größeren Fläche unter der Kurve als das mittlere und das späte Krankheitsstadium. Die kurze Krankheitsdauer zeigte eine kürzere Lag-Phase und größere Fläche unter der Kurve als die mittlere und die lange Krankheitsdauer. Bild 22 (a) zeigt die Fluoreszenzsignale der sCJD-Liquorproben gruppiert nach dem Krankheitsstadium zum Zeitpunkt der Lumbalpunktion und Bild 22 (b) diese gruppiert nach der Krankheitsdauer.

Während der Versuche wurde die Fluoreszenz alle 30 Min. gemessen. Nachfolgend wurden aus den Mittelwerten der Fluoreszenzsignale der Proben die Mittelwerte der Gruppen \pm Standardfehler bestimmt. Diese wurden dann mittels linearer Interpolation verbunden und in Form einer Mittelwert- (dicke Linie) \pm Standardfehlerlinie (dünne Linien) grafisch als Verlauf über die Zeit dargestellt. Das Fehlerfeld ist farblich markiert. Diese Darstellung zeigt aggregierte Daten, weshalb ihr keine individuellen Informationen über die Fläche unter der Kurve, das Signalmaximum und die Lag-Phase entnommen werden können. 
Tabelle 25: Einfluss des Krankheitsstadiums auf die Fluoreszenzsignale - Daten

\begin{tabular}{lcccc}
\hline \multicolumn{2}{c}{ Variable } & früh & mittel & spät \\
\hline \multirow{2}{*}{ AUC } & Mw & 11.066 & 12.434 & 14.702 \\
\multirow{2}{*}{ Max rfu } & SD & 11.554 & 6.590 & 7.902 \\
\multirow{2}{*}{ Lag-Phase } & Mw & 47.767 & 38.845 & 41.865 \\
& SD & 15.789 & 13.906 & 12.865 \\
& Median & 76,5 & 49,0 & 48,5 \\
& IQR & $56,0-79,0$ & $43,0-66,0$ & $42,5-67,5$ \\
\hline
\end{tabular}

Tabelle 26: Einfluss der Krankheitsdauer auf die Fluoreszenzsignale - Daten

\begin{tabular}{lcccc}
\hline \multicolumn{2}{c}{ Variable } & $<\mathbf{3}$ Monate & $\mathbf{3}-\mathbf{6}$ Monate & $>\mathbf{6}$ Monate \\
\hline \multirow{2}{*}{ AUC } & Mw & 17.524 & 12.434 & 10.032 \\
& SD & 7.864 & 6.362 & 7.351 \\
\multirow{2}{*}{ Max rfu } & Mw & 44.558 & 42.404 & 37.872 \\
\multirow{2}{*}{ Lag-Phase } & SD & 14.498 & 12.081 & 13.956 \\
& Median & 41,0 & 48,0 & 68,0 \\
& IQR & $28,5-52,5$ & $43,5-59,5$ & $49,0-80,0$ \\
\hline
\end{tabular}

Tabelle 27: Einfluss von Stadium und Dauer auf die Fluoreszenzsignale - Stat.

\begin{tabular}{rcc}
\hline Variable & $\begin{array}{c}\text { Krankheitsstadium } \\
\text { früh vs. mittel vs. spät }\end{array}$ & $\begin{array}{c}\text { Krankheitsdauer/ Monate } \\
<3 \text { vs. } 4-6 \text { vs. }>6\end{array}$ \\
\hline AUC & $\mathrm{p}>0,05$ & $\mathrm{p}<0,01$ \\
Max rfu & $\mathrm{p}>0,05$ & $\mathrm{p}>0,05$ \\
Lag-Phase & $\mathrm{p}>0,05$ & $\mathrm{p}<0,01$ \\
\hline
\end{tabular}




\subsubsection{Einfluss von krankheitsassoziierten Proteinen}

Die Bestimmungen der Protein-Konzentrationen wurden wie in Unterabschnitt 3.4 und die RT-QuIC wie in Unterabschnitt 3.5 durchgeführt. Es wurde die Konzentration des gesamten $\mathrm{PrP}$ in der Probe bestimmt resp. der Summe aus $\mathrm{PrP}^{\mathrm{C}}$ und $\mathrm{PrP}^{\mathrm{Sc}}$ sowie die des 14-3-3- und des Tau-Proteins.

Bild 23 auf S. 56 zeigt die Konzentrationen des PrP-, des 14-3-3- und des TauProteins in Korrelation mit den Lag-Phasen von willkürlich ausgewählten sCJD-Liquorproben. Es bestand keine Korrelation zwischen den Protein-Konzentrationen und den Lag-Phasen von sC.JD-Liquorproben in der RT-QuIC. Tabelle 28 auf S. 55 führt die Korrelationsanalysen der Protein-Konzentrationen mit den Flächen unter der Kurve, Signalmaxima und Lag-Phasen der sCJD-Liquorproben mittels des Spearmanschen Rangkorrelationskoeffizienten auf.

Tabelle 28: Einfluss krankheitsassoziierter Proteine auf die Fluoreszenzsignale

\begin{tabular}{|c|c|c|c|c|c|c|c|c|c|}
\hline \multirow{2}{*}{ Protein } & \multicolumn{3}{|c|}{ AUC } & \multicolumn{3}{|c|}{ Max rfu } & \multicolumn{3}{|c|}{ Lag-Phase } \\
\hline & $\rho$ & $95 \% \mathrm{CI}$ & p-Wert & $\rho$ & $95 \% \mathrm{CI}$ & p-Wert & $\rho$ & $95 \% \mathrm{CI}$ & p-Wert \\
\hline Prion & $-0,04$ & $-0,46-0,39$ & $>0,05$ & $-0,09$ & $-0,49-0,35$ & $>0,05$ & $-0,02$ & $-0,41-0,38$ & $>0,05$ \\
\hline $14-3-3$ & $-0,11$ & $-0,38-0,18$ & $>0,05$ & $-0,09$ & $-0,37-0,21$ & $>0,05$ & 0,02 & $-0,31-0,34$ & $>0,05$ \\
\hline Tau & $-0,02$ & $-0,29-0,26$ & $>0,05$ & $-0,02$ & $-0,29-0,26$ & $>0,05$ & 0,08 & $-0,24-0,38$ & $>0,05$ \\
\hline
\end{tabular}

\subsection{Nutzung der RT-QuIC als Wirkstoff-Suchtest}

Es wurde der Einfluss von mehreren potentiellen Wirkstoffen auf die Fluoreszenzsignale von Gehirn- und Liquorproben untersucht. Verwertbare Ergebnisse ergaben die Untersuchungen von Doxyzyklin, Ampicillin und Sucrose, jedoch nicht die von Quinacrin, Pentosan Polysulfat und Amphotericin B (Daten nicht gezeigt). Doxyzyklin inhibierte die Fluoreszenzsignale der sCJD-Proben sowohl in Abhängigkeit von der Dosis (ab 0,3 mM) als auch vom Zeitpunkt der Zugabe zur Reaktion (bis zu 24 nach dem Start). Diese Wirkung trat auch dann auf, wenn die Mikrotiterplatte nicht abwechselnd inkubiert und vibriert, sondern ausschließlich inkubiert wurde. Ampicillin und Sucrose beeinflussten die Fluoreszenzsignale nicht.

\subsubsection{Zugabe von Stoffen zu Beginn des Prozesses}

Dem Reaktionsmix wurden die Stoffe Doxyzyklin, Ampicillin und Sucrose zugesetzt und pro Stoff fünf Reaktionsmixe mit verschiedenen Stoffkonzentrationen hergestellt. Die Zusammensetzungen der Reaktionsmixe sind in Tabelle 33 in Unterabschnitt A.4 schematisch aufgeführt. Die RT-QuIC wurde nach Unterabschnitt 3.5 durchgeführt über eine gesamte Versuchsdauer von $80 \mathrm{Std}$. Es wurden sowohl Gehirnproben als auch Liquorproben mittels RT-QuIC analysiert. Nachfolgend wurden die Verläufe der Fluoreszenzsignale mittels der Fläche unter der Kurve charakterisiert und zwischen den Gruppen verglichen. Um den Einfluss der Konzentration von Doxyzyklin auf das 


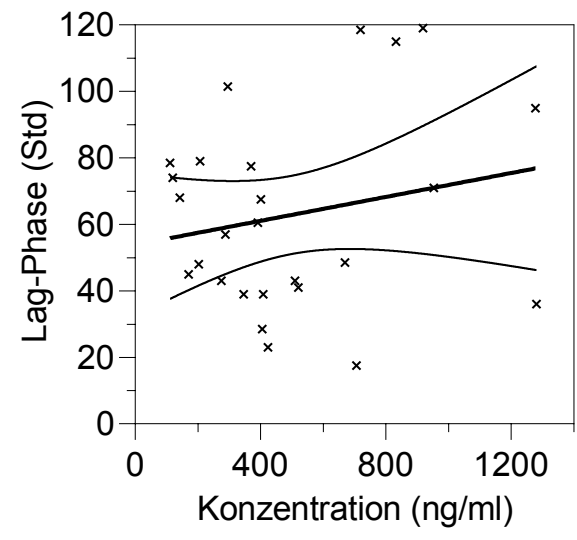

(a) Prion-Protein

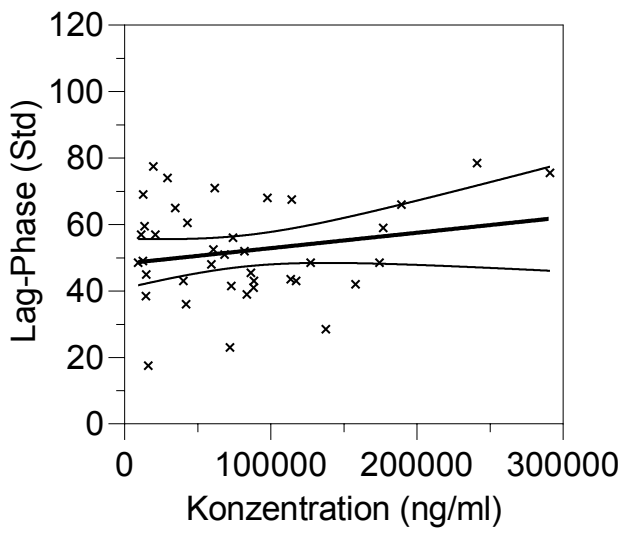

(b) 14-3-3-Protein

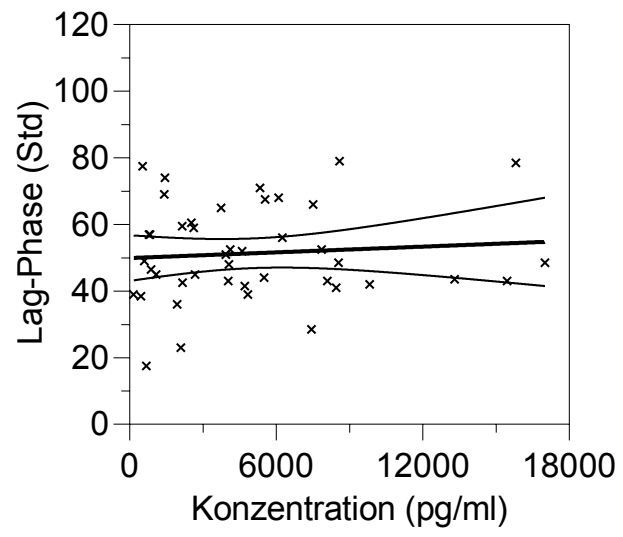

(c) Tau-Protein

Bild 23: Einfluss von krankheitsassoziierten Proteinen auf die Lag-Phase

Es hatte weder die PrP- noch die 14-3-3- oder die Tau-Protein-Konzentration einen Einfluss auf die Lag-Phase von sCJD-Liquorproben. Bild 23 (a) auf S. 56 zeigt die PrPKonzentration, Bild 23 (b) die 14-3-3-Protein-Konzentration und Bild 23 (c) die TauProtein-Konzentration, jeweils in Korrelation mit den Lag-Phasen von willkürlich ausgewählten sCJD Liquorproben. Grafisch dargestellt sind die Messwerte der Proben mit Regressionsgerade \pm Standardabweichung. 
Fluoreszenzsignal zu bestimmen, wurden Proben aus dem frontalen Kortex von fünf gesicherten sCJD MM-Fällen wie in Unterunterabschnitt 3.1.2 aufgearbeitet und mittels RT-QuIC über eine Versuchsdauer von 80 Std analysiert.

Bild 24 auf S. 57 zeigt die Fluoreszenzsignale der sCJD-Gehirnproben, unter Zugabe von Doxyzyklin in verschiedenen Konzentrationen, ab Versuchsbeginn. Mit Erhöhung der Zugabe von Doxyzyklin näherte sich der Kurvenverlauf asymptotisch der Basislinie an. Die Fluoreszenzwerte erreichten ab 0,3 mM Doxyzyklin die $10.000 \mathrm{rfu}$ nicht mehr. Bei Zugabe von $1 \mathrm{mM}$ Doxyzyklin wurde kein Anstieg über die Versuchszeit hinweg mehr verzeichnet. Bild 25 auf S. 58 zeigt die Fläche unter der Kurve der sCJD-Proben

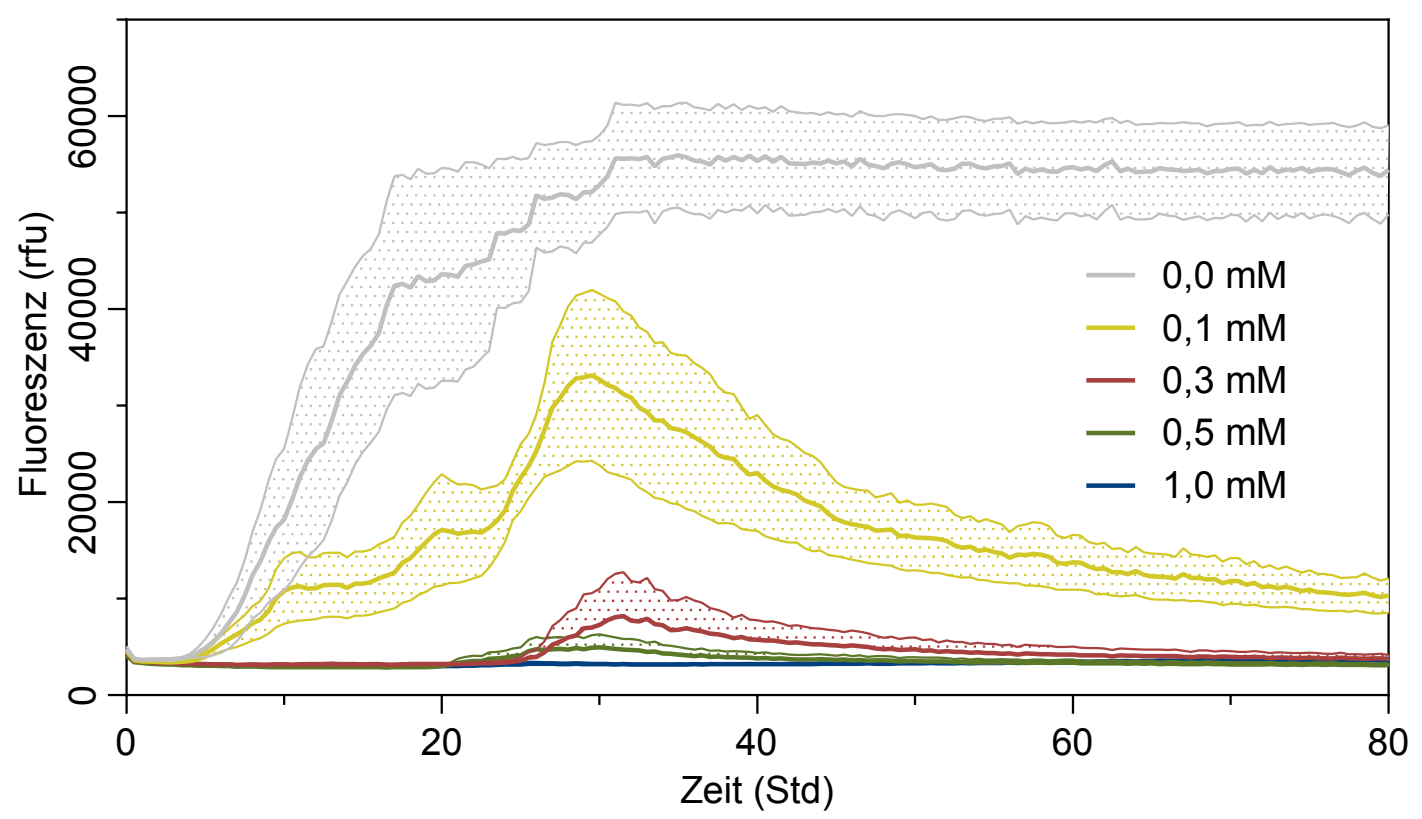

Bild 24: Einfluss von Doxyzyklin auf die sCJD-Fluoreszenzsignale

Es wurden Proben aus dem frontalen Kortex von fünf gesicherten sCJD MM-Fällen aufgearbeitet und mittels RT-QuIC analysiert. Die Fluoreszenzwerte erreichten ab 0,3 mM Doxyzyklin die $10.000 \mathrm{rfu}$ nicht mehr. Bei Zugabe von $1 \mathrm{mM}$ Doxyzyklin wurde kein Anstieg über die Versuchszeit hinweg mehr verzeichnet.

Während der Versuche wurde die Fluoreszenz alle 30 Min. gemessen. Nachfolgend wurden aus den Mittelwerten der Fluoreszenzsignale der Proben die Mittelwerte der Gruppen \pm Standardfehler bestimmt. Diese wurden dann mittels linearer Interpolation verbunden und in Form einer Mittelwert- (dicke Linie) \pm Standardfehlerlinie (dünne Linien) grafisch als Verlauf über die Zeit dargestellt. Das Fehlerfeld ist farblich markiert. Diese Darstellung zeigt aggregierte Daten, weshalb ihr keine individuellen Informationen über die Fläche unter der Kurve, das Signalmaximum und die Lag-Phase entnommen werden können.

unter Zugabe von Doxyzyklin in verschiedenen Konzentrationen. Je mehr Doxyzyklin dem Reaktionsmix zugegeben wurde, desto kleiner wurde sowohl die Fläche unter der Kurve der Gehirnproben $(\mathrm{p} \leq 0,0001)$ als auch die der Liquorproben $(\mathrm{p} \leq 0,0001)$. 
Bild 25 (a) zeigt die Fläche unter der Kurve der sCJD-Gehirnproben. Im Vergleich zur unbehandelten Kontrolle (0,0 mM Doxyzyklin) war die Fläche unter der Kurve von $0,1 \mathrm{mM}$ Doxyzyklin nicht verschieden $(\mathrm{p}>0,05)$. Diese sank ab $0,3 \mathrm{mM}$ Doxyzyklin $(\mathrm{p}$ $\leq 0,05, \mathrm{p} \leq 0,01$ und $\mathrm{p} \leq 0,01$ ). Bild 25 (b) zeigt die Fläche unter der Kurve der sCJDLiquorproben. Im Vergleich zur unbehandelten Kontrolle (0,0 mM Doxyzyklin) war die Fläche unter der Kurve von 0,1 mM, 0,3 mM und 0,5 mM Doxyzyklin nicht verschieden $(\mathrm{p}>0,05)$. Diese sank ab 1,0 mM Doxyzyklin $(\mathrm{p} \leq 0,01)$. Die Kontrollexperimente wurden an sCJD-Liquorproben mit Ampicillin und Sucrose in den gleichen Konzentrationen durchgeführt. Beide Stoffe beeinflussten die Fläche unter der Kurve nicht ( $\mathrm{p}>$ 0,05). Bild 26 auf S. 59 zeigt die Fläche unter der Kurve der sCJD MM-Liquorproben unter Zugabe von Ampicillin und Sucrose in verschiedenen Konzentrationen. Die retrospektiven Kontrollen waren sowohl unter Zugabe von Doxyzyklin als auch unter Ampicillin und Sucrose negativ (vgl. Bild 32 in Anhang C).

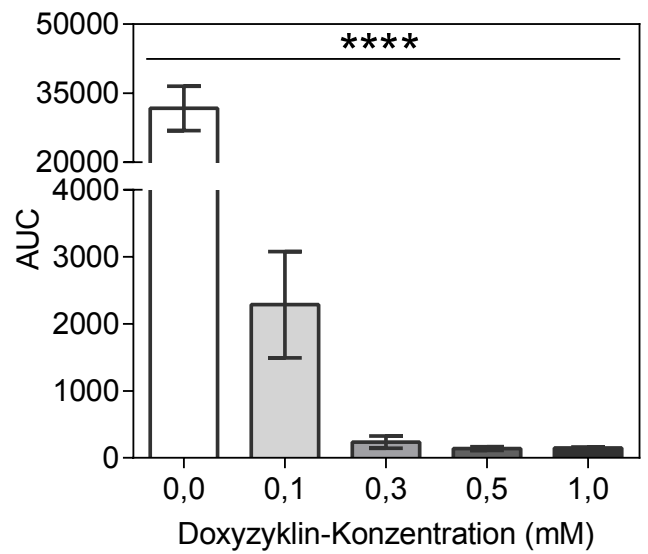

(a) Gehirn

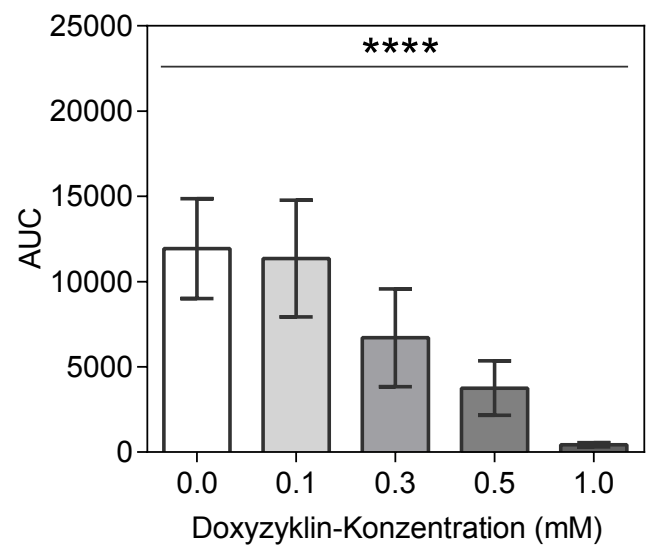

(b) Liquor

Bild 25: Einfluss von Doxyzyklin in versch. Konz. auf die AUC

Je mehr Doxyzyklin vor dem Start der RT-QuIC zugegeben wurde, desto kleiner wurde die Fläche unter der Kurve (AUC) sowohl der sCJD-Gehirnproben als auch der sCJDLiquorproben. Bild 25 (a) zeigt die AUC von $\mathrm{n}=5$ sCJD MM-Gehirnproben und Bild 25 (b) die von $\mathrm{n}=14$ sCJD MM-Liquorproben, jeweils unter Zusatz versch. Konz. Doxyzyklin im Reaktionsmix.

Die AUC sind grafisch dargestellt als Säulendiagramme mit Mittelwert \pm Standardfehler. Zur statistischen Auswertung wurden die Daten der Gruppen auf Normalverteilung geprüft und mittels einfaktorieller Varianzanalyse verglichen. Ein p-Wert $\leq 0,001$ wurde als extrem signifikant $(* * *), \leq 0,01$ als sehr signifikant $(* *), \leq 0,05$ als signifikant $(*)$ und $>0,05$ als nicht signifikant bewertet. 


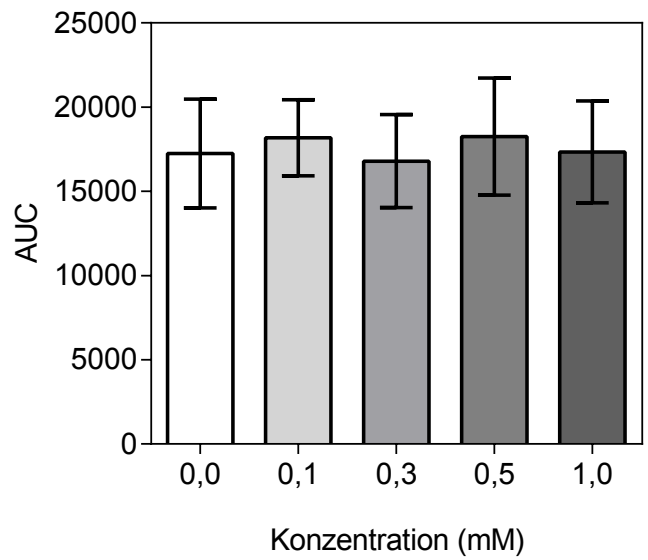

(a) Ampicillin

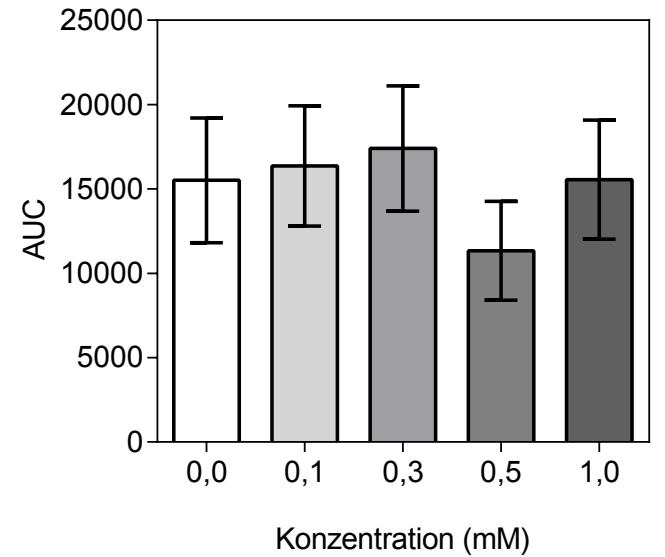

(b) Sucrose

Bild 26: Einfluss von Ampicillin und Sucrose in versch. Konz. auf die AUC

Vor dem Start der RT-QuIC in verschiedenen Konzentrationen zugegeben, zeigten weder Ampicillin noch Sucrose einen Einfluss auf die Fläche unter der Kurve (AUC) von sCJDLiquorproben. Bild 26 (a) zeigt die AUC von $\mathrm{n}=14$ sCJD MM-Liquorproben unter Zugabe von Ampicillin und Bild 26 (b) diese unter Zugabe von Sucrose, jeweils in verschiedenen Konzentrationen.

Die AUC sind grafisch dargestellt als Säulendiagramme mit Mittelwert \pm Standardfehler. Zur statistischen Auswertung wurden die Daten der Gruppen auf Normalverteilung geprüft und mittels einfaktorieller Varianzanalyse verglichen. Ein p-Wert $\leq 0,001$ wurde als extrem signifikant $(* * *), \leq 0,01$ als sehr signifikant $(* *), \leq 0,05$ als signifikant $\left(^{*}\right)$ und $>0,05$ als nicht signifikant bewertet. 


\subsubsection{Zugabe von Stoffen während des Prozesses}

Um den Einfluss des Zeitpunkts der Zugabe von Doxyzyklin, Ampicillin und Sucrose auf das Fluoreszenzsignal von Liquorproben zu bestimmen, wurden Liquorproben von 12 sCJD MM und sechs retrospektiven Kontrollen mittels RT-QuIC analysiert. Die RT-QuIC wurde nach Unterabschnitt 3.5 durchgeführt. Zusätzlich wurden nach den Zeitpunkten 0 Std, 24 Std, 48 Std oder 72 Std nach dem Start der RT-QuIC 5 pl einer 10 mM-Lösung der Stoffe Doxyzyklin, Ampicillin oder Sucrose zum Reaktionsmix hinzugegeben, sodass die finale Stoffkonzentration im Mix 0,5 mM betrug. Dazu wurde die RT-QuIC gestoppt, die Klebefolie der entsprechenden Wells mit Rasierklingen kreuzförmig eingeschnitten, die $5 \mu \mathrm{l}$ hinein pipettiert, die Platte mit einer weiteren Klebefolie wieder verschlossen und die RT-QuIC wieder gestartet. Als Kontrolle wurden Reaktionen verwendet, zu denen keine Lösung hinzugegeben wurde (Ref). Dann wurden die Verläufe der Fluoreszenzsignale mittels der Fläche unter der Kurve charakterisiert und zwischen den Gruppen verglichen.

Bild 27 auf S. 61 zeigt die Fläche unter der Kurve von sCJD MM-Liquorproben, unter Zugabe von 0,5 mM Doxyzyklin, zu verschiedenen Zeitpunkten während des Versuchs. Je früher Doxyzyklin zugegeben wurde, desto kleiner war die jeweilige Fläche unter der Kurve $(\mathrm{p} \leq 0,01)$. Im Vergleich zur Kontrolle ohne Doxyzyklin (Ref) war die Fläche unter der Kurve von $\mathrm{t}=0$ Std und $\mathrm{t}=24$ Std erniedrigt $(\mathrm{p} \leq 0,01$ und $\mathrm{p} \leq 0,05)$. Die Zugaben von Doxyzyklin nach 48 Std und 72 Std hatten keinen Einfluss mehr auf die Fläche unter der Kurve $(\mathrm{p}>0,05)$. Auch unter diesen Bedingungen beeinflussten Ampicillin und Sucrose die Fluoreszenzsignale der sCJD MM-Liquorproben nicht (vgl. Bild 28 auf S. 62). Sowohl unter Zugabe von Doxyzyklin als auch unter Ampicillin und Sucrose waren die retrospektiven Kontrollen negativ (vgl. Bild 33 in Anhang C).

\subsubsection{Einfluss der Vibration auf die Wirkung von Doxyzyklin}

Um den Einfluss der Vibration auf die Wirkung von Doxyzyklin zu bestimmen, wurde eine aus zwei Abschnitten bestehende RT-QuIC durchgeführt. In Abschnitt 1 bestand die RT-QuIC aus sich abwechselnden Inkubations- und Fragmentationsphasen, wie in Unterabschnitt 3.5 beschrieben. In Abschnitt 2 wurde die Fragmentationsphase entfernt, sodass die Mikrotiterplatte ausschließlich inkubierte. Um den Einfluss der Vibration auf die Wirkung von Doxyzyklin auf das Fluoreszenzsignal zu bestimmen, wurden Gehirnproben aus dem frontalen Kortex von fünf sCJD MM aufgearbeitet und mittels RT-QuIC analysiert. Um den Einfluss der Vibration auf die Wirkung von Doxyzyklin auf das Fluoreszenzsignal von Liquorproben zu bestimmen, wurden Liquorproben von fünf sCJD MM mittels RT-QuIC analysiert. In Abschnitt 1 wurden die Proben mit dem Doxyzyklin-freien Reaktionsmix in Tabelle 8 auf S. 25 inkubiert und die RT-QuIC wie in Unterabschnitt 3.5 durchgeführt. Nach Ablauf von $55 \%$ der gesamten Versuchsdauer von 232 Std wurde die RT-QuIC gestoppt, die Klebefolie der entsprechenden Wells mit Rasierklingen kreuzförmig eingeschnitten, 1 pl ein 100 mM-Lösung Doxyzyklin hinein pipettiert, die Platte mit einer weiteren Klebefolie wieder verschlossen und die RT-QuIC wieder gestartet. Zu diesem Zeitpunkt waren bereits alle Fluores- 


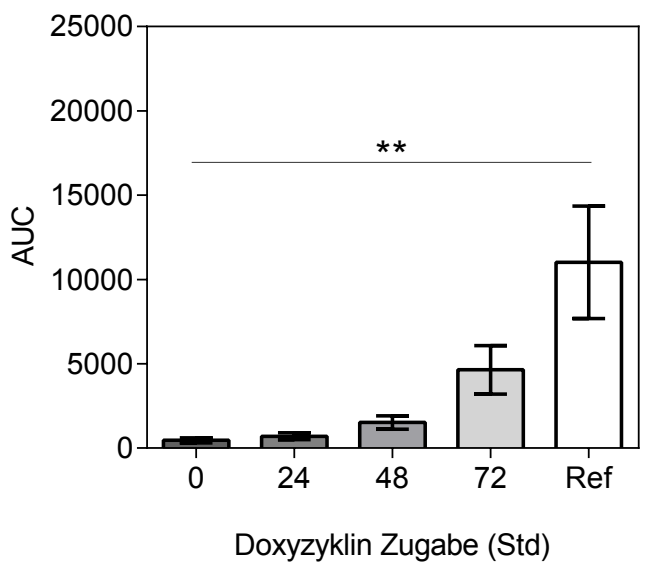

Bild 27: Einfluss von Doxyzyklin auf die AUC bei Zugabe zu versch. Zeitpunkten

Je früher dem Reaktionsmix während der RT-QuIC 0,5 mM Doxyzyklin zugegeben wurde, desto kleiner war die jeweilige Fläche unter der Kurve (AUC) der $\mathrm{n}=12 \mathrm{sCJD}$-Liquorproben.

Die AUC sind grafisch dargestellt als Säulendiagramme mit Mittelwert \pm Standardfehler. Zur statistischen Auswertung wurden die Daten der Gruppen auf Normalverteilung geprüft und mittels einfaktorieller Varianzanalyse verglichen. Ein p-Wert $\leq 0,001$ wurde als extrem signifikant $(* * *), \leq 0,01$ als sehr signifikant $(* *), \leq 0,05$ als signifikant $(*)$ und $>0,05$ als nicht signifikant bewertet.

zenzsignale positiv geworden. Die finale Doxyzyklin-Konzentration betrug $1 \mathrm{mM}$. Als Kontrolle wurde kein Doxyzyklin zugegeben. In Abschnitt 2 wurde die Inkubation fortgesetzt mit dem Unterschied, dass die Mikrotiterplatte nicht mehr vibriert wurde bzw. keine Fragmentationsphase mehr stattfand. Dann wurden die Verläufe der Fluoreszenzsignale mittels der Fläche unter der Kurve charakterisiert und zwischen den Gruppen verglichen.

Bild 29 auf S. 63 zeigt die Fluoreszenzsignale einer sCJD-Gehirnprobe schematisch ab Versuchsbeginn. In Abschnitt 1 wurde die Probe mit dem Doxyzyklin-freien Reaktionsmix inkubiert, mit Inkubations- und Fragmentationsphase. Nach Ablauf von $55 \%$ der gesamten Versuchsdauer begann Abschnitt 2, in dem die Mikrotiterplatte nicht mehr vibriert wurde und Doxyzyklin zugegeben (+ Doxyzyklin) oder nicht zugegeben (-Doxyzyklin) wurde. Die Fläche unter der Kurve der mit Doxyzyklin inkubierten sCJD-Proben war insgesamt niedriger als die der nicht mit Doxyzyklin inkubierten Proben $(\mathrm{p} \leq 0,001)$. Das Abstellen der Vibration wirkte sich nicht auf die Fläche unter der Kurve der nicht mit Doxyzyklin inkubierten Proben aus ( $p>0,05)$. Bild 30 auf S. 63 zeigt die Fläche unter der Kurve der Proben in Abschnitt 2. Sowohl die der Gehirnproben als auch die der Liquorproben war mit Doxyzylin niedriger als ohne Doxyzyklin ((a) $\mathrm{p} \leq 0,001 ;$ (b) $\mathrm{p} \leq 0,01$ ). 


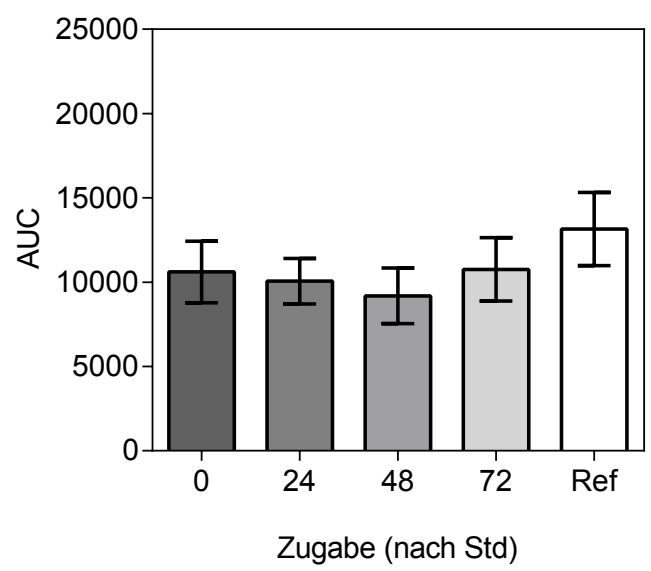

(a) Ampicillin

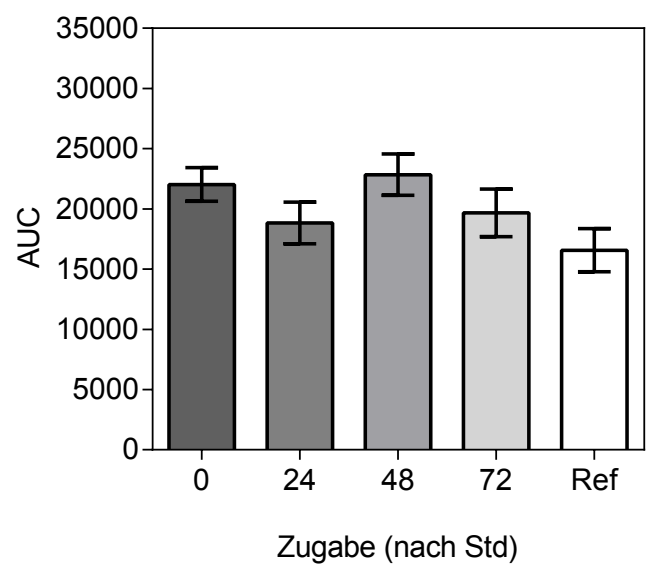

(b) Sucrose

Bild 28: Einfluss von Ampicillin und Sucrose auf die AUC bei Zugabe zu versch. Zeitp.

Zugegeben zu verschiedenen Zeitpunkten während der RT-QuIC zeigten weder 0,5 mM Ampicillin noch Sucrose einen Einfluss auf die Fläche unter der Kurve (AUC) von sCJDLiquorproben. Bild 28 (a) zeigt die AUC von $\mathrm{n}=14$ sCJD MM-Liquorproben unter Zugabe von Ampicillin und Bild 28 (b) diese unter Zugabe von Sucrose, jeweils zu verschiedenen Zeitpunkten während der RT-QuIC.

Die AUC sind grafisch dargestellt als Säulendiagramme mit Mittelwert \pm Standardfehler. Zur statistischen Auswertung wurden die Daten der Gruppen auf Normalverteilung geprüft und mittels einfaktorieller Varianzanalyse verglichen. Ein p-Wert $\leq 0,001$ wurde als extrem signifikant $(* * *), \leq 0,01$ als sehr signifikant $(* *), \leq 0,05$ als signifikant $\left(^{*}\right)$ und $>0,05$ als nicht signifikant bewertet. 


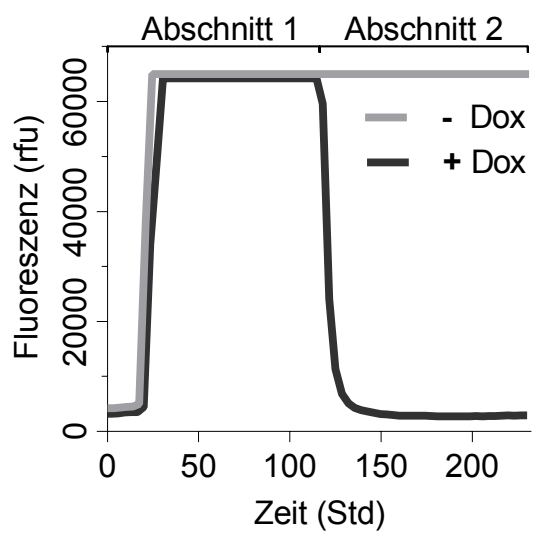

Bild 29: Einfluss der Vibration auf die Wirkung von Doxyzyklin

Schematische Darstellung der Fluoreszenzsignale einer sCJD-Gehirnprobe, unter Zugabe von $1 \mathrm{mM}$ Doxyzyklin und Abstellen der Vibration nach $55 \%$ der gesamten Versuchsdauer. Abschnitt 1 bezeichnet den ersten Versuchsteil, ohne Zugabe von Doxyzyklin und mit Vibration der Mikrotiterplatte. Abschnitt 2 bezeichnet den zweiten Versuchsteil, in dem die Mikrotiterplatte nicht mehr vibriert wurde und Doxyzyklin zugegeben (+ Doxyzyklin) oder nicht zugegeben (-Doxyzyklin) wurde.

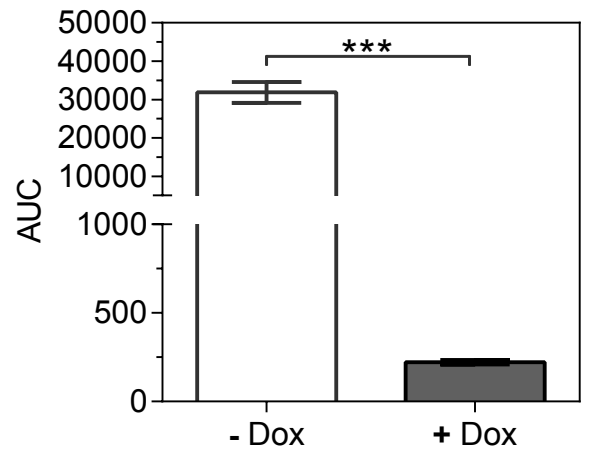

(a) Gehirn

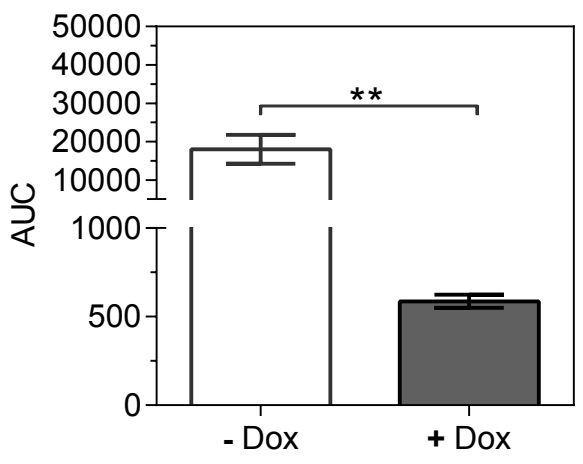

(b) Liquor

Bild 30: Einfluss der Vibration auf die Wirkung von Doxyzyklin auf die AUC

Dargestellt ist die Fläche unter der Kurve (AUC) von (a) $\mathrm{n}=5$ sCJD-Gehirnproben und (b) $\mathrm{n}=5$ sCJD-Liquorproben, ohne (- Doxyzyklin) und mit (+ Doxyzyklin) Zugabe von 1,0 mM Doxyzyklin in Abschnitt 2.

Die AUC sind grafisch dargestellt als Säulendiagramme mit Mittelwert \pm Standardfehler. Zur statistischen Auswertung wurden die Daten der Gruppen auf Normalverteilung geprüft und mittels einfaktorieller Varianzanalyse verglichen. Ein p-Wert $\leq 0,001$ wurde als extrem signifikant $(* * *), \leq 0,01$ als sehr signifikant $(* *), \leq 0,05$ als signifikant $(*)$ und $>0,05$ als nicht signifikant bewertet. 


\section{Diskussion}

\subsection{Methodische Optimierung der RT-QuIC}

Zur Anwendung der RT-QuIC in der Forschung und der humanen Diagnostik bedarf es einer umfassenden Validierung und Standardisierung der Methode. Bisher mangelte es an Studien, welche die laborübergreifende Reproduzierbarkeit sowie den Einfluss von Lagerung, Verwendung und Kontamination humaner Liquorproben auf das RT-QuICErgebnis untersuchen. Um diese Lücke zu schließen, wurden in dieser Arbeit sowohl der bestmögliche Grenzwert und die Validität als auch die Reproduzierbarkeit und die Stabilität des Testverfahrens bestimmt.

Der Grenzwert der RT-QuIC wurde erstmals im Jahr 2012 für sCJD-Liquorproben ermittelt (McGuire u. a. 2012). Dafür wurden ein baugleiches Mikroplattenlesegerät und dieselben Inkubationsbedingungen verwendet wie in dieser Arbeit, jedoch ein anderes Substrat (Hamster- anstatt Hamster-Schaf-recPrP ${ }^{\mathrm{C}}$ ), ein basischerer pH-Wert des PBS-Puffers (pH 7,4 anstatt 6,9) und eine längere Versuchsdauer (90-120 Std anstatt $80 \mathrm{Std}$ ). Der in dieser Arbeit ermittelte Grenzwert von $10.000 \mathrm{rfu}$ stimmt mit dem vormals ermittelten überein, was für die Reproduzierbarkeit der Methode spricht, auch unter geringfügig anderen Bedingungen.

\subsubsection{Hohe Validität}

Die Sensitivität der RT-QuIC betrug für alle getesteten Prionkrankheiten gemittelt $85,5 \%$ und die Spezifität 99,5\%. Diese Werte sind vergleichbar mit denen des 143-3-Proteins, mit $88 \%$ Sensitivität und $96 \%$ Spezifität (Schmitz, Ebert u.a. 2015), welches Teil der standardisierten Liquoranalyse in der Diagnostik von Prionkrankheiten ist. Innerhalb der Prionkrankheiten variierte die Sensitivität der RT-QuIC von $100 \%$ für gCJD (jeweils E200K und V1210I) über $80 \%$ für sCJD bis $57 \%$ für FFI. Diese Ergebnisse befinden sich in Übereinstimmung mit zwei vorangegangenen Studien an sCJD-Liquorproben, die über eine Sensitivität von $80-90 \%$ und eine Spezifität von fast $100 \%$ berichten (Atarashi, Satoh u. a. 2011, McGuire u.a. 2012). Eine weitere Studie berichtet von einer Sensitivität von 87 \% für gCJD E200K sowie jeweils $100 \%$ für gCJD V203I und FFI (Sano u. a. 2013). Verglichen mit den hier ermittelten Werten können diese Unterschiede bedingt sein durch andere Probenzahlen (bspw. 22 FFI anstatt 7) und größere methodische Unterschiede, bspw. ein nicht baugleiches Mikroplattenlesegerät (Infinite M200/F200 von Tecan anstatt FLUOstar ${ }^{\circledR}$ Optima von BMG Labtech), ein anderes Substrat (Humanes- anstatt Hamster-Schaf-recPrP ${ }^{\mathrm{C}}$ ) in einer anderen Konzentration $(0,5 \mathrm{mg} / \mathrm{ml}$ anstatt $0,1 \mathrm{mg} / \mathrm{ml})$, ein anderer Puffer (PIPES mit pH 7,0 anstatt PBS mit pH 6,9) sowie eine andere Inkubationstemperatur $\left(37^{\circ} \mathrm{C}\right.$ anstatt $\left.42{ }^{\circ} \mathrm{C}\right)$ und anderen Inkubationsbedingungen (30 Sek Vibration gefolgt von 30 Sek Pause anstatt 1 Min Vibration gefolgt von 1 Min Pause).

In dieser Arbeit ergab die RT-QuIC zwei potentiell falsch-positive Ergebnisse. Das eine potentiell falsch-positive Ergebnis stammte von einem Patienten der retrospektiven Gruppe mit der Diagnose Morbus Alzheimer. Bei diesem Patienten gab es keinen 
Anlass für einen Verdacht auf eine Prionkrankheit. Weder die klinische Untersuchung noch die 14-3-3-Protein- und Tau-Proteine-Werte im Liquor waren dahingehend auffällig. Da jedoch von diesem Patienten keine neuropathologische Untersuchung vorlag, konnte eine Prionkrankheit nicht sicher ausgeschlossen werden (Zerr 2015-12-11). Ein ähnlich gelagerter Fall einer falsch-positiven Liquorprobe wurde auch in McGuire u. a. 2012 beschrieben. Das andere potentiell falsch-positive Ergebnis stammte von einem Patienten der prospektiven Gruppe. Bei diesem Patienten gaben die 14-3-3-Proteinund Tau-Proteine-Werte im Liquor sowie das MRT-Bild Anlass für einen Verdacht auf eine Prionkrankheit. Aufgrund dieser Befunde wurde der Patient nach Abschluss der Untersuchungen als möglicher CJD-Fall eingestuft. Da jedoch von diesem Patienten keine neuropathologische Untersuchung vorlag, konnte diese Diagnose nicht gesichert werden (Zerr 2015-12-11).

\subsubsection{Sehr gute Reproduzierbarkeit}

Die Reproduzierbarkeit eines biologischen Tests zwischen verschiedenen Experimentatoren kann von einigen Faktoren abhängen, bspw. Unterschieden in den Standardarbeitsanweisungen, den verwendeten Reaktionskomponenten, Arbeitsmaterialien und Analysegeräten sowie den Lagerungs- und Transportbedingungen der zu untersuchenden Proben. In Ringversuch 1 wurden 86 Liquorproben von Laboren zweier Institutionen untersucht mit im Ergebnis guter Übereinstimmung. Folgend wurden Variationen zwischen den Protokollen soweit wie möglich minimiert. Daraufhin wurden in Ringversuch 2 sechs Liquorproben von vier internationalen Referenzzentren untersucht mit im Ergebnis sehr guter Übereinstimmung. Diese Werte übertreffen die mittelmäßige bis gute Reproduzierbarkeit des 14-3-3-Proteins (Fleiß'kappa =0,51 - 0,68; Schmitz, Ebert u. a. 2015).

\subsubsection{Hohe Stabilität}

Zwischen der Probenentnahme beim Patienten und der proteinbiochemischen Untersuchung im Labor können kurze Zeiten der Lagerung der Probe bei verschiedenen Temperaturen liegen, bspw. verursacht durch die Transportbedingungen. Bei der Verwendung der Probe zu Forschungszwecken kann eine Probe mehrmals aufgetaut und wieder eingefroren und über viele Jahre bei $-80{ }^{\circ} \mathrm{C}$ gelagert werden. Bei der Abnahme des Liquors mittels Lumbalpunktion kann eine Probe durch das Blut des Patienten kontaminiert werden. Bisher mangelte es an Studien, welche den Einfluss dieser Faktoren auf die Analyse von humanen Liquorproben mittels RT-QuIC untersuchen. Um diese Lücke zu schließen, wurde der Einfluss der Faktoren Kurzzeitlagerung (bis zu acht Tage bei RT oder $+4{ }^{\circ} \mathrm{C}$ ), Verwendung (bis zu 16× Einfrier-/Auftauzyklen), Langzeitlagerung (bis zu neun Jahre bei $-80^{\circ} \mathrm{C}$ ) und Kontamination durch Blut (bis zu 10.000 Ery/ul oder bis zu acht Tage Inkubation mit 5.000 Ery/ul) auf die Positivitätsraten und die Fluoreszenzsignale der RT-QuIC untersucht.

Die Lagerung und die Verwendung der Liquorproben beeinflussten die RT-QuICErgebnisse nicht. Im Vergleich zu anderen in der Diagnostik von Prionkrankheiten 
verwendeten Biomarkern, wie bspw. das Tau-Protein oder das A $\beta 42$-Protein, die speziell bei höheren Temperaturen während der Lagerung abgebaut werden (Jensen u. a. 2000, Vanderstichele u. a. 2000, Schoonenboom, Niki S M u. a. 2005), ist die gezeigte Stabilität der RT-QuIC ein klarer Vorteil.

In der Routine-Diagnostik am NRZ für TSE treffen 5-10\% der Liquorproben mit Blut kontaminiert ein, woraus sich eine Notwendigkeit für klare Richtlinien in Bezug auf die weitere Handhabung dieser Proben ergibt. In dieser Arbeit führte die Kontamination mit hämolysiertem Blut ( $\mathrm{ab} \geq 1.250$ Ery/pl) wie auch mit frischem Blut (5.000 Ery/ul) zu falsch-negativen Testergebnissen resp. zu einer Inhibition der Reaktion. Ab drei Tagen Inkubationszeit mit frischem Blut war die Hämolyse der Zellen so weit fortgeschritten, dass keine zuverlässigen Ergebnisse mehr beobachtet werden konnten. Daher empfielt es sich, Proben, die länger als drei Tage blutkontaminiert gewesen sind, von der RT-QuIC-Analyse auszuschließen. Zur Erhöhung der diagnostischen Sicherheit wird eine Zentrifugation der Probe für 10 Min bei 2.000 Min. ${ }^{-1}$ unmittelbar nach der Abnahme beim Patienten empfohlen. Die Sensitivität der RT-QuIC gegenüber Kontamination durch Blut kann eine Erklärung für die Variabilität in der Sensitivität der RT-QuIC (80 - 90 \%; Atarashi, Satoh u. a. 2011, McGuire u. a. 2012) bei nur geringfügigen methodischen Abweichungen sein, die möglicherweise auf ebendieser nicht erkannten Kontamination basierte. Im Vergleich zum 14-3-3-Protein (sign. Einfluss ab zwei Tagen; Schmitz, Ebert u. a. 2015) tolerierte die RT-QuIC die 1,5× Inkubationsdauer mit frischem Blut.

Zusammenfassend unterstreichen die hohe Validität, die gute bis sehr gute Reproduzierbarkeit und die hohe Stabilität der RT-QuIC ihre Eignung zur Anwendung in Diagnostik und Forschung. Eine kurze Lagerung für bis zu acht Tage bei RT oder $+4{ }^{\circ} \mathrm{C}$, eine lange Lagerung für bis zu neun Jahre bei $-80{ }^{\circ} \mathrm{C}$, das bis zu $16 \times$ Einfrieren und Auftauen der Probe sowie eine Kontamination mit bis zu 1.250 Ery/ul können als unproblematisch in Bezug auf eine RT-QuIC-Analyse betrachtet werden.

\subsection{Charakterisierung der Fluoreszenzsignale}

Humane Prionkrankheiten zeigen ein heterogenes klinisches und pathologisches Erscheinungsbild - bspw. unterscheiden sich die klinischen Symptome und die Verteilungsmuster des $\mathrm{PrP}^{\mathrm{Sc}}$ im Gehirn zwischen den humanen Prionkrankheiten (Parchi, Castellani u. a. 1996, Collinge, Sidle, Katie C L u. a. 1996, Bruce, Will u. a. 1997, Parchi, Boni u. a. 2012). Neueste Erkenntnisse weisen auf das Vorhandensein mehrerer humaner Prionstämme hin, wie sie schon bei tierischen Prionkrankheiten gezeigt worden sind (Bishop u.a. 2010). Derzeit sind jedoch die für deren Entstehung verantwortlichen Prozesse noch nicht aufgeklärt. Diese Prozesse zu verstehen kann entscheidend zur Entwicklung einer Therapie beitragen.

Mit humanem Gehirnmaterial generierte RT-QuIC-Ergebnisse zeigten erstmals distinkte Fluoreszenzsignale für verschiedene sCJD-Formen (Peden u. a. 2012). Daher wurden in dieser Arbeit die Einflüsse der Form der Prionkrankheit (bspw. gCJD vs. sCJD) und der Form der sCJD (bspw. sCJD MM1), patientenbezogener Faktoren 
(bspw. das Alter), krankheitsbezogener Faktoren (bspw. die Krankheitsdauer) und krankheitsspezifischer Biomarker (bspw. das 14-3-3-Protein) auf die Fluoreszenzsignale von Liquorproben in der RT-QuIC untersucht.

\subsubsection{Differenzierung von gCJD, sCJD und FFI}

Die Fluoreszenzsignale der gCJD-Liquorproben zeigten eine kürzere Lag-Phase und ein höheres Signalmaximum als die der sCJD- und FFI-Liquorproben. Bisher ist dazu nur wenig Information in der Literatur zu finden. Bei Sano u. a. 2013 sind ähnliche individuelle Unterschiede zwischen gCJD und sCJD zu beobachten. Diese ließen sich jedoch per statistischer Analyse nicht bestätigen. Es gibt mehrere mögliche Erklärungen für die hier beobachteten Effekte, wie bspw. Unterschiede in der Konzentration, Struktur und Stabilität der PrP-Moleküle oder in der Infektiosität der $\mathrm{PrP}^{\mathrm{Sc}}$-Aggregate. Bisher stammt das Wissen über die Eigenschaften des gCJD $\mathrm{PrP}^{\mathrm{Sc}}$ aus der Untersuchung von Gehirnmaterial. Demnach wird die Krankheit bei Trägern der gCJD E200K- und gCJD V210I-Mutationen durch eine veränderte Struktur des $\mathrm{PrP}^{\mathrm{C}}$ und einen sich im Laufe des Lebens verändernden PrP-Metabolismus verursacht (Capellari u. a. 2000, Levy u. a. 2002). Diese Konformationsänderungen des $\operatorname{PrP}^{\mathrm{C}}$ könnten dessen Konversion in $\mathrm{PrP}^{\mathrm{Sc}}$ begünstigen, indem Interaktionen des $\mathrm{PrP}^{\mathrm{C}}$ mit zellulären Partnern oder dessen Fibrillisationsprozess beeinflusst werden (Rossetti u. a. 2010). Begünstigende Faktoren können weiterhin die im Vergleich zum gesunden Metabolismus gesteigerte Generierung von PrP-Fragmenten und veränderten Glycoformanteile des $\mathrm{PrP}^{\mathrm{Sc}}$ im Gehirn sein (Capellari u. a. 2000, Hill, Joiner, Beck u. a. 2006). Für die FFI, bei der der N-terminale Teil des $\mathrm{PrP}^{\mathrm{C}}$ eine bedeutende Rolle bei der Konversion des Proteins spielt, wurden einige bemerkenswerte biologische Eigenschaften beobachtet: geringe Mengen an $\mathrm{PrP}^{\mathrm{Sc}}$

im Gehirn von Betroffenen, ein deutlicher Effekt des Prnp Codon 129-Genotyps auf den Krankheitsbeginn und die Pathogenese sowie geringe Transmissionsraten in Tierexperimenten, mit langen Inkubationszeiten im Vergleich zu gCJD E200K und sCJD (Tateishi u. a. 1995, Gambetti, Kong u. a. 2003, Jackson u. a. 2009, Asante u. a. 2009, Friedman-Levi u.a. 2011, Gao u. a. 2012). Während dies nicht das im Vergleich zur sCJD frühe Erkrankungsalter der FFI-Patienten erklärt, so stimmen jedoch die in dieser Arbeit beobachteten vergleichsweise langen Lag-Phasen $(\bar{x}=75$ Std $)$ mit den bekannten biologischen Eigenschaften der FFI überein.

\subsubsection{Einfluss des Prnp Codon 129-Genotyps}

Die molekulare Diversität der sCJD wird seit vielen Jahren studiert und konnte letztendlich in Teilen über die Kombination des $\mathrm{PrP}^{\mathrm{Sc}}$-Typs (1 und 2) mit den drei Ausprägungen des Prnp Codon 129-Polymorphismus (MM, MV und VV) erklärt werden (Parchi, Giese u. a. 1999, Hill, Joiner, Wadsworth u. a. 2003). Die sCJD-Patienten können anhand ihres Prnp Codon 129-Genotyps und der biochemischen Eigenschaften ihres $\mathrm{PrP}^{\mathrm{Sc}}$ in sechs molekulare Formen kategorisiert werden, MM1, MM2, MV1, MV2, VV1 und VV2 (Uro-Coste u. a. 2008). 
Eine Studie, die humanes Gehirnmaterial mittels RT-QuIC untersuchte, berichtet von distinkten RT-QuIC-Ergebnisse einzelner sCJD-Formen, die jedoch statistisch nicht belegt werden konnten (Peden u. a. 2012). Distinkte RT-QuIC-Ergebnisse für Gehirnproben von molekularen sCJD-Formen wurden auch in dieser Arbeit gefunden. Die Fluoreszenzsignale von sCJD MM1- zeigten eine kürzere Lag-Phase und größere Fläche unter der Kurve, als die von sCJD VV2-Gehirnproben. Wurden transgene Mäuse, die verschiedene humane Prnp Codon 129-Genotypen exprimierten (MM, MV oder VV), mit Gehirnmaterial von so kategorisierten Patienten infiziert, dann wurden charakteristische Inkubationszeiten und neuropathologische Läsionsprofile beobachtet. Diesen Experimenten folgend und basierend auf den Transmissionscharakteristika und PKResistenzen dieser Formen, wurde die Existenz von vier humanen $\mathrm{PrP}^{\mathrm{Sc}}$-Stämmen postuliert: MM1/MV1 als klassischer Phänotyp, MV2/VV2, VV1 und MM2 (Bishop u. a. 2010). In dieser Arbeit konnte jedoch kein Einfluss der postulierten vier humanen Prionstämme auf das Fluoreszenzsignal von sC.JD-Liquorproben beobachtet werden. Eine mögliche Erklärung hierfür kann die potentielle Involvierung von Co-Faktoren in die in-vivo-PrP-Konversion im Tiermodell sein (Giannopoulos u. a. 2009, Wang u. a. 2013), die bei der in-vitro-PrP-Konversion in der RT-QuIC nicht verfügbar sind.

Um den möglichen Einfluss des Prnp Codon 129-Genotyps auf die Fluoreszenzsignale von sCJD-Liquorproben zu untersuchen, wurden diese getrennt nach dem $\mathrm{PrP}^{\mathrm{Sc}}$ Typ gruppiert und verglichen. Die sCJD MM1-Form assoziierte mit einer kürzeren Lag-Phase und einem größeren Signalmaximum, verglichen mit den sCJD MV1- und sCJD VV1-Formen. Die Ursache hierfür kann in strukturellen Unterschieden zwischen dem durch Prnp 129M und dem durch Prnp 129V generierten $\operatorname{PrP}^{\mathrm{C}}$ liegen. Das aus dem Prnp 129M resultierende $\operatorname{PrP}^{\mathrm{C}}$ weist eine exponiertere $\alpha$-Helix 1 Region auf, aggregiert schneller und formt mehr Aggregate als das aus dem Prnp 129V resultierende $\mathrm{PrP}^{\mathrm{C}}$ (Pham u. a. 2008). Diese Ergebnisse stimmen weiterhin mit der Beobachtung überein, dass die Homozygotie für die AS Methionin am Prnp Codon 129 ein Risikofaktor für die Entwicklung einer sCJD ist (Alpérovitch u. a. 1999, Parchi, Giese u. a. 1999 und Ladogana u. a. 2005).

Zudem zeigte die gCJD MM-Form eine kürzere Lag-Phase und ein größeres Signalmaximum als die gCJD MV-Form. Dieses Ergebnis stimmt mit der bei sCJD beobachteten Tendenz überein und stützt die Hypothese eines größeren RT-QuICReaktionspotentials im Liquor von Methionin-homozygoten Patienten. Es steht weiterhin im Einklang mit den Beobachtungen, dass der Prnp Codon 129-Genotyp bei gCJD E200K-Patienten ein wesentlicher Risikofaktor ist und sich auf die Pathogenese auswirkt, indem bspw. MM-Träger eine kürzere Krankheitsdauer mit 3,7 \pm 2,0 Monaten aufweisen als MV-Träger mit 7,84 \pm 7,3 Monaten (Mitrová u. a. 2002).

\subsubsection{Einfluss weiterer Faktoren}

Es bleibt die Frage, welche weiteren Faktoren die Kinetik der Fluoreszenz in der RTQuIC möglicherweise beeinflussen. Weder zeigten das Geschlecht der Patienten, noch das Alter bei Krankheitsbeginn und das Krankheitsstadium, in dem sich die Patienten 
zum Zeitpunkt der Lumbalpunktion befanden, einen Einfluss auf die Fluoreszenzsignale der sCJD-Liquorproben. Diese Ergebnisse stimmen mit denen von McGuire u. a. 2012 überein. Interessanterweise zeigte jedoch die kurze Krankheitsdauer eine kürzere Lag-Phase und ein höheres Signalmaximum, verglichen mit der mittleren und langen Krankheitsdauer.

Da die PrP-Konzentration im Liquor keinen Einfluss auf das Fluoreszenzsignal hatte, sind möglicherweise andere Faktoren hierfür maßgebend, wie bspw. die Menge an $\mathrm{PrP}^{\mathrm{Sc}}$ im Liquor. Jedoch zeigte eine serielle Verdünnung von gCJD- und sCJD-Liquorproben keinen signifikanten Unterschied zwischen diesen beiden Gruppen. Außerdem könnten strukturelle Unterschiede des $\mathrm{PrP}^{\mathrm{Sc}}$ oder dessen Aggregate, verursacht durch die gCJDMutationen (Capellari u. a. 2000, Levy u. a. 2002, Rossetti u. a. 2010), entscheidender für das größere RT-QuIC-Reaktionspotential der gCJD- im Vergleich zu den sCJDLiquorproben sein als die Menge an $\mathrm{PrP}^{\mathrm{Sc}}$ im Liquor.

Aus diesen Ergebnisse ergibt sich die Frage nach den Eigenschaften des PrP im Liquor von erkrankten Patienten, die sich vielleicht von denen des PrP im Gehirn der Betroffenen unterscheiden. Einen ersten Hinweis auf Ähnlichkeiten in der RT-QuIC zwischen dem PrP im Gehirn und im Liquor von sCJD-Patienten zeigt der Vergleich der Fluoreszenzsignale der sCJD MM1- und sCJD VV2-Liquorproben mit denen der Gehirnproben. Die Fluoreszenzsignale der sCJD MM1-Liquorproben zeigten eine kürzere Lag-Phase (Median $=45$ Std vs. 51 Std) und größere Fläche unter der Kurve $(\bar{x}=15.935$ vs. 11.859) als die der sCJD VV2-Liquorproben, analog zu denen der sCJD MM1- und sCJD VV2-Gehirnproben.

Die Ergebnisse dieser Arbeit bestätigen das Potential der RT-QuIC, die replikativen Eigenschaften des $\mathrm{PrP}^{\mathrm{Sc}}$ im Liquor zu untersuchen. Zusammenfassend zeigen die hier präsentierten Daten distinkte Eigenschaften des $\mathrm{PrP}^{\mathrm{Sc}}$ im Liquor, die moduliert werden durch die Form der Prionkrankheit, den Prnp Codon 129-Genotyp und die Krankheitsdauer. Somit steht erstmals eine Methode zur Verfügung, um diese Effekte in Patienten während der symptomatischen Phase zu studieren.

\subsection{Nutzung der RT-QuIC als Wirkstoff-Suchtest}

Bis heute wurden viele potentielle Wirkstoffe zur Behandlung von Prionkrankheiten sowohl mittels Zell- und Tiermodellen als auch klinischen Studien am Menschen untersucht (Collins u. a. 2002, Luigi u. a. 2008, Bone u. a. 2008). Hierfür infrage kamen Stoffe, die potentiell den Konversionsprozess von $\mathrm{PrP}^{\mathrm{C}} \mathrm{zu} \mathrm{PrP}^{\mathrm{Sc}}$, die Transmission des $\mathrm{PrP}^{\mathrm{Sc}}$ oder dessen Amyloidbildung inhibierten. Die getesteten Substanzen inhibierten zwar meistens die $\mathrm{PrP}^{\mathrm{Sc}}$-Amplifikation im Zell- oder Tiermodell, wurden jedoch entweder bspw. aufgrund mangelnder Fähigkeit, die Blut-Hirn-Schranke zu überwinden, oder hoher Toxizität nicht am Menschen getestet oder zeigten in klinischen Studien keine signifikante Verbesserung des Krankheitsbildes (Rossi u. a. 2003, Ludewigs u. a. 2007, Zerr 2009).

Eine Einschränkung bei der Translation der zell- oder tierexperimentell gewonnenen Ergebnisse auf die Anwendung beim Menschen ist die Abwesenheit eines Wirkstoff- 
Suchtests, der die krankheitsrelevanten Eigenschaften beim Menschen wiedergibt (Zerr 2009). Die RT-QuIC erlaubt die in vitro-Amplifikation von $\mathrm{PrP}^{\mathrm{Sc}}$ aus humanen Geweben und Körperflüssigkeiten, darunter auch Gehirn und Liquor (Atarashi, Sano u. a. 2011, McGuire u. a. 2012, Sano u. a. 2013, Orrú, Bongianni u. a. 2014, Moda u. a. 2014). Diese wurde bisher zur Anwendung in der Diagnostik humaner Prionkrankheiten und zur Untersuchung potentieller humaner Prionstämme evaluiert und eingesetzt (Cramm, Schmitz, Karch, Zafar u. a. 2015, Cramm, Schmitz, Karch, Mitrová u. a. 2015). Als zellfreier in vitro-Test, der krankheitsspezifische Eigenschaften des eingesetzten humanen Materials wiedergibt (Cramm, Schmitz, Karch, Zafar u. a. 2015) und bereits jetzt weitgehend automatisiert durchgeführt werden kann, hat die RT-QuIC das Potential zum Hochdurchsatz-Wirkstoff-Suchtest.

Zur Nutzung der RT-QuIC als Wirkstoff-Suchtest wurde in dieser Arbeit der Einfluss von mehreren potentiellen Wirkstoffen auf die Amplifikation von $\mathrm{PrP}^{\mathrm{Sc}}$ aus humanen Gehirn- und Liquorproben in der RT-QuIC untersucht. Für beide Probenarten wurde ein inhibierender Einfluss von Doxyzyklin auf die PrP-Konversion beobachtet. Daraus ist die Eignung von im Vergleich zum Gehirn weniger infektiösem Liquor zur Untersuchung potentieller Wirkstoffe gegen Prionkrankheiten mittels RT-QuIC ableitbar.

Doxyzyklin zeigte einen signifikanten und dosisabhängigen Einfluss auf das Fluoreszenzsignal der humanen Gehirn- und Liquorproben, definiert über die Fläche unter der Kurve. Je mehr Doxyzyklin zu Beginn des Versuchs hinzugegeben wurde, desto stärker wurde das Fluoreszenzsignal inhibiert, woraus ein inhibitorischer Einfluss von Doxyzklin auf den Konversionsprozess von $\mathrm{PrP}^{\mathrm{C}}$ zu $\mathrm{PrP}^{\mathrm{Sc}}$ abgeleitet werden kann. Dieses Ergebnis befindet sich in Übereinstimmung mit Studien an Tiermodellen, bei denen Doxyzyklin die Bildung von infektiösem $\mathrm{PrP}^{\mathrm{Sc}}$ verhinderte und somit die Überlebenszeit der Tiere verlängerte (Forloni, Iussich u.a. 2002, Luigi u.a. 2008). Doxyzyklin bindet möglicherweise direkt an $\mathrm{PrP}^{\mathrm{Sc}}$ und verhindert darüber den Konversionsprozess (Tagliavini u. a. 2000, Forloni, Colombo u. a. 2001, Luigi u. a. 2008). Eine mögliche Bindestelle hierfür ist die Aminosäuresequenz 106 - 126 des PrP (Cosentino u. a. 2008).

Doxyzyklin zeigte ebenfalls einen signifikanten Einfluss auf das Fluoreszenzsignal, abhängig vom Zeitpunkt der Zugabe zur RT-QuIC-Reaktion. Je früher Doxyzyklin während des Versuchs zur Reaktion gegeben wurde, desto stärker war seine inhibierende Wirkung. Diese zeigte sich durch ein Absinken der Fluoreszenz nach vorherigem Anstieg und implizierte folgend eine Amyloid-reduzierende Wirkung von Doxyzyklin. Im darauf folgenden Experiment sollte die Frage geklärt werden, ob dieser Fluoreszenzreduzierende Einfluss von Doxyzyklin die Fragmentationsphase der RT-QuIC benötigt, welche zur Fragmentation der PrP-Amyloide und somit zur Generierung neuer Saatpartikel führt. Dazu wurde ein Versuch mit einem Doxyzyklin-freien Reaktionsmix gestartet und nach Ablauf von $55 \%$ der Versuchsdauer, nachdem die Fluoreszenzsignale aller Proben auf ein deutlich positives Signalmaximum gestiegen waren, sowohl Doxyzyklin hinzugegeben als auch die Fragmentationsphase ausgeschaltet. Die Zugabe von Doxyzklin reduzierte das Fluoreszenzsignal, auch unter Aussparung der Fragmentationsphase. Diese Ergebnisse stehen im Einklang mit der Fähigkeit von Doxyzyklin, die Menge an infektiösem PK-resistentem $\mathrm{PrP}^{\mathrm{Sc}}$ zu reduzieren (Tagliavini u. a. 2000, 
Forloni, Iussich u. a. 2002).

Zusammen implizieren diese Ergebnisse, dass Doxyzyklin möglicherweise an mehreren Stellen in den RT-QuIC-Prozess eingreift. Es könnte an die Saatpartikel binden und damit sowohl den PrP-Konversions- als auch den Elongationsschritt inhibieren. Durch Bindung an die PrP-Amyloide könnte Doxyzyklin deren strukturelle Bindung destabilisieren, was unter diesen Versuchsbedingungen letztendlich zu einer Reduktion der PrP-Amyloide führen könnte. Bild 31 auf S. 71 zeigt die potentiellen Ansatzpunkt von Doxyzyklin im RT-QuIC-Prozess.

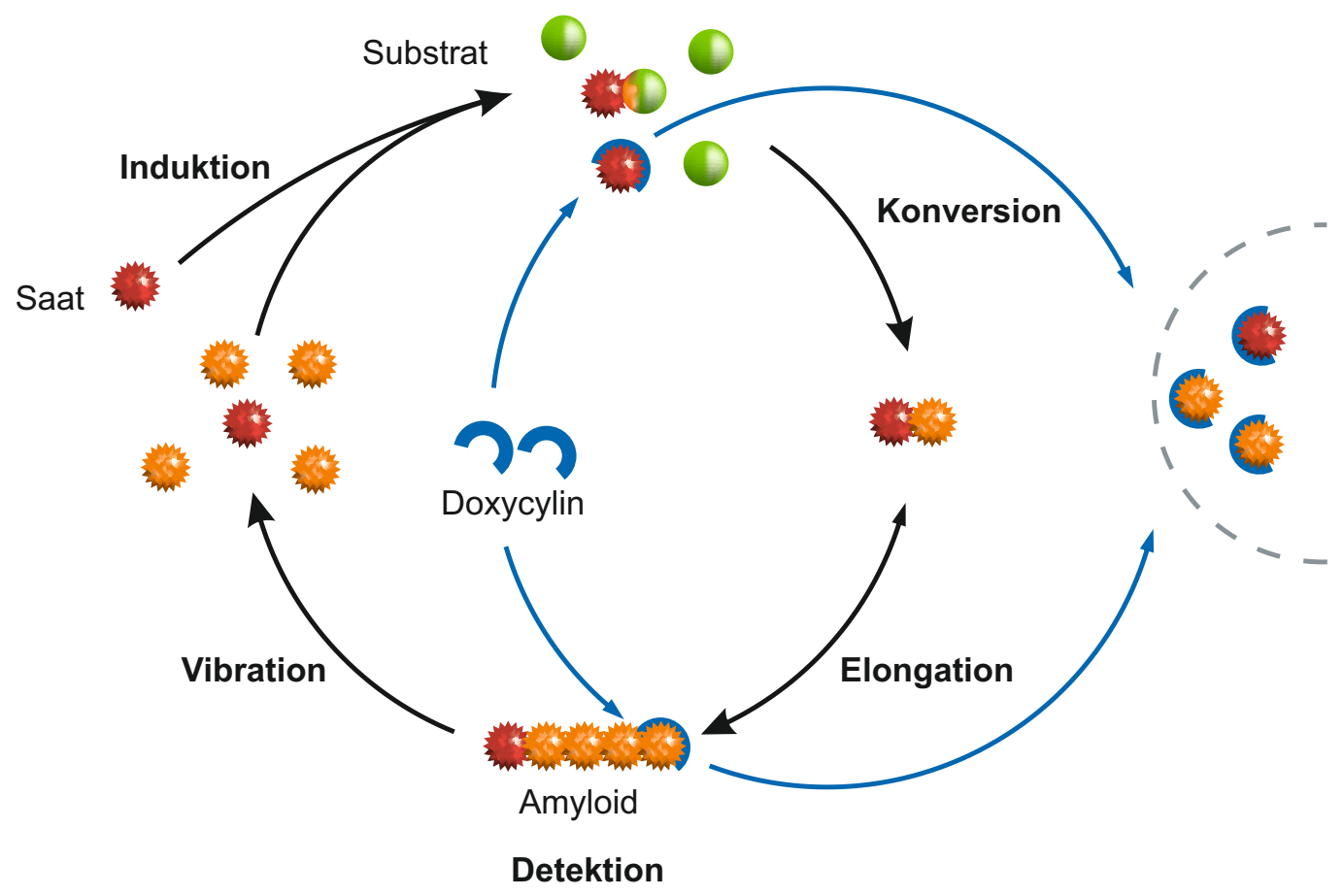

Bild 31: Einfluss von Doxyzyklin auf den RT-QuIC-Prozess

Doxyzyklin greift möglicherweise an mehreren Stellen in den RT-QuIC-Prozess ein. Doxyzyklin könnte an $\mathrm{PrP}^{\mathrm{Sc}}$ binden und dadurch den PrP-Konversions- und Elongationsschritt verhindern. Über eine Bindung an die PrP-Amyloide könnte Doxyzyklin deren strukturelle Integrität schwächen, was unter den Versuchsbedingungen der RT-QuIC zu einer Verringerung der PrP-Amyloide führen könnte.

Diese Ergebnisse stimmen mit denen einer doppelt verblindeten klinischen Phase 2Studie zur Wirkung von Doxyzyklin bei Patienten mit sCJD überein (Varges u. a. 2015). Diese zeigte eine Verlängerung der Überlebenszeit von 208 Tagen ohne Doxyzyklin $(95 \% \mathrm{CI}=136-305)$ auf 346 Tage mit Doxyzyklin $(95 \% \mathrm{CI}=232-371)$ bei Patienten in einem frühen Stadium der sCJD und mit dem Prnp Codon 129-Genotyp MM. Dabei nahmen die Patienten täglich 100 mg Doxyzyklin oral ein. Diskrepanzen zu der Studie von Haïk u. a. 2014, deren Autoren keinen präventiven Effekt bei der Doxyzyklin- 
Behandlung von sCJD-Patienten beobachteten, können durch Faktoren erklärt werden, die die Anti-Prion-Aktivität von Doxyzyklin möglicherweise beeinflussen. Dabei spielt die wichtigste Rolle das Krankheitsstadium. Ein Beginn der Behandlung im frühen Stadium könnte den Anti-Prion-Effekt von Doxyzyklin erhöhen. Da die Mutationen der gCJD und FFI mittels Genanalyse bereits vor Beginn der symptomatischen Phase erkannt werden können (Acevedo-Morantes u. a. 2014), ließe sich sogar eine präventive Behandlung dieser Patienten realisieren.

In dieser Arbeit inhibierte Doxyzyklin die PrP-Konversion ab einer Konzentration von $0,5 \mathrm{mM}$, was etwa $222 \mathrm{\mu g} / \mathrm{ml}$ entspricht. Obwohl Doxyzyklin die Blut-HirnSchranke mit einer Permeabilität von ca. 90 \% überwinden kann, lag dessen mediane Konzentration im humanen Liquor, vier Std nach der oralen Einnahme von $200 \mathrm{mg}$ Doxyzyklin, bei $0,6 \mu \mathrm{g} / \mathrm{ml}\left(Q_{25-75}=0,4-2,5 \mu \mathrm{g} / \mathrm{ml}\right.$; Karlsson u. a. 1996). Zudem wurde Doxyzyklin in einheitlicher Dosis verabreicht, unabhängig vom Geschlecht und Gewicht der Patienten. Dies erklärt vielleicht die unterschiedliche Effizienz der Behandlungen. Eine Verbesserung der Verabreichung von Doxyzyklin, angepasst an das Gewicht der Patienten und mit Blick auf die Abbaurate, könnte die Anti-Prion-Wirkung von Doxyzyklin verbessern.

Zusammenfassend zeigen diese Ergebnisse die sehr gute Eignung der RT-QuIC zur Suche von Stoffen, die den PrP-Konversionsprozess inhibieren oder deren Reaktionsprodukte abbauen. Wesentliche Neuerungen im Vergleich zum Zell- und Tiermodell sind dessen Nutzbarkeit basierend auf Körperflüssigkeiten symptomatischer Patienten, die weitgehende Automatisier- und damit ideale Standardisierbarkeit mit dem Potential zu hohem Durchsatz und die kurze Versuchsdauer. Dies birgt ein hohes translationales Potential zur Wirkstoffsuche gegen die Prionkrankheiten. 


\section{Quellen}

Acevedo-Morantes, Claudia Y. u. a. (2014). „The structure of human prions: from biology to structural models-considerations and pitfalls“. In: Viruses 6.10, S. 38753892. ISSN: 1999-4915. DOI: $10.3390 / v 6103875$.

AJ Roboscreen GmbH (2014). BetaPrion BSE EIA Test Kit: Test for in vitro purifcation and detection of BSE PrPres. Hrsg. von AJ Roboscreen GmbH.

Aldhous, P. (1990). „BSE: spongiform encephalopathy found in cat". In: Nature 345.6272, S. 194. ISSN: 0028-0836. DOI: $10.1038 / 345194 \mathrm{c0}$.

Alper, T. u. a. (1967). „Does the agent of scrapie replicate without nucleic acid?“ In: Nature 214.5090, S. 764-766. ISSN: 0028-0836.

Alpérovitch, Annick u.a. (1999). „Codon 129 prion protein genotype and sporadic Creutzfeldt-Jakob disease“. In: Lancet 353.9165, S. 1673-1674. ISSN: 0140-6736.

Altman, Douglas G. (1991). Practical statistics for medical research. 1st ed. London und New York: Chapman und Hall. ISBN: 9780412386206.

Andréoletti, Olivier u. a. (2012). „Highly efficient prion transmission by blood transfusion“. In: PLoS pathogens 8.6, e1002782. ISSN: 1553-7374. DOI: 10.1371 /journal. ppat.1002782.

Asante, Emmanuel A. u. a. (2009). „Absence of spontaneous disease and comparative prion susceptibility of transgenic mice expressing mutant human prion proteins". In: The Journal of general virology 90.Pt 3, S. 546-558. ISSN: 0022-1317. DOI: 10.1099/vir.0.007930-0.

Atarashi, Ryuichiro, Moore, Roger A. u. a. (2007). „Ultrasensitive detection of scrapie prion protein using seeded conversion of recombinant prion protein". In: Nature methods 4.8, S. 645-650. ISSN: 1548-7105. DOI: 10.1038/nmeth1066.

Atarashi, Ryuichiro, Sano, Kazunori u. a. (2011). „Real-time quaking-induced conversion: a highly sensitive assay for prion detection". In: Prion 5.3, S. 150-153. ISSN: 1933-6896. DOI: $10.4161 /$ pri.5.3.16893.

Atarashi, Ryuichiro, Satoh, Katsuya u. a. (2011). „Ultrasensitive human prion detection in cerebrospinal fluid by real-time quaking-induced conversion". In: Nature medicine 17.2, S. 175-178. ISSN: 1546-170X. DOI: 10.1038/nm. 2294.

Atarashi, Ryuichiro, Wilham, Jason M. u. a. (2008). „Simplified ultrasensitive prion detection by recombinant $\mathrm{PrP}$ conversion with shaking". In: Nature methods 5.3, S. 211-212. ISSN: 1548-7105. DOI: 10.1038/nmeth0308-211.

Baldwin, M. A. u. a. (1990). „Permethylation and tandem mass spectrometry of oligosaccharides having free hexosamine: analysis of the glycoinositol phospholipid anchor glycan from the scrapie prion protein“. In: Analytical biochemistry 191.1, S. 174-182. ISSN: 0003-2697.

Bartz, J. C. u. a. (2000). „Adaptation and selection of prion protein strain conformations following interspecies transmission of transmissible mink encephalopathy". In: Journal of virology 74.12, S. 5542-5547. ISSN: 0022-538X. 
Baskakov, Ilia V. u. a. (2005). „The presence of valine at residue 129 in human prion protein accelerates amyloid formation". In: FEBS letters 579.12, S. 2589-2596. ISSN: 1873-3468. DOI: 10.1016/j.febslet.2005.03.075.

Beringue, V. (2003). „Regional heterogeneity of cellular prion protein isoforms in the mouse brain". In: Brain 126.9, S. 2065-2073. ISSN: 1460-2156. DOI: 10.1093/brain/ awg205.

Bernoulli, C. u.a. (1977). „Danger of accidental person-to-person transmission of Creutzfeldt-Jakob disease by surgery“. In: Lancet (London, England) 1.8009, S. 478479. ISSN: 0140-6736.

Bessen, Richard A. u. a. (1994). „Distinct PrP properties suggest the molecular basis of strain variation in transmissible mink encephalopathy". In: Journal of virology 68.12, S. 7859-7868. ISSN: 0022-538X.

Bishop, Matthew T. u. a. (2010). „Defining sporadic Creutzfeldt-Jakob disease strains and their transmission properties". In: Proceedings of the National Academy of Sciences of the United States of America 107.26, S. 12005-12010. ISSN: 1091-6490. DOI: $10.1073 /$ pnas . 1004688107.

Bolton, D. C. u.a. (1982). „Identification of a protein that purifies with the scrapie prion“. In: Science 218.4579, S. 1309-1311. ISSN: 0036-8075.

Bone, I. u. a. (2008). „Intraventricular pentosan polysulphate in human prion diseases: an observational study in the UK". In: European journal of neurology : the official journal of the European Federation of Neurological Societies 15.5, S. 458-464. ISSN: 1468-1331. DOI: $10.1111 / \mathrm{j} .1468-1331.2008 .02108$.x.

Borchelt, David R. u.a. (1990). „Scrapie and cellular prion proteins differ in their kinetics of synthesis and topology in cultured cells". In: The Journal of cell biology 110.3, S. 743-752. ISSN: 0021-9525.

Bosque, P. J. u. a. (2002). „Prions in skeletal muscle“. In: Proceedings of the National Academy of Sciences 99.6, S. 3812-3817. ISSN: 0027-8424. DOI: $10.1073 /$ pnas . 052707499.

Brandel, Jean-Philippe u. a. (2003). „Distribution of codon 129 genotype in human growth hormone-treated CJD patients in France and the UK". In: Lancet (London, England) 362.9378, S. 128-130. ISSN: 0140-6736. DOI: 10.1016/S0140-6736(03) 13867-6.

Brown, D. R. u. a. (1997). „The cellular prion protein binds copper in vivo“. In: Nature 390.6661, S. 684-687. ISSN: 0028-0836. DOI: 10.1038/37783.

Brown, Paul (1996). „Environmental Causes of Human Spongiform Encephalopathy“. In: Prion Diseases. Hrsg. von Harry F. Baker u. a. Bd. 3. New Jersey: Humana Press, S. 139-154. ISBN: 0-89603-342-2. DOI: 10.1385/0-89603-342-2:139.

Brown, Paul, Brandel, Jean-Philippe u.a. (2012). „Iatrogenic Creutzfeldt-Jakob disease, final assessment". In: Emerging infectious diseases 18.6, S. 901-907. ISSN: 1080-6059. DOI: 10.3201 /eid1806.120116.

Brown, Paul, Cervenáková, L. u. a. (1994). „Iatrogenic Creutzfeldt-Jakob disease: an example of the interplay between ancient genes and modern medicine". In: Neurology 44.2, S. 291-293. ISSN: 0028-3878. 
Brown, Paul, Kenney, K. u. a. (1995). „Intracerebral distribution of infectious amyloid protein in spongiform encephalopathy“. In: Annals of neurology 38.2, S. 245-253. ISSN: 0364-5134. DOI: 10.1002/ana.410380218.

Brown, Paul, Preece, Michael u. a. (2000). „Iatrogenic Creutzfeldt-Jakob disease at the millennium“. In: Neurology 55.8, S. 1075-1081. ISSN: 0028-3878.

Bruce, Moira E. (1996). „Strain Typing Studies of Scrapie and BSE“. In: Prion Diseases. Hrsg. von Harry F. Baker u. a. Bd. 3. New Jersey: Humana Press, S. 223-236. ISBN: 0-89603-342-2. DOI: 10.1385/0-89603-342-2: 223.

Bruce, Moira E. und Dickinson, A. G. (1979). „Biological stability of different classes of scrapie agent". In: Slow transmissible diseases of the nervous system Vol 2. Hrsg. von Stanley B. Prusiner u. a. Bd. 2. New York: Academic Press, S. 71-86.

Bruce, Moira E., Will, Robert G u.a. (1997). „Transmissions to mice indicate that 'new variant' CJD is caused by the BSE agent". In: Nature 389.6650, S. 498-501. ISSN: 0028-0836. DOI: 10.1038/39057.

Budka, Herbert (2001a). „Portrait der letalen familiären Schlaflosigkeit“. In: Prionen und Prionkrankheiten. Hrsg. von Beat Hörnlimann u. a. Berlin und New York: De Gruyter, S. 162-164. ISBN: 3-11-016361-6.

- (2001b). „Portrait des Gerstmann-Sträussler-Schenker-Syndrom (GSS)“. In: Prionen und Prionkrankheiten. Hrsg. von Beat Hörnlimann u. a. Berlin und New York: De Gruyter, S. 158-161. ISBN: 3-11-016361-6.

Budka, Herbert u. a. (1997). „A new Austrian family with fatal familial insomnia: Brain pathology without detectable PrPres“. In: Brain pathology (Zurich, Switzerland) 7, S. 1267. ISSN: 1015-6305.

Büeler, H. u. a. (1992). "Normal development and behaviour of mice lacking the neuronal cell-surface PrP protein“. In: Nature 356.6370, S. 577-582. ISSN: 0028-0836. DOI: $10.1038 / 356577 \mathrm{a}$.

Burger, D. (1965). „Enzephalopathy of mink - 2. Experimental and natural transmission." In: J. Infect. Dis. 115, S. 393-399.

Burnette, W. N. (1981). „"Western blotting": electrophoretic transfer of proteins from sodium dodecyl sulfate-polyacrylamide gels to unmodified nitrocellulose and radiographic detection with antibody and radioiodinated protein A“. In: Analytical biochemistry 112.2, S. 195-203. ISSN: 0003-2697.

Cali, Ignazio u.a. (2006). „Classification of sporadic Creutzfeldt-Jakob disease revisited“. In: Brain : a journal of neurology 129.Pt 9, S. 2266-2277. ISSN: 1460-2156. DOI: $10.1093 /$ brain/aw1224.

Campbell, Neil A. u. a. (2003). Biologie. 6. Aufl. Spektrum Lehrbuch. Heidelberg [u.a.]: Spektrum Akad. Verl. ISBN: 3827413524.

Capellari, Sabina u.a. (2000). „Effect of the E200K mutation on prion protein metabolism. Comparative study of a cell model and human brain". In: The American journal of pathology 157.2, S. 613-622. ISSN: 0002-9440. DOI: 10 . 1016/S00029440 (10) 64572-5.

Cappai, R. u. a. (2001). „Structural biology of prions“. In: Contributions to microbiology 7, S. 32-47. ISSN: 1420-9519. 
Cashman, N. R. u. a. (1990). "Cellular isoform of the scrapie agent protein participates in lymphocyte activation". In: Cell 61.1, S. 185-192. ISSN: 0092-8674.

Castilla, Joaquín, Saá, Paula, Hetz, Claudio u. a. (2005). „In vitro generation of infectious scrapie prions“. In: Cell 121.2, S. 195-206. ISSN: 0092-8674. DOI: 10.1016/j . cell.2005.02.011.

Castilla, Joaquín, Saá, Paula, Morales, Rodrigo u. a. (2006). „Protein misfolding cyclic amplification for diagnosis and prion propagation studies". In: Methods in enzymology 412, S. 3-21. ISSN: 0076-6879. DOI: 10.1016/S0076-6879(06)12001-7.

Caughey, Byron u.a. (1991). „Secondary structure analysis of the scrapie-associated protein PrP 27-30 in water by infrared spectroscopy". In: Biochemistry 30.31, S. 76727680. ISSN: 0006-2960.

Centers for Disease Control and Prevention (1997). „Creutzfeldt-Jakob disease associated with cadaveric dura mater grafts - Japan, January 1979-May 1996". In: MMWR. Morbidity and mortality weekly report 46.45, S. 1066-1069. ISSN: 0149-2195.

Chabry, J. u. a. (1998). „Specific inhibition of in vitro formation of protease-resistant prion protein by synthetic peptides“. In: The Journal of biological chemistry 273.21, S. 13203-13207. ISSN: 0021-9258.

Colby, David W., Giles, Kurt u. a. (2009). „Design and construction of diverse mammalian prion strains". In: Proceedings of the National Academy of Sciences of the United States of America 106.48, S. 20417-20422. ISSN: 1091-6490. DOI: 10.1073/ pnas.0910350106.

Colby, David W., Wain, Rachel u. a. (2010). „Protease-sensitive synthetic prions“. In: PLoS pathogens 6.1, e1000736. ISSN: 1553-7374. DOI: 10 . $1371 /$ journal . ppat . 1000736.

Colby, David W., Zhang, Qiang u.a. (2007). „Prion detection by an amyloid seeding assay". In: Proceedings of the National Academy of Sciences of the United States of America 104.52, S. 20914-20919. ISSN: 1091-6490. DOI: 10.1073/pnas.0710152105.

Collinge, John (1999). „Variant Creutzfeldt-Jakob disease“. In: Lancet (London, England) 354.9175 , S. 317-323. ISSN: 0140-6736. DOI: 10.1016/S0140-6736(99)051284.

Collinge, John, Palmer, M. S. u. a. (1991). „Genetic predisposition to iatrogenic Creutzfeldt-Jakob disease“. In: Lancet (London, England) 337.8755, S. 1441-1442. ISSN: 0140-6736.

Collinge, John, Sidle, Katie C L u. a. (1996). „Molecular analysis of prion strain variation and the aetiology of 'new variant' CJD“. In: Nature 383.6602, S. 685-690. ISSN: 0028-0836. DOI: $10.1038 / 383685 \mathrm{a} 0$.

Collinge, John, Whitfield, Jerome u. a. (2006). „Kuru in the 21st century-an acquired human prion disease with very long incubation periods". In: Lancet (London, England) 367.9528, S. 2068-2074. ISSN: 0140-6736. DOI: 10.1016/S0140-6736(06) 68930-7.

Collins, Steven J. (2006). „Determinants of diagnostic investigation sensitivities across the clinical spectrum of sporadic Creutzfeldt-Jakob disease". In: Brain 129.9, S. 2278 2287. ISSN: 1460-2156. DOI: 10.1093/brain/aw1159. 
Collins, Steven J. u.a. (2002). „Quinacrine does not prolong survival in a murine Creutzfeldt-Jakob disease model". In: Annals of neurology 52.4, S. 503-506. ISSN: 0364-5134. DOI: 10.1002/ana. 10336.

Colovic, Milena u. a. (2003). „Liquid chromatographic determination of minocycline in brain-to-plasma distribution studies in the rat". In: Journal of chromatography. B, Analytical technologies in the biomedical and life sciences 791.1-2, S. 337-343. ISSN: 1570-0232.

Cosentino, Ugo u.a. (2008). „The anti-fibrillogenic activity of tetracyclines on $\operatorname{PrP}$ 106-126: a 3D-QSAR study“. In: Journal of molecular modeling 14.10, S. 987-994. ISSN: 0948-5023. DOI: 10.1007/s00894-008-0348-2.

Cramm, Maria, Schmitz, Matthias, Karch, André, Mitrová, Eva u. a. (2015). „Stability and Reproducibility Underscore Utility of RT-QuIC for Diagnosis of CreutzfeldtJakob Disease“. In: Molecular Neurobiology. ISSN: 1559-1182. DOI: 10.1007/s12035015-9133-2.

Cramm, Maria, Schmitz, Matthias, Karch, André, Zafar, Saima u. a. (2015). „Characteristic CSF prion seeding efficiency in humans with prion diseases". In: Molecular Neurobiology 51.1, S. 396-405. ISSN: 1559-1182. DOI: 10.1007/s12035-014-8709-6.

Creutzfeldt, Hans Gerhard (1920). „Über eine eigenartige herdförmige erkrankung des zentralnervensystems (Vorläufige mitteilung)“. In: Zeitschrift für die gesamte Neurologie und Psychiatrie 57.1, S. 1-18. ISSN: 0303-4194. DOI: 10.1007/BF02866081.

Cuille, J. u. a. (1936). „La maladie dite tremblante du mouton est-elle inoculable?“ In: C. R. Acad. Sci. Paris 203, S. 1552-1554.

Deslys, J. P., Jaegly, A. u. a. (1998). „Genotype at codon 129 and susceptibility to Creutzfeldt-Jakob disease“. In: Lancet (London, England) 351.9111, S. 1251. ISSN: 0140-6736.

Deslys, J. P., Marcé, D. u. a. (1994). „Similar genetic susceptibility in iatrogenic and sporadic Creutzfeldt-Jakob disease“. In: The Journal of general virology 75 ( Pt 1), S. 23-27. ISSN: 0022-1317. DOI: 10.1099/0022-1317-75-1-23.

Deutsche Gesellschaft für Neurologie (2008). Creutzfeldt-Jakob Krankheit: Was gibt es Neues? Leitlinien der DGN 2008. Hrsg. von Deutsche Gesellschaft für Neurologie. URL: http : //www . dgn . org/images/red\%5C_leitlinien/LL\%5C_2008/archiv/ 1108kap\%5C_046.pdf (besucht am 14.10.2015).

Diringer, H. (1990). „Durchbrechen von Speziesbarrieren mit unkonventionellen Viren“. In: Bundesgesundheitsblatt 33.10, S. 435-440. ISSN: 0007-5914.

Diringer, H. u. a. (1988). „Scrapie: a virus-induced amyloidosis of the brain“. In: Ciba Found Symp 135, S. 135-145.

Doh-ura, K. u. a. (1989). „Pro-leu change at position 102 of prion protein is the most common but not the sole mutation related to Gerstmann-Sträussler syndrome". In: Biochemical and biophysical research communications 163.2, S. 974-979. ISSN: 0006291X.

Donne, D. G. u. a. (1997). „Structure of the recombinant full-length hamster prion protein $\operatorname{PrP}(29-231)$ : the N terminus is highly flexible“. In: Proceedings of the National 
Academy of Sciences of the United States of America 94.25, S. 13452-13457. ISSN: 1091-6490.

Douet, Jean Yves u. a. (2014). „Detection of infectivity in blood of persons with variant and sporadic Creutzfeldt-Jakob disease." In: Emerging infectious diseases Jan;20(1), S. 114-117. ISSN: 1080-6059. DOI: 10.3201/eid2001.130353.

Duffy, P. u. a. (1974). „Letter: Possible person-to-person transmission of CreutzfeldtJakob disease“. In: The New England journal of medicine 290.12, S. 692-693. ISSN: 0028-4793.

Engvall, E. u. a. (1971). „Enzyme-linked immunosorbent assay (ELISA). Quantitative assay of immunoglobulin G“. In: Immunochemistry 8.9, S. 871-874. ISSN: 0019-2791.

Finkenstaedt, M. u. a. (1996). „MR imaging of Creutzfeldt-Jakob disease“. In: Radiology 199.3, S. 793-798. ISSN: 0033-8419. DOI: 10.1148/radiology.199.3.8638007.

Forloni, Gianluigi, Colombo, Laura u. a. (2001). „Anti-amyloidogenic activity of tetracyclines: studies in vitro". In: FEBS letters 487.3, S. 404-407. ISSN: 1873-3468.

Forloni, Gianluigi, Iussich, Selina u. a. (2002). „Tetracyclines affect prion infectivity“. In: Proceedings of the National Academy of Sciences of the United States of America 99.16, S. 10849-10854. ISSN: 1091-6490. DOI: 10.1073/pnas.162195499.

Forloni, Gianluigi, Salmona, Mario u. a. (2009). „Tetracyclines and prion infectivity“. In: Infectious disorders drug targets 9.1, S. 23-30. ISSN: 2212-3989.

Fraser, Hugh u. a. (1973). „Scrapie in mice. Agent-strain differences in the distribution and intensity of grey matter vacuolation". In: Journal of comparative pathology 83.1, S. 29-40. ISSN: 0021-9975.

Friedman-Levi, Yael u. a. (2011). „Fatal prion disease in a mouse model of genetic E200K Creutzfeldt-Jakob disease“. In: PLoS pathogens 7.11, e1002350. ISSN: 15537374. DOI: 10.1371 /journal.ppat. 1002350.

Gabriel, J. M. u. a. (1992). „Molecular cloning of a candidate chicken prion protein“. In: Proceedings of the National Academy of Sciences of the United States of America 89.19, S. 9097-9101. ISSN: 1091-6490.

Gajdusek, D. C. u. a. (1966). „Experimental Transmission of a Kuru-like Syndrome to Chimpanzees“. In: Nature 209.5025, S. 794-796. ISSN: 0028-0836. DOI: 10.1038 / $209794 a 0$.

Gambetti, Pierluigi, Dong, Zhiqian u. a. (2008). „A novel human disease with abnormal prion protein sensitive to protease“. In: Annals of neurology 63.6, S. 697-708. ISSN: 0364-5134. DOI: 10.1002 /ana.21420.

Gambetti, Pierluigi, Kong, Qingzhong u. a. (2003). „Sporadic and familial CJD: classification and characterisation". In: British medical bulletin 66, S. 213-239. ISSN: 0007-1420.

Gambetti, Pierluigi, Parchi, Piero u. a. (1995). „Fatal familial insomnia and familial Creutzfeldt-Jakob disease: clinical, pathological and molecular features". In: Brain pathology (Zurich, Switzerland) 5.1, S. 43-51. ISSN: 1015-6305.

Gao, Chen u. a. (2012). „[Mutant D178N prion protein converts spontaneously in RTQuIC assay]". In: Zhonghua shi yan he lin chuang bing du xue za zhi = Zhonghua 
shiyan he linchuang bingduxue zazhi $=$ Chinese journal of experimental and clinical virology 26.5, S. 370-373. ISSN: 1003-9279.

Gerstmann, Josef u. a. (1935). „Über eine eigenartige hereditär- familiäre Erkrankung des Zentralnervensystems". In: Zeitschrift für die gesamte Neurologie und Psychiatrie 154.1, S. 736-762. ISSN: 0303-4194. DOI: 10.1007/BF02865827.

Giannopoulos, Paresa N. u.a. (2009). „Phosphorylation of prion protein at serine 43 induces prion protein conformational change". In: The Journal of neuroscience : the official journal of the Society for Neuroscience 29.27, S. 8743-8751. ISSN: 1529-2401. DOI: $10.1523 /$ JNEUROSCI . 2294-09.2009.

Gibbons, R. A. u. a. (1967). "Nature of the Scrapie Agent". In: Nature 215.5105, S. 1041-1043. ISSN: 0028-0836. DOI: 10.1038/2151041a0.

Goldfarb, L. G., Brown, Paul, Little, B. u. a. (1993). „A new (two-repeat) octapeptide coding insert mutation in Creutzfeldt-Jakob disease“. In: Neurology 43.11, S. 23922394. ISSN: 0028-3878.

Goldfarb, L. G., Brown, Paul, McCombie, W. R. u. a. (1991). „Transmissible familial Creutzfeldt-Jakob disease associated with five, seven, and eight extra octapeptide coding repeats in the PRNP gene". In: Proceedings of the National Academy of Sciences of the United States of America 88.23, S. 10926-10930. ISSN: 1091-6490.

Goldfarb, L. G., Haltia, M. u. a. (1991). "New mutation in scrapie amyloid precursor gene (at codon 178) in Finnish Creutzfeldt-Jakob kindred“. In: Lancet (London, England) 337.8738, S. 425. ISSN: 0140-6736.

Goldfarb, L. G., Petersen, R. B. u. a. (1992). „Fatal familial insomnia and familial Creutzfeldt-Jakob disease: disease phenotype determined by a DNA polymorphism“. In: Science (New York, N.Y.) 258.5083, S. 806-808. ISSN: 0036-8075.

Goldgaber, D. u. a. (1989). „Mutations in familial Creutzfeldt-Jakob disease and Gerstmann-Sträussler-Scheinker's syndrome“. In: Experimental neurology 106.2, S. 204206. ISSN: 0014-4886.

Grieß, Eike u.a. (1999). RFLP - Lexikon der Biologie. Hrsg. von Spektrum Akademischer Verlag. Heidelberg. URL: http://www. spektrum.de/lexikon/biologie/ rflp/56563\%5C\&\%5C_druck=1 (besucht am 15.06.2015).

Griffith, J. S. (1967). „Self-replication and scrapie“. In: Nature 215.5105, S. 1043-1044. ISSN: 0028-0836.

Hadlow, W. J. (1959). „Scrapie and Kuru“. In: The Lancet 274.7097, S. 289-290. ISSN: 01406736. DOI: $10.1016 /$ S0140-6736 (59)92081-1.

Haïk, Stéphane u. a. (2014). „Doxycycline in Creutzfeldt-Jakob disease: a phase 2, randomised, double-blind, placebo-controlled trial“". In: The Lancet. Neurology 13.2, S. 150-158. ISSN: 1474-4465. DOI: 10.1016/S1474-4422(13)70307-7.

Haraguchi, Tokuko u.a. (1989). „Asparagine-linked glycosylation of the scrapie and cellular prion proteins". In: Archives of Biochemistry and Biophysics 274.1, S. 1-13. ISSN: 00039861. DOI: 10.1016/0003-9861(89)90409-8.

Harris, David A. (2003). "Trafficking, turnover and membrane topology of PrP“. In: British medical bulletin 66, S. 71-85. ISSN: 0007-1420. 
Hartsough, G. R. (1965). „Enzephalophathy of mink - 1. Epizootiologic and clinical observations." In: J. Infect. Dis. 115, S. 387-392.

Heinemann, Uta u.a. (2007). „Creutzfeldt-Jakob disease in Germany: a prospective 12-year surveillance“. In: Brain : a journal of neurology 130.Pt 5, S. 1350-1359. ISSN: 1460-2156. DOI: $10.1093 /$ brain/awm063.

Hill, Andrew F., Desbruslais, M. u. a. (1997). „The same prion strain causes vCJD and BSE“. In: Nature 389.6650, S. 448-50, 526. ISSN: 0028-0836. DOI: 10.1038/38925.

Hill, Andrew F., Joiner, Susan, Beck, Jonathan A. u. a. (2006). „Distinct glycoform ratios of protease resistant prion protein associated with PRNP point mutations". In: Brain : a journal of neurology 129.Pt 3, S. 676-685. ISSN: 1460-2156. DOI: 10.1093/brain/aw1013.

Hill, Andrew F., Joiner, Susan, Wadsworth, Jonathan D u. a. (2003). „Molecular classification of sporadic Creutzfeldt-Jakob disease". In: Brain : a journal of neurology 126.Pt 6, S. 1333-1346. ISSN: 1460-2156.

Hölscher, C. u. a. (1998). „Overexpression of nonconvertible PrPc delta114-121 in scrapie-infected mouse neuroblastoma cells leads to trans-dominant inhibition of wild-type $\operatorname{PrP}(\mathrm{Sc})$ accumulation“. In: Journal of virology 72.2, S. 1153-1159. ISSN: 0022-538X.

Horiuchi, M. u. a. (1995). „A cellular form of prion protein (PrPC) exists in many nonneuronal tissues of sheep“. In: The Journal of general virology 76 ( Pt 10), S. 25832587. ISSN: 0022-1317. DOI: 10.1099/0022-1317-76-10-2583.

Hörnlimann, Beat (2001). „Historische Einführung:Prionen und Prionkrankheiten“. In: Prionen und Prionkrankheiten. Hrsg. von Beat Hörnlimann u. a. Berlin und New York: De Gruyter, S. 3-20. ISBN: 3-11-016361-6.

Hornshaw, M. P. u. a. (1995). „Copper binding to the N-terminal tandem repeat region of mammalian and avian prion protein: structural studies using synthetic peptides". In: Biochemical and biophysical research communications 214.3, S. 993-999. ISSN: 0006-291X. DOI: 10.1006/bbrc.1995.2384.

Hsiao, K., Baker, Harry F. u. a. (1989). „Linkage of a prion protein missense variant to Gerstmann-Sträussler syndrome“. In: Nature 338.6213, S. 342-345. ISSN: 0028-0836. DOI: $10.1038 / 338342 \mathrm{a} 0$.

Hsiao, K. und Prusiner, Stanley B. (1990). „Inherited human prion diseases“. In: Neurology 40.12, S. 1820-1827. ISSN: 0028-3878.

Hsich, G. u. a. (1996). "The 14-3-3 brain protein in cerebrospinal fluid as a marker for transmissible spongiform encephalopathies". In: The New England journal of medicine 335.13, S. 924-930. ISSN: 0028-4793. DOI: 10.1056/NEJM199609263351303.

Innogenetics (2010). Innotest hTau Ag: 25684 v14: Key-Code INX74378. Hrsg. von Innogenetics.

Jackson, Walker S. u. a. (2009). „Spontaneous generation of prion infectivity in fatal familial insomnia knockin mice“. In: Neuron 63.4, S. 438-450. ISSN: 1097-4199. DOI: $10.1016 / j$.neuron.2009.07.026.

Jakob, A. M. (1921a). „Über eigenartige Erkrankungen des Zentralnervensystems mit bemerkenswertem anatomischem Befunde (Spastische Pseudosklerose - Encephalo- 
myelopathie mit disseminierten Degenerationsherden)“. In: Dtsch. Z. Nervenheilk. 70, S. 132-146.

Jakob, A. M. (1921b). „Über eine der Multiplen Sklerose klinisch nahestehenden Erkrankung des Zentralnervensystems (Spastische Pseudosklerose) mit bemerkenswertem anatomischem Befunde“. In: Medizinische Klinik 13, S. 372.

James, T. L. u. a. (1997). „Solution structure of a 142-residue recombinant prion protein corresponding to the infectious fragment of the scrapie isoform". In: Proceedings of the National Academy of Sciences of the United States of America 94.19, S. 1008610091. ISSN: 1091-6490.

Janeway, Charles A. (2002). Immunologie. 5. Aufl. Spektrum-Lehrbuch. Heidelberg [u.a.]: Spektrum, Akad. Verl. ISBN: 3827410797.

Jansohn, Monika (2012). Gentechnische Methoden: Eine Sammlung von Arbeitsanleitungen für das molekularbiologische Labor. 5. Auflage. SpringerLink : Bücher. Heidelberg: Spektrum Akademischer Verlag und Imprint: Spektrum Akademischer Verlag. ISBN: 978-3-8274-2429-7.

Jeffrey, M. u. a. (1988). „Spongiform encephalopathy in a nyala (Tragelaphus angasi)“. In: Veterinary pathology 25.5, S. 398-399. ISSN: 0300-9858.

Jensen, M. u. a. (2000). „Quantification of Alzheimer amyloid beta peptides ending at residues 40 and 42 by novel ELISA systems“. In: Molecular medicine (Cambridge, Mass.) 6.4, S. 291-302. ISSN: 1076-1551.

Karlsson, M. u. a. (1996). „Concentrations of doxycycline and penicillin G in sera and cerebrospinal fluid of patients treated for neuroborreliosis". In: Antimicrobial agents and chemotherapy 40.5, S. 1104-1107. ISSN: 0066-4804.

Khurana, Ritu u. a. (2005). "Mechanism of thioflavin T binding to amyloid fibrils“. In: Journal of structural biology 151.3, S. 229-238. ISSN: 1047-8477. DOI: 10.1016/j . jsb.2005.06.006.

Kim, Boe-Hyun u. a. (2004). „The cellular prion protein (PrPC) prevents apoptotic neuronal cell death and mitochondrial dysfunction induced by serum deprivation". In: Brain research. Molecular brain research 124.1, S. 40-50. ISSN: 0169-328X. DOI: 10.1016/j.molbrainres .2004.02.005.

Kim, Jae-Il u. a. (2010). „Mammalian prions generated from bacterially expressed prion protein in the absence of any mammalian cofactors". In: The Journal of biological chemistry 285.19, S. 14083-14087. ISSN: 0021-9258. DOI: $10.1074 / \mathrm{jbc}$. C110 . 113464.

Kimberlin, R. H. u. a. (1978). „Pathogenesis of mouse scrapie: effect of route of inoculation on infectivity titres and dose-response curves“. In: Journal of comparative pathology 88.1, S. 39-47. ISSN: 0021-9975.

Kobayashi, Atsushi u. a. (2015). „The influence of PRNP polymorphisms on human prion disease susceptibility: an update“. In: Acta neuropathologica 130.2, S. 159-170. ISSN: 1432-0533. DOI: 10.1007/s00401-015-1447-7.

Koch, T. K. u. a. (1985). „Creutzfeldt-Jakob disease in a young adult with idiopathic hypopituitarism. Possible relation to the administration of cadaveric human growth 
hormone“. In: The New England journal of medicine 313.12, S. 731-733. ISSN: 0028-4793. DOI: $10.1056 /$ NEJM198509193131206.

Kramer, M. L. u. a. (2001). „Prion protein binds copper within the physiological concentration range“. In: The Journal of biological chemistry 276.20, S. 16711-16719. ISSN: 0021-9258. DOI: $10.1074 / \mathrm{jbc}$. M006554200.

Kretzschmar, Hans A. (2001). „Die Pathologie und Genetik der Prionkrankheiten beim Menschen". In: Prionen und Prionkrankheiten. Hrsg. von Beat Hörnlimann u. a. Berlin und New York: De Gruyter, S. 207-220. ISBN: 3-11-016361-6.

Kretzschmar, Hans A., Prusiner, Stanley B. u. a. (1986). „Scrapie prion proteins are synthesized in neurons". In: The American journal of pathology 122.1, S. 1-5. ISSN: 0002-9440.

Kretzschmar, Hans A., Stowring, L. E. u. a. (1986). „Molecular cloning of a human prion protein cDNA“. In: DNA (Mary Ann Liebert, Inc.) 5.4, S. 315-324. ISSN: 0198-0238.

Kuczius, Thorsten u.a. (2007). „Regional and phenotype heterogeneity of cellular prion proteins in the human brain". In: The European journal of neuroscience 25.9, S. 2649-2655. ISSN: 0953-816X. DOI: $10.1111 / \mathrm{j} .1460-9568.2007 .05518 . x$.

Ladogana, Anna u.a. (2005). „Mortality from Creutzfeldt-Jakob disease and related disorders in Europe, Australia, and Canada“. In: Neurology 64.9, S. 1586-1591. ISSN: 0028-3878. DOI: 10.1212/01. WNL.0000160117.56690.B2.

Laplanche, Jean-Louis, Delasnerie-Lauprêtre, N., Brandel, Jean-Philippe, Chatelain, J. u. a. (1994). „Molecular genetics of prion diseases in France. French Research Group on Epidemiology of Human Spongiform Encephalopathies". In: Neurology 44.12, S. 2347-2351. ISSN: 0028-3878.

Laplanche, Jean-Louis, Delasnerie-Lauprêtre, N., Brandel, Jean-Philippe, Dussaucy, M. u. a. (1995). „Two novel insertions in the prion protein gene in patients with lateonset dementia“. In: Human molecular genetics 4.6, S. 1109-1111. ISSN: 0964-6906.

Laplanche, Jean-Louis, Hachimi, K. H. u. a. (1999). „Prominent psychiatric features and early onset in an inherited prion disease with a new insertional mutation in the prion protein gene“. In: Brain : a journal of neurology 122 ( Pt 12), S. 2375-2386. ISSN: $1460-2156$.

Lawson, Victoria A. u. a. (2005). „Prion protein glycosylation“. In: Journal of neurochemistry 93.4, S. 793-801. ISSN: 0022-3042. DOI: 10.1111/j.1471-4159.2005. 03104.x.

Le Pichon, Claire E u.a. (2009). „Olfactory behavior and physiology are disrupted in prion protein knockout mice“. In: Nature neuroscience 12.1, S. 60-69. ISSN: 15461726. DOI: $10.1038 / \mathrm{nn} .2238$.

Levy, Yaakov u.a. (2002). „Conformational polymorphism of wild-type and mutant prion proteins: Energy landscape analysis“. In: Proteins 47.4, S. 458-468. ISSN: 1097-0134. DOI: 10.1002/prot. 10095.

Lloyd, Sarah E. u.a. (2013). „Genetics of prion diseases“. In: Current Opinion in Genetics \& Development 23.3, S. 345-351. ISSN: 0959437X. DOI: 10.1016/j.gde. 2013.02 .012 . 
Ludewigs, Heike u.a. (2007). „Therapeutic approaches for prion disorders“. In: Expert review of anti-infective therapy 5.4, S. 613-630. ISSN: 1744-8336. DOI: 10.1586 / $14787210.5 \cdot 4.613$.

Lugaresi, Elio u. a. (1986). „Fatal familial insomnia and dysautonomia with selective degeneration of thalamic nuclei“. In: The New England journal of medicine 315.16, S. 997-1003. ISSN: 0028-4793. DOI: 10.1056/NEJM198610163151605.

Luigi, Ada de u. a. (2008). „The efficacy of tetracyclines in peripheral and intracerebral prion infection". In: PloS one 3.3, e1888. ISSN: 1932-6203. DOI: 10.1371/journal. pone.0001888.

Maiti, N. R. u. a. (2001). ,The role of disulfide bridge in the folding and stability of the recombinant human prion protein“. In: The Journal of biological chemistry 276.4, S. 2427-2431. ISSN: 0021-9258. DOI: $10.1074 / \mathrm{jbc} . \mathrm{M} 007862200$.

Mazzoni, I. E. u. a. (2005). ,Lymphoid signal transduction mechanisms linked to cellular prion protein". In: Biochemistry and cell biology = Biochimie et biologie cellulaire 83.5, S. 644-653. ISSN: 0829-8211. DOI: 10.1139/005-058.

MBL International (2015). 14-3-3 Gamma ELISA Kit: User's Manual. Hrsg. von MBL International. URL: http://www.cyclex.co.jp/product/pdf/cy-8082.pdf (besucht am 27.08.2015).

McGowan, J. P. (1922). „Scrapie in sheep.“ In: Scottish J Agric 5, S. 365-375.

McGuire, Lynne I. u. a. (2012). „Real time quaking-induced conversion analysis of cerebrospinal fluid in sporadic Creutzfeldt-Jakob disease". In: Annals of neurology 72.2, S. 278-285. ISSN: 0364-5134. DOI: 10.1002/ana. 23589.

McKinley, M. P. u. a. (1983). „A protease-resistant protein is a structural component of the scrapie prion“. In: Cell 35.1, S. 57-62. ISSN: 0092-8674.

Medori, Rossella u. a. (1992). „Fatal Familial Insomnia, a Prion Disease with a Mutation at Codon 178 of the Prion Protein Gene". In: New England Journal of Medicine 326.7, S. 444-449. ISSN: 0028-4793. DOI: 10.1056/NEJM199202133260704.

Merz, P. A. u.a. (1981). „Abnormal fibrils from scrapie-infected brain“. In: Acta neuropathologica 54.1, S. 63-74. ISSN: 1432-0533.

Meyer, R. K. u.a. (1986). „Separation and properties of cellular and scrapie prion proteins". In: Proceedings of the National Academy of Sciences of the United States of America 83.8, S. 2310-2314. ISSN: 1091-6490.

Mitrová, Eva u. a. (2002). „Creutzfeldt-Jakob disease with E200K mutation in Slovakia: characterization and development". In: Acta virologica 46.1, S. 31-39. ISSN: 0001$723 \mathrm{X}$.

Mitteregger, Gerda u. a. (2007). „The role of the octarepeat region in neuroprotective function of the cellular prion protein". In: Brain pathology (Zurich, Switzerland) 17.2, S. 174-183. ISSN: 1015-6305. DOI: 10.1111/j.1750-3639.2007.00061.x.

Moda, Fabio u.a. (2014). „Prions in the urine of patients with variant CreutzfeldtJakob disease". In: The New England journal of medicine 371.6, S. 530-539. ISSN: 0028-4793. DOI: $10.1056 /$ NEJMoa1404401. 
Morel, Etienne u.a. (2004). „The cellular prion protein $\mathrm{PrPc}$ is expressed in human enterocytes in cell-cell junctional domains". In: The Journal of biological chemistry 279.2, S. 1499-1505. ISSN: 0021-9258. DOI: $10.1074 /$ jbc.M308578200.

Naiki, H. u. a. (1989). „Fluorometric determination of amyloid fibrils in vitro using the fluorescent dye, thioflavin T1“. In: Analytical biochemistry 177.2, S. 244-249. ISSN: 0003-2697.

Norstrom, Eric M. u. a. (2005). „The AGAAAAGA palindrome in PrP is required to generate a productive PrPSc-PrPC complex that leads to prion propagation". In: The Journal of biological chemistry 280.29, S. 27236-27243. ISSN: 0021-9258. DOI: $10.1074 / \mathrm{jbc} . \mathrm{M} 413441200$.

Oesch, B. u. a. (1985). „A cellular gene encodes scrapie PrP 27-30 protein“. In: Cell 40.4, S. 735-746. ISSN: 0092-8674.

Orrú, Christina D., Bongianni, Matilde u.a. (2014). „A test for Creutzfeldt-Jakob disease using nasal brushings". In: The New England journal of medicine 371.6, S. 519-529. ISSN: 0028-4793. DOI: 10.1056/NEJMoa1315200.

Orrú, Christina D. und Caughey, Byron (2011). „Prion seeded conversion and amplification assays". In: Topics in current chemistry 305, S. 121-133. ISSN: 0340-1022. DOI: $10.1007 / 128 \backslash \_2011 \backslash \_184$.

Orrú, Christina D., Wilham, Jason M., Hughson, Andrew G. u.a. (2009). „Human variant Creutzfeldt-Jakob disease and sheep scrapie $\operatorname{PrP}($ res $)$ detection using seeded conversion of recombinant prion protein". In: Protein engineering, design 85 selection : PEDS 22.8, S. 515-521. ISSN: 1741-0134. DOI: 10.1093/protein/gzp031.

Orrú, Christina D., Wilham, Jason M., Raymond, Lynne D. u. a. (2011). „Prion disease blood test using immunoprecipitation and improved quaking-induced conversion“. In: mBio 2.3, e00078-11. ISSN: 2150-7511. DOI: 10.1128/mBio.00078-11.

Orrú, Christina D., Wilham, Jason M., Vascellari, Sarah u. a. (2012). „New generation QuIC assays for prion seeding activity“. In: Prion 6.2, S. 147-152. ISSN: 1933-6896. DOI: $10.4161 /$ pri. 19430.

Otto, M. u. a. (2002). „Tau protein and 14-3-3 protein in the differential diagnosis of Creutzfeldt-Jakob disease“. In: Neurology 58.2, S. 192-197. ISSN: 0028-3878.

Owen, F. u.a. (1990). „An in-frame insertion in the prion protein gene in familial Creutzfeldt-Jakob disease“. In: Brain research. Molecular brain research 7.3, S. 273276. ISSN: 0169-328X.

Palmer, M. S. u. a. (1991). „Homozygous prion protein genotype predisposes to sporadic Creutzfeldt-Jakob disease“. In: Nature 352.6333, S. 340-342. ISSN: 0028-0836. DOI: $10.1038 / 352340 \mathrm{a} 0$.

Pan, K. M. u. a. (1993). „Conversion of alpha-helices into beta-sheets features in the formation of the scrapie prion proteins". In: Proceedings of the National Academy of Sciences of the United States of America 90.23, S. 10962-10966. ISSN: 1091-6490.

Parchi, Piero, Boni, Laura de u. a. (2012). „Consensus classification of human prion disease histotypes allows reliable identification of molecular subtypes: an inter-rater study among surveillance centres in Europe and USA“. In: Acta neuropathologica 124.4, S. 517-529. ISSN: 1432-0533. DOI: $10.1007 / \mathrm{s} 00401-012-1002-8$. 
Parchi, Piero, Capellari, Sabina u.a. (1997). „Typing prion isoforms“. In: Nature 386.6622, S. 232-234. ISSN: 0028-0836. DOI: 10.1038/386232a0.

Parchi, Piero, Castellani, Rudolph u. a. (1996). „Molecular basis of phenotypic variability in sporadic Creutzfeldt-Jakob disease“. In: Annals of neurology 39.6, S. 767-778. ISSN: 0364-5134. DOI: 10.1002/ana.410390613.

Parchi, Piero, Giese, Armin u. a. (1999). „Classification of sporadic Creutzfeldt-Jakob disease based on molecular and phenotypic analysis of 300 subjects". In: Annals of neurology 46.2, S. 224-233. ISSN: 0364-5134.

Parchi, Piero, Strammiello, Rosaria u.a. (2011). „Phenotypic variability of sporadic human prion disease and its molecular basis: past, present, and future". In: Acta neuropathologica 121.1, S. 91-112. ISSN: 1432-0533. DOI: 10.1007 / s00401-0100779-6.

Parchi, Piero, Zou, Wen-Quan u. a. (2000). „Genetic influence on the structural variations of the abnormal prion protein". In: Proceedings of the National Academy of Sciences of the United States of America 97.18, S. 10168-10172. ISSN: 1091-6490.

Pattison, I. H. u. a. (1961). „Scrapie Produced Experimentally in Goats With Special Reference To the Clinical Syndrome". In: Journal of Comparative Pathology and Therapeutics 71, 101-IN10. ISSN: 03681742. DOI: 10.1016/S0368-1742(61)800131.

Peden, Alexander H. u. a. (2012). „,Sensitive and specific detection of sporadic CreutzfeldtJakob disease brain prion protein using real-time quaking-induced conversion". In: The Journal of general virology 93.Pt 2, S. 438-449. ISSN: 0022-1317. DOI: 10.1099/ vir.0.033365-0.

Peters, Peter J. u. a. (2003). ,Trafficking of prion proteins through a caveolae-mediated endosomal pathway“. In: The Journal of cell biology 162.4, S. 703-717. ISSN: 00219525. DOI: $10.1083 / \mathrm{jcb} .200304140$.

Pham, Nancy u. a. (2008). „Normal cellular prion protein with a methionine at position 129 has a more exposed helix 1 and is more prone to aggregate". In: Biochemical and biophysical research communications 368.4, S. 875-881. ISSN: 0006-291X. DOI: 10.1016/j.bbrc.2008.01.172.

Pocchiari, Maurizio, Puopolo, Maria u. a. (2004). „Predictors of survival in sporadic Creutzfeldt-Jakob disease and other human transmissible spongiform encephalopathies“. In: Brain : a journal of neurology 127.Pt 10, S. 2348-2359. ISSN: 1460-2156. DOI: $10.1093 /$ brain/awh249.

Pocchiari, Maurizio, Salvatore, M. u. a. (1993). „A new point mutation of the prion protein gene in Creutzfeldt-Jakob disease“. In: Annals of neurology 34.6, S. 802-807. ISSN: 0364-5134. DOI: 10.1002/ana.410340608.

Prusiner, Stanley B. (1982). "Novel proteinaceous infectious particles cause scrapie“. In: Science 216.4542, S. 136-144. ISSN: 0036-8075. DOI: 10.1126/science.6801762.

- (1989). „Scrapie prions“. In: Annual review of microbiology 43, S. 345-374. ISSN: 0066-4227. DOI: 10.1146/annurev.mi.43.100189.002021.

- (1993). „Genetic and infectious prion diseases“. In: Archives of neurology 50.11, S. 1129-1153. ISSN: 0003-9942. 
Prusiner, Stanley B. (2001). „Die Geschichte der Erforschung von Prionen“. In: Prionen und Prionkrankheiten. Hrsg. von Beat Hörnlimann u. a. Berlin und New York: De Gruyter, S. 36-49. ISBN: 3-11-016361-6.

Prusiner, Stanley B., Bolton, D. C. u. a. (1982). „Further purification and characterization of scrapie prions“. In: Biochemistry 21.26, S. 6942-6950. ISSN: 0006-2960.

Prusiner, Stanley B. und DeArmond, Stephen J. (1994). „Prion diseases and neurodegeneration". In: Annual review of neuroscience 17, S. 311-339. ISSN: 0147-006X. DOI: 10.1146/annurev.ne.17.030194.001523.

Prusiner, Stanley B., McKinley, M. P. u. a. (1983). „Scrapie prions aggregate to form amyloid-like birefringent rods". In: Cell 35.2 Pt 1, S. 349-358. ISSN: 0092-8674.

Puckett, C. u.a. (1991). „Genomic structure of the human prion protein gene“. In: American journal of human genetics 49.2, S. 320-329. ISSN: 0002-9297.

Ramljak, Sanja u.a. (2008). „Physiological role of the cellular prion protein (PrPc): protein profiling study in two cell culture systems“. In: Journal of proteome research 7.7, S. 2681-2695. ISSN: 1535-3893. DOI: 10.1021/pr7007187.

Ricketts, M. N. u. a. (1997). „Is Creutzfeldt-Jakob disease transmitted in blood?“ In: Emerging infectious diseases 3.2, S. 155-163. ISSN: 1080-6059. DOI: 10 . 3201 / eid0302.970208.

Riek, Roland u. a. (1996). „NMR structure of the mouse prion protein domain $\operatorname{PrP}(121$ 231)“. In: Nature 382.6587, S. 180-182. ISSN: 0028-0836. DOI: 10.1038/382180a0.

Riesner, Detlev (2003). „Biochemistry and structure of $\operatorname{PrP}(\mathrm{C})$ and $\operatorname{PrP}(\mathrm{Sc})$ “. In: British medical bulletin 66, S. 21-33. ISSN: 0007-1420.

Rossetti, Giulia u.a. (2010). „Structural facets of disease-linked human prion protein mutants: a molecular dynamic study“. In: Proteins 78.16, S. 3270-3280. ISSN: 10970134. DOI: $10.1002 /$ prot. 22834.

Rossi, Giacomina u. a. (2003). „Therapeutic approaches to prion diseases“. In: Clinics in laboratory medicine 23.1, S. 187-208. ISSN: 0272-2712.

Saá, Paula u. a. (2006). „Ultra-efficient replication of infectious prions by automated protein misfolding cyclic amplification". In: The Journal of biological chemistry 281.46, S. 35245-35252. ISSN: 0021-9258. DOI: 10.1074/jbc. M603964200.

Saborio, Gabriela P. u. a. (2001). „Sensitive detection of pathological prion protein by cyclic amplification of protein misfolding“. In: Nature 411.6839, S. 810-813. ISSN: 0028-0836. DOI: $10.1038 / 35081095$.

Safar, J., G. u.a. (1998). „Eight prion strains have $\operatorname{PrP}(\mathrm{Sc})$ molecules with different conformations". In: Nature medicine 4.10, S. 1157-1165. ISSN: 1546-170X. DOI: $10.1038 / 2654$.

Sakaguchi, S. u. a. (1996). „Loss of cerebellar Purkinje cells in aged mice homozygous for a disrupted PrP gene“. In: Nature 380.6574, S. 528-531. ISSN: 0028-0836. DOI: $10.1038 / 380528 \mathrm{a} 0$.

Salvatore, M. u. a. (1994). „Polymorphisms of the prion protein gene in Italian patients with Creutzfeldt-Jakob disease“. In: Human genetics 94.4, S. 375-379. ISSN: 03406717. 
Sande, M. A. u. a. (1991). „Antimicrobial agents: tetracyclines, chloramphenicol, erythromycin, and miscellaneous antibacterial agents." In: Goodman and Gilman's The Pharmacological Basis of Therapeutics. Hrsg. von A. G. Gilman u. a. Goodman and Gilman's The Pharmacological Basis of Therapeutics. Pergamon Press, S. 11171145. ISBN: 9780029465684.

Sano, Kazunori u.a. (2013). "Early detection of abnormal prion protein in genetic human prion diseases now possible using real-time QUIC assay“. In: PloS one 8.1, e54915. ISSN: 1932-6203. DOI: 10.1371/journal.pone.0054915.

Schätzl, H. M. u. a. (1995). „Prion protein gene variation among primates“. In: Journal of molecular biology 245.4, S. 362-374. ISSN: 0022-2836.

Schmitz, Matthias, Ebert, Elisabeth u. a. (2015). „Validation of 14-3-3 Protein as a Marker in Sporadic Creutzfeldt-Jakob Disease Diagnostic“. In: Molecular neurobiology. ISSN: 1559-1182. DOI: 10.1007/s12035-015-9167-5.

Schmitz, Matthias, Greis, Catharina u. a. (2014). „Loss of prion protein leads to agedependent behavioral abnormalities and changes in cytoskeletal protein expression". In: Molecular neurobiology 50.3, S. 923-936. ISSN: 1559-1182. DOI: 10.1007/s12035014-8655-3.

Schmitz, Matthias, Lüllmann, Katharina u.a. (2014). „Association of prion protein genotype and scrapie prion protein type with cellular prion protein charge isoform profiles in cerebrospinal fluid of humans with sporadic or familial prion diseases". In: Neurobiology of aging 35.5, S. 1177-1188. ISSN: 1558-1497. DOI: $10.1016 / \mathrm{j}$. neurobiolaging.2013.11.010.

Schmitz, Matthias, Zafar, Saima u. a. (2015). „Behavioral abnormalities in prion protein knockout mice and the potential relevance of PrP C for the cytoskeleton". In: Prion 8.6, S. 381-386. ISSN: 1933-6896. DOI: 10.4161/19336896.2014.983746.

Schoonenboom, Niki S M u. a. (2005). „Effects of processing and storage conditions on amyloid beta (1-42) and tau concentrations in cerebrospinal fluid: implications for use in clinical practice“. In: Clinical chemistry 51.1, S. 189-195. ISSN: 0009-9147. DOI: $10.1373 /$ clinchem. 2004.039735.

Schulz-Schaeffer, Walter J. u. a. (1996). „Polymorphism at codon 129 of the prion protein gene determines cerebellar pathology in Creutzfeldt-Jakob disease". In: Clinical neuropathology 15.6, S. 353-357. ISSN: 0722-5091.

Shyng, S. L. u. a. (1993). „A prion protein cycles between the cell surface and an endocytic compartment in cultured neuroblastoma cells". In: The Journal of biological chemistry 268.21, S. 15922-15928. ISSN: 0021-9258.

Siemens Healthcare Diagnostics (2011). Hemastix-Teststreifen. Hrsg. von Siemens Healthcare Diagnostics.

Sigurdsson, B. (1954). „Rida, a chronic encephalitis of sheep. With general remarks on infectious which develop slowly and some of their special characteristics". In: British Veterinary Journal 110, S. 341-354.

Silva, R. de u. a. (1994). „Neuropathological phenotype and 'prion protein' genotype correlation in sporadic Creutzfeldt-Jakob disease". In: Neuroscience letters 179.1-2, S. 50-52. ISSN: 0304-3940. 
Simon, D. u. a. (1998). „Krankenversorgung und Instrumentensterilisation bei CJKPatienten und CJK-Verdachtsfällen". In: Bundesgesundheitsblatt 41.7, S. 279-285. ISSN: 0007-5914. DOI: 10.1007/BF03042975.

Soto, Claudio u. a. (2002). „Cyclic amplification of protein misfolding: application to prion-related disorders and beyond“. In: Trends in neurosciences 25.8, S. 390-394. ISSN: 0166-2236.

Stahl, N., Baldwin, M. A. u. a. (1993). „Structural studies of the scrapie prion protein using mass spectrometry and amino acid sequencing". In: Biochemistry 32.8, S. 19912002. ISSN: 0006-2960.

Stahl, N., Borchelt, David R. u. a. (1987). „Scrapie prion protein contains a phosphatidylinositol glycolipid“. In: Cell 51.2, S. 229-240. ISSN: 0092-8674.

Stewart, Lesley A. u.a. (2008). „Systematic review of therapeutic interventions in human prion disease“. In: Neurology 70.15, S. 1272-1281. ISSN: 0028-3878. DOI: 10.1212/01.wn1.0000308955.25760.c2.

Stöckel, J. u. a. (1998). „Prion protein selectively binds copper(II) ions“. In: Biochemistry 37.20, S. 7185-7193. ISSN: 0006-2960. DOI: 10.1021/bi972827k.

Sturzenegger, Matthias (2001). „Die Klinik der Prionkrankheiten des Menschen“. In: Prionen und Prionkrankheiten. Hrsg. von Beat Hörnlimann u. a. Berlin und New York: De Gruyter, S. 247-260. ISBN: 3-11-016361-6.

Surewicz, Witold K. u.a. (2011). „Prion protein and its conformational conversion: a structural perspective“. In: Topics in current chemistry 305, S. 135-167. ISSN: 0340-1022. DOI: $10.1007 / 128 \backslash \_2011 \backslash \_165$.

Tagliavini, Fabrizio u. a. (2000). ,Tetracycline affects abnormal properties of synthetic PrP peptides and $\operatorname{PrP}(\mathrm{Sc})$ in vitro". In: Journal of molecular biology 300.5, S. 13091322. ISSN: 0022-2836. DOI: $10.1006 /$ jmbi.2000.3840.

Taraboulos, A. u. a. (1992). „Regional mapping of prion proteins in brain“. In: Proceedings of the National Academy of Sciences of the United States of America 89.16, S. 7620-7624. ISSN: 1091-6490.

Tateishi, J. u. a. (1995). „First experimental transmission of fatal familial insomnia“. In: Nature 376.6539, S. 434-435. ISSN: 0028-0836. DOI: 10.1038/376434a0.

Thadani, V. u. a. (1988). „Creutzfeldt-Jakob disease probably acquired from a cadaveric dura mater graft. Case report". In: Journal of neurosurgery 69.5, S. 766-769. ISSN: 0022-3085. DOI: $10.3171 /$ jns.1988.69.5.0766.

Trevitt, Clare R. u.a. (2006). „A systematic review of prion therapeutics in experimental models“. In: Brain : a journal of neurology 129.Pt 9, S. 2241-2265. ISSN: 1460-2156. DOI: $10.1093 /$ brain/aw1150.

Uro-Coste, Emmanuelle u. a. (2008). „Beyond PrP res type 1/type 2 dichotomy in Creutzfeldt-Jakob disease“. In: PLoS pathogens 4.3, e1000029. ISSN: 1553-7374.

van Gool, W A u.a. (1995). „Hypokinesia and presenile dementia in a Dutch family with a novel insertion in the prion protein gene“. In: Brain : a journal of neurology 118 ( Pt 6), S. 1565-1571. ISSN: 1460-2156.

Vanderstichele, Hugo u. a. (2000). „Standardization of measurement of beta-amyloid(142) in cerebrospinal fluid and plasma“. In: Amyloid : the international journal of ex- 
perimental and clinical investigation : the official journal of the International Society of Amyloidosis 7.4, S. 245-258. ISSN: 1350-6129.

Varges, Daniela u. a. (2015). „Doxycycline in early CJD - double-blinded randomized phase II and observational study“.

Vey, Martin u.a. (1996). „Subcellular colocalization of the cellular and scrapie prion proteins in caveolae-like membranous domains". In: Proceedings of the National Academy of Sciences of the United States of America 93.25, S. 14945-14949. ISSN: 1091-6490.

Viles, J. H. u. a. (1999). „Copper binding to the prion protein: structural implications of four identical cooperative binding sites". In: Proceedings of the National Academy of Sciences of the United States of America 96.5, S. 2042-2047. ISSN: 1091-6490.

Walmsley, Adrian R. u. a. (2009). ,alpha-cleavage of the prion protein occurs in a late compartment of the secretory pathway and is independent of lipid rafts". In: Molecular and cellular neurosciences 40.2, S. 242-248. ISSN: 1095-9327. DOI: 10 . $1016 / \mathrm{j} \cdot \mathrm{mcn}$. 2008 . 10.012.

Wang, Fei u. a. (2013). „Role of lipid in forming an infectious prion?“ In: Acta biochimica et biophysica Sinica 45.6, S. 485-493. ISSN: 1745-7270. DOI: 10.1093/abbs / gmt038.

Weemen, B K van u. a. (1971). „Immunoassay using antigen-enzyme conjugates“. In: FEBS letters 15.3, S. 232-236. ISSN: 1873-3468.

Weiß, Christel (2013). Basiswissen Medizinische Statistik. Berlin und Heidelberg: Springer Berlin Heidelberg. ISBN: 978-3-642-34260-8. DOI: 10 . 1007/978-3-64234261-5.

Wells, G. A. u. a. (1987). "A novel progressive spongiform encephalopathy in cattle“. In: The Veterinary record 121.18, S. 419-420. ISSN: 0042-4900.

Wilham, Jason M. u. a. (2010). „Rapid end-point quantitation of prion seeding activity with sensitivity comparable to bioassays". In: PLoS pathogens 6.12, e1001217. ISSN: 1553-7374. DOI: $10.1371 /$ journal .ppat.1001217.

Will, Robert G (2001). „Portrait der neuen Variante der Creutzfeldt-Jakob-Krankheit (nvCJD)“. In: Prionen und Prionkrankheiten. Hrsg. von Beat Hörnlimann u. a. Berlin und New York: De Gruyter, S. 152-156. ISBN: 3-11-016361-6.

Williams, E. S. u. a. (1980). „Chronic wasting disease of captive mule deer: a spongiform encephalopathy“. In: $J$ Wildl Dis 16(1), S. 89-98.

Windl, Otto u. a. (1999). "Molecular genetics of human prion diseases in Germany“. In: Human genetics 105.3, S. 244-252. ISSN: 0340-6717.

World Health Organization (1998). Global Surveillance, Diagnosis and Therapy of Human Transmissible Spongiform Encephalopathies: Report of a WHO Consultation. Hrsg. von World Health Organization. Geneva und Switzerland. URL: http://www . who. int/csr/resources/publications/bse/whoemczdi989.pdf?ua=1 (besucht am 10.04.2015).

Zahn, R. u. a. (2000). „NMR solution structure of the human prion protein“. In: Proceedings of the National Academy of Sciences of the United States of America 97.1, S. 145-150. ISSN: 1091-6490. 
Zerr, Inga (2009). „Therapeutic trials in human transmissible spongiform encephalopathies: recent advances and problems to address". In: Infectious disorders drug targets 9.1, S. 92-99. ISSN: 2212-3989.

- (2012). Biomarker based diagnosis of rapid progressive dementias - optimisation of diagnostic protocols: Antragsnummer 24/8/12. Hrsg. von Klinik für Neurologie. Göttingen.

- (2015-12-11). Falsch-positive Liquorproben in der RT-QuIC: Stand der Diagnosestellung der beiden Patienten. Mündlich. Unter Mitarb. von Maria Cramm.

Zerr, Inga, Bodemer, Monika u. a. (1998). „Detection of 14-3-3 protein in the cerebrospinal fluid supports the diagnosis of Creutzfeldt-Jakob disease“. In: Annals of neurology 43.1, S. 32-40. ISSN: 0364-5134. DOI: 10.1002/ana.410430109.

Zerr, Inga, Kallenberg, Kai u. a. (2009). „Updated clinical diagnostic criteria for sporadic Creutzfeldt-Jakob disease“. In: Brain : a journal of neurology 132.Pt 10, S. 2659 2668. ISSN: 1460-2156. DOI: 10.1093/brain/awp191.

Zerr, Inga, Pocchiari, Maurizio u. a. (2000). „Analysis of EEG and CSF 14-3-3 proteins as aids to the diagnosis of Creutzfeldt-Jakob disease“. In: Neurology 55.6, S. 811-815. ISSN: 0028-3878.

Zigas, V. u. a. (1957). „Kuru: clinical study of a new syndrome resembling paralysis agitans in natives of the Eastern Highlands of Australian New Guinea“. In: The Medical journal of Australia 44.21, S. 745-754. ISSN: 0025-729X.

Zomosa-Signoret, Viviana u. a. (2008). „Physiological role of the cellular prion protein“. In: Veterinary research 39.4, S. 9. ISSN: 0928-4249. DOI: 10.1051/vetres: 2007048.

Zou, Wen-Quan u. a. (2003). „Identification of novel proteinase K-resistant C-terminal fragments of PrP in Creutzfeldt-Jakob disease". In: The Journal of biological chemistry 278.42, S. 40429-40436. ISSN: 0021-9258. DOI: 10.1074/ jbc.M308550200. 


\section{A. Material}

\section{A.1. Geräte}

Tabelle 29 führt die in dieser Arbeit verwendeten Geräte und deren Hersteller auf.

Tabelle 29: Geräte

\begin{tabular}{lll}
\hline Gerät & Bezeichnung & Hersteller \\
\hline Blutanalysegerät & AcT 5 diff & Beckman Coulter \\
Computer & Core i3 n-series & Dell \\
Eismaschine & Brucheismaschine ZBE 30-10 & Ziegra \\
ELISA-Platten-Lesegerät & Wallac 1420 Victor & PerkinElmer \\
Gefrierschrank $-20{ }^{\circ} \mathrm{C}$ & Economy & Liebherr \\
Gefrierschrank $-80{ }^{\circ} \mathrm{C}$ & MDF 46086-S & Sanyo \\
Homogenisator & Polytron PT1300D & Fisher Scientific \\
Kühlschrank $+4{ }^{\circ} \mathrm{C}$ & HR-4110 & Medilab \\
Mikrotiterplatten-Lesegerät & FLUOstar ${ }^{\circledR}$ Optima & BMG LABTECH \\
pH-Meter & Professional Meter PP-15 & Sartorius \\
Pipette $0,5-10 \mu l$ & Research plus 0,5-10 & Eppendorf \\
Pipette $2-20 \mu l$ & Research plus 2-20 & Eppendorf \\
Pipette $10-100 \mu l$ & Research plus 10-100 & Eppendorf \\
Pipette $20-200 \mu l$ & Research plus 20-200 & Eppendorf \\
Pipette $100-1.000 \mu l$ & Research plus 100-1000 & Eppendorf \\
Thermomixer & Thermomixer comfort & Eppendorf \\
Ultraschallgerät & Transsonic 310/H & Elma \\
Vortexer & Vortex Genie 2 & Scientific Industries \\
Waage Ablesbarkeit $0,01 \mathrm{~g}$ & CP 3202 P & Sartorius \\
Waage Ablesbarkeit $0,001 \mathrm{~g}$ & TE313S-DS & Sartorius \\
Zentrifuge & 5415 C & Eppendorf \\
\hline
\end{tabular}

\section{A.2. Verbrauchsmaterial}

Tabelle 30 führt das in dieser Arbeit verwendete Verbrauchsmaterial mit Hersteller auf.

Tabelle 30: Verbrauchsmaterial

\begin{tabular}{lll}
\hline Verbrauchsmaterial & Bezeichnung & Hersteller \\
\hline Blutabnahmeröhre & S-Monovette 2,7 ml & Sarstedt \\
Filter $0,22 \mu \mathrm{M}$ & Millex-GP 0,22 $\mathrm{\mu M}$ Syringe Filter & Millipore \\
Filter $100 \mathrm{kDa}$ & Nanosep 100k OMEGA Filter & Pall \\
Klebefolie & Sealing tape & Nunc \\
\hline \multicolumn{2}{l}{ Fortsetzung auf der nächsten Seite. } \\
\hline
\end{tabular}


Tabelle 30: Verbrauchsmaterial (Fortsetzung)

\begin{tabular}{|c|c|c|}
\hline Verbrauchsmaterial & Bezeichnung & Hersteller \\
\hline Mikrotiterplatte & 96 Well Optical Bottom Plate & Fisher-Scientific \\
\hline Pipettenspitze $0,1-10 \mu l$ & Filter Tip $10 \mu l$ neutral & Sarstedt \\
\hline Pipettenspitze $2-200 \mu l$ & Pipettenspitze $200 \mu \mathrm{l}$ gelb & Sarstedt \\
\hline Pipettenspitze $50-1000 \mu \mathrm{l}$ & Pipettenspitze 1000 pl blau & Sarstedt \\
\hline Rasierklinge & CK07.1 & Carl Roth \\
\hline Reagiergefäß $0,5 \mathrm{ml}$ & Safe Lock Tube $0,5 \mathrm{ml}$ & Eppendorf \\
\hline Reagiergefäß $1,5 \mathrm{ml}$ & Safe Lock Tube 1,5 ml & Eppendorf \\
\hline Reagiergefäß $2,0 \mathrm{ml}$ & Reagiergefäß $2,0 \mathrm{ml}$ & Sarstedt \\
\hline Spritze & $5 \mathrm{ml}$ Spritze & Ecoject \\
\hline Zentrifugenröhre $15 \mathrm{ml}$ & Falcon 15 ml Conical Centrifuge Tubes & BD Falcon \\
\hline Zentrifugenröhre $50 \mathrm{ml}$ & Röhre $50 \mathrm{ml}, 114 \times 28 \mathrm{~mm}, \mathrm{PP}$ & Sarstedt \\
\hline
\end{tabular}

\section{A.3. Anorganische und organische Stoffe}

Tabelle 31 führt die in dieser Arbeit verwendeten anorganischen und organischen Stoffe mit CAS-Nr., Reinheitsgrad und Hersteller auf.

Tabelle 31: Anorganische und organische Stoffe

\begin{tabular}{llll}
\hline Stoff & CAS-Nr. & Reinheitsgrad & Hersteller \\
\hline Ampicillin & $69-53-4$ & $\geq 95,0 \%$ & Fluka \\
Dinatriumhydrogenphosphat & $7558-79-4$ & $\geq 99,0 \%$ & Sigma-Aldrich \\
Doxyzyklin & $24390-14-5$ & $\geq 98,0 \%$ & Sigma \\
Ethidiumbromid & $1239-45-8$ & $\geq 95,0 \%$ & Fluka \\
Ethylendiamintetraessigsäure & $60-00-4$ & $\geq 98,5 \%$ & Sigma-Aldrich \\
Natriumchlorid & $7647-14-5$ & $\geq 99,5 \%$ & Roth \\
Natriumdihydrogenphosphat & $7558-80-7$ & $\geq 99,0 \%$ & Sigma-Aldrich \\
Natriumdodecylsulfat & $151-21-3$ & $\geq 98,5 \%$ & Sigma \\
Sucrose & $57-50-1$ & $\geq 99,5 \%$ & Sigma \\
Thioflavin-T & $2390-54-7$ & $\approx 75,0 \%$ & Sigma \\
Tris/HCl & $1185-53-1$ & $\geq 99,0 \%$ & Aldrich \\
\hline
\end{tabular}

\section{A.4. Lösungen und Puffer}

Tabelle 32 führt die in dieser Arbeit verwendeten gebrauchsfertigen Lösungen und deren Hersteller auf. 
Tabelle 32: Gebrauchsfertige Lösungen und Puffer

\begin{tabular}{ll}
\hline Lösung & Hersteller \\
\hline EDTA $(0,5 \mathrm{M})$ & Fluka Analytical \\
Natriumchlorid $(5 \mathrm{M})$ & SAFC Biosciences \\
Natriumhydroxid $(50 \%(\mathrm{v} / \mathrm{v}))$ & Roth \\
Phosphatgepufferte Salzlösung $(1 \times)$ & Biochrome \\
\hline
\end{tabular}

Tabelle 33 führt die Stoffkonzentrationen der RT-QuIC-Mixe, zu denen entweder Doxyzyklin, Ampicilin oder Sucrose hinzu gefügt wurden, auf.

Tabelle 33: Stoffkonzentrationen in den RT-QuIC-Mixen mit zusätzlichen Wirkstoffen

\begin{tabular}{lrrrrrr}
\hline \multirow{2}{*}{ Stoff } & \multicolumn{5}{c}{ Konzentration } & \multirow{2}{*}{ Einheit } \\
\cline { 2 - 6 } & Mix A & Mix B & Mix C & Mix D & Mix E & \\
\hline $\mathrm{NaCl}$ & 170 & 170 & 170 & 170 & 170 & $\mathrm{mM}$ \\
$5 \times \mathrm{PBS}(\mathrm{pH} 6,9)$ & 1 & 1 & 1 & 1 & 1 & $\times$ \\
EDTA & 1 & 1 & 1 & 1 & 1 & $\mathrm{mM}$ \\
Th-T & 10 & 10 & 10 & 10 & 10 & $\mu \mathrm{\mu M}$ \\
$\mathrm{recPrPC}$ & 0,1 & 0,1 & 0,1 & 0,1 & 0,1 & $\mathrm{mg} / \mathrm{ml}$ \\
Dox / Amp / Suc & 0,0 & 0,1 & 0,3 & 0,5 & 1,0 & $\mathrm{mM}$ \\
\hline
\end{tabular}

\section{A.5. Gebrauchsfertige Reaktionssysteme}

Tabelle 34 führt die in dieser Arbeit verwendeten gebrauchsfertigen Reaktionssysteme und deren Hersteller auf.

Tabelle 34: Gebrauchsfertige Reaktionssysteme

\begin{tabular}{ll}
\hline Reaktionssystem & Hersteller \\
\hline BetaPrion BSE-EISA Test Kit & AJ Roboscreen \\
Circulex 14-3-3- Gamma ELISA Kit & MBL International \\
INNOTEST hTAU Ag Kit & Innogenetics \\
Hemastix Teststreifen & Siemens Healthcare \\
\hline
\end{tabular}

\section{A.6. Programme}

Tabelle 35 führt die in dieser Arbeit verwendeten Programme mit Version, Entwickler und Einsatz auf. 
B. Tabellen

Tabelle 35: Programme

\begin{tabular}{llll}
\hline Programm & Version & Entwickler & Einsatz \\
\hline Citavi & 4.3 & Swiss Academic Software & Literaturverwaltung \\
Graphpad Prism & 6.05 & GraphPad Software & Statistik, Bildbearbeitung \\
LaTeX & 2.02 & Leslie Lamport & Textverarbeitung \\
Optima Data Analysis & $2.22 . R 3$ & BMG LABTECH & Datenexport \\
Microsoft Excel & 2010 & Microsoft Corporation & Datenanalyse \\
Optima Control & $2.20 . R 2$ & BMG LABTECH & Gerätesteuerung \\
\hline
\end{tabular}

\section{B. Tabellen}

Tabelle 36: Einfluss der Kurzzeitlagerung auf die Positivitätsraten - Daten

\begin{tabular}{|c|c|c|c|c|c|c|c|c|}
\hline \multirow{2}{*}{ Variable } & \multicolumn{4}{|c|}{ RT / Tage } & \multicolumn{4}{|c|}{$+\mathbf{4}^{\circ} \mathrm{C} /$ Tage } \\
\hline & 0 & 1 & 3 & 8 & 0 & 1 & 3 & 8 \\
\hline Minimum & 0,00 & 33,33 & 0,00 & 33,33 & 0,00 & 0,00 & 0,00 & 33,33 \\
\hline $\mathrm{Q}_{25}$ & 66,67 & 66,67 & 41,67 & 54,17 & 66,67 & 50,00 & 75,00 & 66,67 \\
\hline Median & 100,00 & 100,00 & 83,34 & 66,67 & 100,00 & 100,00 & 100,00 & 83,34 \\
\hline $\mathrm{Q}_{75}$ & 100,00 & 100,00 & 100,00 & 100,00 & 100,00 & 100,00 & 100,00 & 100,00 \\
\hline Maximum & 100,00 & 100,00 & 100,00 & 100,00 & 100,00 & 100,00 & 100,00 & 100,00 \\
\hline Mittelwert & 79,17 & 83,33 & 72,22 & 73,61 & 79,17 & 77,78 & 86,11 & 79,17 \\
\hline Standardabweichung & 31,08 & 26,59 & 34,33 & 26,07 & 31,08 & 41,03 & 30,01 & 23,70 \\
\hline Standardfehler & 8,97 & 7,68 & 9,91 & 7,53 & 8,97 & 11,84 & 8,66 & 6,84 \\
\hline Unteres $95 \%$ CI & 59,42 & 66,44 & 50,41 & 57,05 & 59,42 & 51,71 & 67,04 & 64,11 \\
\hline Oberes $95 \%$ CI & 98,91 & 100,20 & 94,03 & 90,18 & 98,91 & 103,80 & 105,20 & 94,23 \\
\hline
\end{tabular}

Tabelle 37: Einfluss von Verw. und Kurzzeitlag. auf die Positivitätsraten - Daten

\begin{tabular}{|c|c|c|c|c|c|c|c|c|}
\hline \multirow{2}{*}{ Variable } & \multicolumn{5}{|c|}{ Einfrier-/Auftauzyklen / Anzahl } & \multicolumn{3}{|c|}{$-\mathbf{8 0}{ }^{\circ} \mathrm{C} /$ Jahre } \\
\hline & 0 & 2 & 4 & 8 & 16 & $2-3$ & $5-6$ & $8-9$ \\
\hline Minimum & 0,00 & 0,00 & 0,00 & 0,00 & 0,00 & 33,33 & 33,33 & 0,00 \\
\hline $\mathrm{Q}_{25}$ & 33,33 & 41,67 & 66,67 & 33,33 & 33,33 & 33,33 & 66,67 & 75,00 \\
\hline Median & 100,00 & 100,00 & 83,34 & 83,34 & 66,67 & 100,00 & 100,00 & 100,00 \\
\hline $\mathrm{Q}_{75}$ & 100,00 & 100,00 & 100,00 & 100,00 & 100,00 & 100,00 & 100,00 & 100,00 \\
\hline Maximum & 100,00 & 100,00 & 100,00 & 100,00 & 100,00 & 100,00 & 100,00 & 100,00 \\
\hline Mittelwert & 69,44 & 72,22 & 77,78 & 66,67 & 60,61 & 75,00 & 83,33 & 83,33 \\
\hline Standardabweichung & 41,34 & 39,78 & 29,59 & 40,20 & 38,93 & 32,18 & 26,59 & 33,33 \\
\hline Standardfehler & 11.93 & 11.48 & 8,54 & 11.61 & 11.74 & 9,29 & 7.68 & 9.62 \\
\hline Unteres $95 \%$ CI & 43,18 & 46,95 & 58,98 & 41,12 & 34,46 & 54,55 & 66,44 & 62,15 \\
\hline Oberes $95 \%$ CI & 95,71 & 97,50 & 96,58 & 92,21 & 86,76 & 95,44 & 100,20 & 104,50 \\
\hline
\end{tabular}


Tabelle 38: Einfluss einer Blutkontamination auf die Positivitätsraten - Daten 1

\begin{tabular}{rrrrrrr}
\hline \multirow{2}{*}{ Variable } & \multicolumn{5}{c}{ Zellzahl $/$ Erythrozythen pro $\mathrm{\mu l}$} \\
& 0 & 78 & 313 & 1.250 & 5.000 & 10.000 \\
\hline Minimum & 0,00 & 33,30 & 66,60 & 0,00 & 0,00 & 0,00 \\
$\mathrm{Q}_{25}$ & 33,30 & 66,65 & 66,60 & 0,00 & 0,00 & 0,00 \\
Median & 100,00 & 100,00 & 100,00 & 33,30 & 0,00 & 0,00 \\
$\mathrm{Q}_{75}$ & 100,00 & 100,00 & 100,00 & 74,95 & 0,00 & 0,00 \\
Maximum & 100,00 & 100,00 & 100,00 & 100,00 & 0,00 & 0,00 \\
Mittelwert & 72,91 & 85,18 & 88,87 & 38,87 & 0,00 & 0,00 \\
Standardabweichung & 38,92 & 29,41 & 17,25 & 38,96 & 0,00 & 0,00 \\
Standardfehler & 9,73 & 9,80 & 7,041 & 15,91 & 0,00 & 0,00 \\
Unteres 95 \% CI & 52,17 & 62,57 & 70,77 & $-2,02$ & 0,00 & 0,00 \\
Oberes 95 \% CI & 93,64 & 107,80 & 107,0 & 79,75 & 0,00 & 0,00 \\
\hline
\end{tabular}

Tabelle 39: Einfluss einer Blutkontamination auf die Positivitätsraten - Daten 2

\begin{tabular}{rrrrrrr}
\hline \multirow{2}{*}{ Variable } & \multicolumn{7}{c}{ Hämolyse $/$ Tage } \\
& Ref & 0 & 1 & 2 & 3 & 8 \\
\hline Minimum & 0,00 & 0,00 & 0,00 & 0,00 & 0,00 & 0,00 \\
$Q_{25}$ & 16,65 & 16,65 & 8,33 & 8,33 & 0,00 & 0,00 \\
Median & 66,60 & 100,00 & 66,60 & 83,30 & 49,95 & 0,00 \\
$Q_{75}$ & 100,00 & 100,00 & 91,65 & 100,00 & 91,65 & 0,00 \\
Maximum & 100,00 & 100,00 & 100,00 & 100,00 & 100,00 & 33,30 \\
Mittelwert & 62,48 & 70,83 & 54,14 & 62,49 & 45,81 & 4,16 \\
Standardabweichung & 41,54 & 45,21 & 39,58 & 45,21 & 43,41 & 11,77 \\
Standardfehler & 14,69 & 15,98 & 14,00 & 15,98 & 15,35 & 4,16 \\
Unteres 95 \% CI & 27,74 & 33,03 & 21,04 & 24,69 & 9,52 & $-5,68$ \\
Oberes 95 \% CI & 97,21 & 108,6 & 87,23 & 100,3 & 82,10 & 14,01 \\
\hline
\end{tabular}


Tabelle 40: Einfluss von Lagerung und Verw. auf die Positivitätsraten - Stat.

\begin{tabular}{lc}
\hline Faktor & p-Wert \\
\hline Lagerung bei RT & $>0,05$ \\
Lagerung bei $+4{ }^{\circ} \mathrm{C}$ & $>0,05$ \\
Lagerung bei $-80{ }^{\circ} \mathrm{C}$ & $>0,05$ \\
Einfrier-/Auftau Zyklen & $>0,05$ \\
\hline
\end{tabular}

Tabelle 41: Einfluss einer Blutkontamination auf die Positivitätsraten - Stat.

\begin{tabular}{lc}
\hline Faktor & p-Wert \\
\hline Zellzahl & $\leq 0,0001$ \\
0 vs. 78 & $>0,05$ \\
0 vs. 313 & $>0,05$ \\
0 vs. 1.250 & $>0,05$ \\
0 vs. 5.000 & $\leq 0,01$ \\
0 vs. 10.000 & $\leq 0,01$ \\
Hämolyse & $\leq 0,001$ \\
Ref vs. 0 & $>0,05$ \\
Ref vs. 1 & $>0,05$ \\
Ref vs. 2 & $>0,05$ \\
Ref vs. 3 & $>0,05$ \\
Ref vs. 8 & $\leq 0,01$ \\
\hline
\end{tabular}

Tabelle 42: Einfluss der Kurzzeitlagerung auf die Fluoreszenzsignale - Daten 1

\begin{tabular}{|c|c|c|c|c|c|c|c|c|c|c|c|c|}
\hline \multirow{2}{*}{ Variable } & \multicolumn{3}{|c|}{ o Tage } & \multicolumn{3}{|c|}{1 Tag } & \multicolumn{3}{|c|}{3 Tage } & \multicolumn{3}{|c|}{8 Tage } \\
\hline & $\mathrm{t}_{10}{ }^{4}$ & Max rfu & $\mathrm{AUC}$ & $\mathrm{t}_{10^{4}}$ & Max rfu & $\mathrm{AUC}$ & $\mathrm{t}_{10^{4}}$ & Max rfu & $\mathrm{AUC}$ & $\mathrm{t}_{10^{4}}$ & Max rfu & $\mathrm{AUC}$ \\
\hline Minimum & 21,5 & 60467 & 9280 & 17,0 & 49265 & 9919 & 21,0 & 37644 & 7921 & 26,5 & 35121 & 13838 \\
\hline $\mathrm{Q}_{25}$ & 26,0 & 63010 & 16848 & 25,9 & 63822 & 19091 & 34,4 & 43073 & 16269 & 34,5 & 64432 & 21437 \\
\hline Median & 30,0 & 65000 & 23525 & 39,0 & 65000 & 26295 & 39,3 & 63739 & 23808 & 56,0 & 65000 & 25310 \\
\hline $\mathrm{Q}_{75}$ & 53,5 & 65000 & 30009 & 56,1 & 65000 & 32490 & 71,0 & 65000 & 33001 & 64,0 & 65000 & 32021 \\
\hline Maximum & 68,3 & 65000 & 33358 & 57,5 & 65000 & 37213 & 78,0 & 65000 & 38458 & 80,0 & 65000 & 37367 \\
\hline Mittelwert & 36,5 & 63985 & 22812 & 39,2 & 63210 & 25682 & 48,1 & 57027 & 22868 & 50,1 & 62370 & 26256 \\
\hline Standardfehler & 15,7 & 1527 & 7476 & 14,5 & 4563 & 7962 & 20,0 & 11148 & 10558 & 17,8 & 8587 & 7275 \\
\hline Standardabweichung & 4,7 & 460 & 2158 & 4,6 & 1317 & 2298 & 6,3 & 3361 & 3183 & 5,4 & 2479 & 2100 \\
\hline Unteres $95 \%$ CI & 26,0 & 62959 & 18062 & 28,8 & 60310 & 20623 & 33,7 & 49538 & 15775 & 38,2 & 56914 & 21634 \\
\hline Oberes $95 \% \mathrm{CI}$ & 47,0 & 65010 & 27562 & 49,6 & 66109 & 30740 & 62,4 & 64517 & 29961 & 62,1 & 67826 & 30878 \\
\hline
\end{tabular}


B. Tabellen

Tabelle 43: Einfluss der Kurzzeitlagerung auf die Fluoreszenzsignale - Daten 2

\begin{tabular}{|c|c|c|c|c|c|c|c|c|c|c|c|c|}
\hline \multirow{2}{*}{ Variable } & \multicolumn{3}{|c|}{ o Tage } & \multicolumn{3}{|c|}{1 Tag } & \multicolumn{3}{|c|}{3 Tage } & \multicolumn{3}{|c|}{8 Tage } \\
\hline & $\mathrm{t}_{10^{4}}$ & Max rfu & $\mathrm{AUC}$ & $\mathrm{t}_{10} 4$ & Max rfu & $\mathrm{AUC}$ & $\mathrm{t}_{10^{4}}$ & Max rfu & $\mathrm{AUC}$ & $\mathrm{t}_{10^{4}}$ & Max rfu & $\mathrm{AUC}$ \\
\hline Minimum & 37,3 & 25135 & 5192 & 24,5 & 10058 & 677 & 34,5 & 20526 & 1584 & 34,5 & 22187 & 2459 \\
\hline $\mathrm{Q}_{25}$ & 39,5 & 50250 & 12293 & 35,6 & 17654 & 1991 & 44,5 & 43467 & 6984 & 42,3 & 43843 & 3155 \\
\hline Median & 51,5 & 62182 & 15595 & 44,0 & 48202 & 7945 & 49,0 & 58375 & 15995 & 51,5 & 49994 & 9447 \\
\hline $\mathrm{Q}_{75}$ & 53,8 & 65000 & 25152 & 55,4 & 61366 & 19494 & 66,8 & 64105 & 21879 & 72,5 & 59013 & 18134 \\
\hline Maximum & 59,5 & 65000 & 27142 & 67,5 & 65000 & 29988 & 79,5 & 65000 & 23036 & 74,5 & 65000 & 26199 \\
\hline Mittelwert & 48,3 & 55401 & 16823 & 44,8 & 42998 & 11328 & 54,2 & 52939 & 13598 & 54,5 & 48922 & 11101 \\
\hline Standardfehler & 7,7 & 13473 & 7716 & 13,3 & 21342 & 9600 & 14,3 & 14617 & 7651 & 14,1 & 12595 & 7955 \\
\hline Standardabweichung & 2,3 & 4062 & 2228 & 4,4 & 6749 & 2771 & 4,3 & 4622 & 2307 & 4,5 & 3636 & 2296 \\
\hline Unteres $95 \% \mathrm{CI}$ & 43,1 & 46349 & 11920 & 34,6 & 27731 & 5228 & 44,6 & 42483 & 8458 & 44,4 & 40919 & 6047 \\
\hline Oberes $95 \%$ CI & 53,5 & 64452 & 21726 & 55,1 & 58265 & 17427 & 63,7 & 63395 & 18738 & 64,6 & 56924 & 16156 \\
\hline
\end{tabular}

Tabelle 44: Einfluss der Kurzzeitlagerung bei auf die Fluoreszenzsignale - Daten 3

\begin{tabular}{|c|c|c|c|c|c|c|c|c|c|}
\hline \multirow{2}{*}{ Variable } & \multicolumn{3}{|c|}{ 2-3 Jahre } & \multicolumn{3}{|c|}{5 - 6 Jahre } & \multicolumn{3}{|c|}{8 - 9 Jahre } \\
\hline & $\mathrm{t}_{10^{4}}$ & Max rfu & AUC & $\mathrm{t}_{10^{4}}$ & Max rfu & $\mathrm{AUC}$ & $t_{10^{4}}$ & Max rfu & $\mathrm{AUC}$ \\
\hline $\mathrm{um}$ & 17,5 & 37425 & 8003 & 19,5 & 46855 & 14034 & 21,5 & 41942 & 10533 \\
\hline $\mathrm{Q}_{25}$ & 20,6 & 61481 & 18798 & 22,6 & 59211 & 21499 & 27,6 & 51901 & 16437 \\
\hline Median & 27,0 & 65000 & 30382 & 30,3 & 65000 & 27469 & 29,8 & 64983 & 25755 \\
\hline $\mathrm{Q}_{75}$ & 35,8 & 65000 & 37024 & 47,0 & 65000 & 34693 & 35,3 & 65000 & 31183 \\
\hline & 49,5 & 0 & 38344 & 55,0 & 65000 & 37849 & 39,5 & 65000 & 36654 \\
\hline Mittelwert & 28,8 & 61640 & 26834 & 34,4 & 62059 & 27408 & 30,8 & 60102 & 24472 \\
\hline Standardfehler & 10,6 & 8044 & 11041 & 13,4 & 5478 & 7560 & 5,5 & 8066 & 8816 \\
\hline Standardabweichung & 3,7 & 2322 & 3187 & 4,2 & 1581 & 2182 & 1,7 & 2432 & 2658 \\
\hline Unteres $95 \%$ CI & 20,0 & 56529 & 19819 & 24,8 & 58579 & 22605 & 26,9 & 54683 & 18549 \\
\hline Oberes $95 \%$ CI & 37,6 & 66751 & 33850 & 43,9 & 65540 & 32212 & 34,7 & 65521 & 30394 \\
\hline
\end{tabular}

Tabelle 45: Einfluss von Einfrier-/Auftauzyklen auf die Fluoreszenzsignale - Daten 1

\begin{tabular}{|c|c|c|c|c|c|c|c|c|c|}
\hline \multirow{2}{*}{ Variable } & \multicolumn{3}{|c|}{$\mathbf{0} \times$} & \multicolumn{3}{|c|}{$2 \times$} & \multicolumn{3}{|c|}{$4 \times$} \\
\hline & $\mathrm{t}_{10^{4}}$ & Max rfu & AUC & $\mathrm{t}_{10^{4}}$ & Max rfu & $\mathrm{AUC}$ & $\mathrm{t}_{10^{4}}$ & Max rfu & $\mathrm{AUC}$ \\
\hline imum & 26,0 & 22422 & 1560 & 25,5 & 46567 & 7682 & 23,0 & 27508 & 2276 \\
\hline $\mathrm{Q}_{25}$ & 31,6 & 51764 & 8069 & 32,3 & 50663 & 9120 & 31,5 & 40688 & 5384 \\
\hline Median & 50,1 & 58804 & 14371 & 46,4 & 59855 & 15827 & 38,5 & 51267 & 11061 \\
\hline $\mathrm{Q}_{75}$ & 61,1 & 64868 & 19181 & 67,6 & 65000 & 25233 & 77,0 & 60125 & 26624 \\
\hline mum & 71,5 & 65000 & 35254 & 72,0 & 65000 & 33384 & 78,5 & 65000 & 35972 \\
\hline Mittelwert & 47,7 & 55290 & 15005 & 49,5 & 58029 & 17955 & 50,2 & 50040 & 15070 \\
\hline Standardfehler & 16,4 & 13744 & 9707 & 18,0 & 7507 & 9355 & 22,1 & 12035 & 11916 \\
\hline Standardabweichung & 5,8 & 4346 & 3070 & 5,7 & 2374 & 2958 & 6,6 & 3629 & 359 \\
\hline Unteres $95 \%$ CI & 34,0 & 45458 & 8061 & 36,6 & 52659 & 11262 & 35,4 & 41955 & 7065 \\
\hline Oberes $95 \%$ CI & 61,4 & 65122 & 21949 & 62,4 & 63399 & 24647 & 65,0 & 58125 & 23075 \\
\hline
\end{tabular}


Tabelle 46: Einfluss von Einfrier-/Auftauzyklen auf die Fluoreszenzsignale - Daten 2

\begin{tabular}{|c|c|c|c|c|c|c|}
\hline \multirow{2}{*}{ Variable } & \multicolumn{3}{|c|}{$8 \times$} & \multicolumn{3}{|c|}{$16 \times$} \\
\hline & $t_{10^{4}}$ & Max rfu & AUC & $t_{10^{4}}$ & Max rfu & AUC \\
\hline Minimum & 26,5 & 14802 & 516 & 24,0 & 35157 & 3202 \\
\hline $\mathrm{Q}_{25}$ & 32,3 & 28565 & 1768 & 33,5 & 41563 & 7206 \\
\hline Median & 52,3 & 58929 & 14962 & 42,5 & 64990 & 16527 \\
\hline $\mathrm{Q}_{75}$ & 74,8 & 62836 & 27770 & 66,5 & 65000 & 27453 \\
\hline Maximum & 77,0 & 65000 & 34202 & 75,5 & 65000 & 36070 \\
\hline Mittelwert & 52,8 & 47698 & 14225 & 46,6 & 54730 & 17809 \\
\hline Standardfehler & 20,6 & 19036 & 12608 & 18,2 & 12797 & 11914 \\
\hline Standardabweichung & 7,3 & 6020 & 3801 & 6,9 & 4266 & 3971 \\
\hline Unteres $95 \%$ CI & 35,5 & 34080 & 5755 & 29,7 & 44893 & 8651 \\
\hline Oberes $95 \% \mathrm{CI}$ & 70,0 & 61315 & 22695 & 63,4 & 64567 & 26968 \\
\hline
\end{tabular}

Tabelle 47: Einfluss von Lagerung und Verwendung auf die Positivitätsraten - Stat.

\begin{tabular}{lccc}
\hline \multirow{2}{*}{ Faktor } & \multicolumn{3}{c}{ p-Wert } \\
\cline { 2 - 4 } & $\mathrm{t}_{10^{4}}$ & Max rfu & AUC \\
\hline Lagerung bei RT & $>0,05$ & $>0,05$ & $>0,05$ \\
Lagerung bei $+4{ }^{\circ} \mathrm{C}$ & $>0,05$ & $>0,05$ & $>0,05$ \\
Lagerung bei $-80{ }^{\circ} \mathrm{C}$ & $>0,05$ & $>0,05$ & $>0,05$ \\
Einfrier-/Auftau Zyklen & $>0,05$ & $>0,05$ & $>0,05$ \\
\hline
\end{tabular}

Tabelle 48: Einfluss einer Blutkontamination auf die Fluoreszenzsignale - Daten 1

\begin{tabular}{|c|c|c|c|c|c|c|}
\hline \multirow{2}{*}{ Variable } & \multicolumn{2}{|c|}{0 Ery $/ \mu \mathrm{l}$} & \multicolumn{2}{|c|}{78 Ery $/ \mu \mathrm{l}$} & \multicolumn{2}{|c|}{313 Ery $/ \mu \mathrm{l}$} \\
\hline & Max rfu & AUC & Max rfu & AUC & Max rfu & AUC \\
\hline Minimum & 15845 & 2536 & 11139 & 6164 & 61485 & 24526 \\
\hline $\mathrm{Q}_{25}$ & 42406 & 7092 & 38698 & 6820 & 62490 & 26715 \\
\hline Median & 45325 & 10543 & 55482 & 23133 & 65000 & 31757 \\
\hline $\mathrm{Q}_{75}$ & 63061 & 22788 & 63017 & 31391 & 65000 & 40978 \\
\hline Maximum & 65000 & 44980 & 65000 & 34261 & 65000 & 42795 \\
\hline Mittelwert & 47928 & 15702 & 49793 & 19860 & 64052 & 33109 \\
\hline Standardfehler & 14175 & 12592 & 17758 & 11677 & 1529 & 7338 \\
\hline Standardabweichung & 3788 & 3365 & 5919 & 4129 & 624 & 2996 \\
\hline Unteres $95 \%$ CI & 39743 & 8431 & 36143 & 10098 & 62447 & 25408 \\
\hline Oberes $95 \% \mathrm{CI}$ & 56112 & 22972 & 63443 & 29623 & 65656 & 40809 \\
\hline
\end{tabular}


Tabelle 49: Einfluss einer Blutkontamination auf die Fluoreszenzsignale - Daten 2

\begin{tabular}{|c|c|c|c|c|c|c|}
\hline \multirow{2}{*}{ Variable } & \multicolumn{2}{|c|}{ 1.250 Ery $/ \mu \mathrm{l}$} & \multicolumn{2}{|c|}{$5.000 \mathrm{Ery} / \mu \mathrm{l}$} & \multicolumn{2}{|c|}{ 10.000 Ery $/ \mu \mathrm{l}$} \\
\hline & Max rfu & $\overline{\mathrm{AUC}}$ & Max rfu & AUC & Max rfu & AUC \\
\hline Minimum & 36564 & 7323 & 7746 & 121 & 7724 & 131 \\
\hline $\mathrm{Q}_{25}$ & 43673 & 11418 & 7778 & 124 & 7785 & 133 \\
\hline Median & 65000 & 28018 & 8478 & 403 & 8327 & 398 \\
\hline $\mathrm{Q}_{75}$ & 65000 & 35627 & 8695 & 450 & 8844 & 450 \\
\hline Maximum & 65000 & 36725 & 8855 & 460 & 9898 & 510 \\
\hline Mittelwert & 57891 & 25021 & 8331 & 327 & 8429 & 333 \\
\hline Standardfehler & 14218 & 12980 & 458 & 159 & 784 & 161 \\
\hline Standardabweichung & 7109 & 6490 & 187 & 65 & 320 & 66 \\
\hline Unteres $95 \%$ CI & 35267 & 4368 & 7850 & 159 & 7606 & 164 \\
\hline Oberes $95 \%$ CI & 80515 & 45674 & 8812 & 494 & 9251 & 503 \\
\hline
\end{tabular}

Tabelle 50: Einfluss einer Blutkontamination auf die Fluoreszenzsignale - Daten 3

\begin{tabular}{|c|c|c|c|c|c|c|}
\hline \multirow{2}{*}{ Variable } & \multicolumn{2}{|c|}{ Ref } & \multicolumn{2}{|c|}{0 Tage } & \multicolumn{2}{|c|}{1 Tag } \\
\hline & Max rfu & $\mathrm{AUC}$ & Max rfu & $\mathrm{AUC}$ & Max rfu & AUC \\
\hline Minimum & 35393 & 145 & 44436 & 160 & 44008 & 160 \\
\hline $\mathrm{Q}_{25}$ & 39615 & 154 & 46190 & 182 & 45752 & 183 \\
\hline Median & 45524 & 191 & 49434 & 207 & 56573 & 233 \\
\hline $\mathrm{Q}_{75}$ & 52463 & 269 & 57371 & 294 & 60526 & 366 \\
\hline Maximum & 61104 & 331 & 64192 & 343 & 65000 & 370 \\
\hline Mittelwert & 46358 & 211 & 51561 & 231 & 54587 & 258 \\
\hline Standardfehler & 8728 & 69 & 7190 & 67 & 7970 & 89 \\
\hline Standardabweichung & 3563 & 28 & 2936 & 28 & 3254 & 36 \\
\hline Unteres $95 \%$ CI & 37199 & 138 & 44015 & 160 & 46223 & 165 \\
\hline Oberes $95 \%$ CI & 55518 & 283 & 59107 & 301 & 62951 & 352 \\
\hline
\end{tabular}


Tabelle 51: Einfluss einer Blutkontamination auf die Fluoreszenzsignale - Daten 4

\begin{tabular}{rrrrrrrrrr}
\hline \multirow{2}{*}{ Variable } & \multicolumn{2}{c}{ 2 Tage } & & \multicolumn{2}{c}{ 3 Tage } & & \multicolumn{2}{c}{ 8 Tage } \\
\cline { 2 - 3 } & Max rfu & AUC & & Max rfu & AUC & & Max rfu & AUC \\
\hline Minimum & 40147 & 136 & & 57015 & 232 & & 4611 & 7 \\
$Q_{25}$ & 44915 & 153 & & 61008 & 251 & & 5136 & 8 \\
Median & 56210 & 249 & & 65000 & 351 & & 6809 & 12 \\
$Q_{75}$ & 62446 & 346 & & 65000 & 423 & & 7749 & 23 \\
Maximum & 65000 & 489 & & 65000 & 482 & & 8568 & 29 \\
Mittelwert & 54278 & 264 & & 63403 & 340 & & 6613 & 14 \\
Standardfehler & 9572 & 127 & & 3571 & 96 & & 1402 & 8 \\
Standardabweichung & 3908 & 52 & & 1597 & 43 & & 496 & 3 \\
Unteres 95 \% CI & 44233 & 130 & & 58969 & 220 & & 5441 & 8 \\
Oberes 95 \% CI & 64323 & 397 & & 67837 & 459 & & 7785 & 21 \\
\hline
\end{tabular}

Tabelle 52: Einfluss einer Blutkontamination auf die Fluoreszenzsignale - Stat.

\begin{tabular}{lcc}
\hline \multirow{2}{*}{ Faktor } & \multicolumn{2}{c}{ p-Wert } \\
\cline { 2 - 3 } & Max rfu & AUC \\
\hline Zellzahl & $\leq 0,0001$ & $\leq 0,0001$ \\
0 vs. 78 & $>0,05$ & $>0,05$ \\
0 vs. 313 & $>0,05$ & $>0,05$ \\
0 vs. 1.250 & $>0,05$ & $>0,05$ \\
0 vs. 5.000 & $\leq 0,01$ & $\leq 0,01$ \\
0 vs. 10.000 & $\leq 0,001$ & $\leq 0,01$ \\
Hämolyse & $\leq 0,001$ & $\leq 0,001$ \\
Ref vs. 0 & $>0,05$ & $>0,05$ \\
Ref vs. 1 & $>0,05$ & $>0,05$ \\
Ref vs. 2 & $>0,05$ & $>0,05$ \\
Ref vs. 3 & $>0,05$ & $>0,05$ \\
Ref vs. 8 & $\leq 0,001$ & $\leq 0,001$ \\
\hline
\end{tabular}


Tabelle 53: Einfluss der Kurzzeitlag. auf die Fluoreszenzsign. von Kontr. - Daten

\begin{tabular}{|c|c|c|c|c|c|c|c|c|}
\hline \multirow{2}{*}{ Variable / Max rfu } & \multicolumn{4}{|c|}{ RT / Tage } & \multicolumn{4}{|c|}{$+4^{\circ} \mathrm{C} /$ Tage } \\
\hline & 0 & 1 & 3 & 8 & 0 & 1 & 3 & 8 \\
\hline Minimum & 5727 & 6115 & 5900 & 6530 & 5998 & 5920 & 5650 & 5391 \\
\hline $\mathrm{Q}_{25}$ & 5784 & 6217 & 6052 & 6676 & 6055 & 5939 & 5850 & 5830 \\
\hline Median & 6166 & 6554 & 6852 & 7161 & 6230 & 6292 & 6058 & 6255 \\
\hline $\mathrm{Q}_{75}$ & 6779 & 7589 & 8488 & 8021 & 6900 & 6604 & 6357 & 6444 \\
\hline Maximum & 8028 & 9903 & 10084 & 8068 & 8143 & 6671 & 6615 & 6496 \\
\hline Mittelwert & 6375 & 7032 & 7291 & 7275 & 6527 & 6284 & 6095 & 6133 \\
\hline Standardfehler & 853 & 1428 & 1566 & 666 & 810 & 327 & 327 & 419 \\
\hline Standardabweichung & 348 & 583 & 639 & 272 & 331 & 134 & 134 & 171 \\
\hline Unteres $95 \%$ CI & 5480 & 5534 & 5648 & 6576 & 5677 & 5940 & 5751 & 5694 \\
\hline Oberes $95 \% \mathrm{CI}$ & 7271 & 8531 & 8934 & 7974 & 7376 & 6627 & 6438 & 6573 \\
\hline
\end{tabular}

Tabelle 54: Einfluss der Verw. und Langzeitlag. auf die Fluoreszenzsign. von Kontr.

\begin{tabular}{|c|c|c|c|c|c|c|c|c|}
\hline \multirow{2}{*}{ Variable / Max rfu } & \multicolumn{5}{|c|}{ Einfrier-/Auftauzyklen / Anzahl } & \multicolumn{3}{|c|}{$-80{ }^{\circ} \mathrm{C} /$ Jahre } \\
\hline & 0 & 2 & 4 & 8 & 16 & $2-3$ & $5-6$ & $8-9$ \\
\hline $\mathrm{m}$ & 5307 & 5390 & 5458 & 5585 & 730 & 4727 & 4467 & 4676 \\
\hline $\mathrm{Q}_{25}$ & 5516 & 6111 & 5722 & 4 & 50 & 4733 & 4992 & 5086 \\
\hline Median & 6147 & 6397 & 6102 & 5982 & 6438 & 5591 & 5479 & 5527 \\
\hline $\mathrm{Q}_{75}$ & 6470 & 6467 & 7054 & 6178 & 8439 & 6636 & 6055 & 6076 \\
\hline Maximum & 6522 & 6512 & 8678 & 6206 & 8495 & 8089 & 6094 & 6339 \\
\hline Mittelwert & 6027 & 6250 & 6444 & 5951 & 6946 & 5814 & 5455 & 5547 \\
\hline & 490 & 425 & 1149 & 241 & 1206 & 1264 & 629 & 605 \\
\hline Standardabweichung & 200 & 174 & 469 & 99 & 492 & 516 & 257 & 247 \\
\hline Unteres $95 \%$ CI & 5512 & 5804 & 5237 & 5698 & 5681 & 4487 & 4795 & 4912 \\
\hline Oberes $95 \%$ CI & 6541 & 6696 & 7650 & 6204 & 8211 & 7141 & 6114 & 6181 \\
\hline
\end{tabular}


Tabelle 55: Einfluss einer Blutkont. auf die Fluoreszenzsign. von Kontr. - Daten 1

\begin{tabular}{rrrrrrr}
\hline \multirow{2}{*}{ Variable / Max rfu } & \multicolumn{6}{c}{ Zellzahl / Ery/ $\mu$ l } \\
\cline { 2 - 7 } & 0 & 78 & 313 & 1.250 & 5.000 & 10.000 \\
\hline Minimum & 4616 & 3280 & 3182 & 3237 & 3231 & 3208 \\
$Q_{25}$ & 5529 & 3331 & 3241 & 3246 & 3248 & 3221 \\
Median & 5834 & 3390 & 3292 & 3442 & 3306 & 3250 \\
$Q_{75}$ & 7649 & 7980 & 7869 & 7713 & 7794 & 7856 \\
Maximum & 8196 & 8186 & 8147 & 7883 & 8279 & 8262 \\
Mittelwert & 6471 & 4918 & 4825 & 5184 & 5209 & 5256 \\
Standardfehler & 1280 & 2427 & 2433 & 2335 & 2442 & 2535 \\
Standardabweichung & 427 & 9901 & 993 & 83 & 923 & 958 \\
Unteres 95 \% CI & 5488 & 2370 & 2272 & 3025 & 2951 & 2911 \\
Oberes 95 \% CI & 7455 & 7465 & 7378 & 7344 & 7468 & 7601 \\
\hline
\end{tabular}

Tabelle 56: Einfluss einer Blutkont. auf die Fluoreszenzsign. von Kontr. - Daten 2

\begin{tabular}{rrrrrrr}
\hline \multirow{2}{*}{ Variable / Max rfu } & \multirow{2}{*}{ Ref } & \multicolumn{5}{c}{ Hämolyse / Tage } \\
\cline { 3 - 7 } & & 0 & 1 & 2 & 3 & 8 \\
\hline Minimum & 4717 & 4749 & 4845 & 4836 & 4557 & 4688 \\
$Q_{25}$ & 5297 & 6725 & 5350 & 5411 & 5157 & 5358 \\
Median & 7113 & 7653 & 7399 & 7339 & 7364 & 7394 \\
$Q_{75}$ & 8153 & 8663 & 8643 & 8343 & 8515 & 8430 \\
Maximum & 8650 & 9075 & 9417 & 8740 & 8962 & 8742 \\
Mittelwert & 6864 & 7486 & 7167 & 7041 & 7003 & 7054 \\
Standardfehler & 1458 & 1392 & 1668 & 1475 & 1665 & 1548 \\
Standardabweichung & 516 & 492 & 589 & 522 & 589 & 547 \\
Unteres 95 \% CI & 5645 & 6322 & 5773 & 5807 & 5611 & 5760 \\
Oberes 95\% CI & 8083 & 8649 & 8562 & 8274 & 8394 & 8348 \\
\hline
\end{tabular}


Tabelle 57: Einfluss von Dox in versch. Konz. auf die AUC von sCJD-Gehirnproben

\begin{tabular}{rrrrrr}
\hline \multirow{2}{*}{ Variable / AUC } & \multicolumn{5}{c}{ Doxyzyklin $/ \mathrm{mM}$} \\
\cline { 2 - 6 } & 0,0 & 0,1 & 0,3 & 0,5 & 1,0 \\
\hline Minimum & 18486 & 1050 & 118 & 91 & 104 \\
$\mathrm{Q}_{25}$ & 21300 & 1200 & 119 & 94 & 112 \\
Median & 33216 & 1356 & 137 & 116 & 165 \\
$\mathrm{Q}_{75}$ & 41380 & 3840 & 403 & 198 & 175 \\
Maximum & 46272 & 5337 & 598 & 230 & 181 \\
Mittelwert & 31715 & 2287 & 236 & 140 & 148 \\
Standardfehler & 10837 & 1774 & 206 & 58 & 34 \\
Standardabweichung & 4846 & 793 & 92 & 26 & 15 \\
Unteres 95 \% CI & 18260 & 85 & -19 & 67 & 106 \\
Oberes 95 \% CI & 45171 & 4489 & 492 & 213 & 190 \\
\hline
\end{tabular}




\section{Bilder}

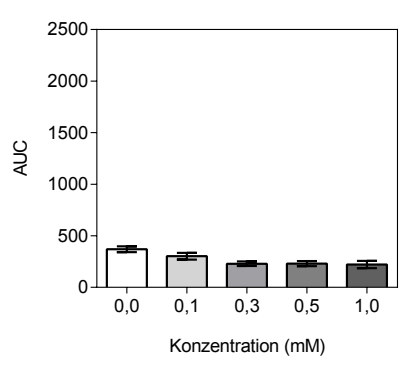

(a) Doxyzyklin

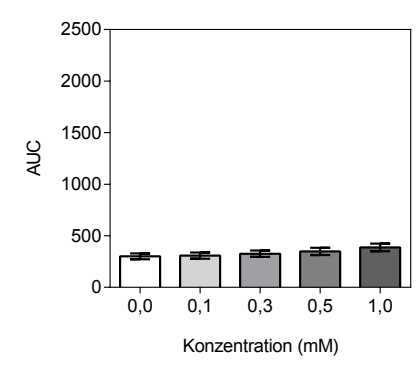

(b) Ampicillin

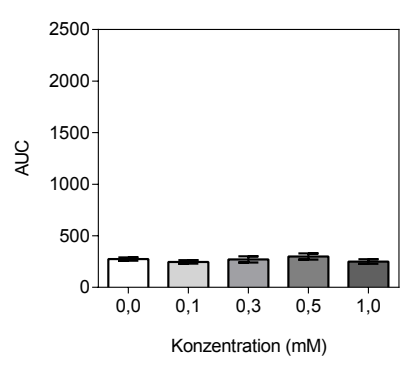

(c) Sucrose

Bild 32: Einfluss von Dox, Amp und Suc in versch. Konz. auf die AUC von Kontr.

Vor dem Start der RT-QuIC in verschiedenen Konzentrationen zugegeben zeigten weder Dox, Amp noch Suc einen Einfluss auf die Fläche unter der Kurve (AUC) von Liquorproben von retr. Kontrollen. Bild 32 (a) zeigt die AUC von $\mathrm{n}=12$ retr. Kontrollen unter Zugabe von Dox, Bild 32 (b) diese unter Zugabe von Amp und Bild 32 (c) diese unter Zugabe von Suc, jeweils in verschiedenen Konzentrationen. Die AUC sind grafisch dargestellt als Säulendiagramme mit Mittelwert \pm Standardfehler.

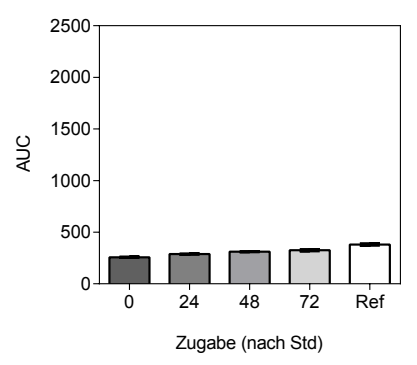

(a) Doxyzyklin

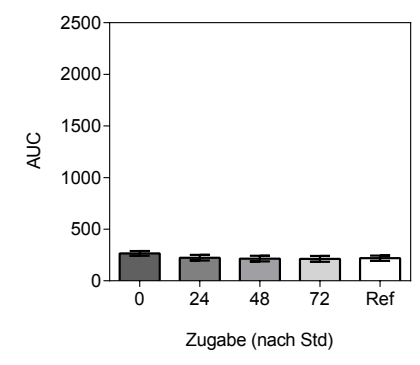

(b) Ampicillin

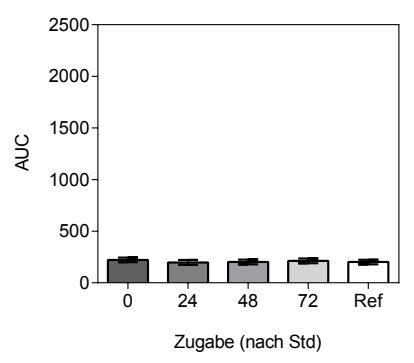

(c) Sucrose

Bild 33: Einfluss von Dox, Amp und Suc auf die AUC von Kontr. zu versch. Zeitp.

$\mathrm{Zu}$ verschiedenen Zeitpunkten während des Versuchs zugegeben zeigten weder 0,5 mM Dox, Amp noch Suc einen Einfluss auf die Fläche unter der Kurve (AUC) von Liquorproben von retr. Kontrollen. Bild 33 (a) zeigt die AUC von $\mathrm{n}=12$ retr. Kontrollen unter Zugabe von Dox, Bild 33 (b) diese unter Zugabe von Amp und Bild 33 (c) diese unter Zugabe von Suc, jeweils zu verschiedenen Zeitpunkten während des Versuchs. Die AUC sind grafisch dargestellt als Säulendiagramme mit Mittelwert \pm Standardfehler. 